Final Report

FHWA/IN/JTRP-2004/35

\title{
NON-DESTRUCTIVE ESTIMATION OF PAVEMENT THICKNESS, STRUCTURAL NUMBER AND SUBGRADE RESILIENCE ALONG INDOT HIGHWAYS
}

\author{
By \\ Samy Noureldin, Ph.D., PE \\ Research Section Manager/Engineer \\ Transportation, Safety and Pavement Management Systems \\ Karen Zhu, Ph.D. \\ Senior Systems Analyst \\ Dwayne Harris \\ Transportation Systems Research Engineer \\ Shuo Li, Ph.D, PE \\ Traffic and Safety Research Engineer \\ Division of Research \\ Indiana Department of Transportation \\ 1205 Montgomery Street \\ West Lafayette, IN 47906 \\ Joint Transportation Research Program \\ Project No. C-36-31L \\ File No. 2-11-12 \\ SPR-2408 \\ Prepared in Cooperation with the \\ Indiana Department of Transportation and the \\ U.S. Department of Transportation \\ Federal Highway Administration
}

The contents of this report reflect the views of the author who is responsible for the facts and the accuracy of the data presented herein. The contents do not necessarily reflect the official views or policies of the Indiana Department of Transportation or the Federal Highway Administration at the time of publication. This report does not constitute a standard, specification, or regulation.

Purdue University

West Lafayette, IN 47907

May 2005 


\section{TECHNICAL Summary}

INDOT Research

Technology Transfer and Project Implementation Information

TRB Subject Code: 24-4Pavement Evaluation and Testing

Publication No.: FHWA/IN/JTRP-2004/35, SPR-2408

May 2005

Final Report

\section{Non-Destructive Estimation of Pavement Thickness, Structural Number and Subgrade Resilience along INDOT Highways}

\section{Introduction}

Indiana Department of Transportation, INDOT, manages approximately 11,000 miles highway system of Interstates, U.S. Roads and State Routes employing a reliable management system. This system employs automated collected pavement surface condition data which includes pavement condition rating, PCR, international roughness index, IRI, rut depth, pavement quality index, PQI, pavement surface texture and skid resistance.

INDOT (as well as most State Highway Agencies) does not routinely employ pavement deflection for network level pavement evaluation. Information about pavement layer thicknesses and moduli by location is often not readily available and hence undue coring and destructive testing are often employed. This practice needed to be gradually improved especially when employing the "200X AASHTO Guide" for mechanistic based designs of new as well as rehabilitated pavements. Information about pavement thickness, pavement layers deflection and moduli, structural capacity (or adequacy), and resiliency of pavement support by location along highway pavement segments within INDOT jurisdiction needs to be obtained. Nondestructive testing of pavements appears to be the most practical approach to address that need.

The use of nondestructive testing has become an integral part for evaluation and rehabilitation strategies of pavements in recent years. Pavement evaluation employing the Falling Weight Deflectometer (FWD) and the Ground Penetrating Radar (GPR) can provide valuable information about the pavement structural characteristics and be a very useful tool for project prioritization purposes and estimation of construction budget at the network level. By estimating pavement layer thicknesses and stiffness properties, more reliable projections of network rehabilitation strategies and needs can be established, thus resulting in cost effective use of available funds. Expenses involved in data collection, limited resources and lack of simplified analysis procedures used to be the traditional obstacles for the use of FWD and GPR in pavement evaluation at the network level. The main objectives of the research study presented herein are:

- To investigate employing the FWD and GPR in pavement evaluation at the network level and to provide recommendations necessary for their future use in this context.

- To develop simple non destructive procedures for estimating pavement layer thicknesses, pavement surface deflection, and pavement layer mechanistic characteristics that can be retrieved knowing roadway name, direction and reference post.

- To use inventory data to investigate variability in pavement structural parameters, and estimate remaining life, required overlay thickness and the information necessary for structural reliability analysis and safety factors computations for INDOT highway pavements.

- To prepare the information necessary for the required steps in implementing the new AASHTO Guide mechanistic - empirical pavement design procedures. 


\section{Findings}

This report presents a comprehensive pavement evaluation using the FWD and GPR. A network level FWD and GPR testing program was conducted to overcome traditional obstacles for the use of FWD and GPR in pavement evaluation at that level namely; expenses involved in data collection, limited resources and lack of simplified analysis procedures. This testing program included Interstate Highways I 64, I - 65, I - 69, I - 70 and I - 74 and a number of U.S. Roads and State Routes. Main findings can be summarized as follows:

- Network level testing employing the FWD and the GPR is a doable worthwhile, technically sound program that can provide a baseline of structural capacities of in service pavements in Indiana. Periodical generation of necessary data will be useful for determining how best to quantify the loss in structural capacity and help in improving the estimation of construction budgets.

- Information that is obtained through network level testing employing the FWD and GPR can be used for pavement design, maintenance, rehabilitation and management purposes.

- U.S. Roads and State Routes may need more emphasis in network level deflection testing than Interstate Highways.

- A pavement thickness and structural capacity inventory of INDOT Interstate Highways is created. INDOT Interstate Highway pavements are currently in a very good structural condition.
- Critical FWD deflection values for pavement management purposes are developed for different traffic levels. These values are normalized to a standard load and temperature.

- GPR estimates concrete thickness of concrete pavements, HMA thickness of flexible pavement and HMA thickness of composite pavements almost perfectly. GPR thickness estimation of pavement layers underneath these layers is not as accurate and needs adjustment through very limited coring.

- FWD estimates total pavement thickness when using the simplified method presented in this report. FWD also estimates combined thickness of bound layers. This estimate matched the GPR estimate in some situation or was slightly lower.

- FWD and GPR are not expected to completely eliminate the need for coring. GPR can be used to establish the coring requirements to help interpret the GPR data fill the gaps in thickness estimation and verify thickness results.

- Pooled overall standard deviation for INDOT interstate highways, $\mathrm{S}_{\mathrm{o}}$ is 0.497 . For a reliability level used in the design of $90 \%$, the safety factor in pavement design is in the range of 3.8 to 5.2 .

\section{Implementation}

- FWD data on 2200 lane miles of the INDOT network is recommended annually for network level pavement evaluation. Only three FWD tests per mile in the driving lane of one bound direction are recommended. The information collected will allow the equivalent of $100 \%$ coverage of the whole network in 5 years.

- GPR data is recommended to replace cores extracted for the purposes of both pavement and shoulder thickness evaluation. GPR data collection is also recommended at the project level and for special projects.

- GPR data is recommended to be collected once every 5 years for pavement thickness inventory purposes.

- Both FWD and GPR data is recommended to be used as part of the pavement management system (together with automated collected data of international roughness index, IRI, pavement condition rating, PCR, rut depth, pavement quality index, PQI, texture and skid resistance). 


\section{Contacts}

For more information:

Dr. Samy Noureldin

Dr. Karen Zhu

Mr. Dwayne Harris

Indiana Department of Transportation

Division of Research

1205 Montgomery Street

P.O. Box 2279

West Lafayette, IN 47906

Phone: (765) 463-1521

Fax: (765) 497-1665
Joint Transportation Research Program

School of Civil Engineering

Purdue University

West Lafayette, IN 47907

Phone: (765) 494-9310

Fax: (765) 496-7996

itrp@ecn.purdue.edu

http://www.purdue.edu/jtrp 
TECHNICAL REPORT STANDARD TITLE

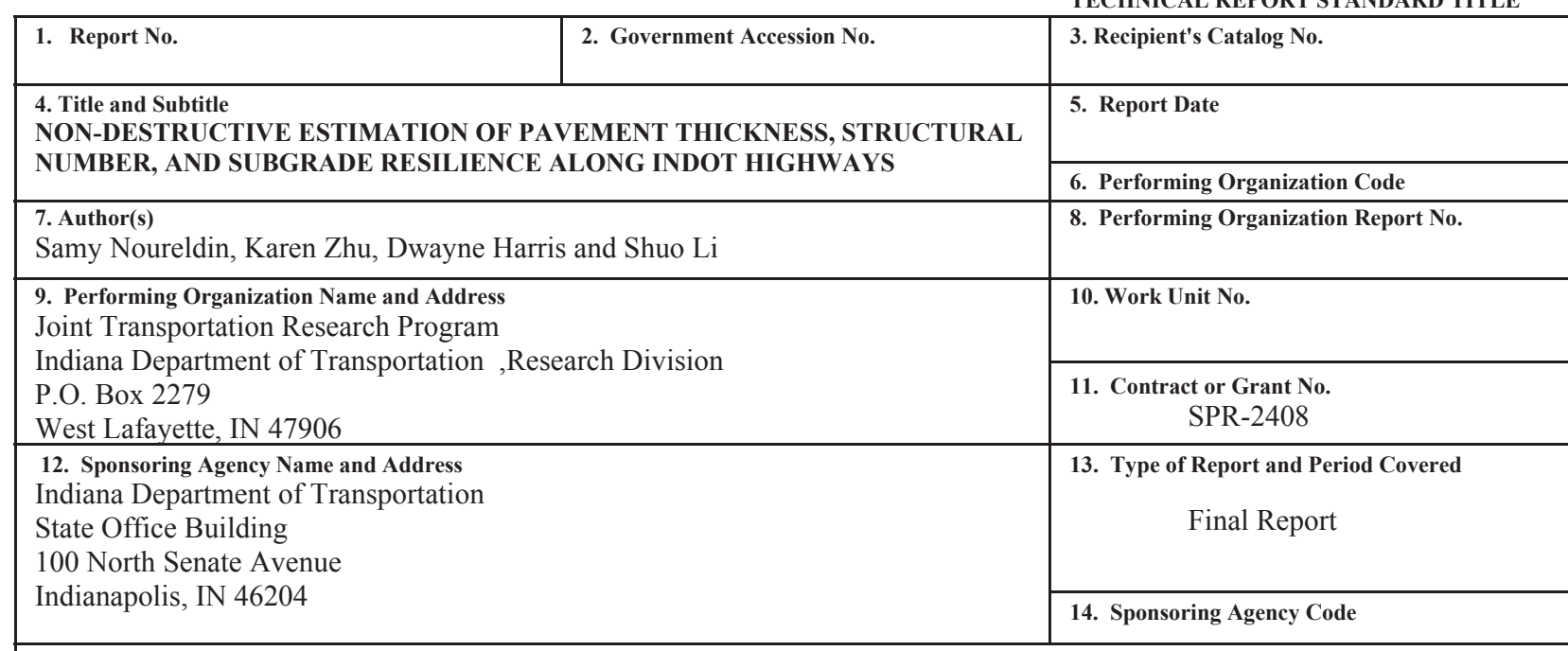

15. Supplementary Notes

Prepared in cooperation with the Indiana Department of Transportation and Federal Highway Administration

16. Abstract

Nondestructive testing has become an integral part for evaluation and rehabilitation strategies of pavements in recent years. Pavement evaluation employing the Falling Weight Deflectometer (FWD) and the Ground Penetrating Radar (GPR) can provide valuable information about pavement performance characteristics and be a very useful tool for project prioritization purposes and estimation of construction budget at the network level.

FWD deflection testing is an accurate tool for determining pavement structural capacity and estimating the required thickness of overlays and hence is an accurate tool for planning for or estimating required current and future construction budgets. GPR is the only tool that a highway agency may use to develop an inventory of pavement layers thicknesses in the most efficient manner possible. By estimating pavement layer thicknesses and stiffness properties more reliable projections of network rehabilitation strategies and needs can be established, thus resulting in cost effective use of available funds.

Traditional obstacles for the use of FWD and GPR in pavement evaluation at the network level used to be expenses involved in data collection, limited resources and lack of simplified analysis procedures.

This report presents Indiana experience in pavement evaluation with the FWD and GPR at the network level. A network level FWD and GPR testing program is implemented as a part of a study to overcome those traditional obstacles. This testing program included Interstate Highways I - 64, I - 65, I - 69, I- 70 and $I-74$ and a number of U.S. Roads and State Routes.

It is concluded that network level testing employing the FWD and GPR is a worthwhile, technically sound program that will provide a baseline of structural capacities of in-service pavements in Indiana. Periodical generation of necessary data will be useful for determining how best to quantify structural capacity and estimate annual construction budget.

FWD data on 2200 lane miles of the INDOT network is recommended annually for network level pavement evaluation. Only three FWD tests per mile are recommended. This amount of testing can easily be conducted in one testing season. The information collected will allow the equivalent of $100 \%$ coverage of the whole network in 5 years. GPR data is recommended to be collected once every 5 years (if another thickness inventory is needed), after the successful network thickness inventory conducted in this study. GPR data collection is also recommended at the project level and for special projects.

Both FWD and GPR data is recommended to be used as part of the pavement management system (together with automated collected data of international roughness index, IRI, pavement condition rating, PCR, rut depth, pavement quality index, PQI, and skid resistance).

17. Key Words

Pavement Layers Thickness, FWD, GPR, Backcalculation of Layer Moduli, Deflection, Layer Coefficients, Effective Structural Number, Remaining Life, Reliability, Factor of Safety.
18. Distribution Statement

No Restrictions. This document is available to the public through National Technical Information

19. Security Classification (of this report)

20. Security Classification (of this page)

21. No. of Pages

22. Price

Form DOT F 1700.7 (8-69) 


\section{ACKNOWLEDGMENTS}

This research project was sponsored by the Indiana Department of Transportation in cooperation with the Federal Highway Administration through the Joint Transportation Research Program (JTRP) of Purdue University. Researchers would like to acknowledge study advisory committee members; Mr. Lee Gallivan, from FHWA, Mr. William Flora, Mr. Kumar Dave, Mr. John Weaver and Mr. Nayyar Zia from INDOT and Prof. Vince Drnevich from Purdue for their valuable assistance and technical guidance in the course of performing this study. Researchers also would like to acknowledge all FWD testing program coordinators and testing crew; Mr. Larry Bateman, Mr. David Hinshaw, Mr. Mike Murdock, Mr. Danny Heath and Mr. Jim Wooten. Sincere thanks are extended to David Hinshaw and Aaron Ping for their assistance in data collection. 


\section{TABLE OF CONTENTS}

$\begin{array}{lll}\text { Chapter } 1 & \text { INTRODUCTION } & 1\end{array}$

1.1 Problem Statement 1

$\begin{array}{lll}1.2 & \text { Objectives } & 3\end{array}$

1.3 Research Scope and Approach 3

Chapter 2 THEORITICAL BACKGROUND AND LITERATURE REVIEW 6

2.1 Ground Penetrating Radar, GPR 6

2.1.1 GPR Assembly 6

2.1.2 Main GPR Fundamentals for Pavement Thickness Estimation 6

$\begin{array}{lr}\text { 2.1.3 GPR Traffic Control Measures } & 13\end{array}$

2.2 Falling Weigh Deflectometer, FWD 14

$\begin{array}{lll}\text { 2.2.1 FWD Assembly } & 14\end{array}$

2.2.2 Main FWD Fundamentals for Pavement Characterization 14

$\begin{array}{ll}\text { 2.2.3 Backcalculation of pavement layer moduli } & 15\end{array}$

2.2.4 FWD Testing Traffic Control Measures 21

Chapter $3 \quad$ EXPERIMENTAL DESIGN AND TESTING PROGRAM 22

$\begin{array}{llr}3.1 & \text { Roadway Selection } & 22\end{array}$

$\begin{array}{lll}3.2 & \text { Data Collection } & 23\end{array}$

3.2.1 Data Collection Employing the FWD 23

$\begin{array}{ll}\text { 3.2.2 Data Collection Employing the GPR } & 23\end{array}$

$\begin{array}{ll}\text { 3.2.3 Coring Data } & 23\end{array}$

3.3 Response Variables 23

\begin{tabular}{l|l} 
Chapter 4 & TESTING RESULTS
\end{tabular}

4.1 GPR at the Project Level 27

4.2 FWD at the Network Level 29

4.2.1 Interstates Structural Conditions 29

4.2.2 Interstates Structural Comparisons $\quad \mathbf{6 2}$

4.2.3 U.S. Roads and State Routes Structural Conditions

4.2.4 U.S. Roads and State Routes Structural Comparisons 81

$\begin{array}{lll}\text { 4.3 } & \text { GPR at the Network Level } & 83\end{array}$

$\begin{array}{lll}\text { 4.3.1 GPR - FWD Thickness Comparisons } & 83\end{array}$

4.4 Coring - GPR Thickness Comparisons 90

$\begin{array}{lll}\text { Chapter } 5 & \text { FINDINGS AND RECOMMENDATIONS } & 92\end{array}$

$\begin{array}{llr}5.1 & \text { Findings } & 92\end{array}$

$\begin{array}{lll}5.2 & \text { Recommendations } & 93\end{array}$

5.2.1 Recommendations for Implementation 93

5.2.2 Recommendations for Further Research 93

$\begin{array}{ll}\text { REFERENCES } & 94\end{array}$ 


\section{LIST OF TABLES}

Table 2.1: Relative Dielectric Constant 11

Table 2.2: $\quad$ GPR Minimum Detectable Pavement layer Thickness 13

Table 2.3: Pavement Structural Condition as Defined by Center Deflection in mils (25.4 microns) for a 9000 Pounds (40 Kilo Newton) Load at $68^{\circ}$ F $\left(20^{\circ} \mathrm{C}\right) \quad 15$

Table 2.4: Temperature Correction Factors for FWD Center Deflection 15

Table 2.5: Material Coefficients for Fatigue Cracking Analysis 20

Table 2.6: Material Coefficients for Permanent Deformation (Rutting) Analysis 20

\section{LIST OF FIGURES}

Figure 1.1: Interstate Network State Map for Indiana 4

Figure 2.1: Ground Penetrating Radar Mounted on a Van 6

Figure 2.2: GPR Scan Record from a 12" Concrete Pavement on a 10" Old JRCP on an 8"Aggregate Base on I - 65

Figure 2.3: GPR Scan Record from a 13" HMA Pavement on a 10" Rubblized JRCP on an 8" Aggregate Base on I - 65

Figure 2.4: GPR Scan Record from a 7.5" Fiber Modified HMA Pavement on a 10" Cracked and Seated JRCP on an 8" Aggregate Base on I - 65 10

Figure 2.5: Calibration of GPR Using Metal Plates before Pavement Surface Testing 11

Figure 2.6: Amplitudes Associated with Pavement Surface and Interfaces between Layers 12

Figure 2.7: Falling Weight Deflectometer 14

Figure 3.1: Interstate Highways, U.S. Roads and State Routes Tested During the Study 22

Figure 3.2: Equivalent Overlay Thickness Employing Two layer Analysis 26

Figure 4.1: GPR Thickness Analysis for a 12" Concrete Pavement on a 10" Old JRCP on an 8" Aggregate Base on I - 65

Figure 4.2: GPR Thickness Analysis for a 13" HMA Pavement on a 10" Rubblized JRCP on an 8" Aggregate Base on I - 65

Figure 4.3: GPR Thickness Analysis for a 7.5" Fiber Modified HMA Pavement on a 10" Cracked and Seated JRCP on an 8" Aggregate Base on I - 65

Figure 4.4 a: Profile of Pavement Surface Deflection along Interstate I - 64

Figure 4.4 b: Profile of Pavement Layer Moduli along Interstate I - $64 \quad 31$

Figure 4.4 c: Profile of Pavement Layer Coefficients along Interstate I - 64 32

Figure 4.4 d: Profile of Pavement Structural Numbers along Interstate I - 64 33

Figure 4.4 e: Profile of Pavement Layers Thickness along Interstate I - 64

Figure 4.4 f: Profile of Pavement Remaining Life along Interstate I - 64

Figure 4.4 g: Profile of Required Overlay Thickness along Interstate I - 64 36

Figure 4.5 a: Profile of Pavement Surface Deflection along Interstate I - 65 37

Figure 4.5 b: Profile of Pavement Layer Moduli along Interstate I - 65 38

Figure 4.5 c: Profile of Pavement Layer Coefficients along Interstate I - 65

Figure 4.5 d: Profile of Pavement Structural Numbers along Interstate I - 65

Figure 4.5 e: Profile of Pavement Layers Thickness along Interstate I - 65

Figure 4.5 f: Profile of Pavement Remaining Life along Interstate I - 65 42

Figure 4.5 g: Profile of Required Overlay Thickness along Interstate I - 65

Figure 4.6 a: Profile of Pavement Surface Deflection along Interstate I - 69

Figure 4.6 b: Profile of Pavement Layer Moduli along Interstate I - 69

Figure 4.6 c: Profile of Pavement Layer Coefficients along Interstate I - 69 46

Figure 4.6 d: Profile of Pavement Structural Numbers along Interstate I - 69 47

Figure 4.6 e: Profile of Pavement Layers Thickness along Interstate I - $69 \quad 48$ 
Figure 4.6 f: Profile of Pavement Remaining Life along Interstate I - 69

Figure 4.6 g: Profile of Required Overlay Thickness along Interstate I - 69

Figure 4.7 a: Profile of Pavement Surface Deflection along Interstate I - 70

Figure 4.7 b: Profile of Pavement Layer Moduli along Interstate I - 70

Figure 4.7 c: Profile of Pavement Layer Coefficients along Interstate I - 70

Figure 4.7 d: Profile of Pavement Structural Numbers along Interstate I - 70

Figure 4.7 e: Profile of Pavement Layers Thickness along Interstate I - 70

Figure 4.7 f: Profile of Pavement Remaining Life along Interstate I - 70

Figure 4.7 g: Profile of Required Overlay Thickness along Interstate I - 70

Figure 4.8 a: Profile of Pavement Surface Deflection along Interstate I - 74

Figure 4.8 b: Profile of Pavement Layer Moduli along Interstate I - 74

Figure 4.8 c: Profile of Pavement Layer Coefficients along Interstate I - 74

Figure 4.8 d: Profile of Pavement Structural Numbers along Interstate I - 74

Figure 4.8 e: Profile of Pavement Layers Thickness along Interstate I - 74

Figure 4.8 f: Profile of Pavement Remaining Life along Interstate I - 74

Figure 4.8 g: Profile of Required Overlay Thickness along Interstate I - 74

Figure 4.9 a: Interstate Comparisons; Pavement Surface Deflection

Figure 4.9 b: Interstate Comparisons; Estimated in situ Subgrade CBR

Figure 4.9 c: Interstate Comparisons; Backcalculated Pavement Layer Moduli

Figure 4.9 d: Interstate Comparisons; Pavement Layer Coefficients 
Figure 4.16 c: U.S. Roads and State Routes Comparisons; Pavement Layer Coefficients

Figure 4.17: Profile of GPR and FWD Thickness Estimation along I - 64

Figure 4.18: Profile of GPR and FWD Thickness Estimation along I - 65

Figure 4.19: Profile of GPR and FWD Thickness Estimation along I - 69

Figure 4.20: Profile of GPR and FWD Thickness Estimation along I - 70

Figure 4.21: Profile of GPR and FWD Thickness Estimation along I - 74

Figure 4.22: Profile of GPR and FWD Thickness Estimation along US - 41

89

Figure 4.23: Profile of GPR and FWD Thickness Estimation along SR - 32

89

Figure 4.24: Profile of GPR and Core Thickness along US - 41

Figure 4.25: Profile of GPR and Core Thickness along SR - 32 


\section{LIST OF TABLES}

Table 2.1: Relative Dielectric Constant 11

Table 2.2: $\quad$ GPR Minimum Detectable Pavement layer Thickness 13

Table 2.3: Pavement Structural Condition as Defined by Center Deflection in mils (25.4 microns) for a 9000 Pounds (40 Kilo Newton) Load at $68^{\circ}$ F $\left(20^{\circ} \mathrm{C}\right) \quad 15$

Table 2.4: Temperature Correction Factors for FWD Center Deflection 15

Table 2.5: Material Coefficients for Fatigue Cracking Analysis 20

Table 2.6: Material Coefficients for Permanent Deformation (Rutting) Analysis 20

\section{LIST OF FIGURES}

Figure 1.1: Interstate Network State Map for Indiana 4

Figure 2.1: Ground Penetrating Radar Mounted on a Van 6

Figure 2.2: GPR Scan Record from a 12" Concrete Pavement on a 10" Old JRCP on an 8"Aggregate Base on I - 65

Figure 2.3: GPR Scan Record from a 13" HMA Pavement on a 10" Rubblized JRCP on an 8" Aggregate Base on I - 65

Figure 2.4: GPR Scan Record from a 7.5" Fiber Modified HMA Pavement on a 10" Cracked and Seated JRCP on an 8" Aggregate Base on I - 65 10

Figure 2.5: Calibration of GPR Using Metal Plates before Pavement Surface Testing 11

Figure 2.6: Amplitudes Associated with Pavement Surface and Interfaces between Layers 12

Figure 2.7: Falling Weight Deflectometer 14

Figure 3.1: Interstate Highways, U.S. Roads and State Routes Tested During the Study 22

Figure 3.2: Equivalent Overlay Thickness Employing Two layer Analysis 26

Figure 4.1: GPR Thickness Analysis for a 12" Concrete Pavement on a 10" Old JRCP on an 8" Aggregate Base on I - 65

Figure 4.2: GPR Thickness Analysis for a 13" HMA Pavement on a 10" Rubblized JRCP on an 8" Aggregate Base on I - 65

Figure 4.3: GPR Thickness Analysis for a 7.5" Fiber Modified HMA Pavement on a 10" Cracked and Seated JRCP on an 8" Aggregate Base on I - 65

Figure 4.4 a: Profile of Pavement Surface Deflection along Interstate I - 64

Figure 4.4 b: Profile of Pavement Layer Moduli along Interstate I - $64 \quad 31$

Figure 4.4 c: Profile of Pavement Layer Coefficients along Interstate I - 64 32

Figure 4.4 d: Profile of Pavement Structural Numbers along Interstate I - 64 33

Figure 4.4 e: Profile of Pavement Layers Thickness along Interstate I - 64

Figure 4.4 f: Profile of Pavement Remaining Life along Interstate I - 64

Figure 4.4 g: Profile of Required Overlay Thickness along Interstate I - 64 36

Figure 4.5 a: Profile of Pavement Surface Deflection along Interstate I - 65 37

Figure 4.5 b: Profile of Pavement Layer Moduli along Interstate I - 65 38

Figure 4.5 c: Profile of Pavement Layer Coefficients along Interstate I - 65

Figure 4.5 d: Profile of Pavement Structural Numbers along Interstate I - 65

Figure 4.5 e: Profile of Pavement Layers Thickness along Interstate I - 65

Figure 4.5 f: Profile of Pavement Remaining Life along Interstate I - 65 42

Figure 4.5 g: Profile of Required Overlay Thickness along Interstate I - 65

Figure 4.6 a: Profile of Pavement Surface Deflection along Interstate I - 69

Figure 4.6 b: Profile of Pavement Layer Moduli along Interstate I - 69

Figure 4.6 c: Profile of Pavement Layer Coefficients along Interstate I - 69 46

Figure 4.6 d: Profile of Pavement Structural Numbers along Interstate I - 69 47

Figure 4.6 e: Profile of Pavement Layers Thickness along Interstate I - $69 \quad 48$ 
Figure 4.6 f: Profile of Pavement Remaining Life along Interstate I - 69

Figure 4.6 g: Profile of Required Overlay Thickness along Interstate I - 69

Figure 4.7 a: Profile of Pavement Surface Deflection along Interstate I - 70

Figure 4.7 b: Profile of Pavement Layer Moduli along Interstate I - 70

Figure 4.7 c: Profile of Pavement Layer Coefficients along Interstate I - 70

Figure 4.7 d: Profile of Pavement Structural Numbers along Interstate I - 70

Figure 4.7 e: Profile of Pavement Layers Thickness along Interstate I - 70

Figure 4.7 f: Profile of Pavement Remaining Life along Interstate I - 70

Figure 4.7 g: Profile of Required Overlay Thickness along Interstate I - 70

Figure 4.8 a: Profile of Pavement Surface Deflection along Interstate I - 74

Figure 4.8 b: Profile of Pavement Layer Moduli along Interstate I - 74

Figure 4.8 c: Profile of Pavement Layer Coefficients along Interstate I - 74

Figure 4.8 d: Profile of Pavement Structural Numbers along Interstate I - 74

Figure 4.8 e: Profile of Pavement Layers Thickness along Interstate I - 74

Figure 4.8 f: Profile of Pavement Remaining Life along Interstate I - 74

Figure 4.8 g: Profile of Required Overlay Thickness along Interstate I - 74

Figure 4.9 a: Interstate Comparisons; Pavement Surface Deflection

Figure 4.9 b: Interstate Comparisons; Estimated in situ Subgrade CBR

Figure 4.9 c: Interstate Comparisons; Backcalculated Pavement Layer Moduli

Figure 4.9 d: Interstate Comparisons; Pavement Layer Coefficients 
Figure 4.16 c: U.S. Roads and State Routes Comparisons; Pavement Layer Coefficients

Figure 4.17: Profile of GPR and FWD Thickness Estimation along I - 64

Figure 4.18: Profile of GPR and FWD Thickness Estimation along I - 65

Figure 4.19: Profile of GPR and FWD Thickness Estimation along I - 69

Figure 4.20: Profile of GPR and FWD Thickness Estimation along I - 70

Figure 4.21: Profile of GPR and FWD Thickness Estimation along I - 74

Figure 4.22: Profile of GPR and FWD Thickness Estimation along US - 41

89

Figure 4.23: Profile of GPR and FWD Thickness Estimation along SR - 32

89

Figure 4.24: Profile of GPR and Core Thickness along US - 41

Figure 4.25: Profile of GPR and Core Thickness along SR - 32 


\section{Chapter 1}

\section{INTRODUCTION}

\subsection{Problem Statement}

The Indiana Department of Transportation, INDOT, manages approximately 11,000 miles (17,700 kilometers) highway system of Interstates, U.S. Roads and State Routes employing a reliable management system. This system employs automated collected pavement surface condition data which includes pavement condition rating, PCR, international roughness index, IRI, rut depth, pavement quality index, PQI, pavement surface micro and macro-texture and skid resistance.

INDOT (as well as most State Highway Agencies) does not routinely employ pavement deflection data as a mechanistic tool for network level evaluation. Information regarding pavement layers thickness and stiffness by location is often not readily available and hence undue coring and destructive testing are often employed. This practice needed to be gradually improved especially with the national movement toward employing mechanistic based designs for new as well as rehabilitated pavements associated with issuing the "200X AASHTO Guide". Information about existing pavement thickness, pavement layers structural stiffness (or adequacy), pavement deflection and resiliency of pavement support by location along highway pavement segments within INDOT jurisdiction needs to be obtained. Nondestructive testing of pavements appears to be the most practical approach to address that need.

The use of nondestructive testing has become an integral part for evaluation and rehabilitation strategies of pavements in recent years. Pavement evaluation employing the Falling Weight Deflectometer (FWD) and the Ground Penetrating Radar (GPR) can provide valuable information about the pavement structural characteristics and be a very useful tool for project prioritization purposes and estimation of construction budget at the network level. By estimating pavement layer thicknesses and stiffness properties more reliable projections of network rehabilitation strategies and needs can be established, thus resulting in cost effective use of available funds (1). Expenses involved in data collection, limited resources and lack of simplified analysis procedures used to be the traditional obstacles for the use of FWD and GPR in pavement evaluation at the network level.

The majority of state departments of transportation (DOT's) design their newly constructed as well as rehabilitated pavements employing the 1993 AASHTO Guide (2) which is the primary design document for highway pavements. The current guide as well as the previous guides is based on empirical methods developed during the AASHO road test. 
In 1996, AASHTO committed to making its new guide (to be released in 200X), a mechanistic empirical design procedure (3). The success of this new procedure will depend on the proper preparation of State DOT's such that the required pieces of information to implement mechanistic-empirical design are either already available or in the process of being collected. These pieces of information include collecting data related to pavement layers thickness and stiffness, surface deflection and subgrade resilience of pavements.

FWD is the most widely used device for collecting pavement surface deflection data and providing information related to mechanistic pavement design and material properties. Layers stiffness and subgrade resilience can be backcalculated employing FWD deflection basin information $(4-10)$. Deflection testing of existing pavements employing the FWD was recently standardized by AASHTO and ASTM (AASHTO T 256, ASTM D 4694 and ASTM D 5858), $(11,12)$. In the last 20 years the FWD has become an essential tool for the evaluation of the structural capacity and integrity of existing, rehabilitated and newly constructed pavements.

GPR pavement related technology was developed during the SHRP program (13). GPR operates by transmitting short pulses of electromagnetic energy into the pavement. These pulses are reflected back to the radar antenna with the amplitude and arrival time that is related to the thickness and material properties of the pavement layers $(14,15)$.

GPR provides a safe, nondestructive method for estimating pavement layers thicknesses. When GPR is mounted on a van, layer thickness profiles can be generated from radar survey data at highway speed. Thickness information are often very essential for pavement design engineers in order to determine how deep they can mill the pavement surface before resurfacing when rehabilitating a pavement.

GPR technology is also extremely useful for pavement management, providing highway agencies to quickly collect inventory data on all pavements under their jurisdiction. GPR data collection is nondestructive and hence the need for frequent full depth pavement coring can be substantially reduced $(14,15)$. Core sampling is more time intensive and provides less data than GPR. Consider that the typical coring frequency for rehabilitation projects is three cores per lane mile. GPR analysis computes pavement thicknesses at 3 feet intervals and it does so without disrupting traffic. GPR data collection thus provides a more complete picture of the pavement thickness of a given stretch of highway in the time that it takes to drive across it. Coring becomes prohibitively impractical to use for network level inventories of pavement layer thicknesses. Thickness determination of existing pavement layers employing the GPR was recently standardized as an ASTM D - 4748 (11). 


\subsection{Objectives:}

The main objectives of the research study presented herein are:

1. To investigate employing the FWD and GPR in pavement evaluation at the network level and to provide recommendations necessary for their future use in this context.

2. To develop simple non destructive procedures for estimating pavement layers thicknesses, pavement surface deflection, and pavement layers mechanistic characteristics that can be retrieved knowing roadway name, bound direction and reference post.

3. To use inventory data to investigate variability in pavement structural parameters, and estimate remaining life, required overlay thickness and the information necessary for structural reliability analysis and safety factors computations for Indiana highway pavements.

4. To prepare the information necessary for the first steps in implementing AASHTO 200X mechanistic - empirical pavement design procedures.

\subsection{Research Scope and Approach:}

The research work was planned in accordance to the following eight tasks:

\section{- $\quad$ Task 1 ; Equipment Procurement}

A Ground Penetration Radar (GPR) system was purchased for the study from a company that manufactures, installs provides service and warranty for the system. Training technicians and operators costs were included with the total cost of the system. The system has the capabilities to obtain thickness of pavement layers.

Four Falling Weight Deflectometers are available for the Research Division within INDOT and were used for data collection.

\section{- Task 2 ; Experimental Design \& Roadway Selection}

Interstate network was selected to be the main emphasis of the study (Figure 1.1). A number of U.S. roads and state routes roadway segments were also selected for comparative purposes. 


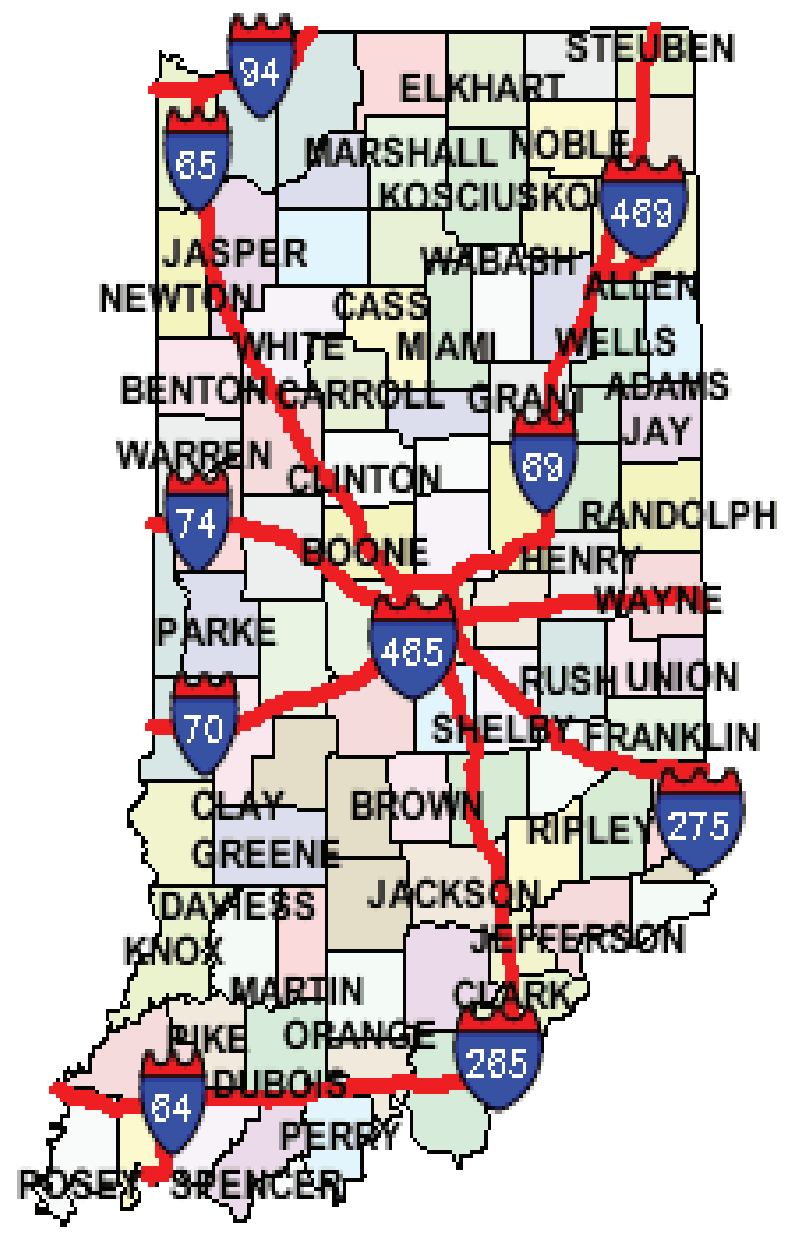

(1)

Map prowided by INDOT - 2002.

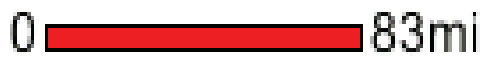

Figure 1.1: Interstate Network State Map for Indiana 


\section{- Task 3 ; Data Collection Employing the FWD}

The FWD was to be used to test the driving lane of each roadway under consideration. Deflection was measured at 3 locations per kilometer, every $304.8 \mathrm{~m}$ (5 locations per mile, every $1000 \mathrm{ft}$ ) employing a load of 40 kilo Newton (9000 pounds). Measurements were taken at

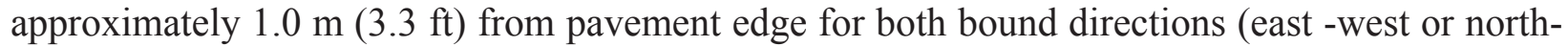
south). These measurements were obtained during 2001 and 2002 construction seasons.

\section{- Task 4 ; Data Collection Employing the GPR}

The GPR was used to continuously display thickness of pavement layers for the driving lane of each roadway under consideration. GPR thickness data were to be estimated at 5 points per mile (consistent with FWD data).

\section{- Task 5; Analysis for In Situ Pavement Material Properties}

Structural number and subgrade resilient modulus were to be estimated at each FWD testing location from deflection data employing BACKAL backcalculation techniques. Profiles of these pavement parameters were to be determined for the various pavement segments.

\section{- Task 6; Thickness Analysis}

Total pavement thickness was to be estimated from FWD data employing backcalculation analysis. Estimated values were to be validated with values obtained through the GPR. A limited number of pavement cores were to be obtained for thickness measurements as a verification sample.

\section{- $\quad$ Task 7 ; Remaining Life Estimation}

Remaining life in terms of ESALs was to be determined for the various pavement segments employing deflection data as well as structural number and resilient modulus data. Variability parameters were to be investigated on each pavement structural parameter (deflection, thickness, structural number and subgrade resilient modulus). Variability in terms of coefficients of variation was to be investigated. 


\section{Chapter 2}

\section{THEORITICAL BACKGROUND AND LITERATURE REVIEW}

\subsection{Ground Penetrating Radar, GPR}

\section{$\underline{\text { 2.1.1 GPR Assembly }}$}

GPR system consists of a control unit; wave form generators, amplifiers, waveguides, transmitting and receiving antenna, and recording equipment. Figure 2.1 shows the GPR mounted on a van. Transmission cycle consists of generating, amplifying, and transmitting a radar wave into the pavement (16). Receiving cycle consists of receiving and amplifying the reflected radar wave (16). Recording cycle includes converting the signal from analog to digital, storing the digital data, and displaying the data on a computer monitor (16). Control unit controls the operation of all of these cycles. A lap top computer is part of the control unit to aid in controlling the system and storing the data.
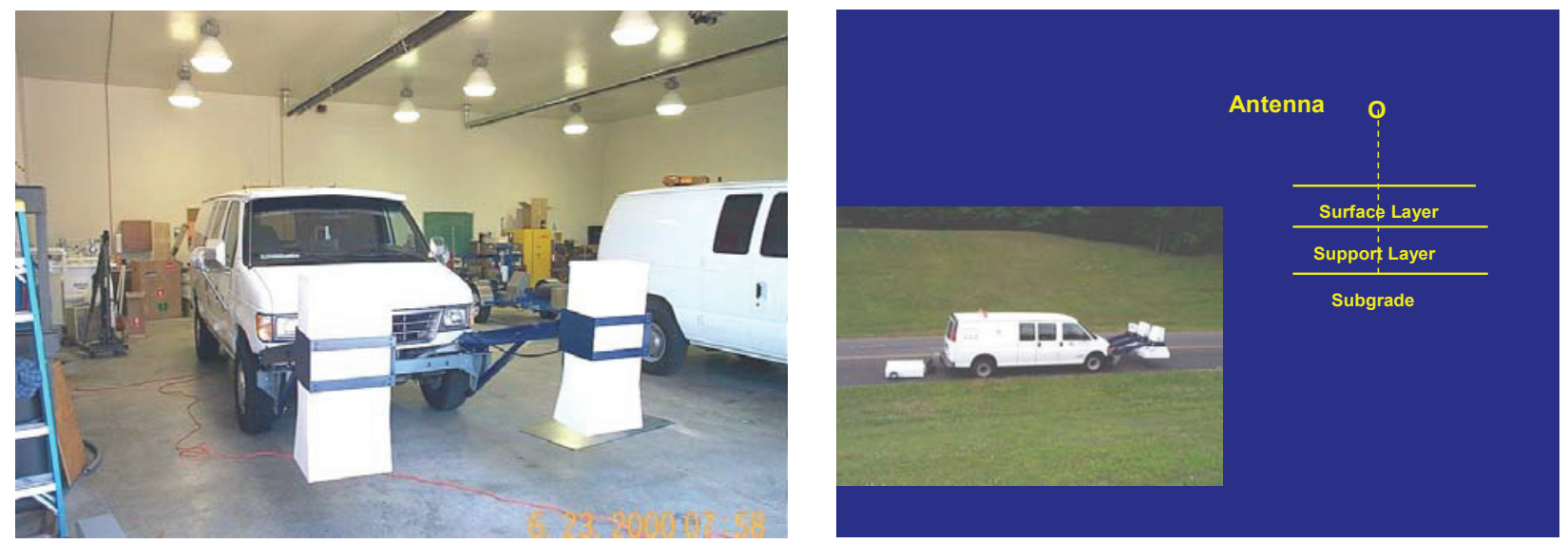

Figure 2.1: Ground Penetrating Radar Mounted on a Van

\subsubsection{Main GPR Fundamentals for Pavement Thickness Estimation}

GPR is a high resolution geophysical technique that utilizes electromagnetic radar waves to scan shallow subsurface, provide information on pavement layer thickness or locate targets (16 - 19). Frequency of GPR antenna affects depth of penetration $(16-19)$. Lower frequency antennas penetrate further, but higher frequency antennas yield higher resolution. To successfully provide pavement thickness information or scan an interface, the following conditions have to be present $(16-19)$; 
- The physical properties of the pavement layers must allow for penetration of the radar wave.

- The interface between pavement layers must reflect the radar wave with sufficient energy to be recorded.

- The difference in physical properties between layers separated by interfaces must be significant.

Physical (electrical) properties of pavement layers, thickness of pavement layers, and magnitude of difference between electrical properties of successive pavement layers impact the ability to detect thickness information using GPR $(16-19)$. Depth of penetration of radar wave into a pavement layer depends on electrical properties of that layer. Radar wave will penetrate much deeper in an electric resistive layer than in an electric conductive layer. Layers with similar physical properties will be detected as one layer $(16-19)$.

Conductive losses occur when electromagnetic energy is transformed into thermal energy to provide for transport of charge carriers through a specific medium. Presence of moisture or clay content in a pavement layer will cause significant conductive losses and hence will increase the dielectric permittivity and decrease depth of penetration $(16-19)$.

GPR measurement of pavement layer thickness is calculated from the travel time of the radar wave;

\section{Pavement Layer Thickness, inches $=\frac{5.9 \Delta t}{\sqrt{\varepsilon_{r}}}$}

$\Delta t=$ two- way travel time in nanoseconds (the time the radar wave travels to the target interface and back).

$\mathcal{E}_{r}=$ relative apparent dielectric constant of pavement layer.

Travel time is determined by interpretation of GPR scan (Figures 2.2 to 2.4). The Y-axis of a GPR scan is the two way travel time (in nanoseconds).

The relative apparent dielectric constant of a pavement layer, $\boldsymbol{\varepsilon}_{r}$, can be calculated knowing the amplitude of a radar wave reflected off the surface of that pavement layer (obtained during testing)and the amplitude of a radar wave reflected off a metal plate (16-19). First amplitude is determined when testing on the road and the second amplitude is determined during calibration process conducted daily before data collection. Figure 2.5 shows the GPR during calibration.

The relative dielectric constant of a pavement layer can also be backcalculated knowing the real pavement layer thickness through coring. 


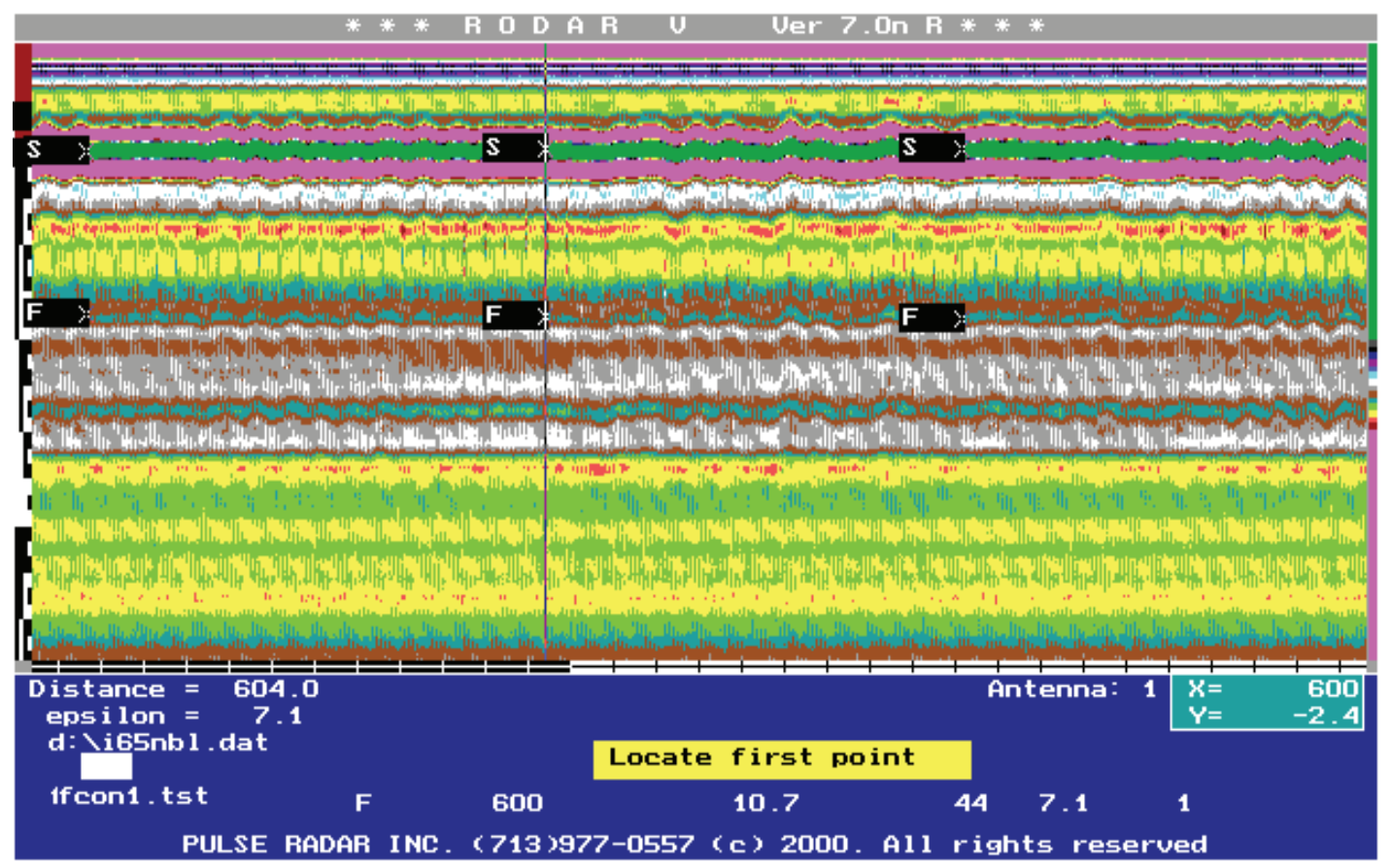

I - 65 North Bound Driving Lane

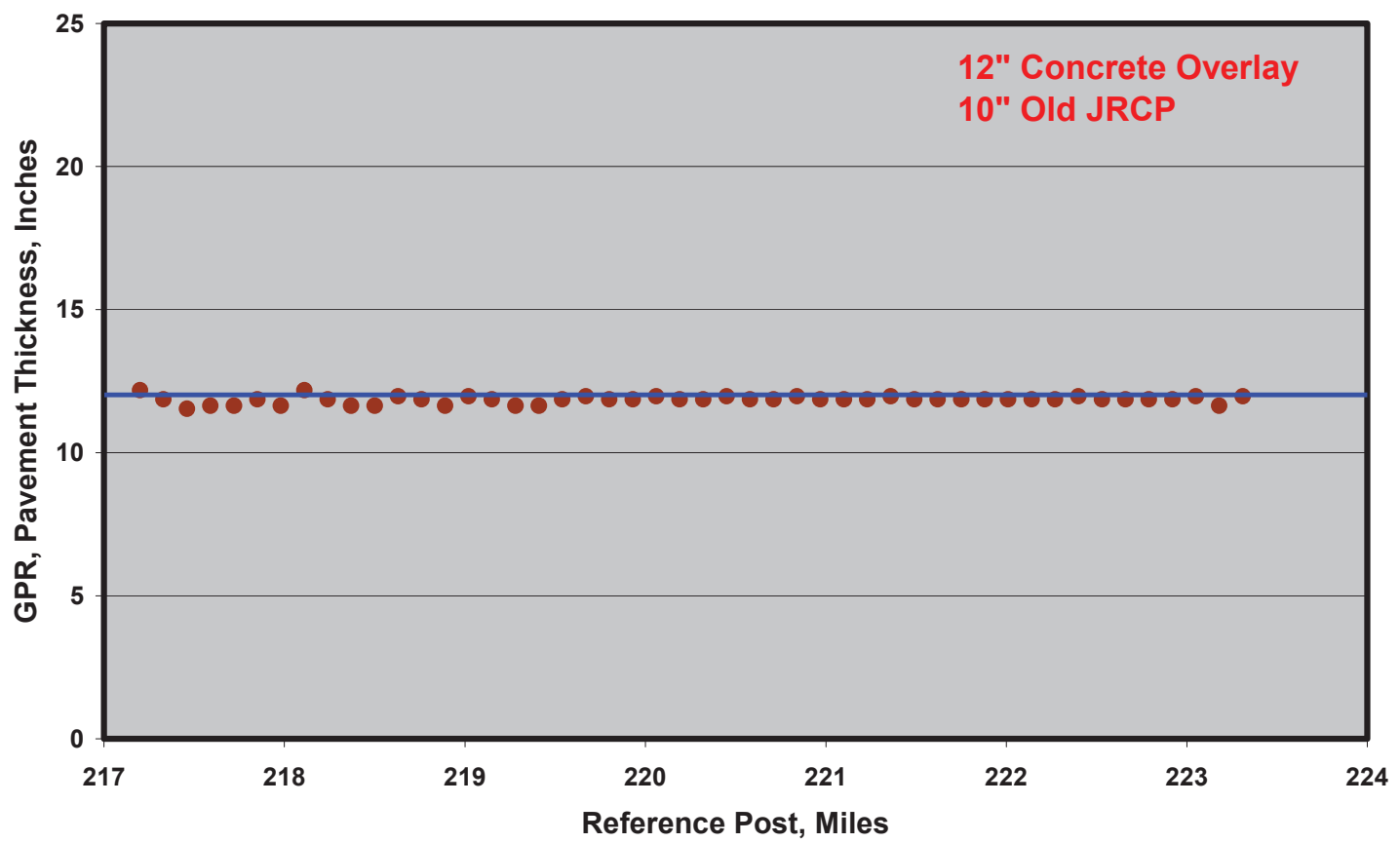

Figure 2.2: GPR Scan Record from a 12" Concrete Pavement on a 10" Old JRCP on an 8" Aggregate Base on I - 65 


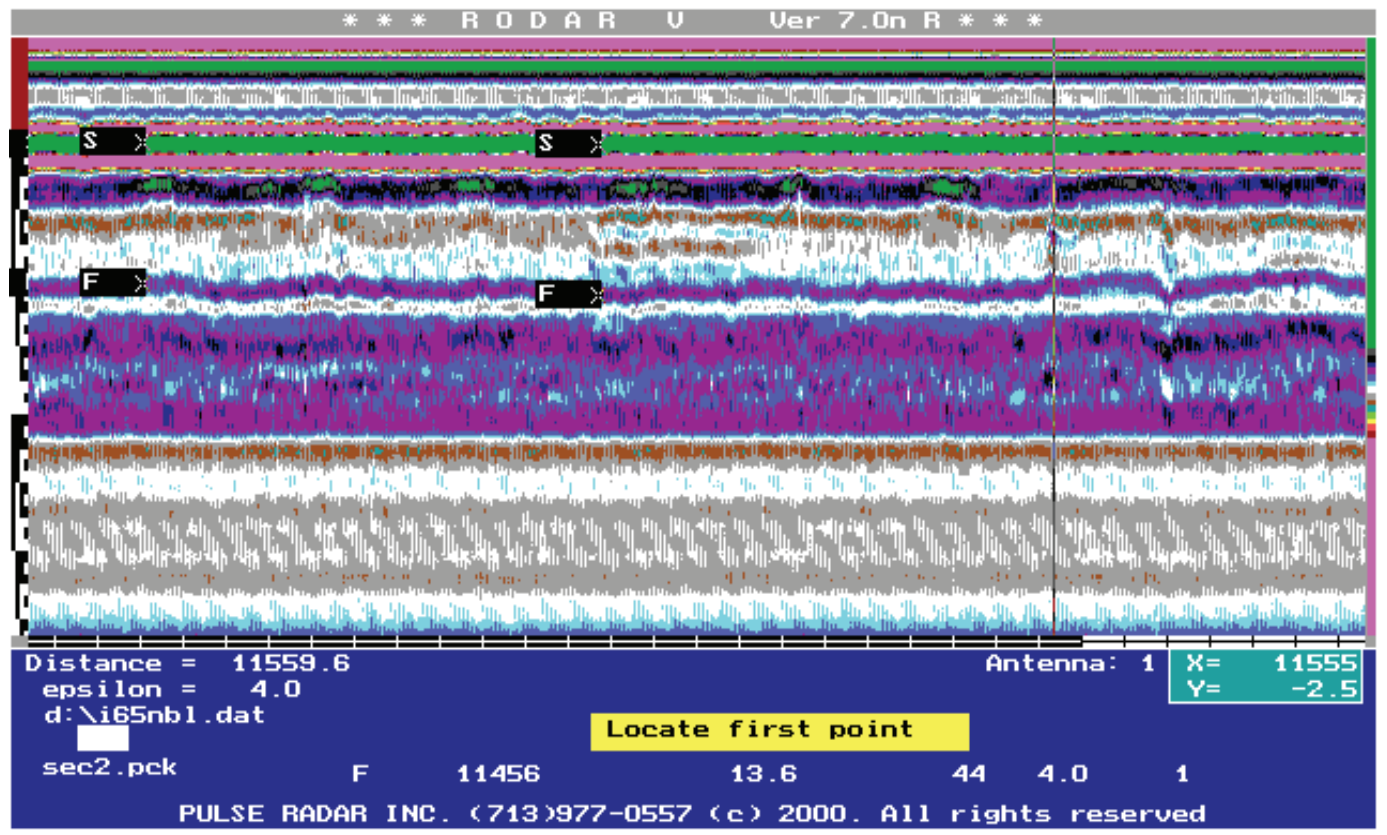

I - 65 North Bound Driving Lane

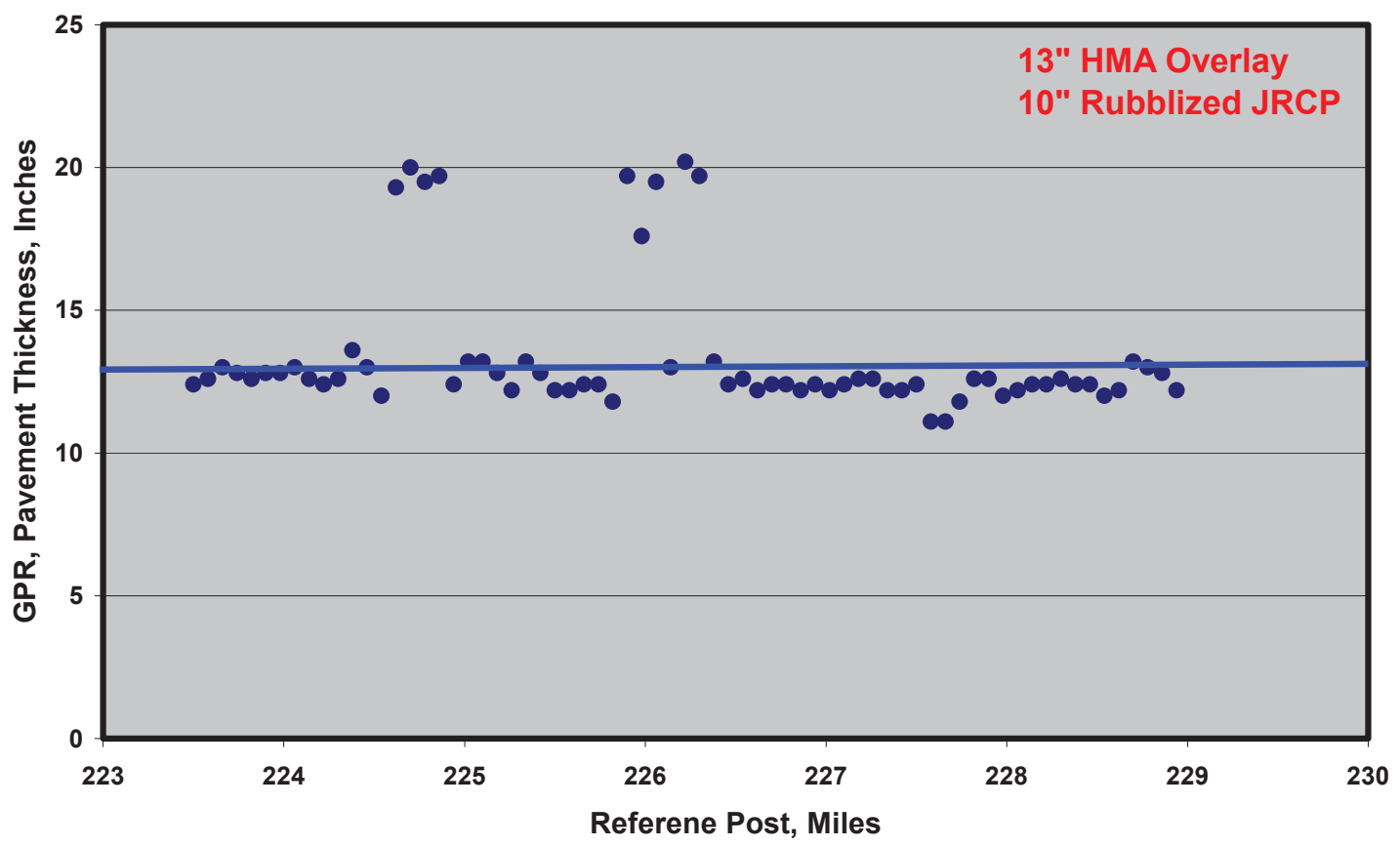

Figure 2.3: GPR Scan Record from a 13" HMA Pavement on a 10" Rubblized JRCP on an 8" Aggregate Base on I - 65 


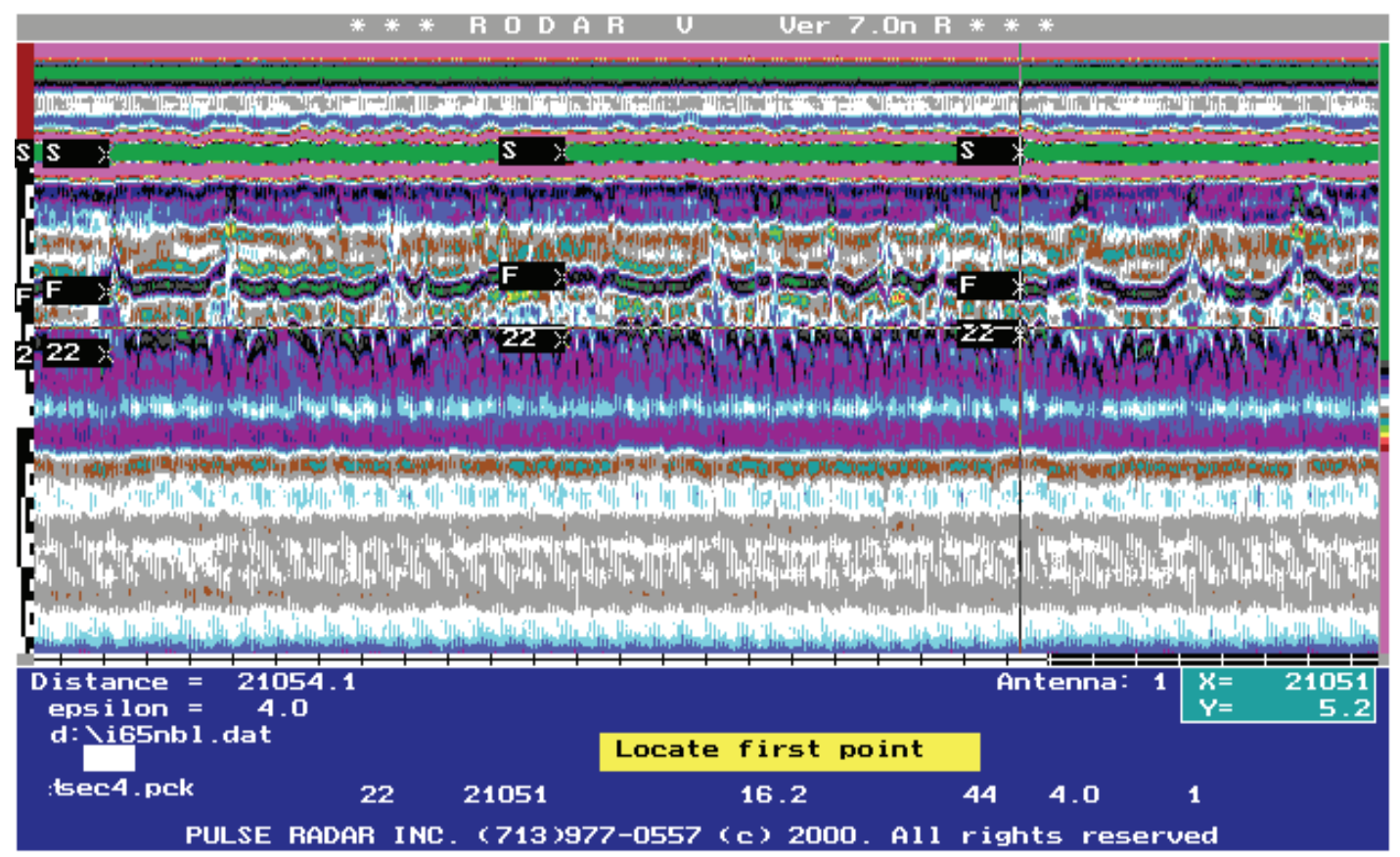

I - 65 North Bound Driving Lane

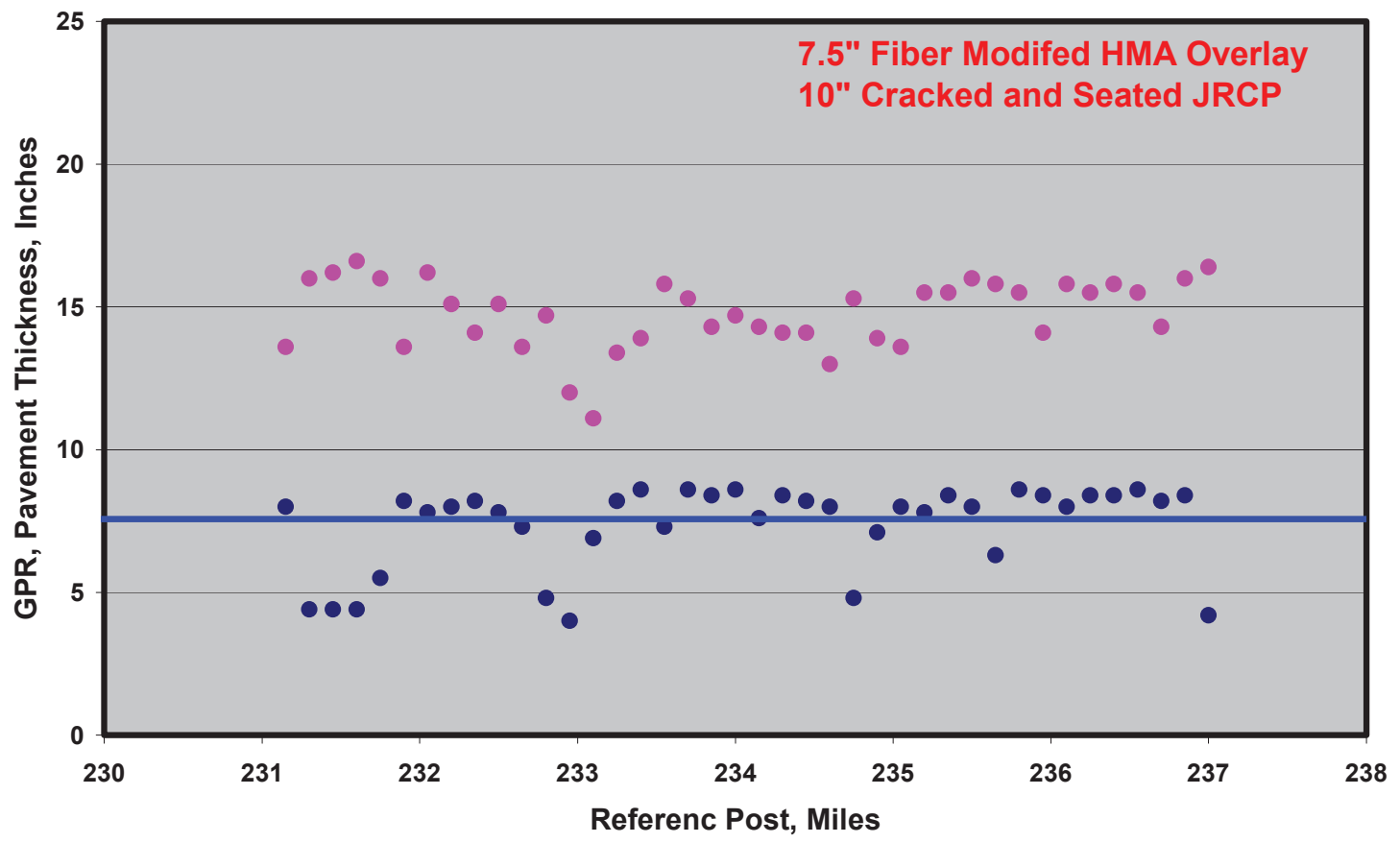

Figure 2.4: GPR Scan Record from a 7.5” Fiber Modified HMA Pavement on a 10" Cracked and Seated JRCP on an 8" Aggregate Base on I - 65 


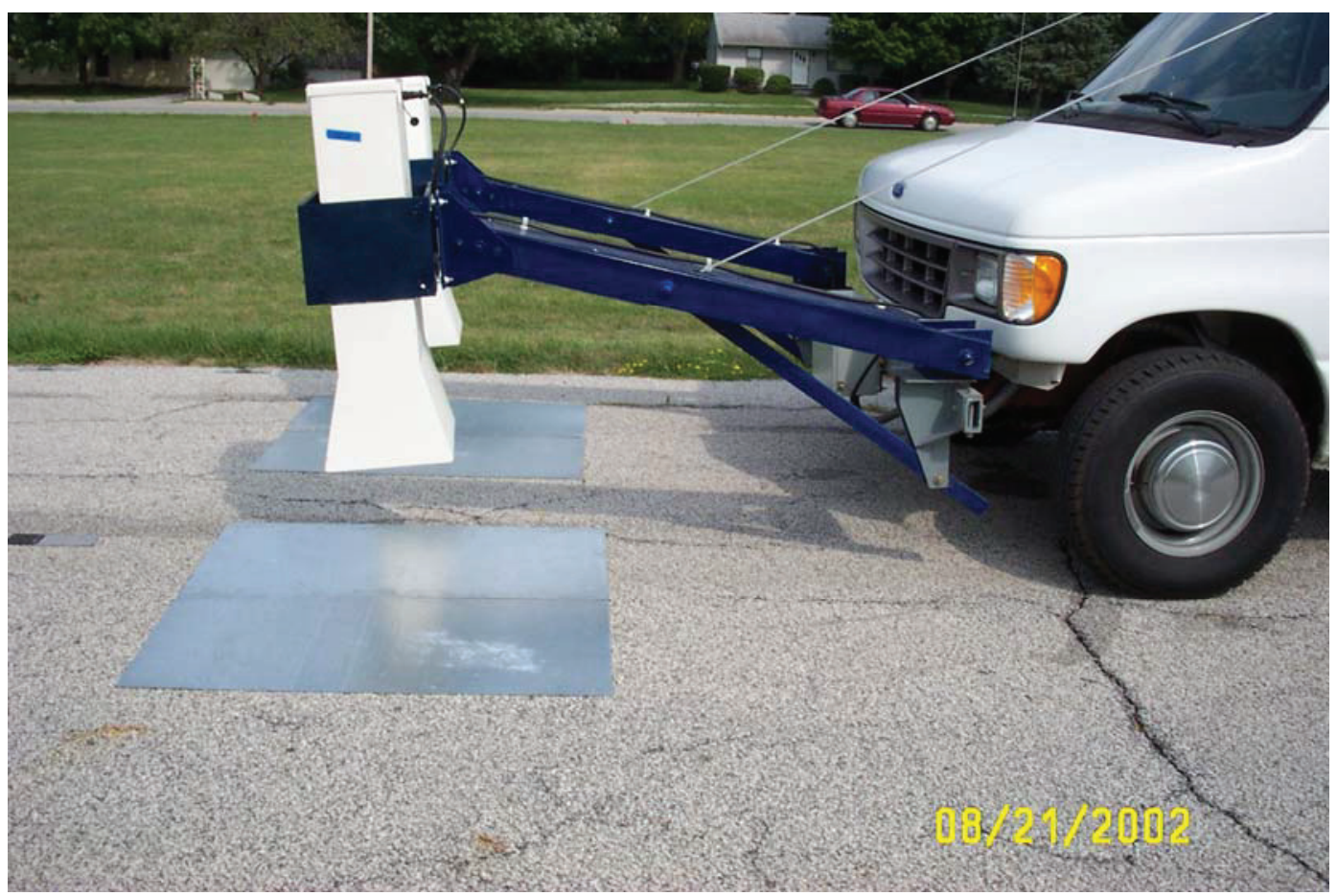

Figure 2.5: Calibration of GPR Using Metal Plates before Pavement Surface Testing

Table 2.1 presents relative dielectric constants for some materials. Dielectric constants for INDOT pavements were found to be in the vicinity of 4.0 for asphalt surfaces and 7.1 for concrete surfaces. Presence of water in a pavement layer increases relative dielectric constant of that layer.

Table 2.1: Relative Apparent Dielectric Constant (15)

\begin{tabular}{|c|c|c|}
\hline Material & Mean & Range \\
\hline Portland Cement Concrete & 9 & $\mathbf{6}-\mathbf{1 2}$ \\
\hline Asphalt Concrete and Dry Sand & $\mathbf{5}$ & $\mathbf{3}-\mathbf{7}$ \\
\hline Rock & 9 & $\mathbf{6}-\mathbf{1 2}$ \\
\hline Dry Aggregate Base/ Subbase & 7 & $\mathbf{5}-\mathbf{9}$ \\
\hline Wet Aggregate Base/Subbase & $\mathbf{1 5}$ & $\mathbf{1 0 - 2 0}$ \\
\hline Subgrade & $\mathbf{1 5}$ & $\mathbf{5 - 2 5 ^ { * }}$ \\
\hline Air & $\mathbf{1}$ & \\
\hline Water & $\mathbf{8 0}$ & \\
\hline
\end{tabular}

* Note: Values $\geq 15$ represent full saturation and values $\geq 10$ represent partial saturation. 
GPR data can be collected such that a trace can be recorded every $3 \mathrm{ft}(914 \mathrm{~mm})$ or less depending on traveling speed. The X-axis of a GPR scan represents both the time and distance along the travel path. The Y-axis of the GPR scan is the two-way travel time. GPR scan should not be interpreted as a pavement cross section. The bands at the top of a radar scan (which represent the information above peak amplitudes) are disregarded. These bands are due to antenna design and do not represent interfaces. The peak amplitude represents the reflection of the air pavement surface interface. Bands that are associated with identifiable amplitudes and changes with location (traveling distance) are considered an interface and used for thickness calculations. Figure 2.6 shows the amplitudes associated with pavement surface and the interfaces between pavement layers. Bands are sometimes caused by antenna ringing down. These bands do not represent reflections and hence are also disregarded.

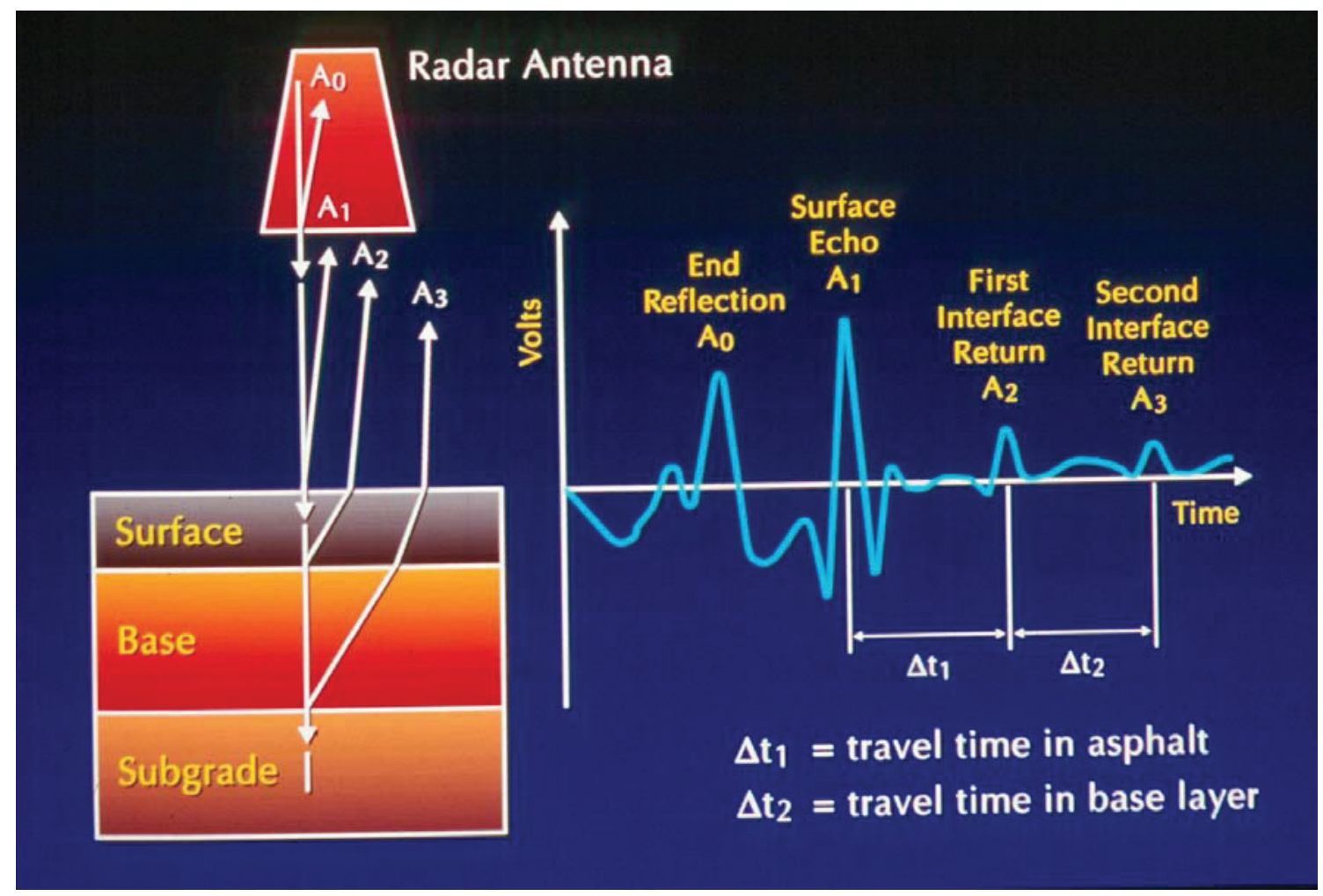

Figure 2.6: Amplitudes Associated with Pavement Surface and Interfaces between Layers 
There is a minimum detectable layer thickness that is dependent upon the frequency of the antenna. Higher frequency antennas offer higher resolution; however, the depth of penetration and power available decrease. Lower frequency antennas allow deeper penetration and more power, but the resolution decreases. Minimum detectable layer thickness is related to resolution. Values for minimum detectable pavement layer thickness are given in Table 2.2.

Table 2.2: GPR Minimum Detectable Pavement layer Thickness

\begin{tabular}{|c|c|c|c|c|}
\hline Antenna Frequency & \multicolumn{2}{|c|}{$500 \mathrm{MHz}$} & \multicolumn{2}{c|}{$\mathbf{G H z}$} \\
\hline Surface Type & Asphalt & Concrete & Asphalt & Concrete \\
\hline Dielectric Constant & 4.0 & 7.1 & 4.0 & 7.1 \\
\hline Minimum Thickness, inches & $\mathbf{3 . 0 0}$ & $\mathbf{2 . 2 5}$ & 1.5 & 1.125 \\
\hline
\end{tabular}

\subsubsection{GPR Traffic Control Measures}

GPR testing does not require traffic control measures during data collection. Data collection can be done at $55 \mathrm{mph}$ travel speed. 


\subsection{Falling Weigh Deflectometer, FWD}

\section{$\underline{\text { 2.2.1 FWD Assembly }}$}

Falling Weight Deflectometer, FWD, is a device that applies an impact Force (load) on a 12 inches $(3000 \mathrm{~mm})$ diameter circular plate to pavement surface (Figure 2.7). Force magnitude is the multiplication of a falling mass by impact acceleration. Sensors located at loading center and at fixed radii from loading center measure resulting surface deflections. Resulting set of deflections is known as the deflection basin. Deflection testing for Indiana Department of Transportation, INDOT, is conducted using a fleet of 4 FWD's that are calibrated periodically using a local accredited calibration center based on SHRP protocols and AASHTO standards.
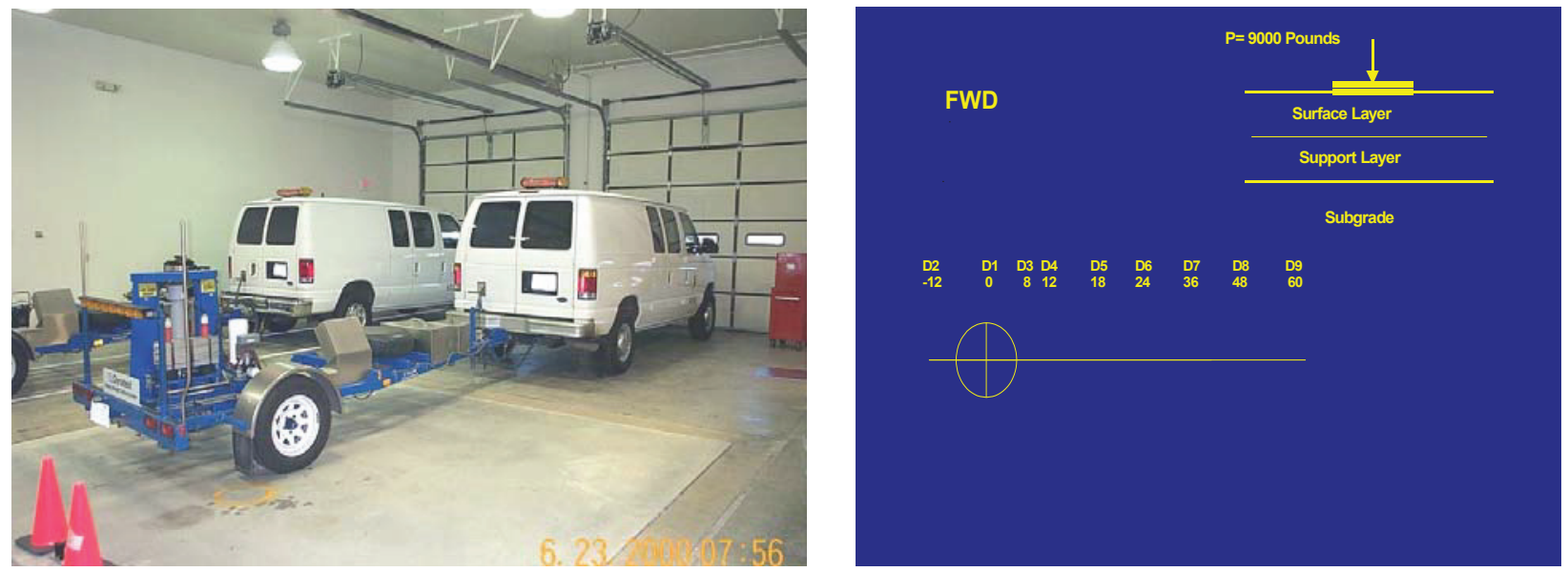

Figure 2.7: Falling Weight Deflectometer

\subsubsection{Main FWD Fundamentals for Pavement Characterization}

FWD center deflection data reflects the overall structural capacity of the pavement. This data usually need to be normalized to a standard load (generally 9000 pounds for highways) and a standard temperature (generally $68^{\circ} \mathrm{F}$ ). Normalized center deflection data can be directly used for pavement evaluation and overlay design. Table 2.3 presents pavement structural condition as defined by center deflection and used for general pavement structural evaluation (20). It should be noted that values presented in Table 2.3 are applicable for HMA, concrete or Composite pavements given the fact that ESALs computation for HMA pavement differs between HMA and concrete pavements. 
Table 2.3: Pavement Structural Condition as Defined by Center Deflection in mils (25.4 microns) for a 9000 Pounds (40 Kilo Newton) Load at $68^{\circ} \mathrm{F}\left(20^{\circ} \mathrm{C}\right)$

\begin{tabular}{|c|c|c|c|c|c|c|}
\hline $\begin{array}{c}\text { ESALs, Millions } \\
\text { Condition }\end{array}$ & $>\mathbf{3 0}$ & $10-30$ & $3-10$ & $1-3$ & $0.3-1$ & $<0.3$ \\
\hline Excellent & $<4$ & $<5$ & $<6$ & $<8$ & $<10$ & $<12$ \\
\hline Very Good & $4-6$ & $5-7$ & $6-8$ & $8-10$ & $10-12$ & $12-14$ \\
\hline Good & $6-8$ & $7-9$ & $8-10$ & $10-12$ & $12-14$ & $14-16$ \\
\hline Fair & $8-10$ & $9-11$ & $10-12$ & $12-14$ & $14-16$ & $16-18$ \\
\hline Poor & $>10$ & $>11$ & $>12$ & $>14$ & $>16$ & $>18$ \\
\hline
\end{tabular}

Table 2.4 presents the HMA pavement temperature correction values used by INDOT in accordance to the 1993 AASHTO Guide (2). Corrected center deflection is the measured deflection divided by the correction factor. Correction factors are based on mean pavement temperature calculated using air and surface temperature data collected by the FWD.

Table 2.4: HMA Pavement Temperature Correction Factors for FWD Center Deflection

\begin{tabular}{|l|l|l|l|l|l|l|l|l|l|l|}
\hline $\begin{array}{l}\text { Mean Pavement } \\
\text { Temperature, }{ }^{\mathbf{0}} \mathrm{F}\end{array}$ & 41 & 50 & 59 & 68 & 77 & 86 & 95 & 104 & 113 & 122 \\
\hline $\begin{array}{l}\text { Temperature } \\
\text { Correction Factor }\end{array}$ & $\mathbf{0 . 7 4}$ & $\mathbf{0 . 8 1}$ & $\mathbf{0 . 9 0}$ & $\mathbf{1 . 0 0}$ & $\mathbf{1 . 1 1}$ & 1.22 & 1.34 & 1.46 & 1.59 & 1.72 \\
\hline
\end{tabular}

\section{$\underline{\text { 2.2.3 Backcalculation of pavement layer moduli }}$}

Backcalculation of pavement layer moduli using FWD deflection basin measurements is commonly performed through a number of techniques that are currently available $(4,5)$. ELMOD, MODULUS, MODTAG and MODCOMP are among those well known techniques that are typically used by pavement researchers and practitioners. In these techniques, pavement remaining lives in both fatigue and permanent deformation are computed and used for pavement evaluation and design purposes $(4,5)$.

These backcalculation techniques require layer thickness information through coring or GPR information. It is impossible to use these techniques without thickness information and hence, it becomes almost impossible to use these techniques for pavement structural characterization at the network level. It is also impossible to use these techniques to perform backcalculation analysis at every FWD testing point for a huge amount of data without significant averaging a large number of testing points together. A lot of information about pavement layer characteristics is usually lost due to this "averaging" process. 
Characteristics of pavement layers, thickness of pavement layers, and the magnitude of difference between material properties of successive pavement layers impact the ability to detect the thickness and moduli information using FWD. Pavement layers with similar material properties will be detected as one pavement layer.

A simplified method for calculating pavement layer moduli and thicknesses directly from FWD deflection basin was developed by Noureldin (7). In this method (BACKCAL), layer moduli are estimated using FWD sensors that deflect exactly the same as the interfaces between pavement layers. Central sensor is at the first interface. Sensors used for moduli calculation are also used for calculating estimated layer thicknesses (7). Pavement layer moduli and thicknesses determined by this method were validated in a number of other research and field studies 8 10). All computations using this method are made with a spreadsheet that allows analysis of data for every FWD testing point. Because this method does not require thickness information and its simplicity, it provides a useful tool in analyzing FWD deflection data at the network level and for those situations in which thickness information is not available. This method was also proven to be successful for project level evaluation and for investigating sensitivity of pavement layers to stress levels temperature and moisture levels (7).

The main advantage of this technique is that thickness data is not required for the backcalculation process and hence it provides a useful tool in analyzing FWD deflection data particularly at the network level.

BACKAL computations are conducted using the following equations:

\section{Subgrade Modulus, $E_{\text {Subgrade, }}$ Ksi}

$$
\mathrm{E}_{\text {Subgrade }}=\frac{2149}{\mathrm{r}_{\mathrm{x}} \mathrm{D}_{\mathrm{x}}} \times \frac{\text { Actual FWD Load, Pounds }}{9000}
$$

- $\mathrm{r}_{\mathrm{x}} \mathrm{D}_{\mathrm{x}}=$ largest deflection radii multiplication (i.e. $\mathrm{r}_{8} \mathrm{D}_{8}, \mathrm{r}_{12} \mathrm{D}_{12}, \mathrm{r}_{18} \mathrm{D}_{18}, \mathrm{r}_{24} \mathrm{D}_{24}, \mathrm{r}_{36} \mathrm{D}_{36}, \mathrm{r}_{48} \mathrm{D}_{48}$ and $\mathrm{r}_{60} \mathrm{D}_{60}$ ). Radii and deflection units are in inches and mils, respectively.

Subgrade modulus obtained using this equation matches exactly with that obtained using the 1993 AASHO Guide algorithm (2), if the same sensor used to calculate that modulus is picked. To estimate the subgrade resilient modulus, MR, values obtained using the above equation is divided by 3 as prescribed in the 1993 AASHTO Guide (2). Pavement support layer (base and subbase) moduli are estimated employing the same equation and using measurements of sensors located between the sensor used for subgrade modulus computation and the sensor underneath the loading center.

Derivations of the above equation and the following equations are given in the appendix. 


$$
\mathrm{E}_{\mathrm{P}}=\frac{716-\frac{2149}{\mathrm{r}_{\mathrm{x}}}}{\mathrm{D}_{0}-\mathrm{D}_{\mathrm{x}}} \times \frac{\text { Actual FWD Load, Pounds }}{9000}
$$

- $\mathrm{E}_{\mathrm{P}}=$ Pavement Modulus (combined for pavement layers on top of the subgrade) in Ksi

- $r_{x}$ and $D_{x}$ are the same as for subgrade, (i.e. the values associated with maximum $r_{x} D_{x}$ ) and $\mathrm{D}_{0}$ is the center deflection in mils.

The above equation can also be used to calculate the surface layer modulus only. In this case $\mathrm{D}_{8}$ (the closest sensor located at 8 " from loading center) is designated as $D_{x}$. as follows;

\section{Surface Modulus, $E_{\text {Surface, }}$ Ksi}

$$
\mathrm{E}_{\text {Surface }}=\frac{716-\frac{2149}{8}}{\mathrm{D}_{0}-\mathrm{D}_{8}} \times \frac{\text { Actual FWD Load, Pounds }}{9000}
$$

When thickness data is known or the surface layer is thin (lower than 4") the following equation of equivalent thickness is preferred in calculating the surface modulus.

$$
\mathrm{E}_{\text {Surface }}=\left(\frac{\sqrt[3]{\mathrm{E}_{\mathrm{P}}} \mathrm{T}_{\mathrm{P}}-\sqrt[3]{\mathrm{E}_{\text {Support }}} \mathrm{T}_{\text {Support }}}{\mathrm{T}_{\text {Surface }}}\right)^{3}
$$

- $\quad \mathrm{E}_{\text {Surface }}=$ Surface Modulus in Ksi

- $\mathrm{E}_{\mathrm{P}} \& \mathrm{E}_{\text {Support }}$ are pavement \& support moduli and $\mathrm{T}_{\mathrm{P}}, \mathrm{T}_{\text {Support }} \& \mathrm{~T}_{\text {Surface }}$ are the layer thicknesses in inches. 
Layer moduli backcalculation is conducted for FWD data before any temperature correction. Backcalculated asphalt concrete layer modulus only is then normalized to a standard temperature (usually ${ }^{\circ} 68 \mathrm{~F}$ ).

\section{Temperature Corrected $E_{\text {Surface }}=E_{\text {Surface } / \text { Correction Factor }}$}

\section{Correction Factor $=(1.0000008)^{314432-T^{3}}$}

- $\quad \mathrm{T}=$ mean temperature of asphalt concrete layer, ${ }^{0} \mathrm{~F}$, measured at the mid - depth of that layer or calculated using air and surface temperature data collected by the FWD.

Total Thickness, $T_{x}$, inches

$$
\mathrm{T}_{\mathrm{x}}=0.5\left[\frac{\mathrm{D}_{\mathrm{o}}-\mathrm{D}_{\mathrm{x}}}{\mathrm{D}_{\mathrm{x}}\left(\frac{\mathrm{r}_{\mathrm{x}}}{3}-1\right)}\right]^{1 / 3} \times\left(4 \mathrm{r}_{\mathrm{x}}{ }^{2}-36\right)^{1 / 2}
$$

- $r_{x}$ and $D_{x}$ are the same as defined above, (i.e. the values associated with maximum $r_{x} D_{x}$ ) and $\mathrm{D}_{0}$ is the center deflection in mils.

Surface Thickness, $T_{\text {Surface, }}$ inches

$$
\mathrm{T}_{\text {Surface }}=23.2379\left[\frac{\mathrm{D}_{\mathrm{o}}-\mathrm{D}_{12}}{3 \mathrm{D}_{12}}\right]^{1 / 3}
$$

- $\mathrm{D}_{0}$ and $\mathrm{D}_{12}$ are (the center deflection and the deflection of the sensor located at radii of 12 inches) in mils. 


\section{Layer Coefficients and Structural Numbers}

AASHTO layer coefficients and structural numbers are calculated employing backcalculated moduli and using the following equations reported by Noureldin (7) and based on the 1993 AASHTO Guide (2);

Surface Layer Coefficient, $a_{1}$

$$
a_{1}=\left(\frac{\text { Temp. Corrected Surface Modulus, Ksi }}{11 \times 10^{3}}\right)^{1 / 3}
$$

Support Layer Coefficient, $a_{2}$

$$
\mathrm{a}_{2}=\left(\frac{\text { Support Modulus, Ksi }}{11 \times 10^{3}}\right)^{1 / 3}
$$

Structural Numbers are calculated by multiplying the layer coefficient of a specific layer by its thickness.

\section{Use of Backcalculated Moduli Values in Mechanistic Empirical Pavement Analysis}

Backcalculated moduli and thickness values can be employed to calculate stresses and strains at specific locations within the pavement system. Computer software such as ELSYM 5, CHEVRON or BISAR can be used for that purpose (21-28).

Pavement remaining life to failure in ESALs due to fatigue cracking and permanent deformations (rutting) can be calculated employing these stresses, strains and moduli (21-28) as follows;

Remaining Life to Failure in Fatigue Cracking

$$
\log \text { ESALs }=a-b \log \varepsilon_{t}-c \log \mathbf{E}_{\text {HMA }}
$$

Remaining Life to Failure in Permanent Deformation

$$
\log \mathrm{ESALs}=\mathrm{d}-\mathrm{e} \log \varepsilon_{\mathrm{c}}
$$


- $\varepsilon_{\mathrm{t}}=$ maximum tensile strain within hot mix asphalt, HMA, layer (microstrain)

- $\varepsilon_{\mathrm{c}}=$ compressive strain on the top of subgrade layer (microstrain) or unbound granular layer (base or subbase).

- $\mathrm{ESALs}=$ number of $18 \mathrm{kips}(80 \mathrm{KN})$ single axle load repetitions to an acceptable degree of cracking or an acceptable rut depth.

- $\mathrm{E}_{\mathrm{HMA}}=\mathrm{HMA}$ stiffness modulus, $\mathrm{MPa}(1 \mathrm{MPa}=145 \mathrm{psi})$

- $\mathrm{a}, \mathrm{b}, \mathrm{c}, \mathrm{d}, \mathrm{e}=$ material coefficients (material coefficients suggested by some procedures are given in Tables 2.5 and 2.6) .

Table 2.5: Material Coefficients for Fatigue Cracking Analysis

\begin{tabular}{|c|c|c|c|c|}
\hline Procedure & Reference & a & b & c \\
\hline ILLI-PAVE & 22 & 12.699 & 3 & 0 \\
\hline Finn, et al & 21 & 15.536 & 3.291 & 0.854 \\
\hline
\end{tabular}

Table 2.6: Material Coefficients for Permanent Deformation (Rutting) Analysis

\begin{tabular}{|c|c|c|c|}
\hline Procedure & Reference & d & e \\
\hline Nottingham & 23 & 15.5 & 3.57 \\
\hline Shell & 24 & 17 & 4.0 \\
\hline Asphalt Institute & 25 & 18 & 4.477 \\
\hline Chevron & 26 & 18 & 4.4843 \\
\hline
\end{tabular}


Remaining life in ESALs can also be estimated employing the 1993 AASHTO design equation, using backcalculated moduli values and setting a specific serviceability range of

$\Delta \mathrm{PSI}=1.7$ i.e. $(\mathbf{4 . 2 - 2 . 5 )}$;

$$
\log _{10} \text { ESALs }=9.36 \log _{10}(\mathrm{SN}+1)-0.20+\frac{\log _{10}\left[\frac{\Delta \mathrm{PSI}}{4.2-1.5}\right]}{0.4+\frac{1094}{(\mathrm{SN}+1)^{5.19}}}+2.32 \log _{10}(\mathrm{MR})-8.07
$$

- $\mathrm{M}_{\mathrm{R}}=$ Subgrade resilient modulus in psi (which can be obtained from dividing backcalculated subgrade modulus by 3 ).

- $\mathrm{SN}=$ Total pavement structural number which can also be obtained via backcalculation analysis.

\subsubsection{FWD Testing Traffic Control Measures}

FWD testing is conducted on the driving lane while testing vehicle is at complete stop and hence requires traffic control measures for road users and testing operators' safety requirements. On multi-lane highways a dump truck (called a buffer truck) loaded with sand and preferably equipped with an attenuator or arrow board follows the FWD in the testing lane approximately 100 to 200 feet behind. The sole purpose of this truck is to absorb the impact of any vehicle that disregards the previous two dump trucks. A second dump truck loaded with sand and equipped with an arrow board follows the testing crew in the testing lane approximately 500 to 1,000 feet from the FWD. A third dump truck loaded with sand and equipped with an arrow board (or transition sign if the arrow board is unavailable) is also used. This truck follows the FWD on the shoulder approximately 3,000 feet behind. On low volume multi-lane highways only two dump trucks may be used with one on the shoulder and the one following the FWD approximately 100200 feet behind. 


\section{Chapter 3}

\section{EXPERIMENTAL DESIGN AND TESTING PROGRAM}

\subsection{Roadway Selection}

Indiana interstate highways I $-64, \mathrm{I}-65, \mathrm{I}-69, \mathrm{I}-70$ and I -74 are selected to provide as much comprehensive coverage for the Interstate network system as possible (Figure 5). State Roadways; US - 6, US - 20, US - 24, US - 30 and US - 41 and State Routes SR - 1, SR - 3, SR -5 , SR $-19, \mathrm{SR}-32, \mathrm{SR}-37, \mathrm{SR}-49, \mathrm{SR}-67$, and $\mathrm{SR}-250$ are selected such that districts, facility types and pavement types, are represented (Figure 3.1).
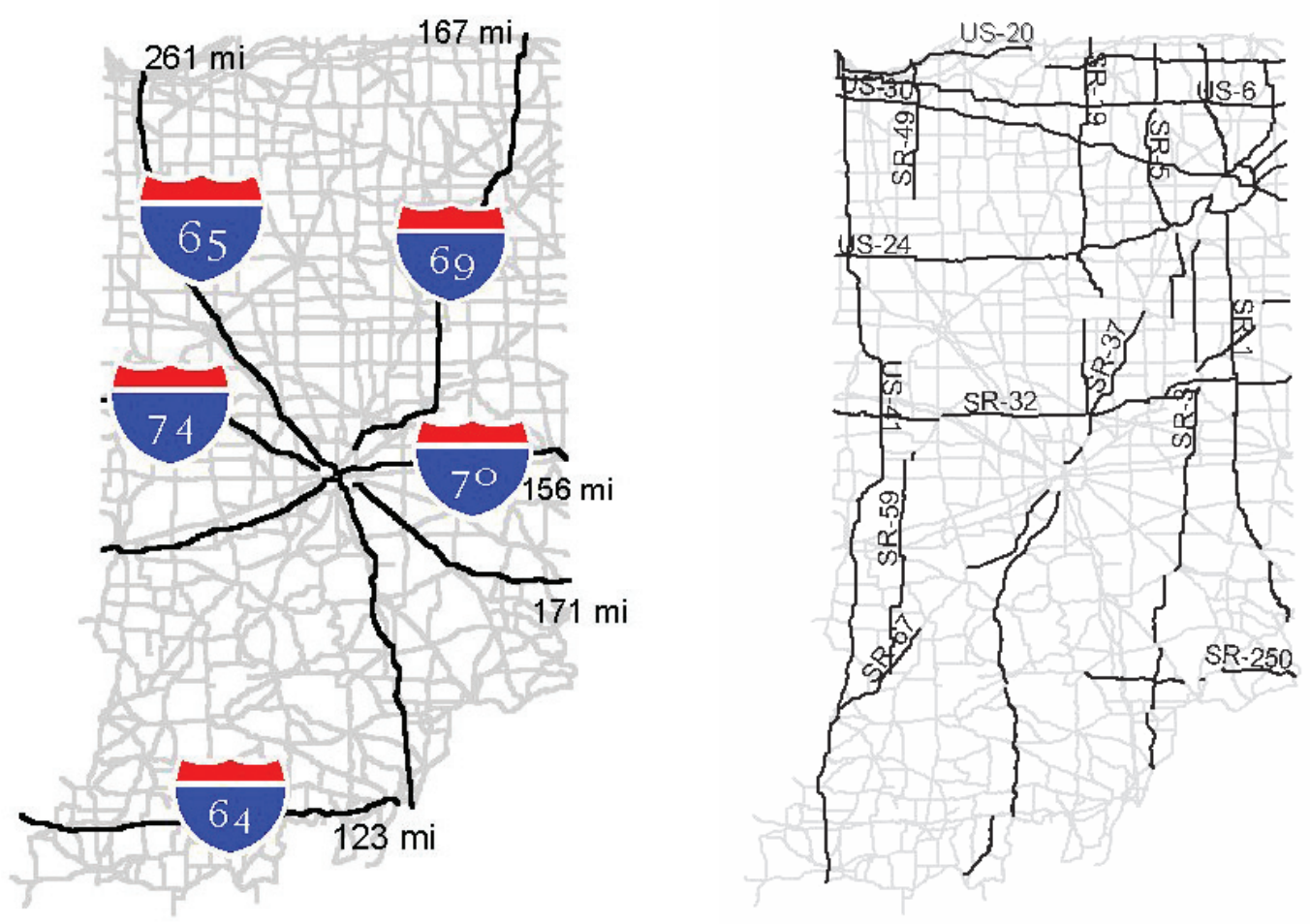

Figure 3.1: Interstate Highways, U.S. Roads and State Routes Tested During the Study 


\subsection{Data Collection}

\subsubsection{Data Collection Employing the FWD}

The FWD is used to test the driving lane for both bound directions (east - west or north - south) of each selected roadway. Deflections are measured at 5 locations per mile, (every $1000 \mathrm{ft}$ ). Measurements are taken at approximately $3 \mathrm{ft}$ from pavement edge. These measurements are obtained during the construction seasons of 2001 and 2002. Deflection testing was not conducted within cities or on locations where traffic may be disrupted or hazard to testing operator or road user is expected. Based on this scope, 12000 FWD measurements are taken.

\subsubsection{Data Collection Employing the GPR}

The GPR is used to test the driving lane for both bound directions (east - west or north - south) of each selected roadway at highway speed. Although the GPR can continuously display thickness of pavement layers, it was decided to measure the thickness at 5 locations per mile, (every $1000 \mathrm{ft}$ ) to be consistent with the data collected by the FWD. These measurements are obtained during the construction seasons of 2001.

\subsubsection{Coring Data}

A limited number of pavement cores were obtained for thickness measurements as a verification sample and to compare thicknesses obtained through coring with those obtained employing the FWD and the GPR. A core per mile is extracted from some selected roadways.

\subsection{Response Variables}

The following pavement characteristics are selected as response variables:

- FWD center deflection normalized to a load of 9000 pounds and temperature of $68^{\circ} \mathrm{F}$ in accordance to the 1993 AASHTO Guide (2). Correction factor is based on mean pavement temperature calculated using air and surface temperature data collected by the FWD.

- Pavement layers (subgrade, support and surface) moduli backcalculated from FWD data using the simplified method developed by Noureldin (7). All computations using this method are made with a spreadsheet requiring no thickness information. Results obtained using this method match with those obtained through using the 1993 AASHO Guide algorithm (2). The backcalculation process is conducted for FWD data before any temperature correction. Backcalculated HMA surface modulus values are normalized to $68^{\circ} \mathrm{F}$ temperature.

- FWD estimated total pavement thickness and surface thickness. Pavement surface and total thicknesses are backcalculated from FWD data using the simplified method developed by Noureldin (7). 
- GPR estimated thicknesses of pavement layers.

- Surface and support layer coefficients calculated employing moduli values and the formula reported by Noureldin (7) and the 1993 AASHTO Guide (2).

- Surface, support and total effective structural numbers.

- Remaining life in terms of ESALs. Lowest remaining life in fatigue, permanent deformation and serviceability (1993 AASHTO design Equation) was calculated and correlated only with corrected measured FWD center deflection for a 5 miles segment of each selected roadway. This remaining life-center deflection relationship was generalized on all segments to provide a simple estimation of remaining life from FWD center deflection only;

$$
\text { ESALs }=\frac{5.6 \times 10^{10}}{\mathrm{D}_{\mathrm{o}}^{4.6}}
$$

- $\mathrm{D}_{\mathrm{o}}=$ Normalized Temperature Corrected Center Deflection in mills.

- Overlay thickness required. Overlay thickness is estimated using corrected measured FWD center deflection, deflection values given in Table 2.3 as target deflection values and employing two layer analysis as follows;.

a) Determine Existing Overall Pavement Modulus, Existing pavement, Ksi;

$$
\text { Eexisting pavement, } \mathrm{Ksi}=\frac{728}{\mathrm{D}_{\mathrm{o}}}
$$

b) Determine the two layers deflection factor, $\mathrm{F}_{2}$

$$
\mathrm{F}_{2}=\frac{\mathrm{D}_{\text {Target }}}{\mathrm{D}_{\mathrm{o}}}
$$

- $\mathrm{D}_{\text {Target }}=$ Target pavement surface center deflection after the overlay in mills. 
c) Determine moduli ratio $\mathrm{E}_{\text {overlay }} / \mathrm{E}_{\text {existing pavement }}$

d) Determine equivalent overlay thickness in inches, Z, using Figure 3.2

e) Determine overlay thickness.

$$
\text { Overlay Thickness, inches }=\mathrm{Z} *\left[\frac{\mathrm{E}_{\text {exising pavement }}}{\mathrm{E}_{\text {overlay }}}\right]^{1 / 3}
$$

- Coring measured thicknesses of pavement layers. A limited number of pavement cores were obtained for thickness measurements as a verification sample and to compare thicknesses obtained through coring with those obtained employing the FWD and the GPR. A core per mile is extracted from some selected roadways.

All response variables are averaged for each mile of the roadways selected. Variability and reliability parameters are investigated for each response variable. Variability in terms of coefficients of variation is employed for reliability analyses and safety factors computations for all Interstate highways. 
Equivalent Overlay Thickness, Z, Inches

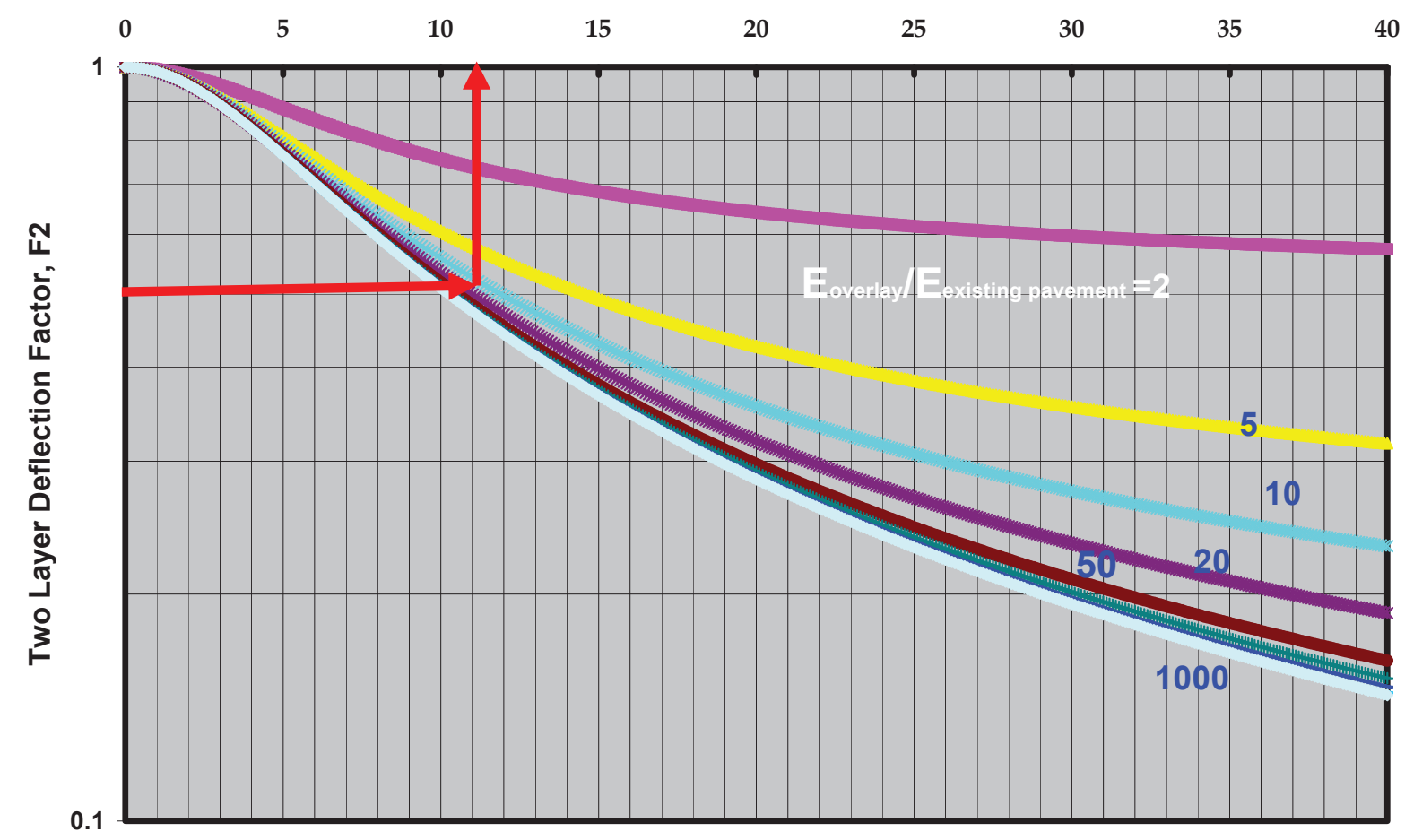

Figure 3.2: Equivalent Overlay Thickness Employing Two layer Analysis (After Burmister; 29)

Example:

- Target FWD pavement surface center deflection after the overlay, $\mathrm{D}_{\text {Target }}=6$ mils

- Existing FWD pavement surface center deflection, $\mathrm{D}_{\mathrm{o}}=12$ mils

- HMA overlay modulus, $\mathrm{E}_{\text {overlay }}=610 \mathrm{Ksi}$

- $\quad \mathrm{E}_{\text {existing pavement }}=728 / 12=61 \mathrm{Ksi}$

- $\mathrm{F}_{2}=6 / 12=0.5$

- $\quad E_{\text {overlay }} / E_{\text {existing pavement }}=610 / 61=10$

- From Figure 3.2, $\mathrm{Z}=11$ inches

- $\quad$ HMA Overlay Thickness $=11 X(61 / 610)^{1 / 3}=5.1$ inches 


\section{Chapter 4}

\section{TESTING RESULTS}

\subsection{GPR at the Project Level}

Figures 4.1 through 4.3 present GPR pavement thickness analysis along I - 65 north bound driving lane from Reference Post 217 to Reference Post 238. GPR estimated the thickness of the 12" concrete overlay perfectly (Figure 4.1). However, pavement layers underneath the concrete overlay were not picked by the GPR at all (Figure 4.1). GPR also estimated the thickness of the 13" HMA overlay almost perfectly (Figure 4.2). However, the 10" rubblized JRCP pavement layer underneath the HMA overlay was not consistently picked by the GPR (Figure 4.2). In addition, it appears that the GPR underestimated the thickness of the rubblized layer. The 8" aggregate base was not picked by the GPR at all (Figure 4.2). GPR also estimated the thickness of the pavement layer representing the 7.5" fiber modified HMA and the pavement layer representing the 10" cracked and seated JRCP (Figure 4.3). The 8" aggregate base was also not picked by the GPR at all (Figure 4.3).

I - 65 North Bound Driving Lane

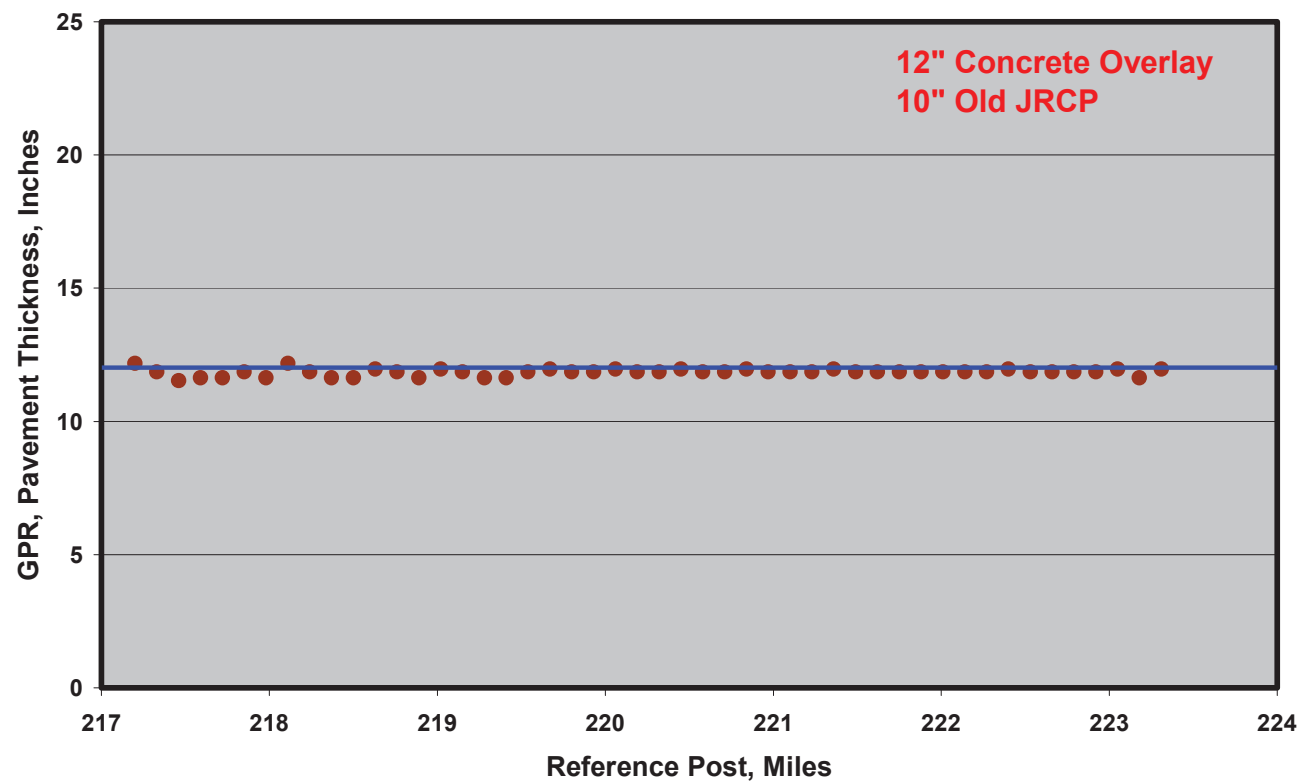

Figure 4.1: GPR Thickness Analysis for a 12" Concrete Pavement on a 10" Old JRCP on an 8” Aggregate Base on I - 65 
I - 65 North Bound Driving Lane

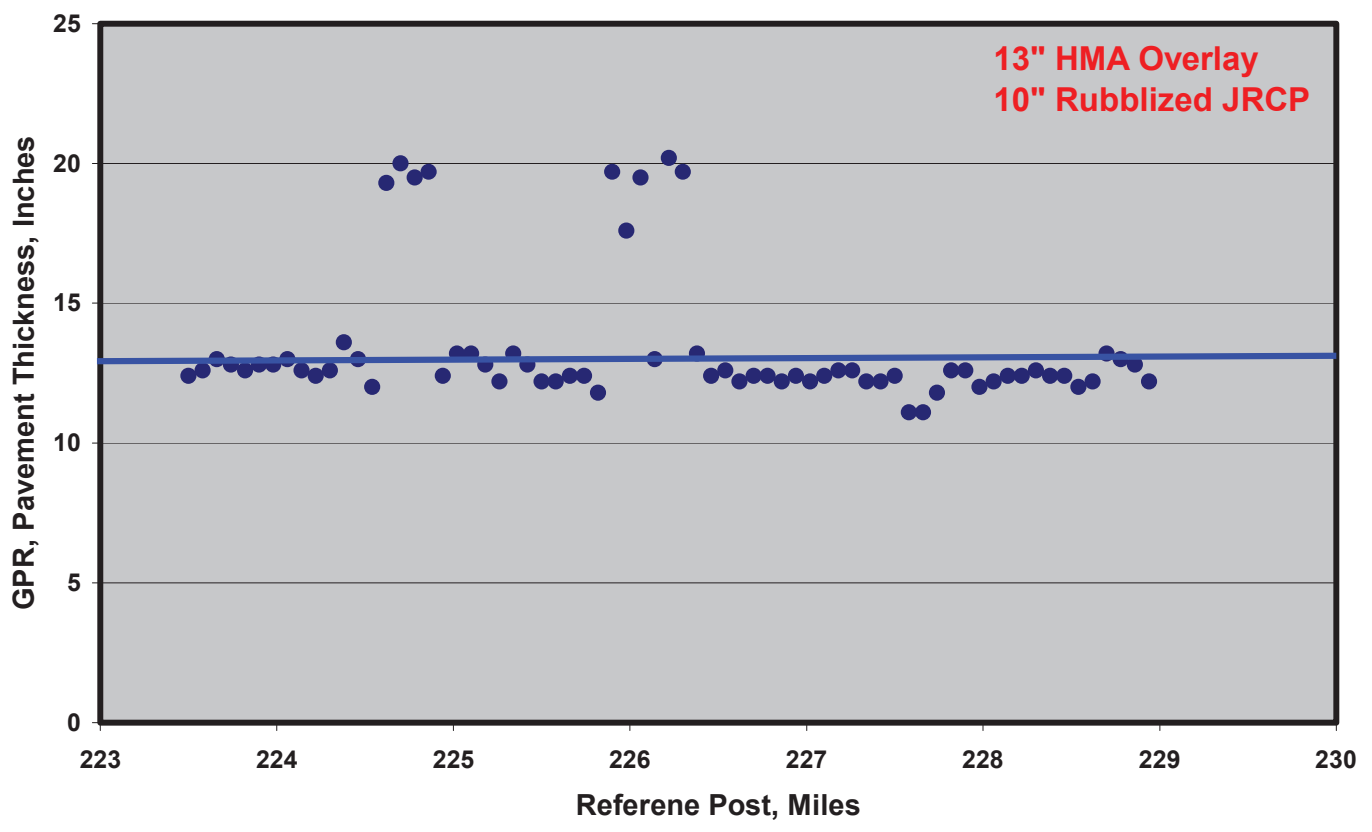

Figure 4.2: GPR Thickness Analysis for a 13" HMA Pavement on a 10" Rubblized JRCP on an 8" Aggregate Base on I - 65

I - 65 North Bound Driving Lane

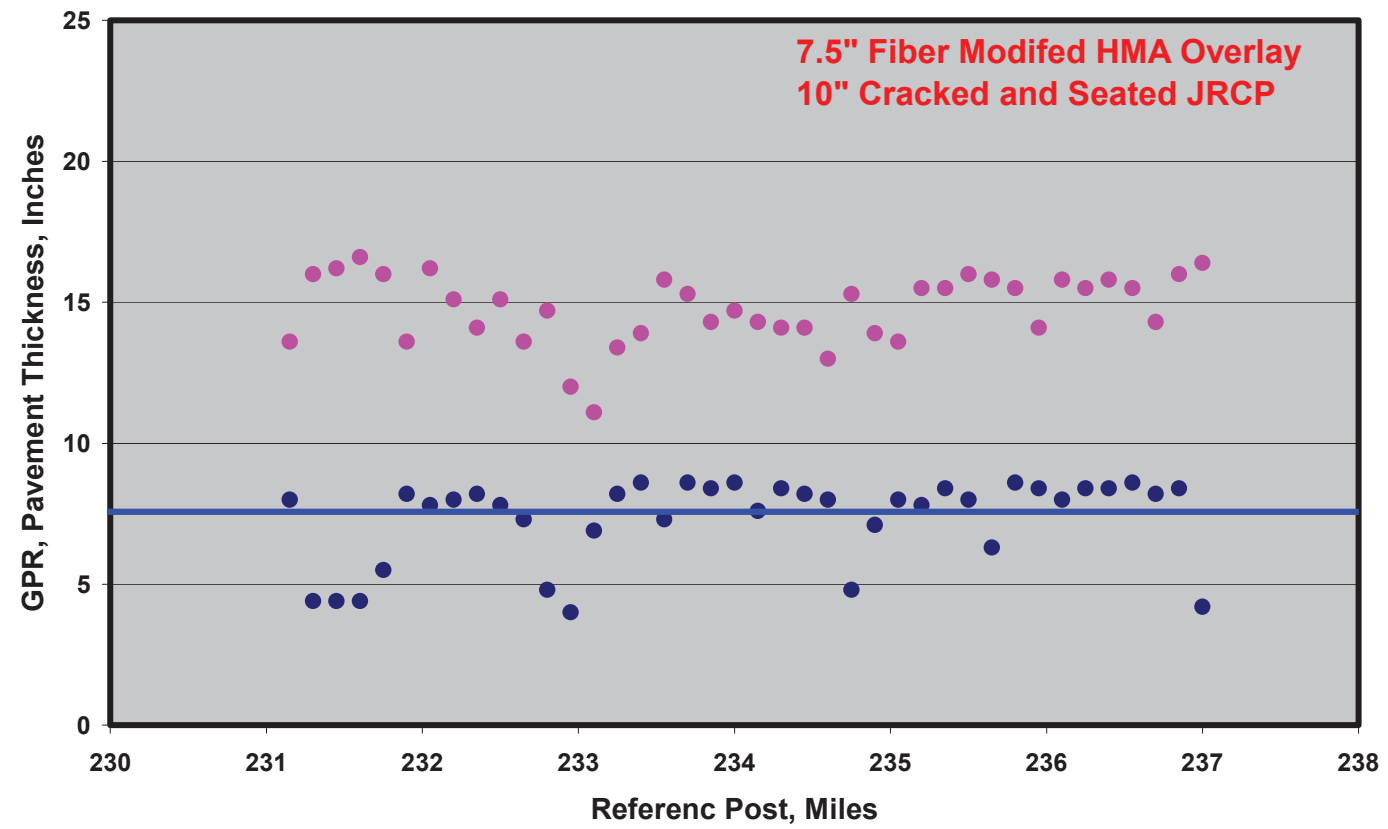

Figure 4.3: GPR Thickness Analysis for a 7.5" Fiber Modified HMA Pavement on a 10" Cracked and Seated JRCP on an 8" Aggregate Base on I - 65 


\subsection{FWD at the Network Level}

\section{$\underline{\text { 4.2.1 Interstates Structural Conditions }}$}

Figures 4.4 through 4.8 (a to g) present profiles of FWD center deflections (normalized and temperature corrected), backcalculated pavement layer moduli, pavement layer coefficients, effective structural numbers, estimated pavement layer thicknesses, estimated structural remaining life and required overlay thickness along I - 64, I - 65, I - 69, I - 70, and I - 74. Gaps apparent in these profiles are those stretches that are inside cities.

It should be noted that every point represents the average value of 5 measurements per mile. However, it was observed during the analysis process that only 3 measurements per mile would have provided almost the same information. The wealth of information that can be obtained from these profiles and used for pavement design, maintenance, rehabilitation and management purposes is apparent.

Pavement surface layer (whether it is asphalt, concrete or composite) exhibited variability in its structural characteristics in its moduli values compared to pavement support and subgrade layers. This can be attributed to pavement type, layer location or both. Moduli values differ considerably with pavement type and whether it is asphalt, concrete or composite. In addition, support and subgrade layers are usually well protected (for Interstate Highways) by the surface layers and that protection usually marginalize the changes in its characteristics with time and traffic and the increase in the variability in its characteristics.

These profiles suggest that all INDOT Interstate Highways are structurally sound. However, this does not necessarily mean that no rehabilitation activities are needed and the functional condition is the same as the structural condition. Improvements in pavement functional characteristics (ride quality, friction and other non structural distresses) usually dominate the decisions for Interstate rehabilitation. 


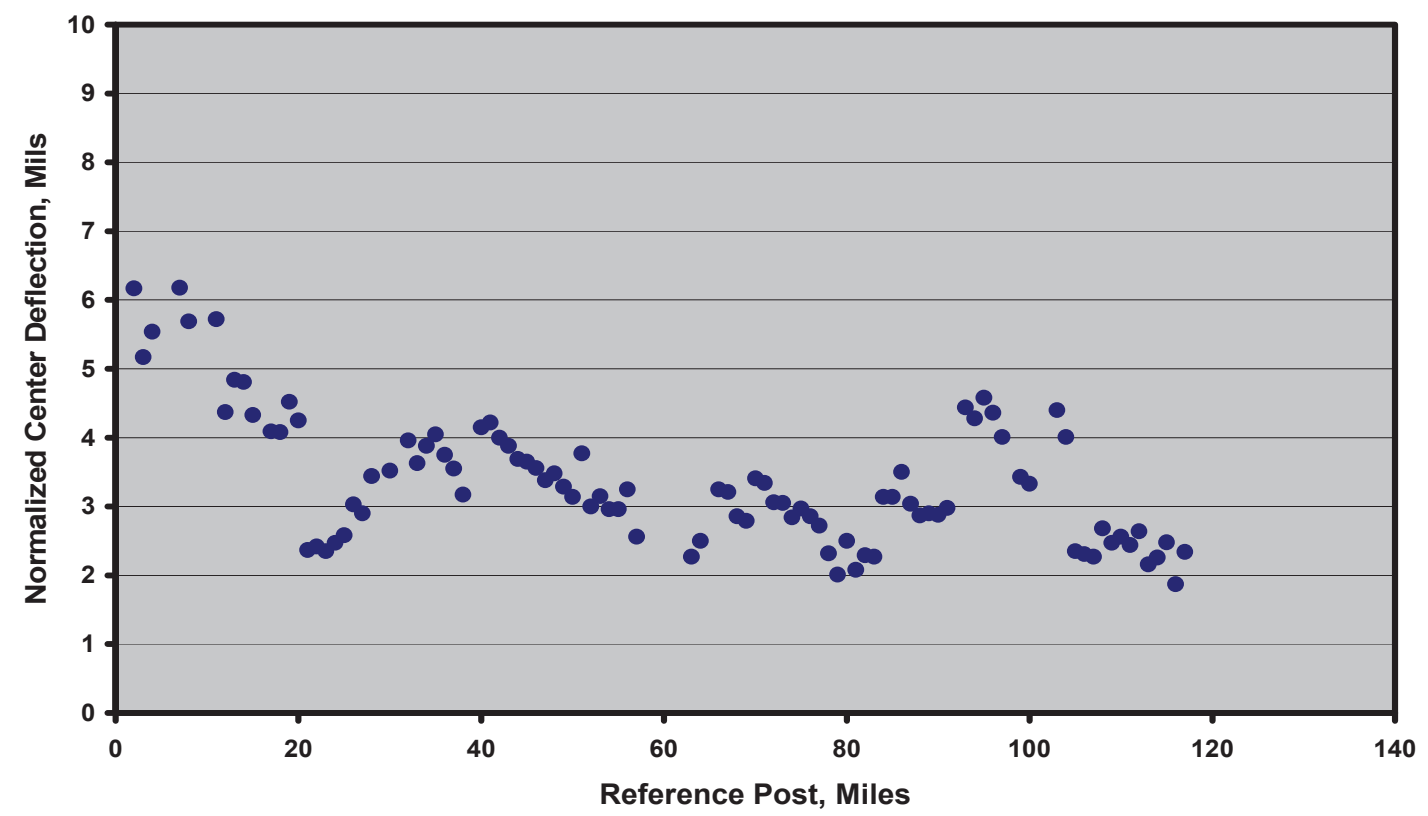

I - 64 West Bound Driving Lane

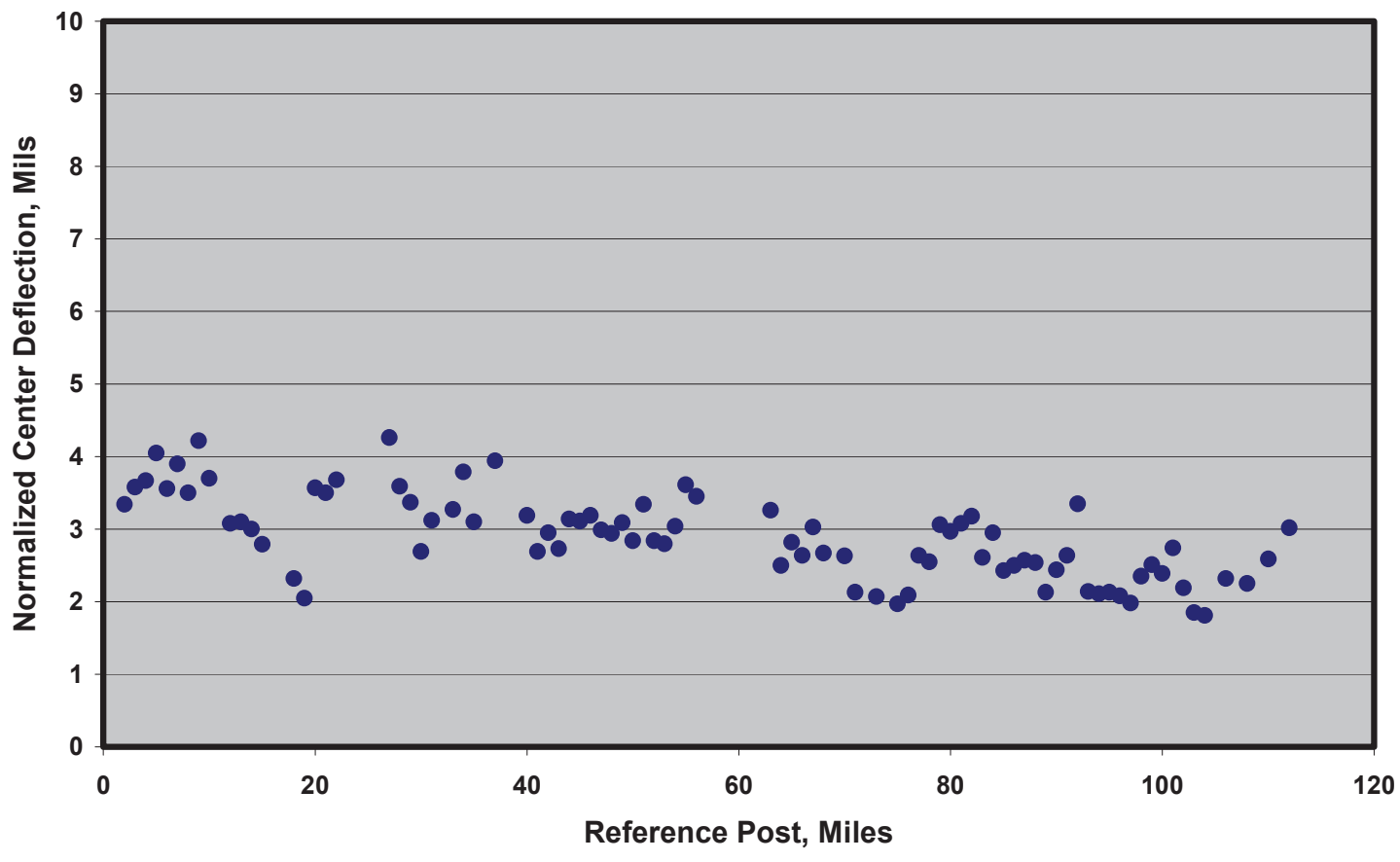

Figure 4.4 a: Profile of Pavement Surface Deflection along Interstate I - 64 


\section{I - 64 East Bound Driving Lane}

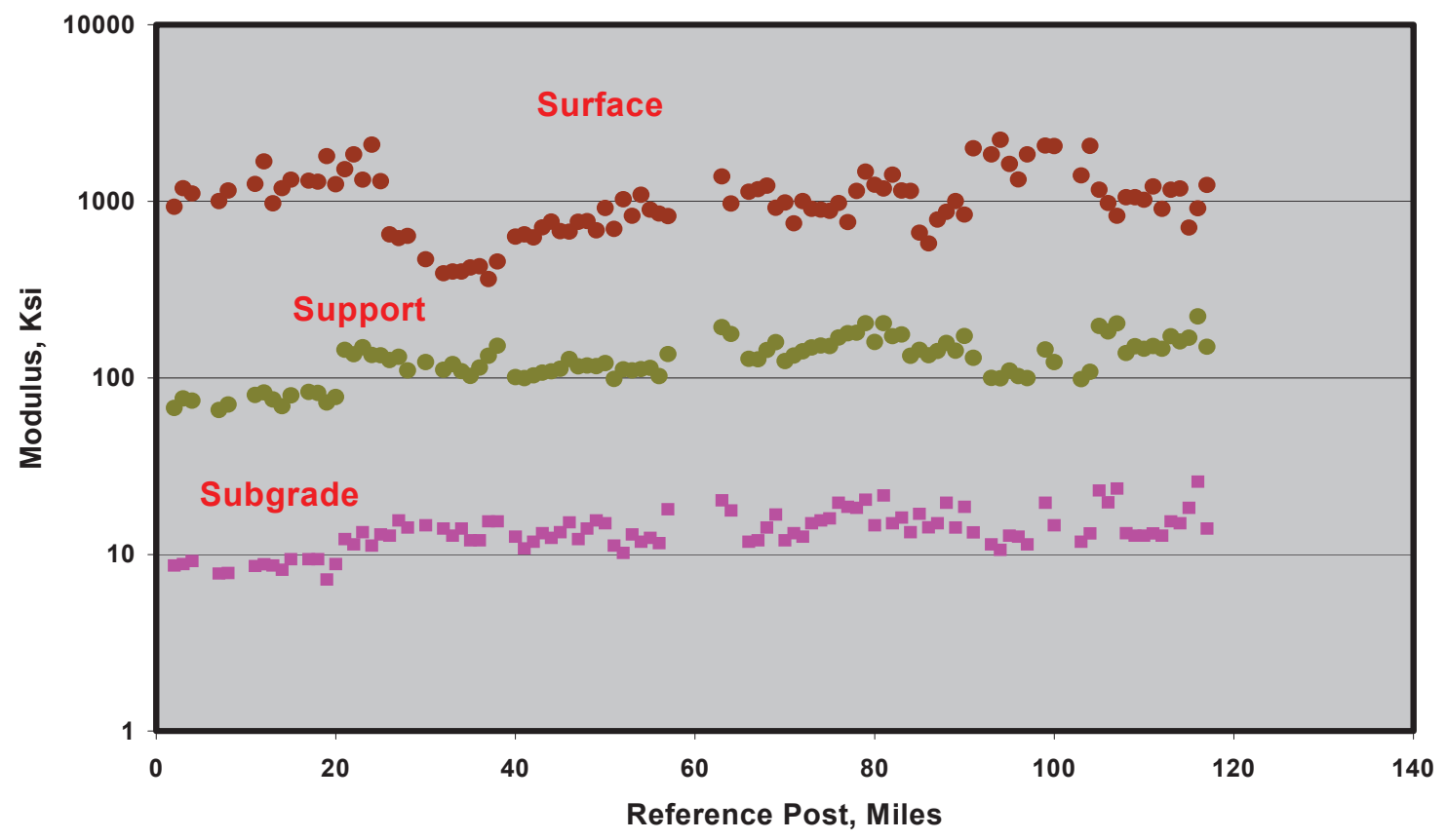

I - 64 West Bound Driving Lane

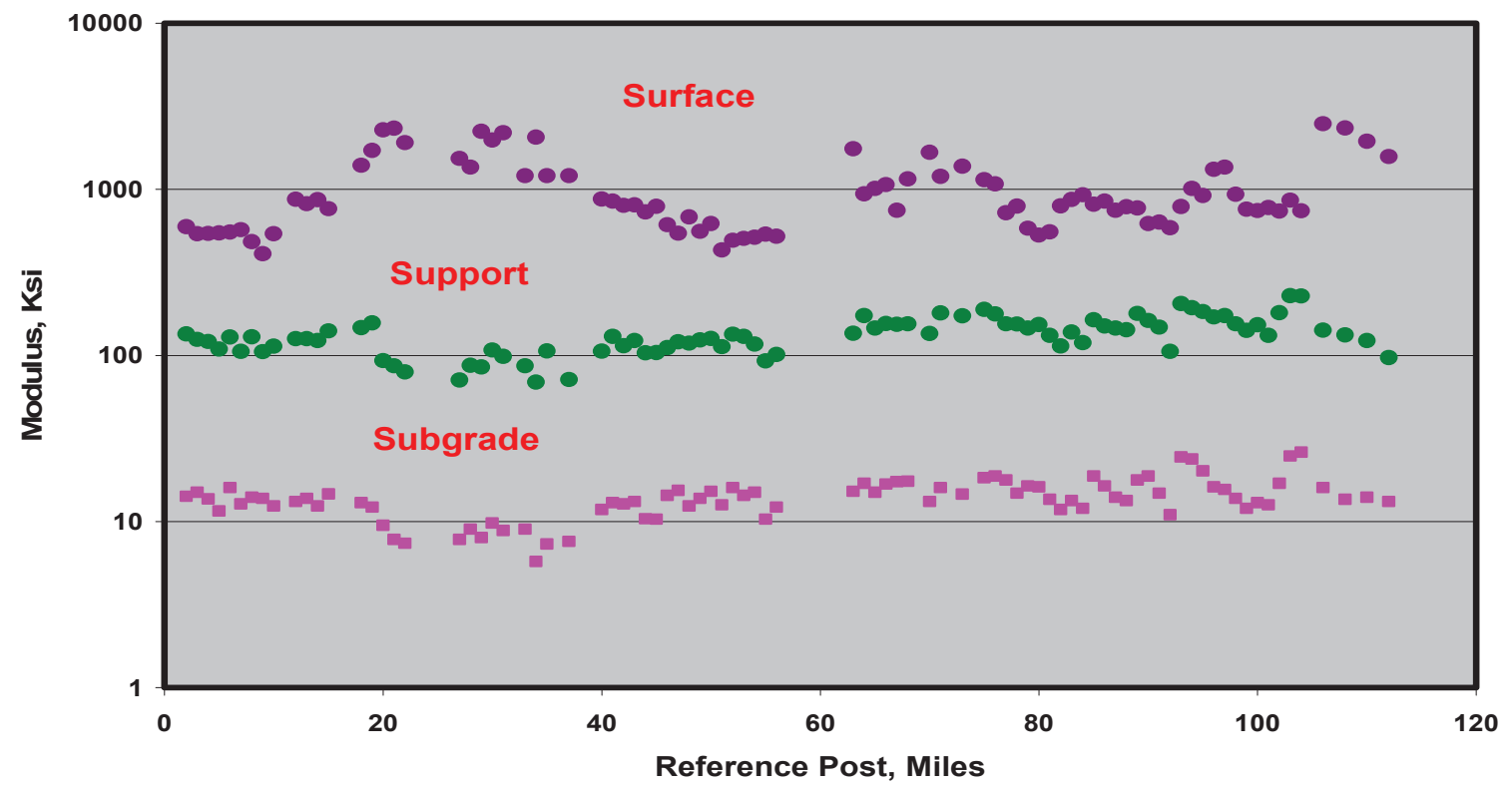

Figure 4.4 b: Profile of Pavement Layer Moduli along Interstate I - 64 


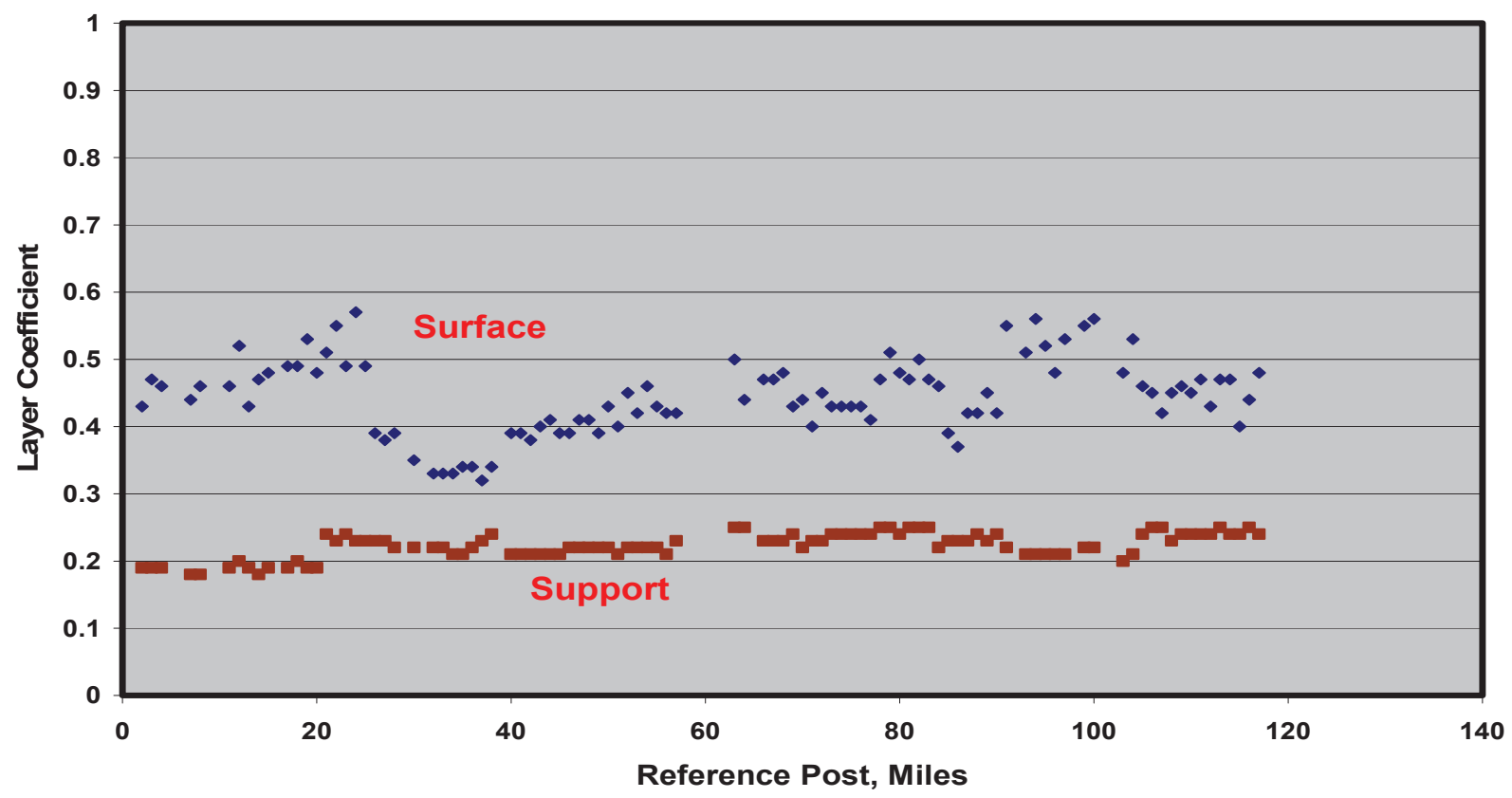

I - 64 West Bound Driving Lane

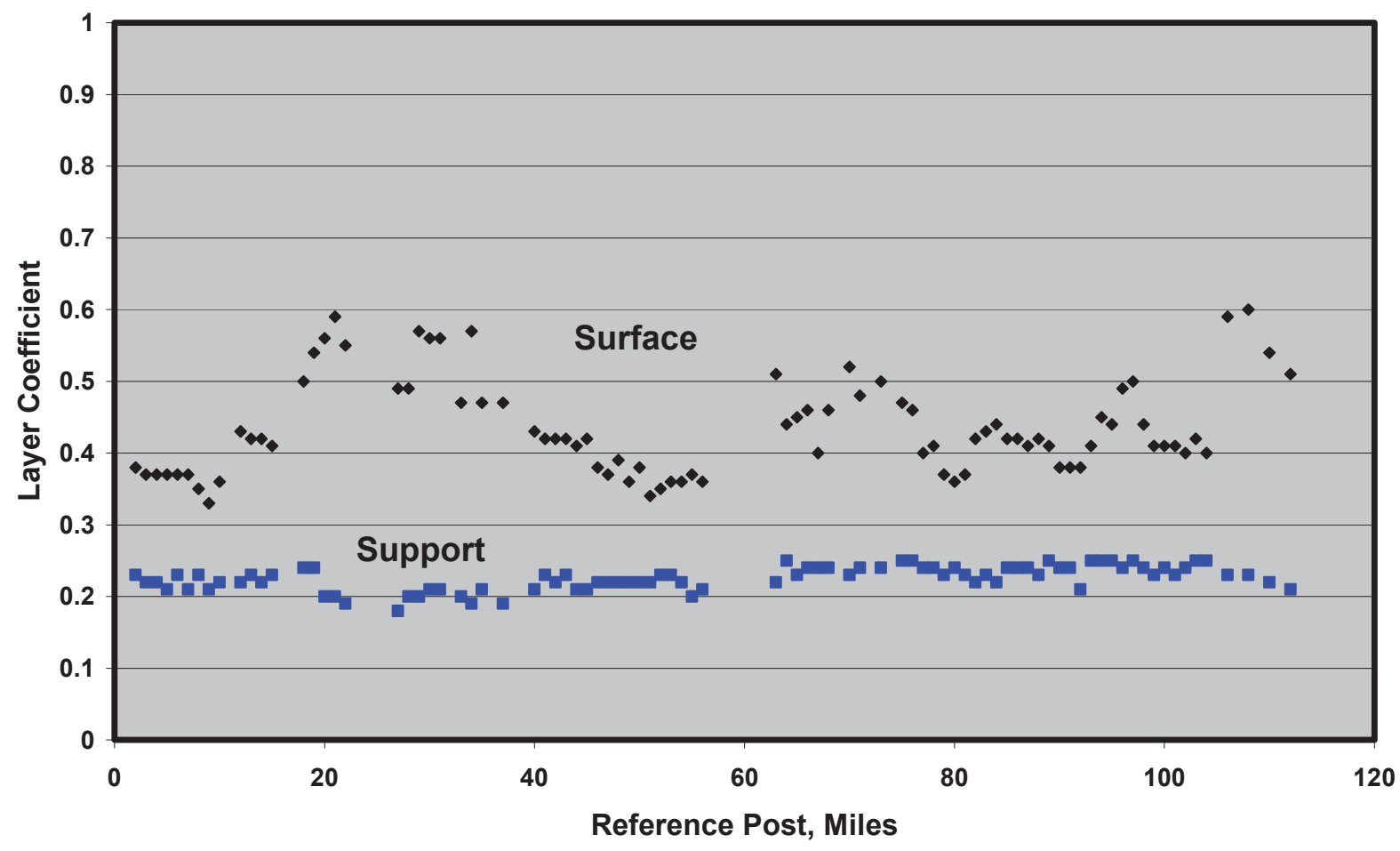

Figure 4.4 c: Profile of Pavement Layer Coefficients along Interstate I - 64 


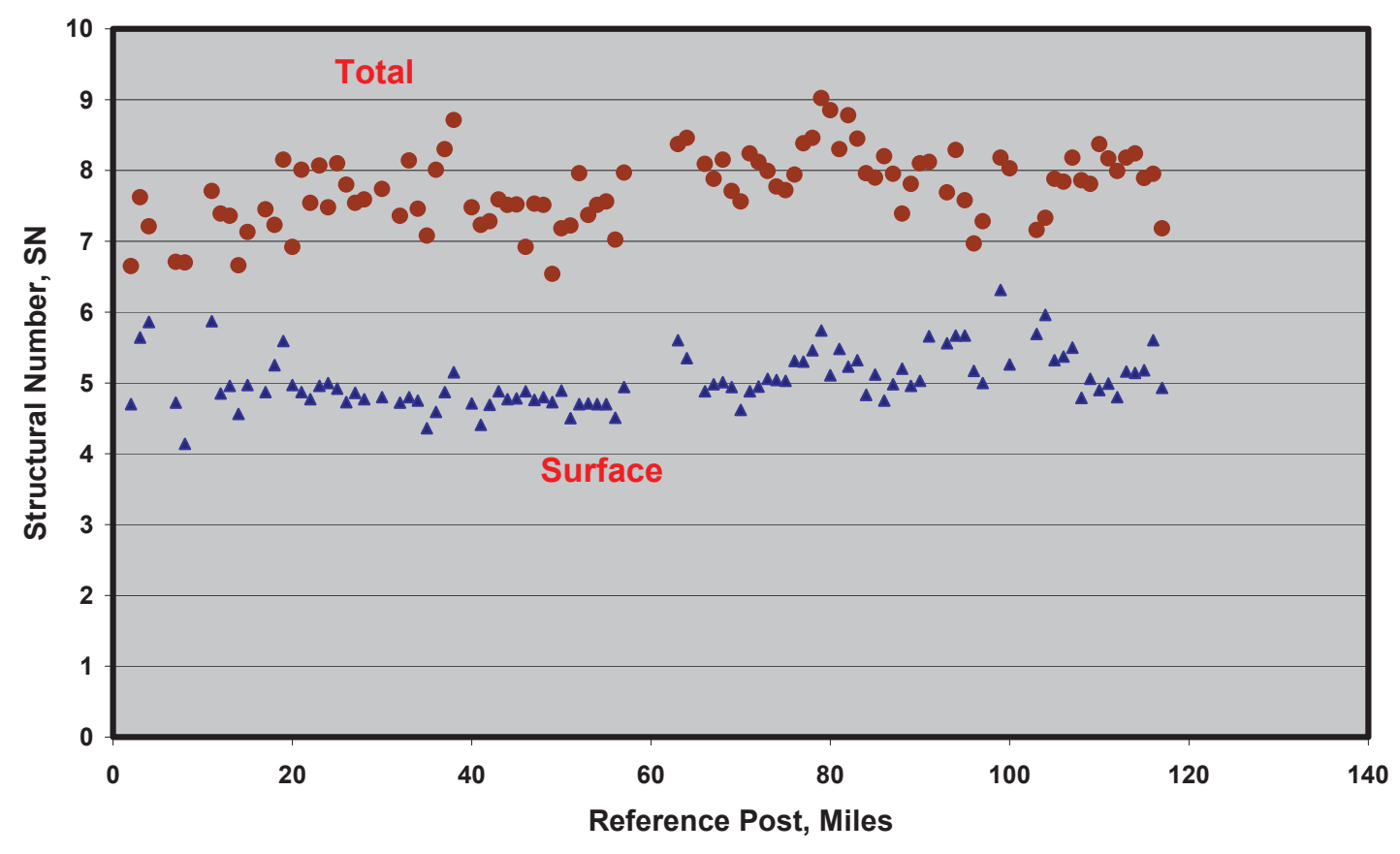

I - 64 West Bound Driving Lane

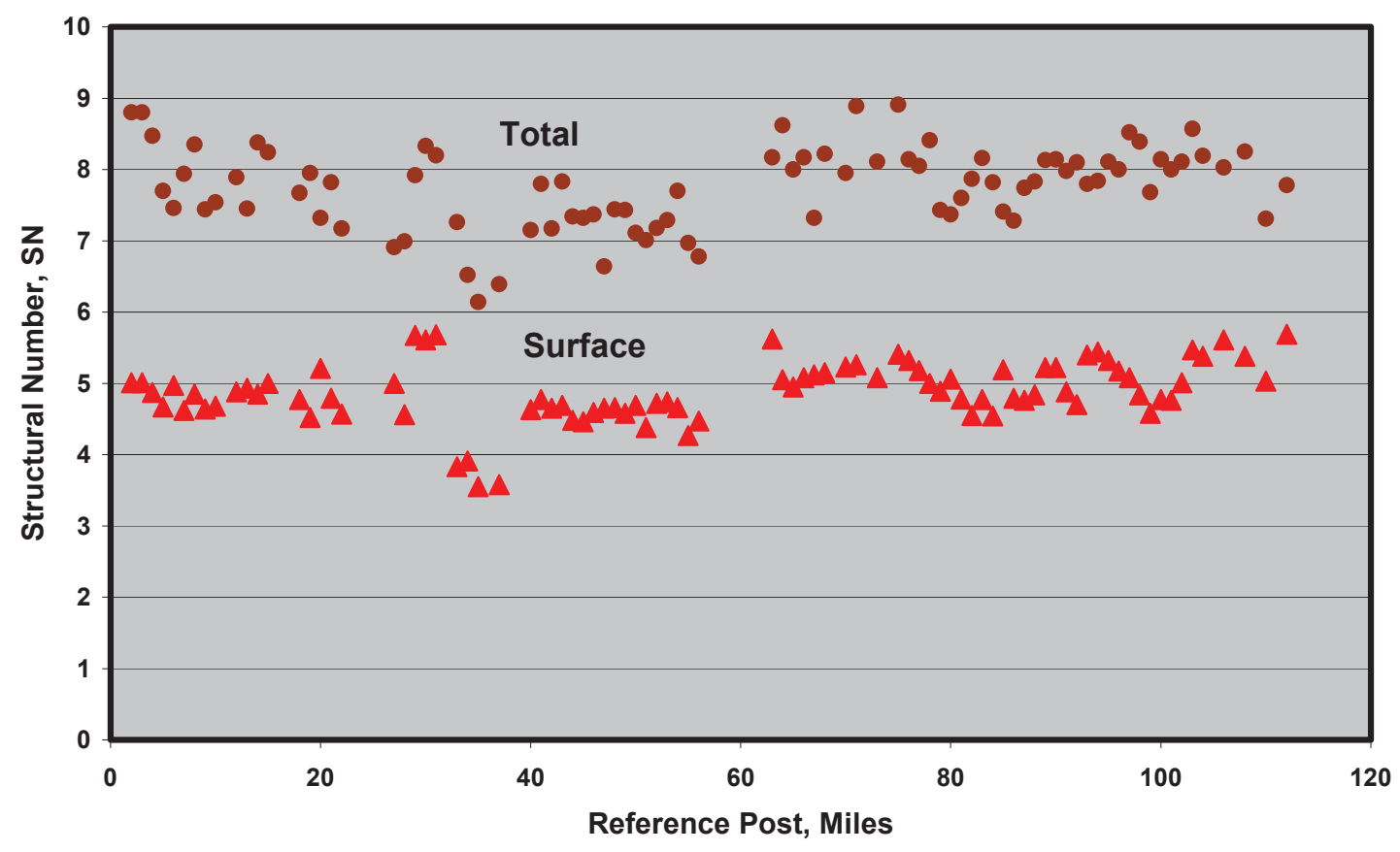

Figure 4.4 d: Profile of Pavement Structural Numbers along Interstate I - 64 


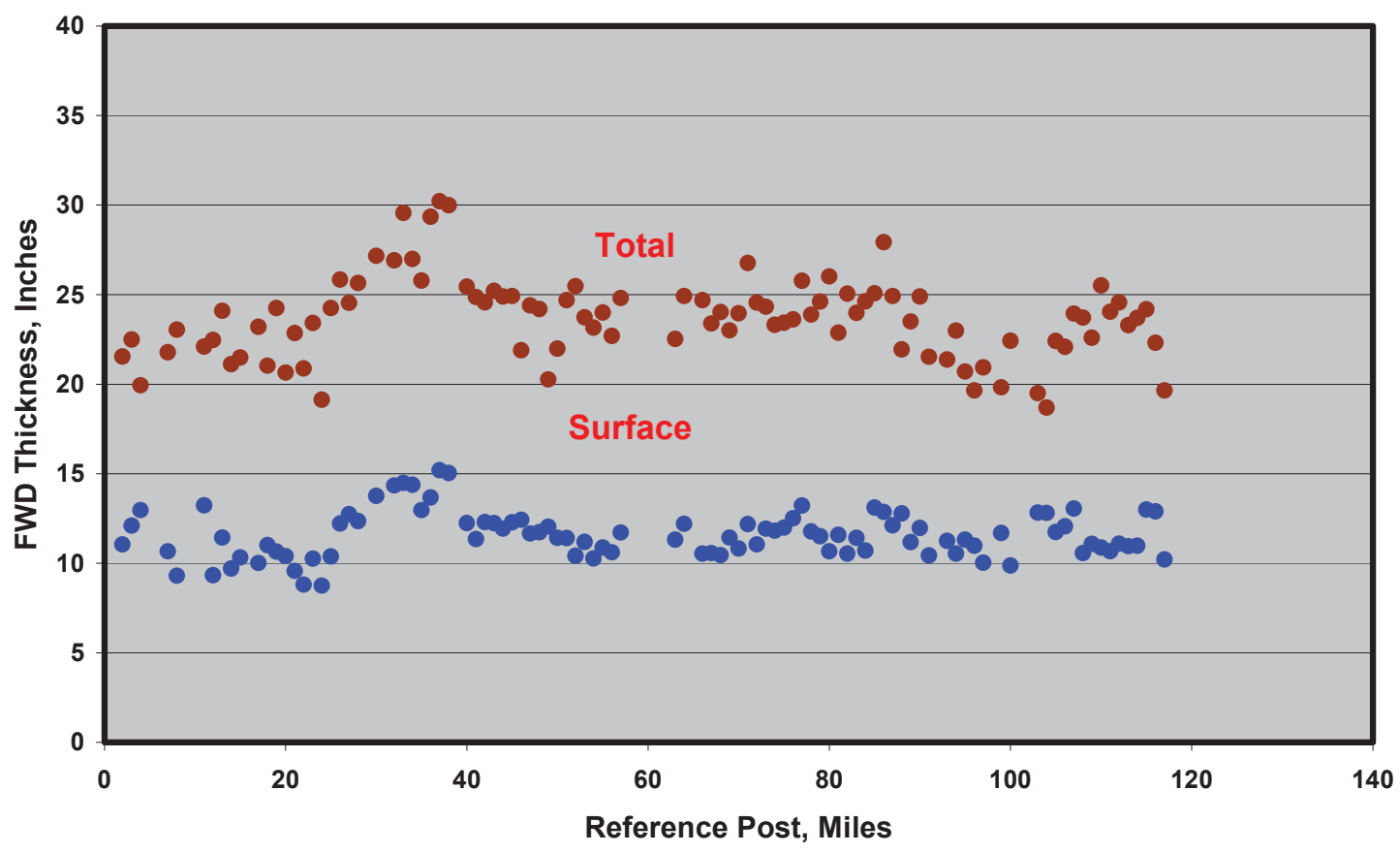

I - 64 West Bound Driving Lane

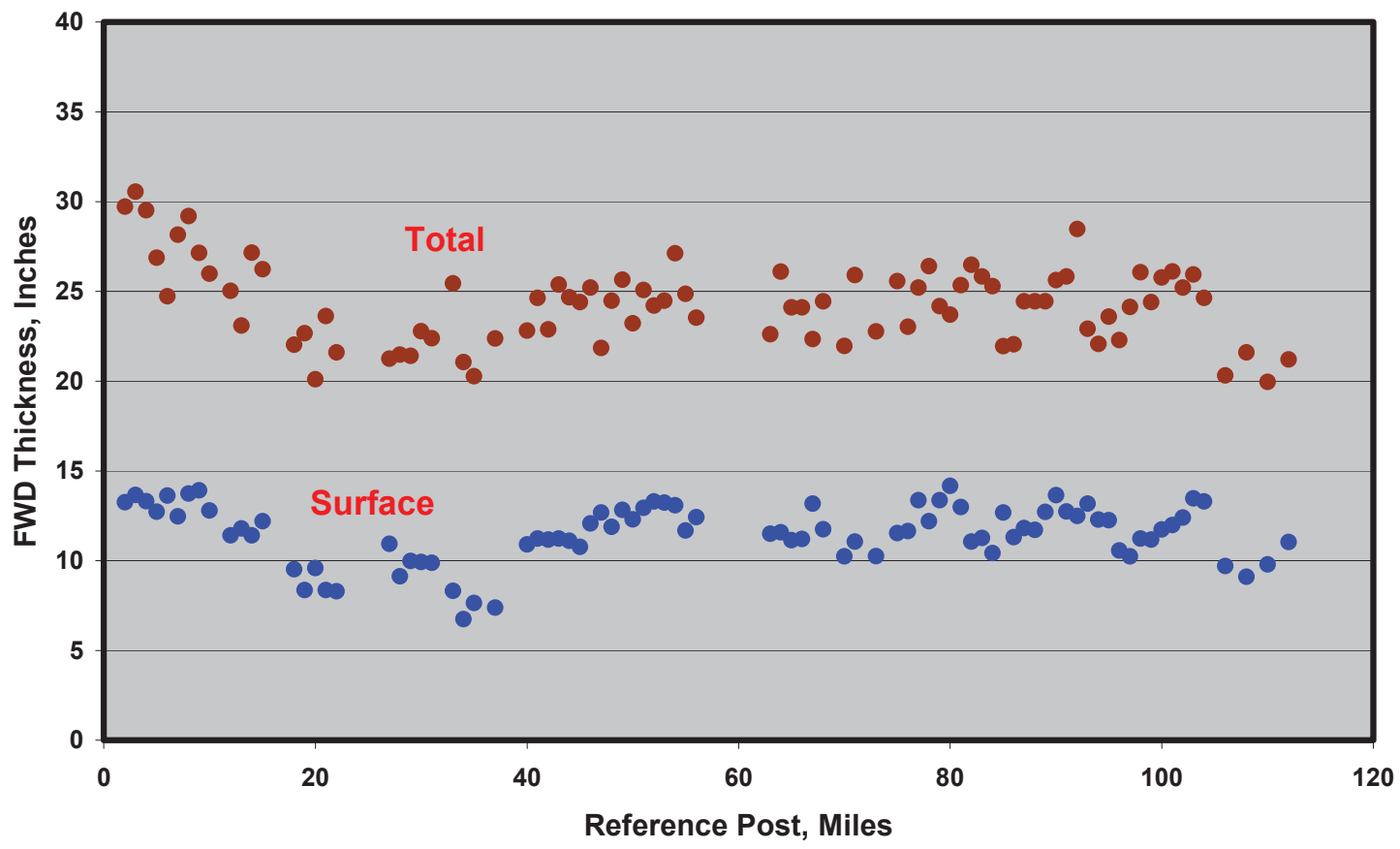

Figure 4.4 e: Profile of Pavement Layers Thickness along Interstate I - 64 


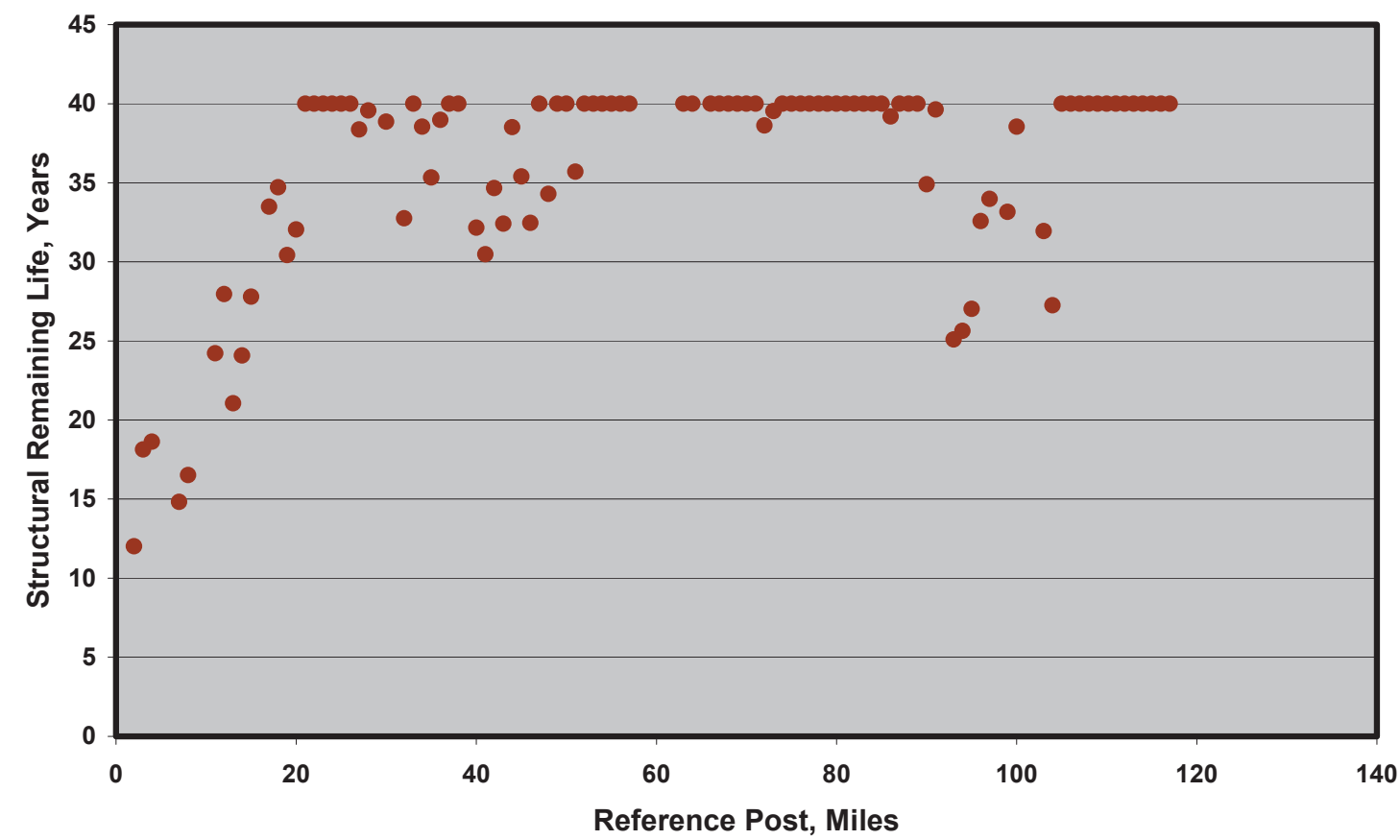

I - 64 West Bound Driving Lane

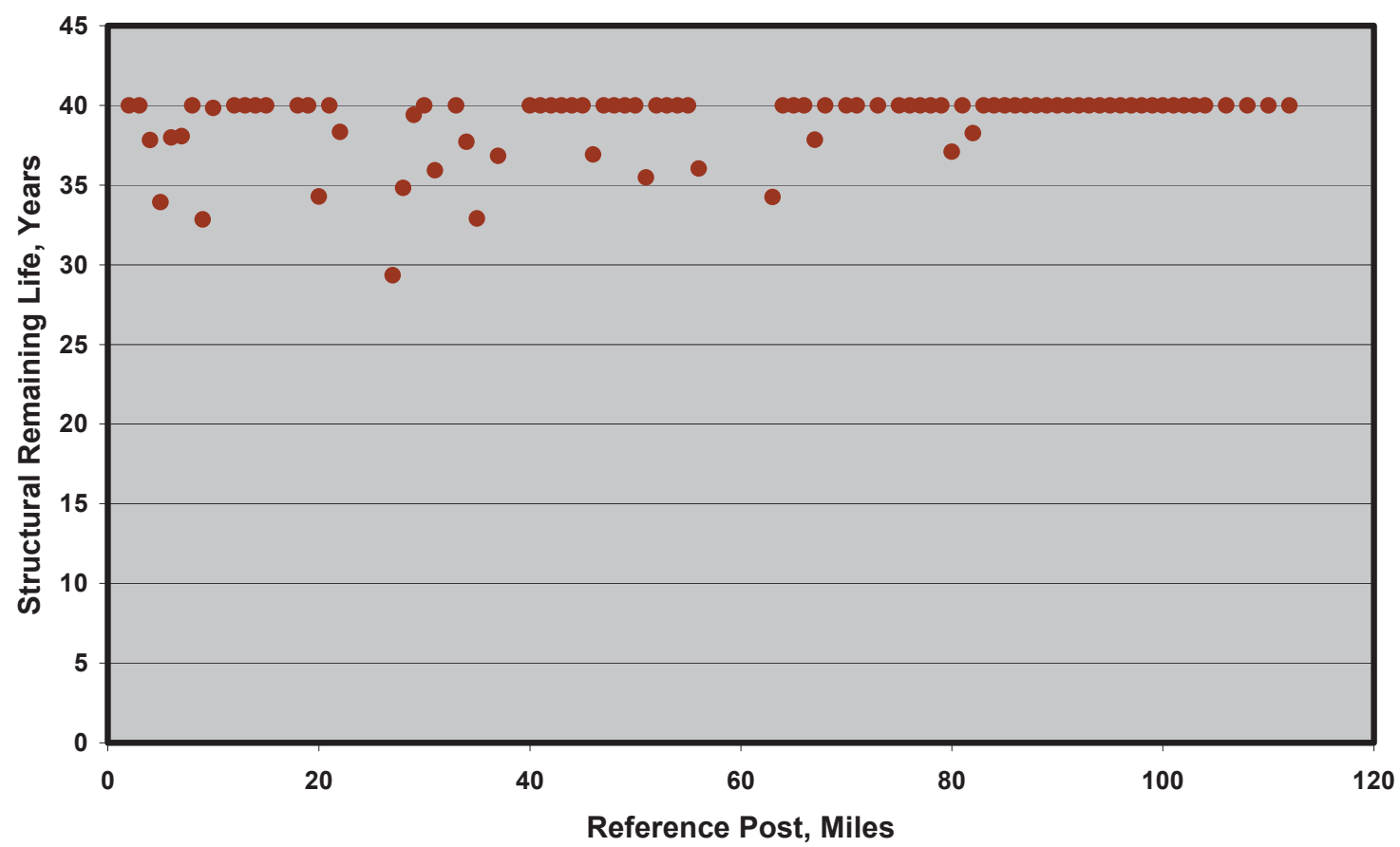

Figure 4.4 f: Profile of Pavement Remaining Life along Interstate I - 64 


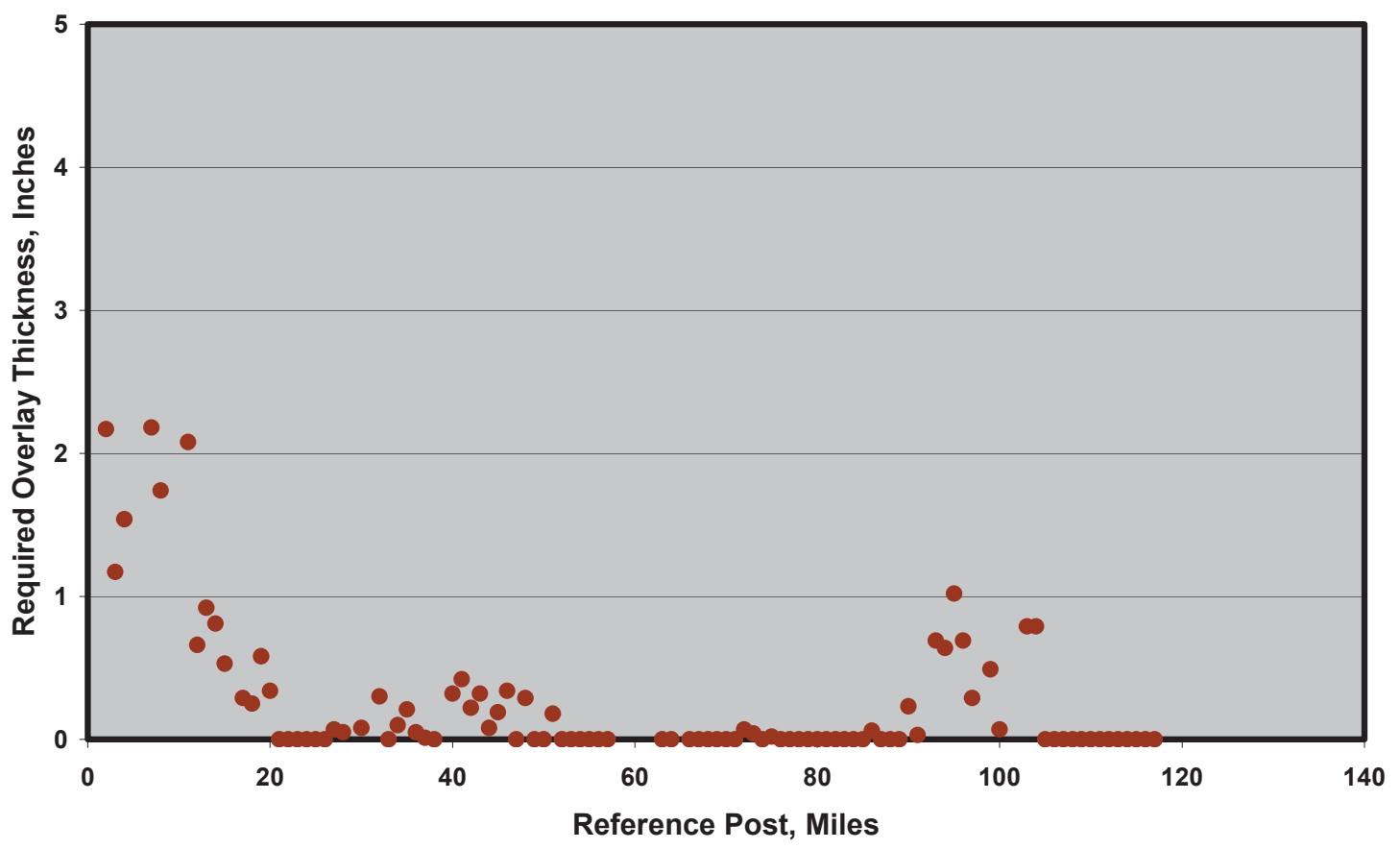

I - 64 West Bound Driving Lane

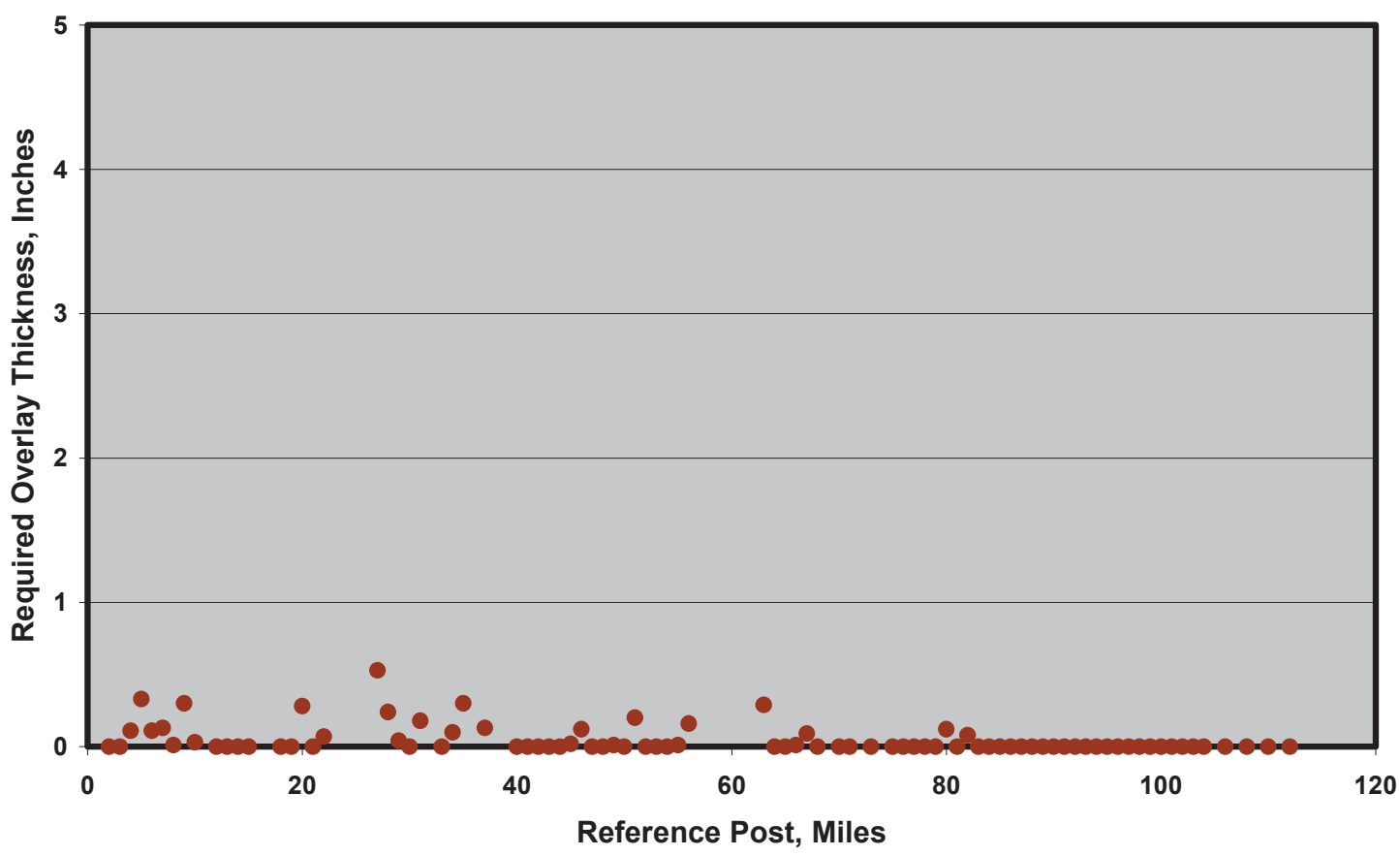

Figure 4.4 g: Profile of Required Overlay Thickness along Interstate I - 64 


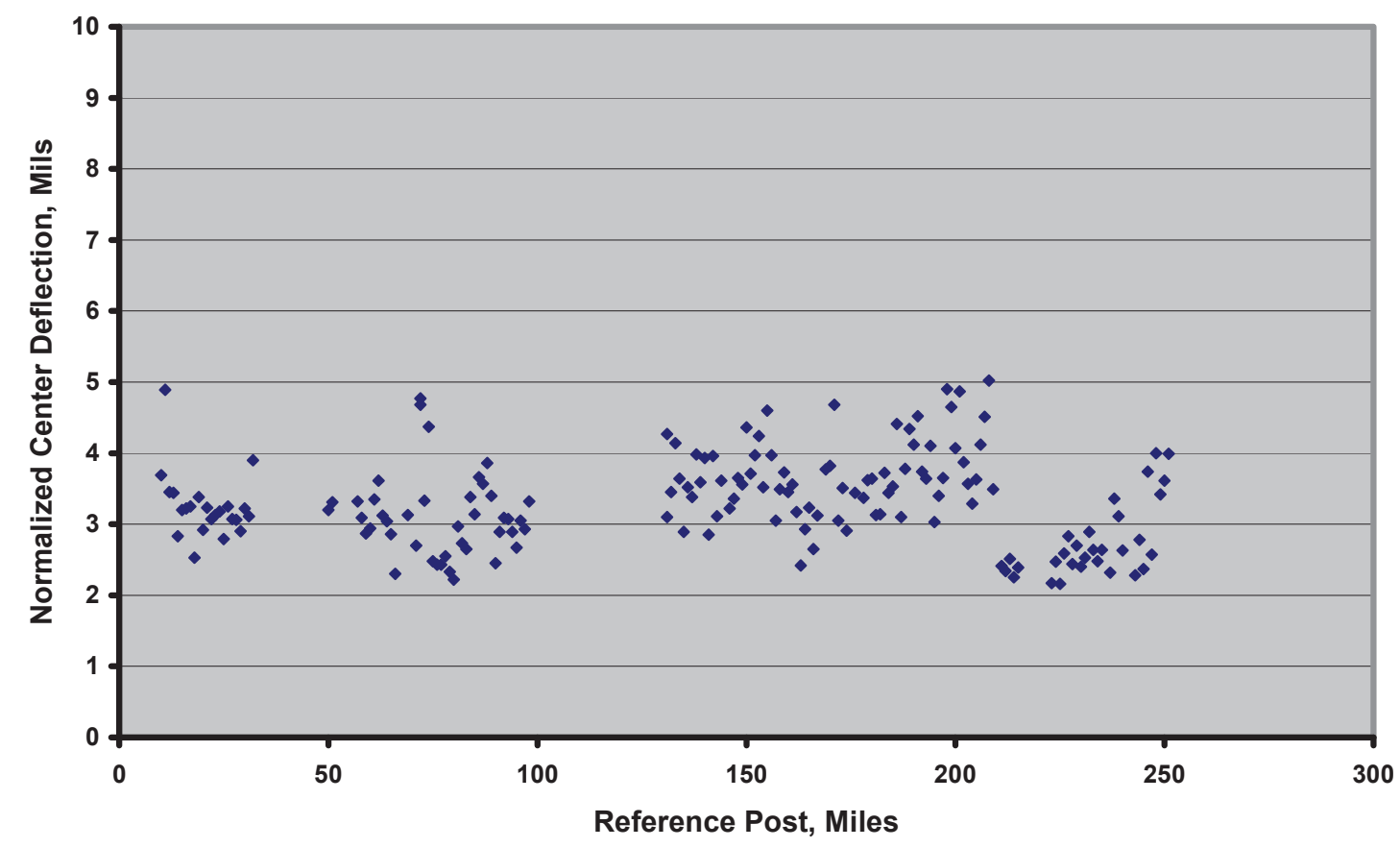

I - 65 South Bound Driving Lane

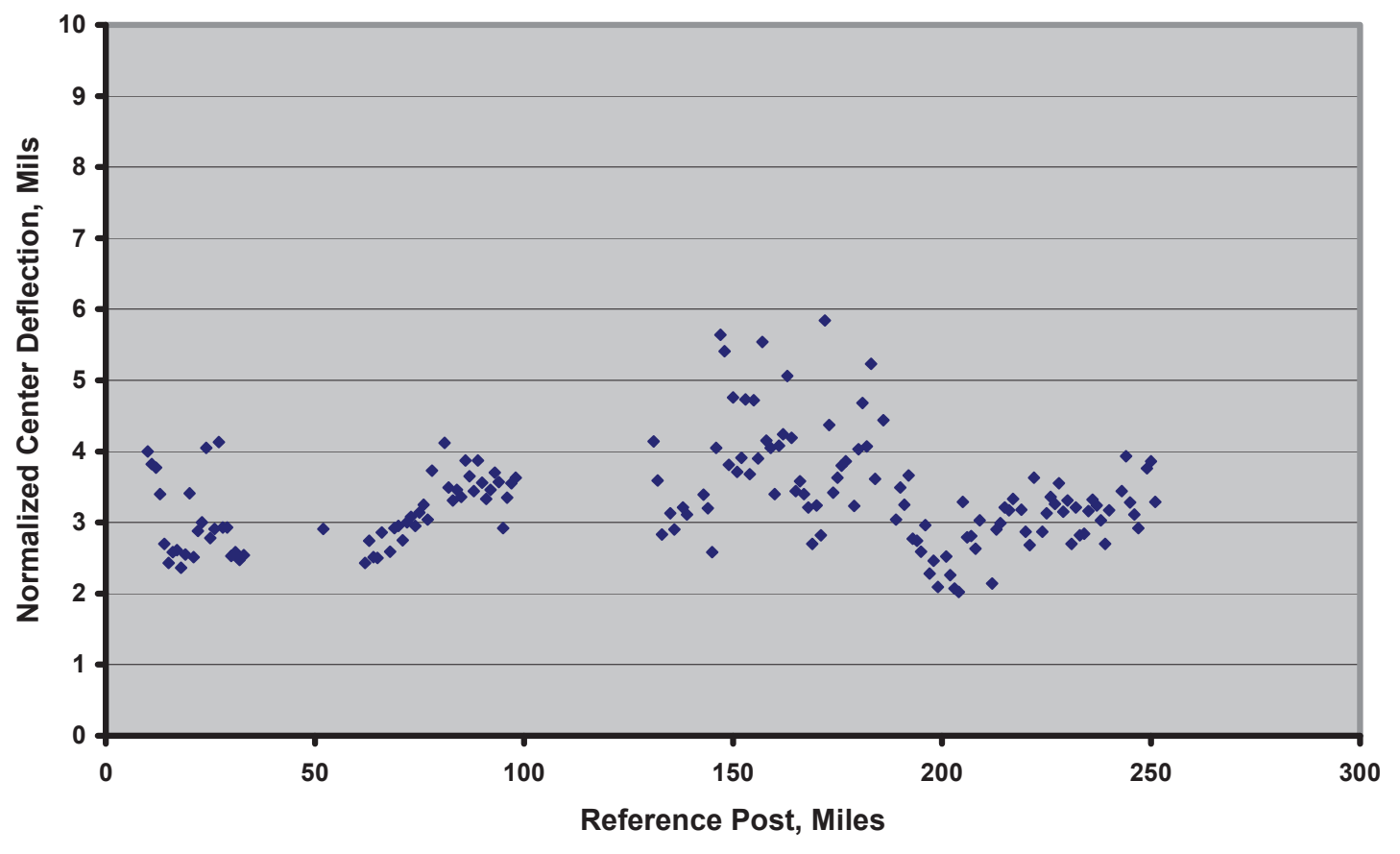

Figure 4.5 a: Profile of Pavement Surface Deflection along Interstate I - 65 


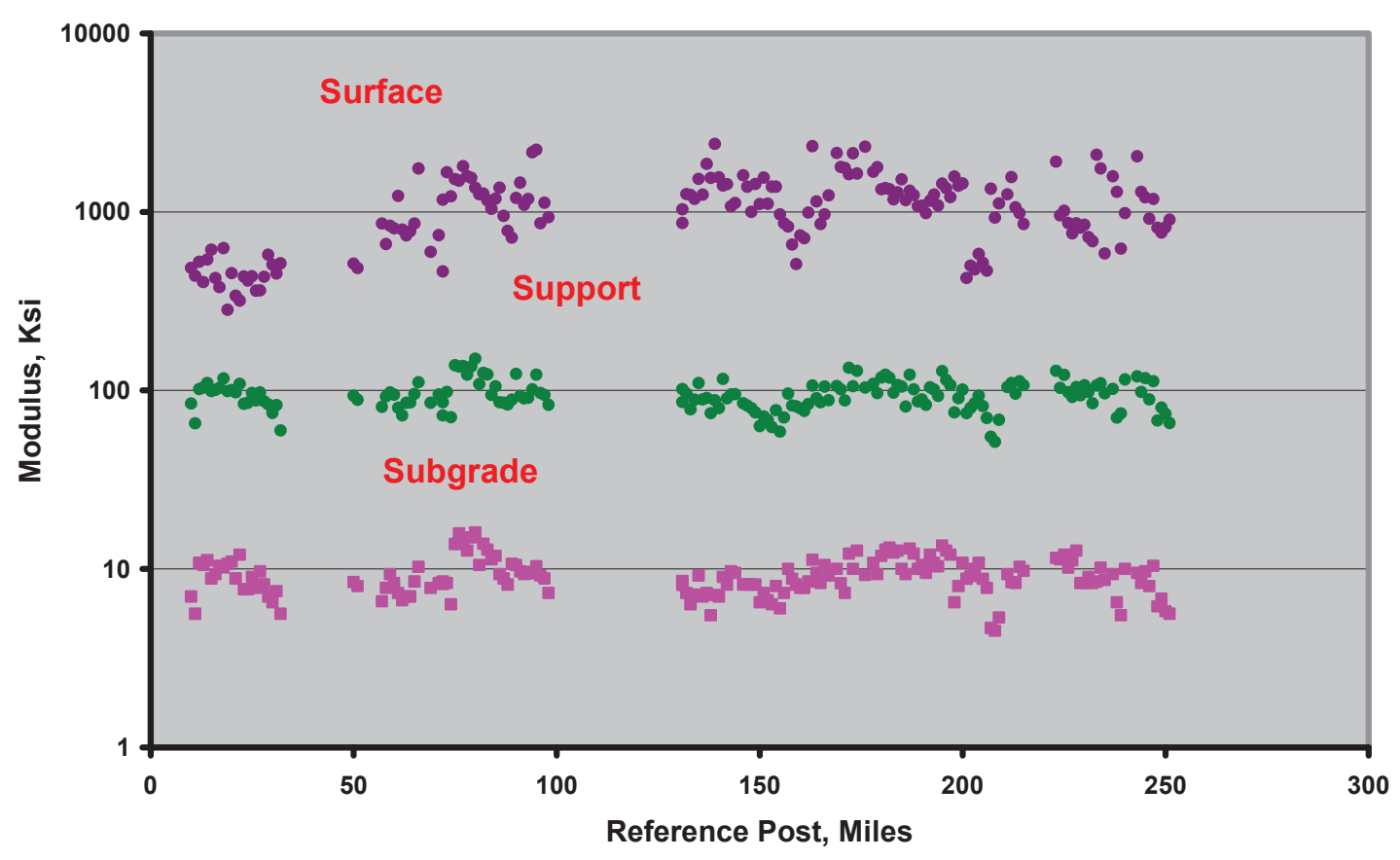

\section{I - 65 South Bound Driving Lane}

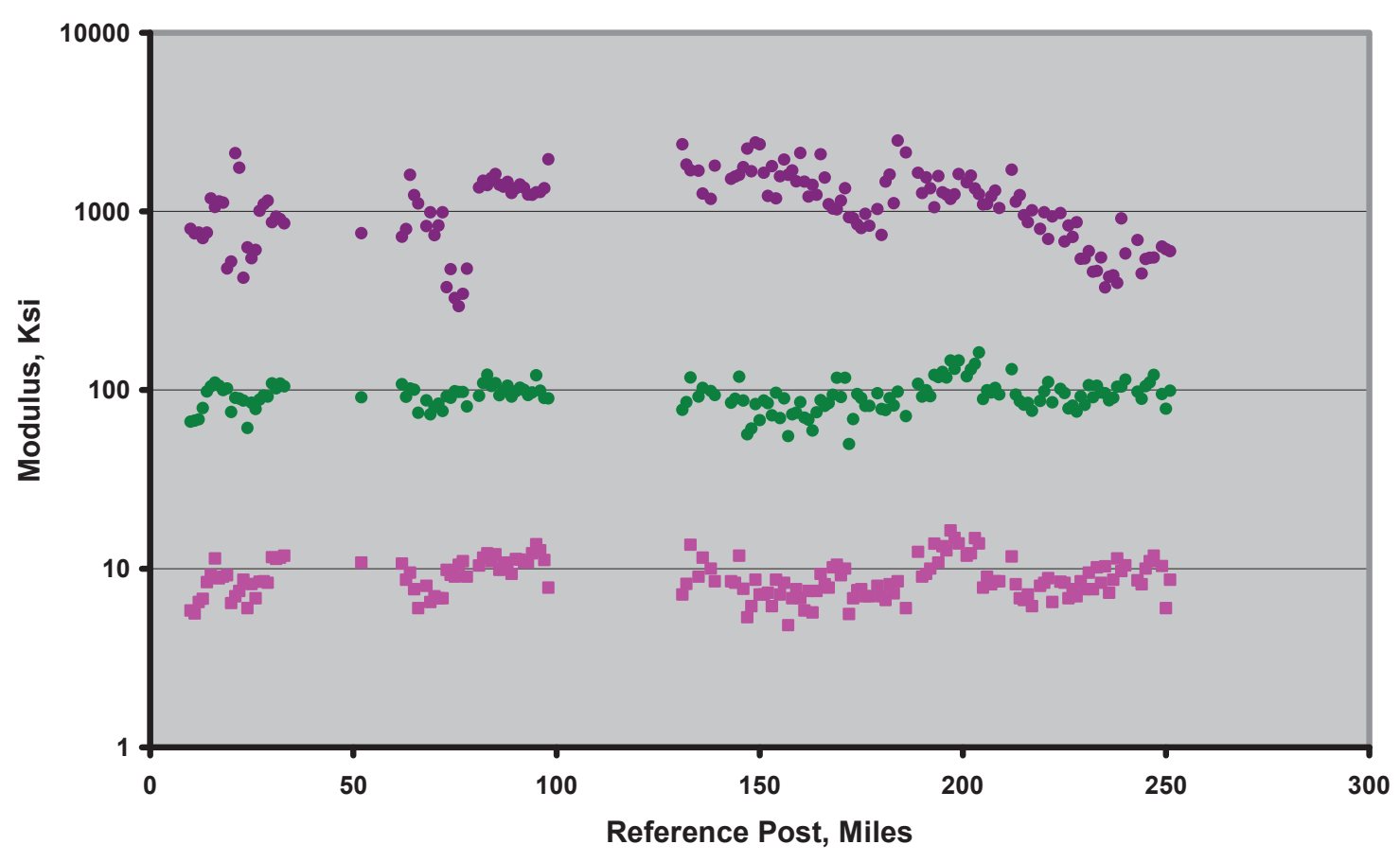

Figure 4.5 b: Profile of Pavement Layer Moduli along Interstate I - 65 


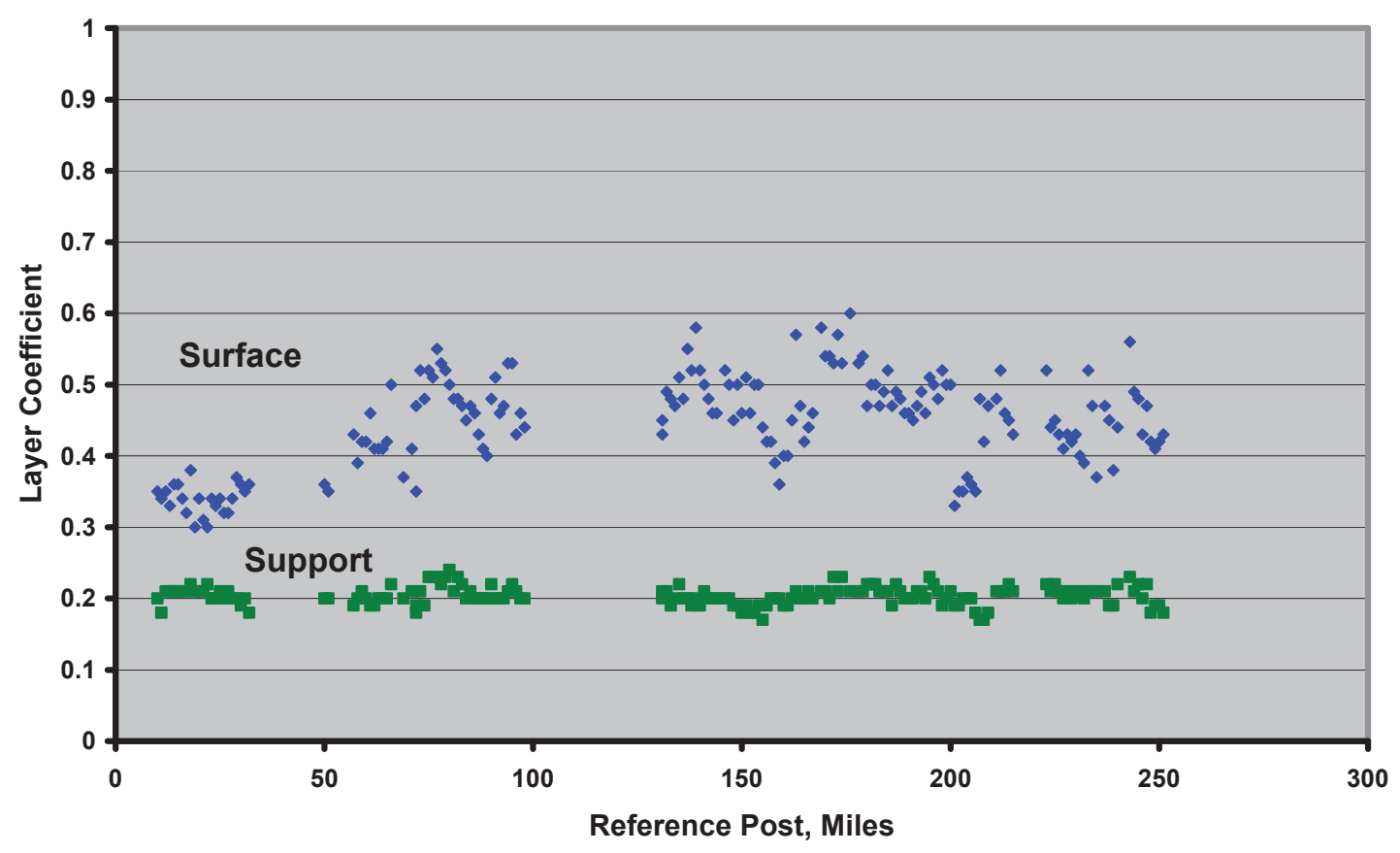

I - 65 South Bound Driving Lane

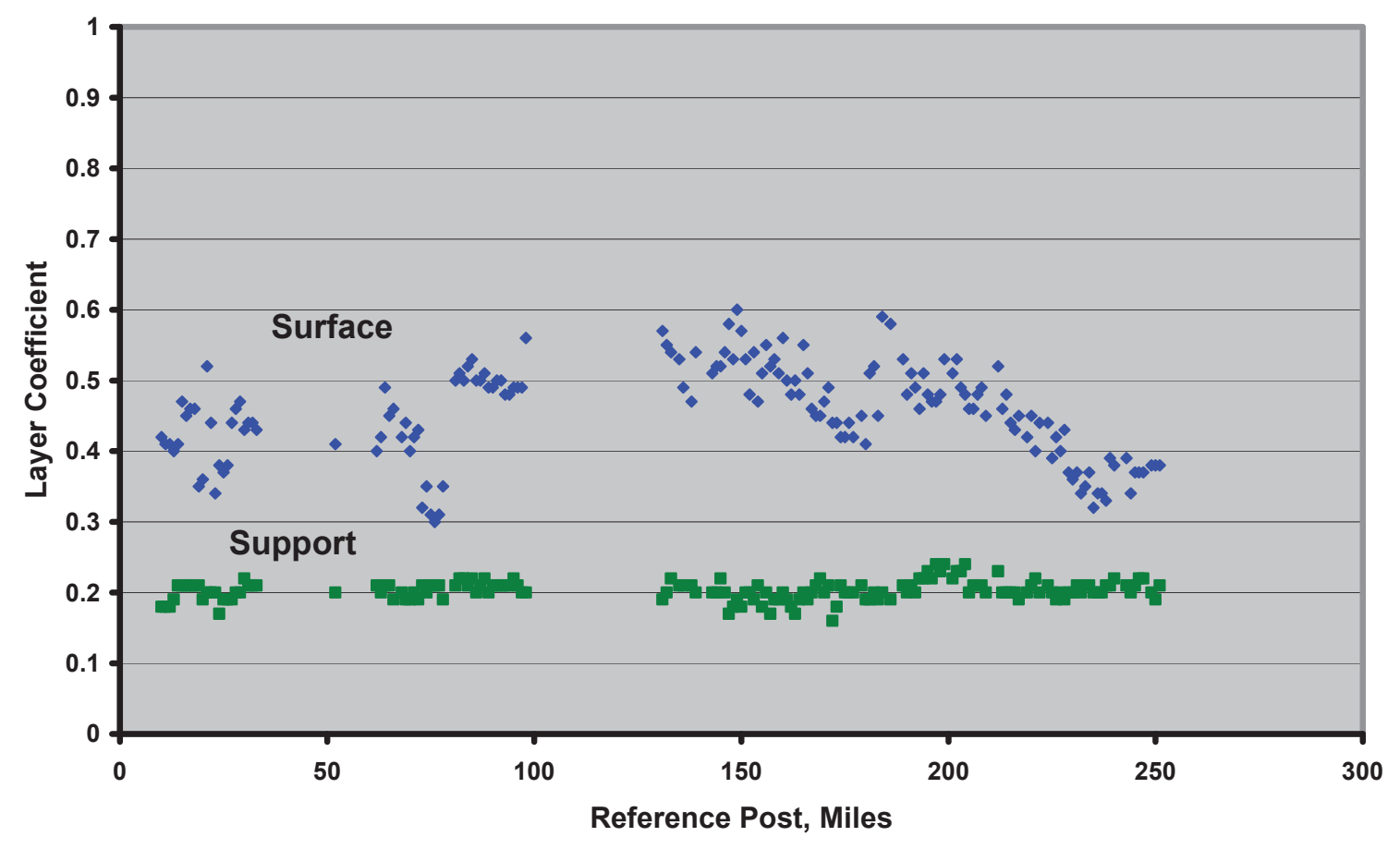

Figure 4.5 c: Profile of Pavement Layer Coefficients along Interstate I - 65 


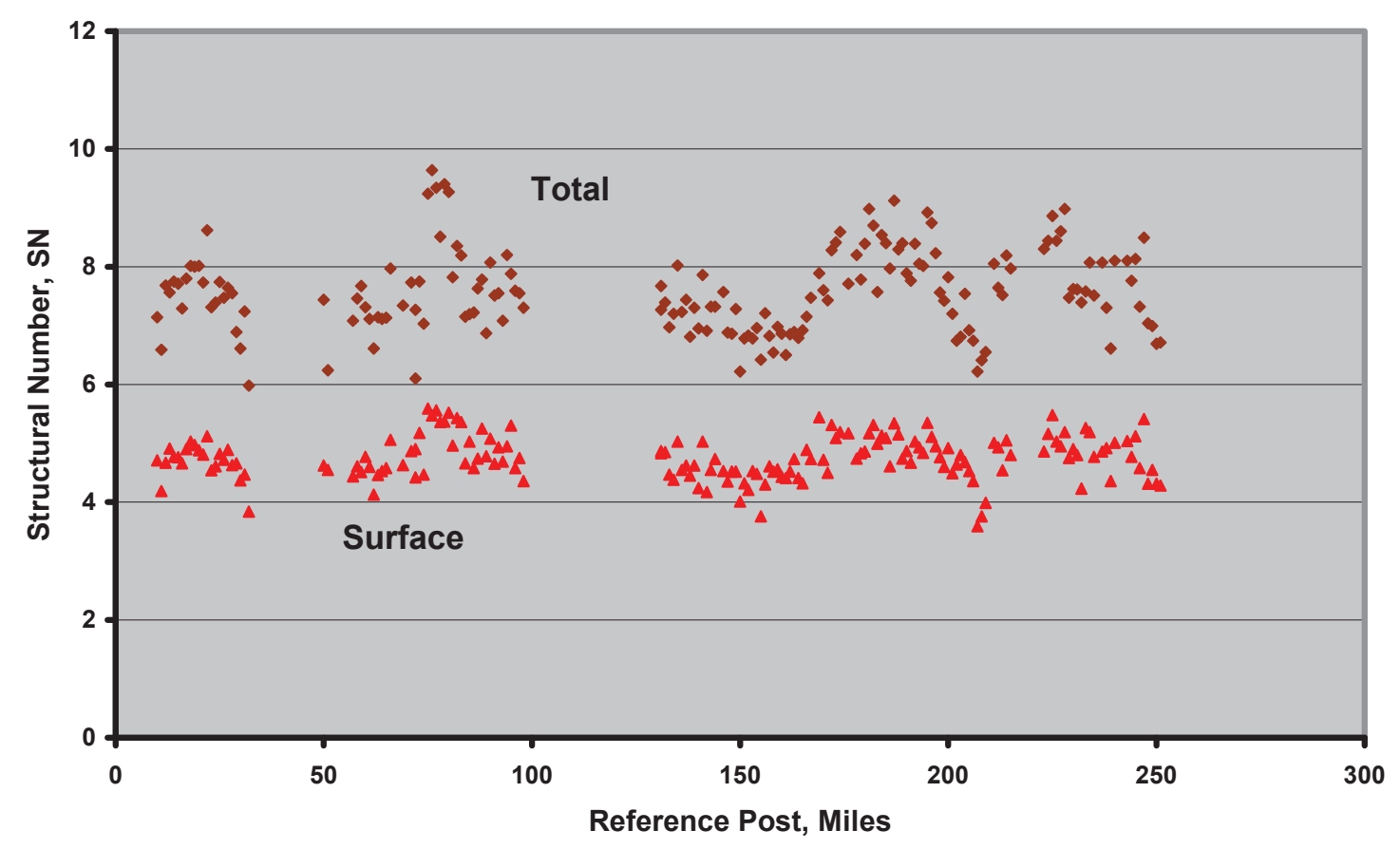

\section{I - 65 South Bound Driving Lane}

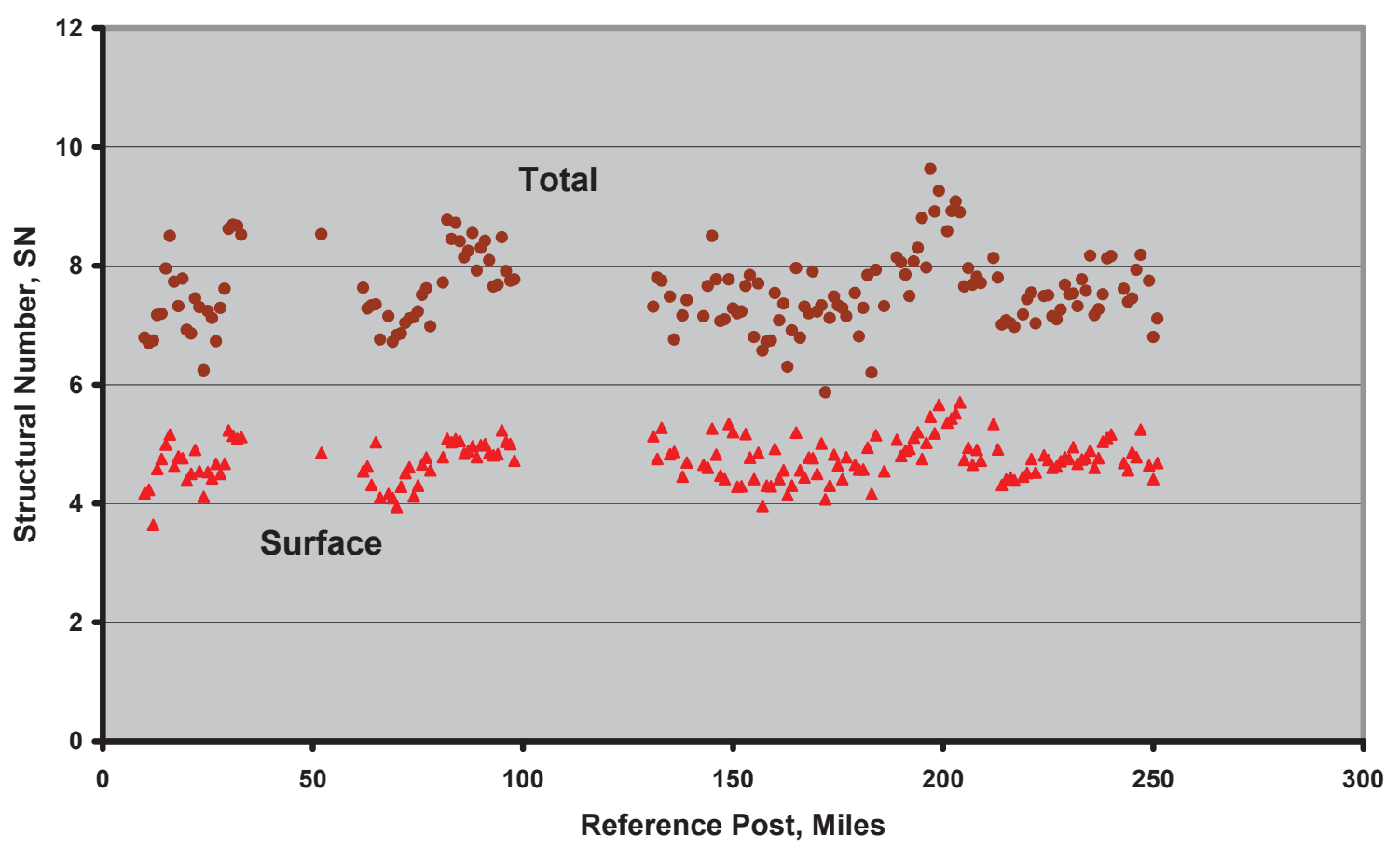

Figure 4.5 d: Profile of Pavement Structural Numbers along Interstate I - 65 


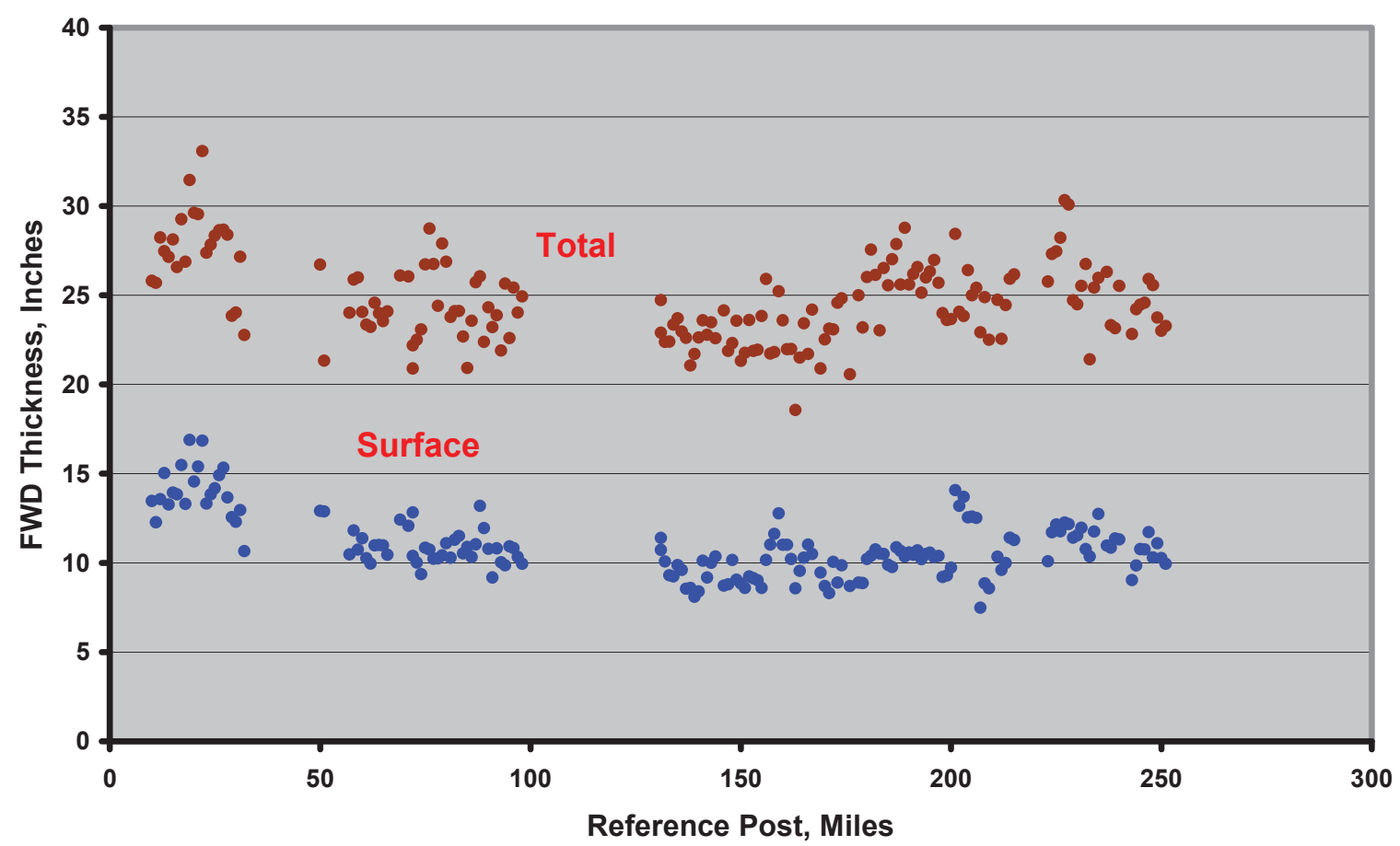

I - 65 South Bound driving Lane

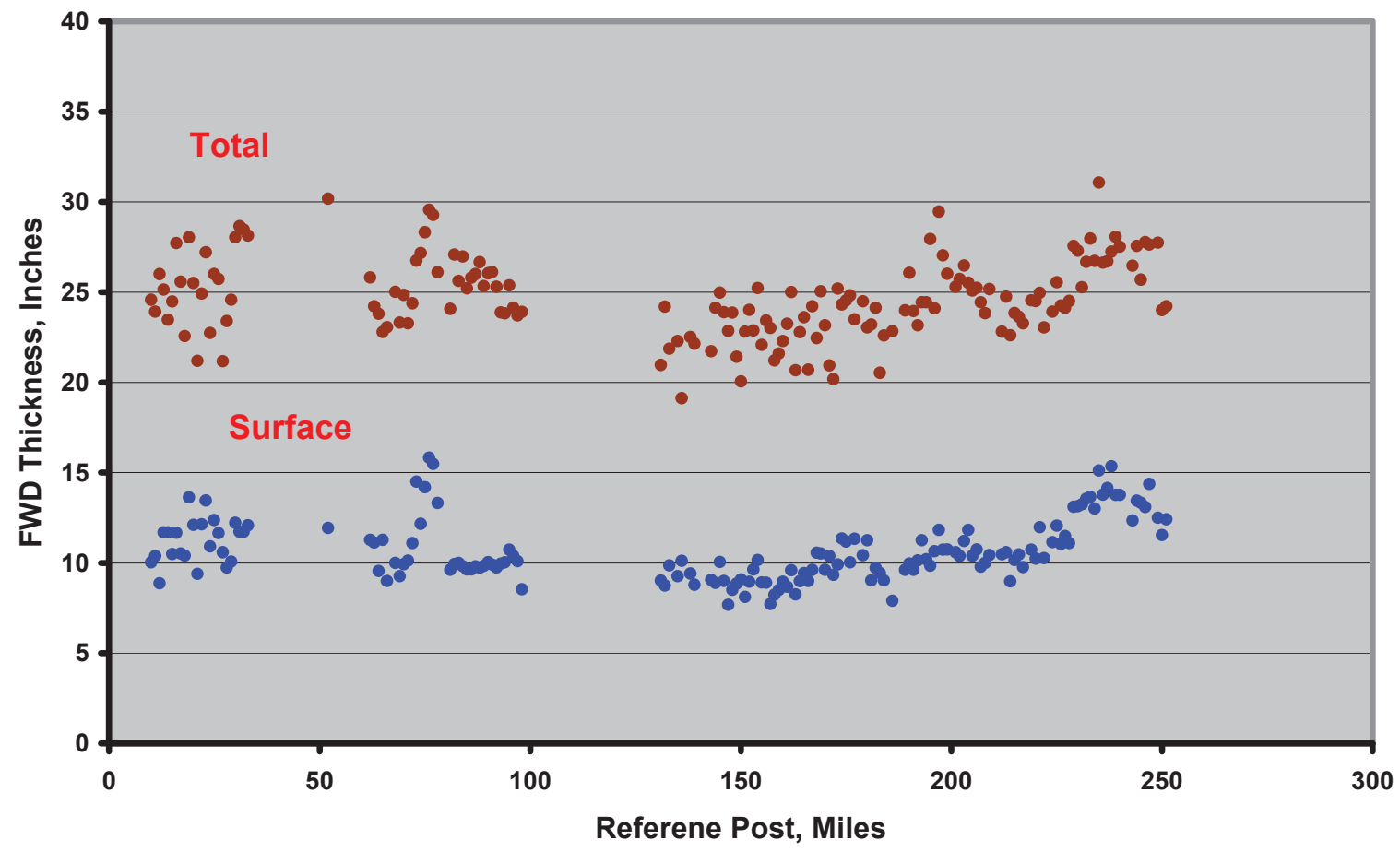

Figure 4.5 e: Profile of Pavement Layers Thickness along Interstate I - 65 


\section{I - 65 North Bound Driving Lane}

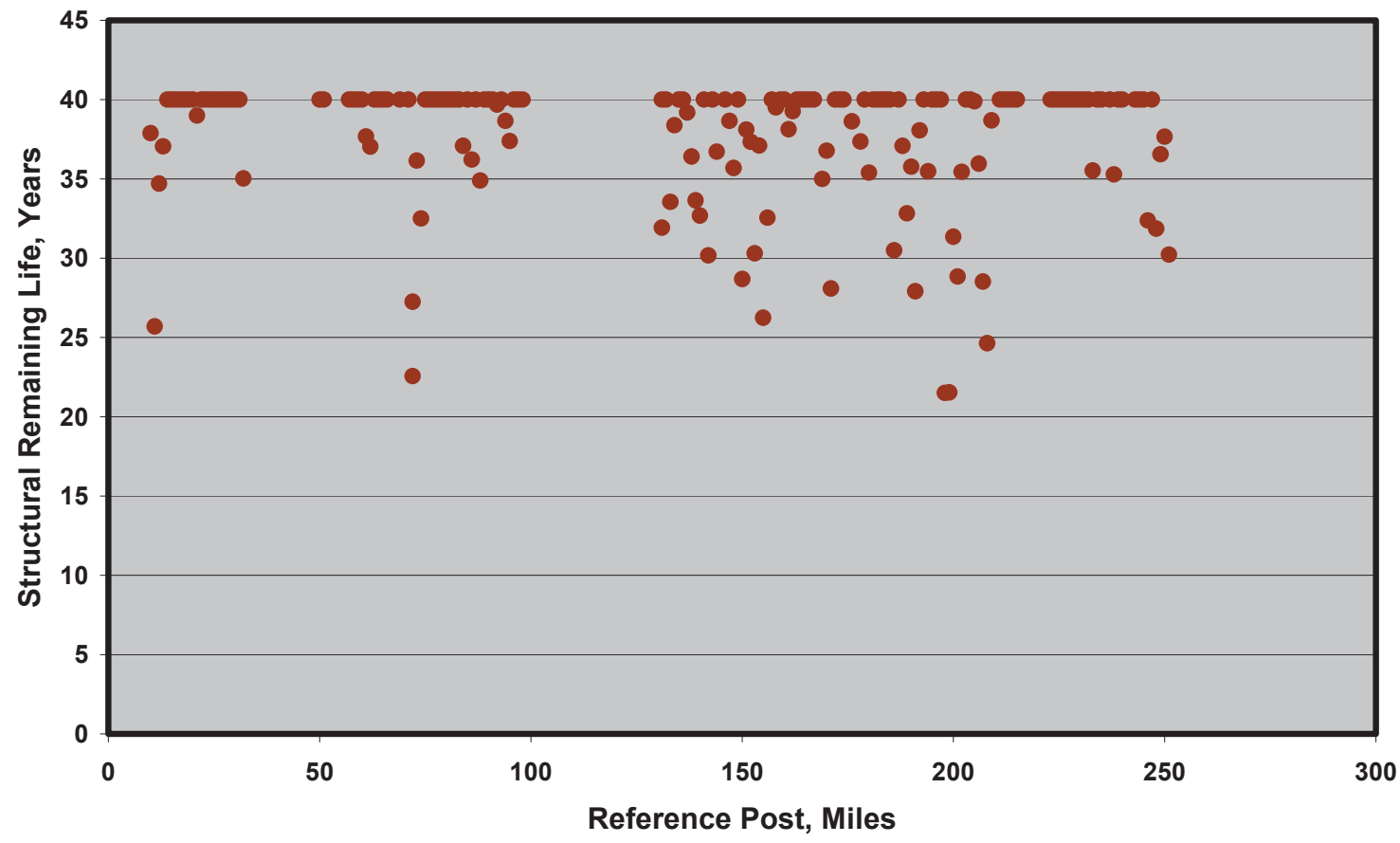

I - 65 South Bound Driving Lane

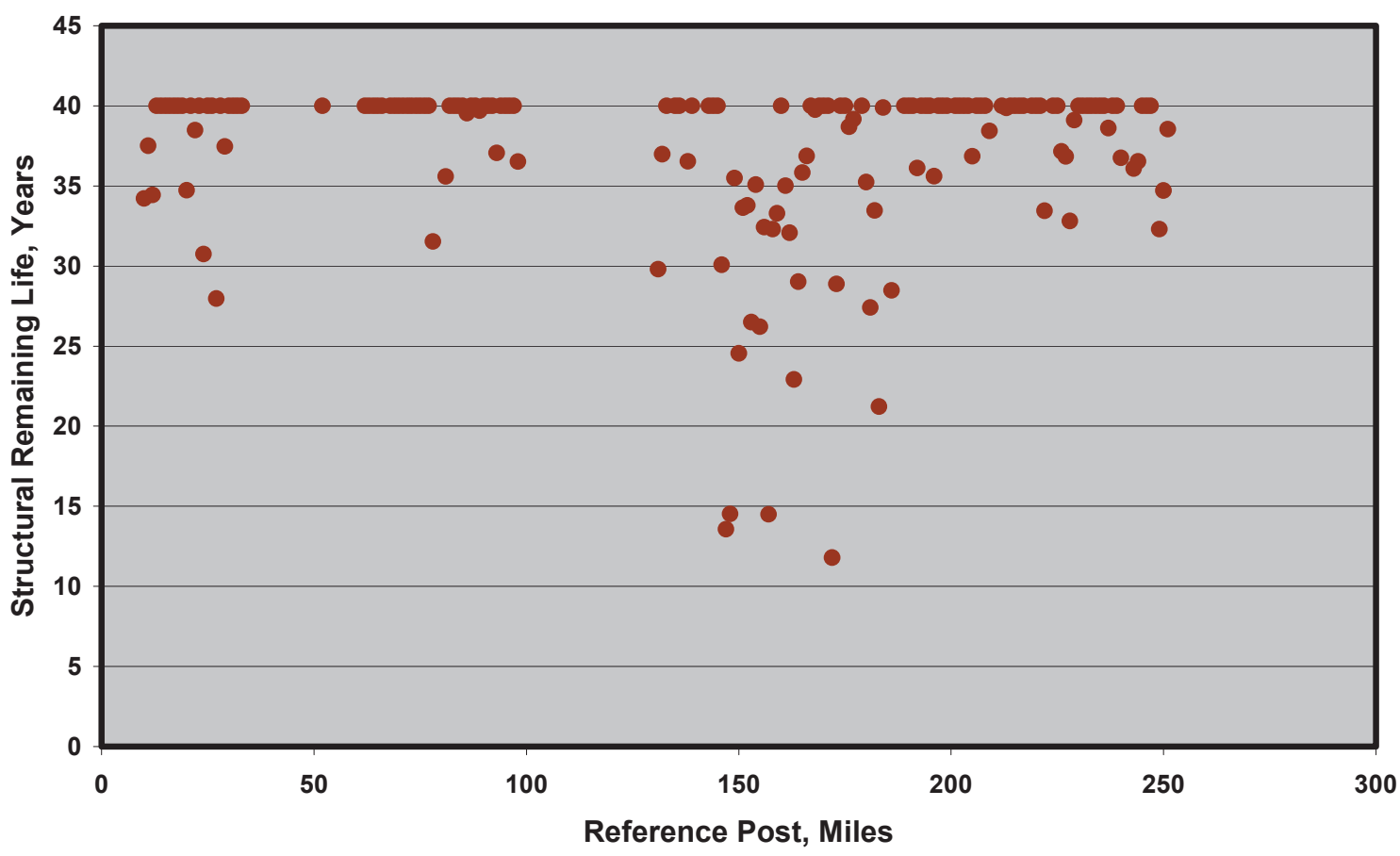

Figure 4.5 f: Profile of Pavement Remaining Life along Interstate I - 65 


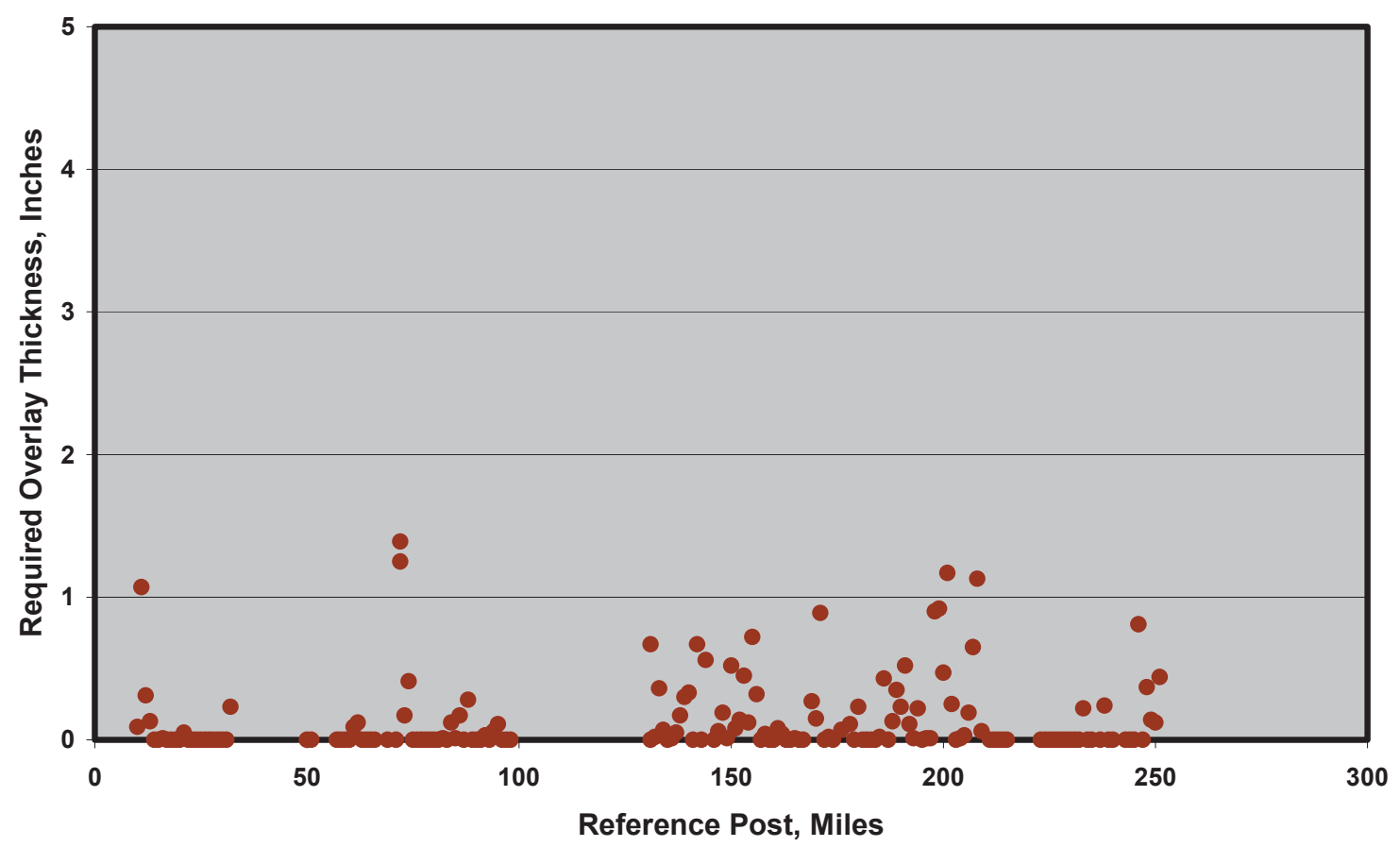

I - 65 South Bound Driving Lane

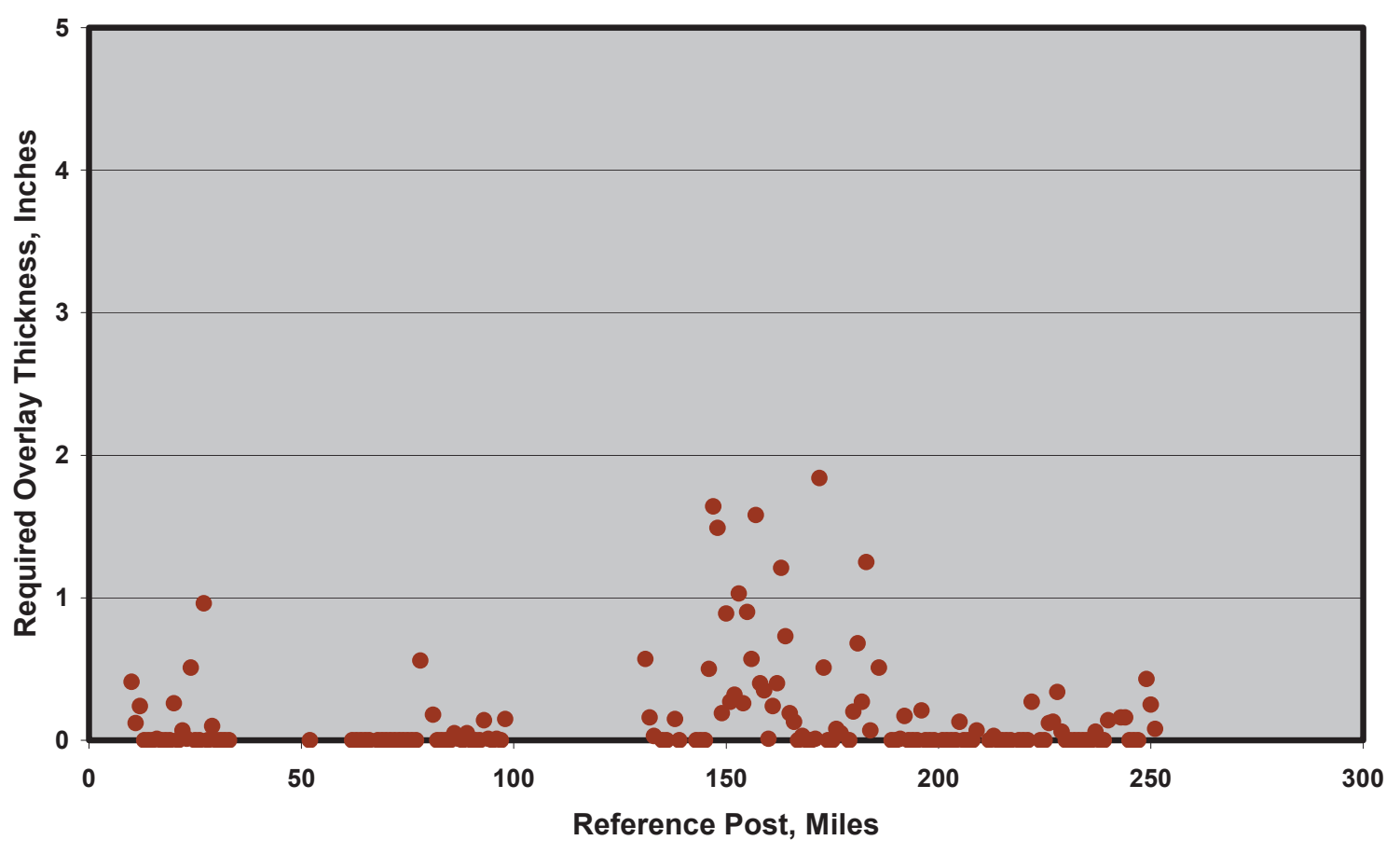

Figure 4.5 g: Profile of Required Overlay Thickness along Interstate I - 65 


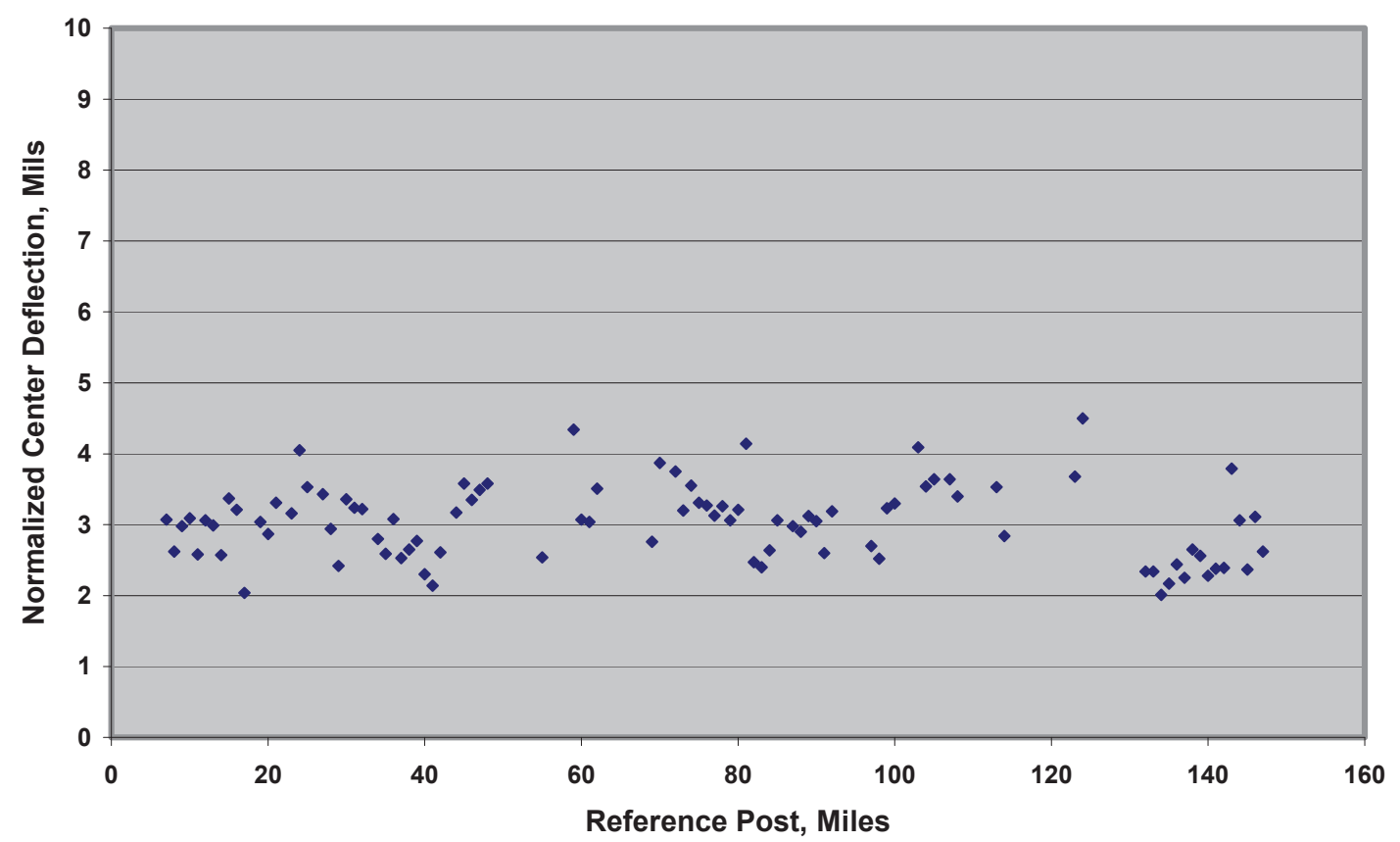

I - 69 South Bound Driving Lane

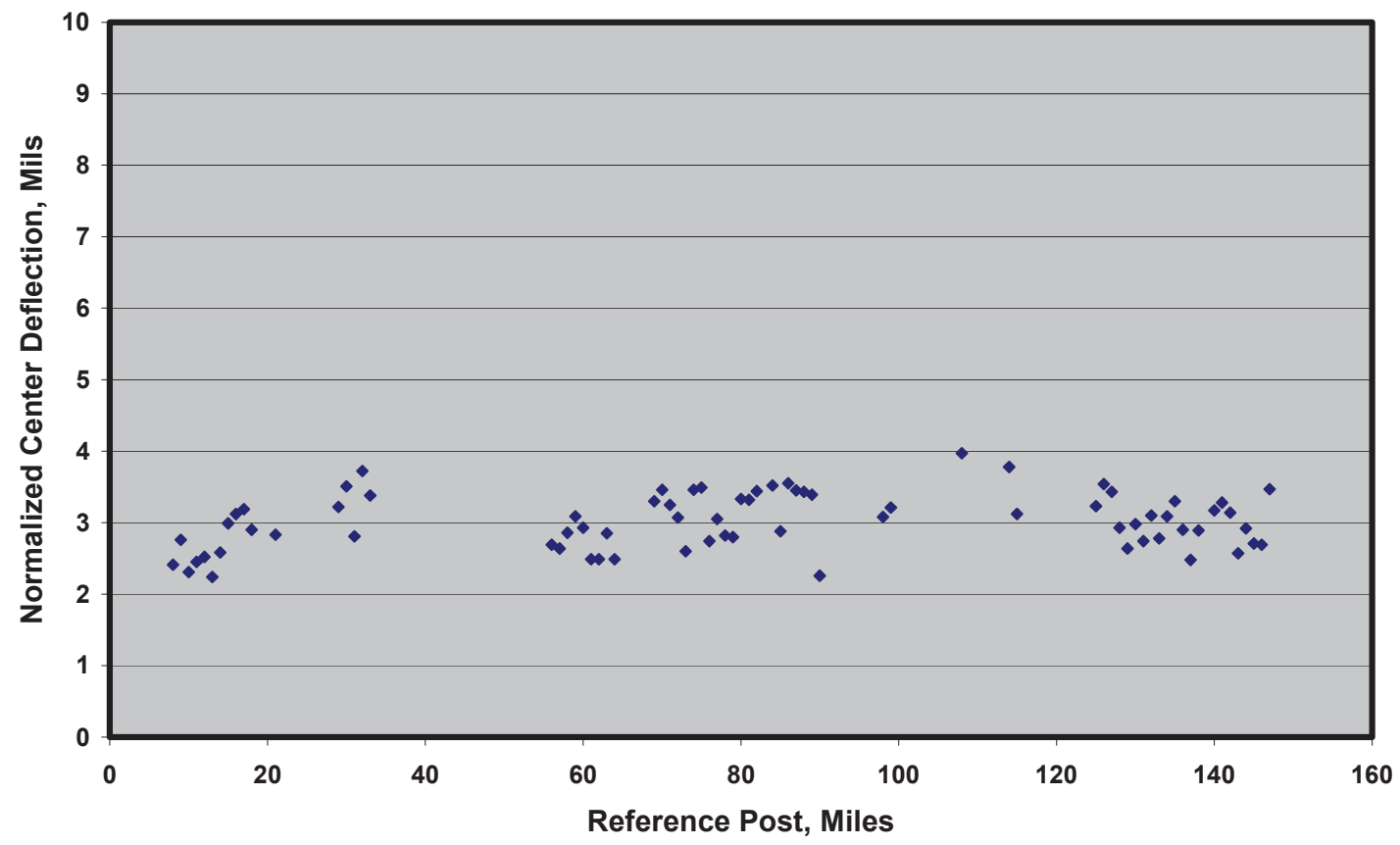

Figure 4.6 a: Profile of Pavement Surface Deflection along Interstate I - 69 
I - 69 South Bound Driving Lane

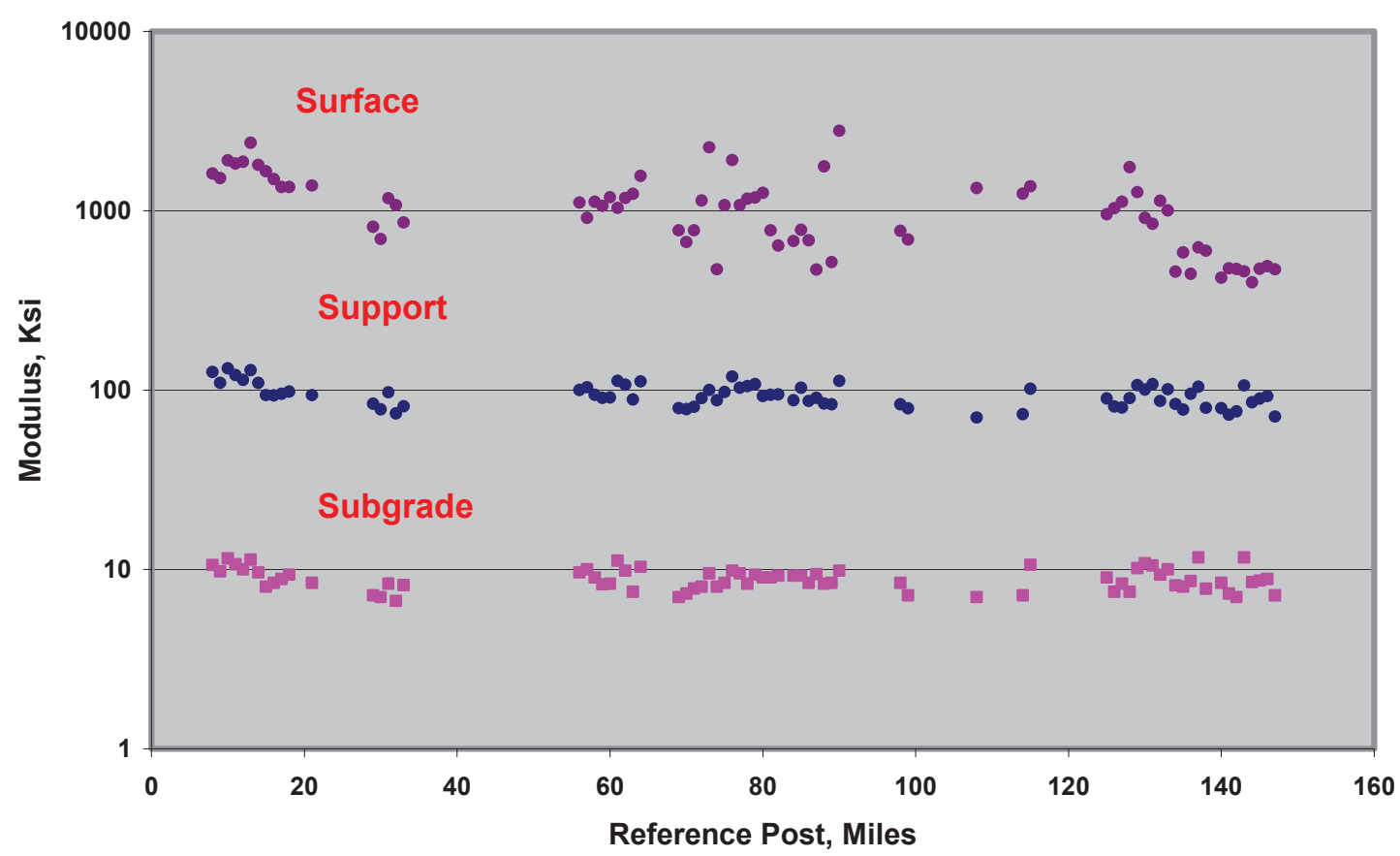

I - 69 North Bound Driving Lane

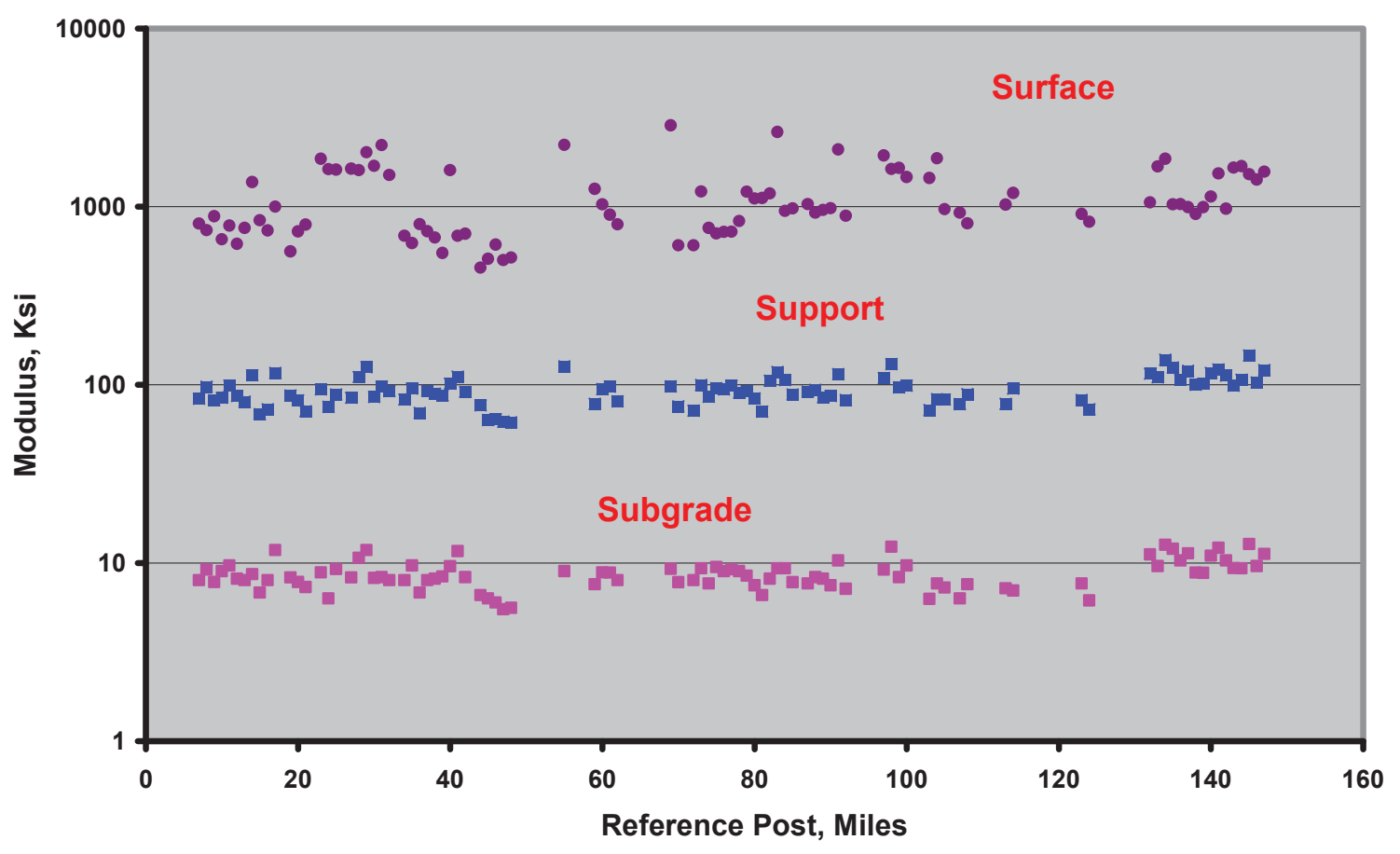

Figure 4.6 b: Profile of Pavement Layer Moduli along Interstate I - 69 


\section{I - 69 North Bound Driving Lane}

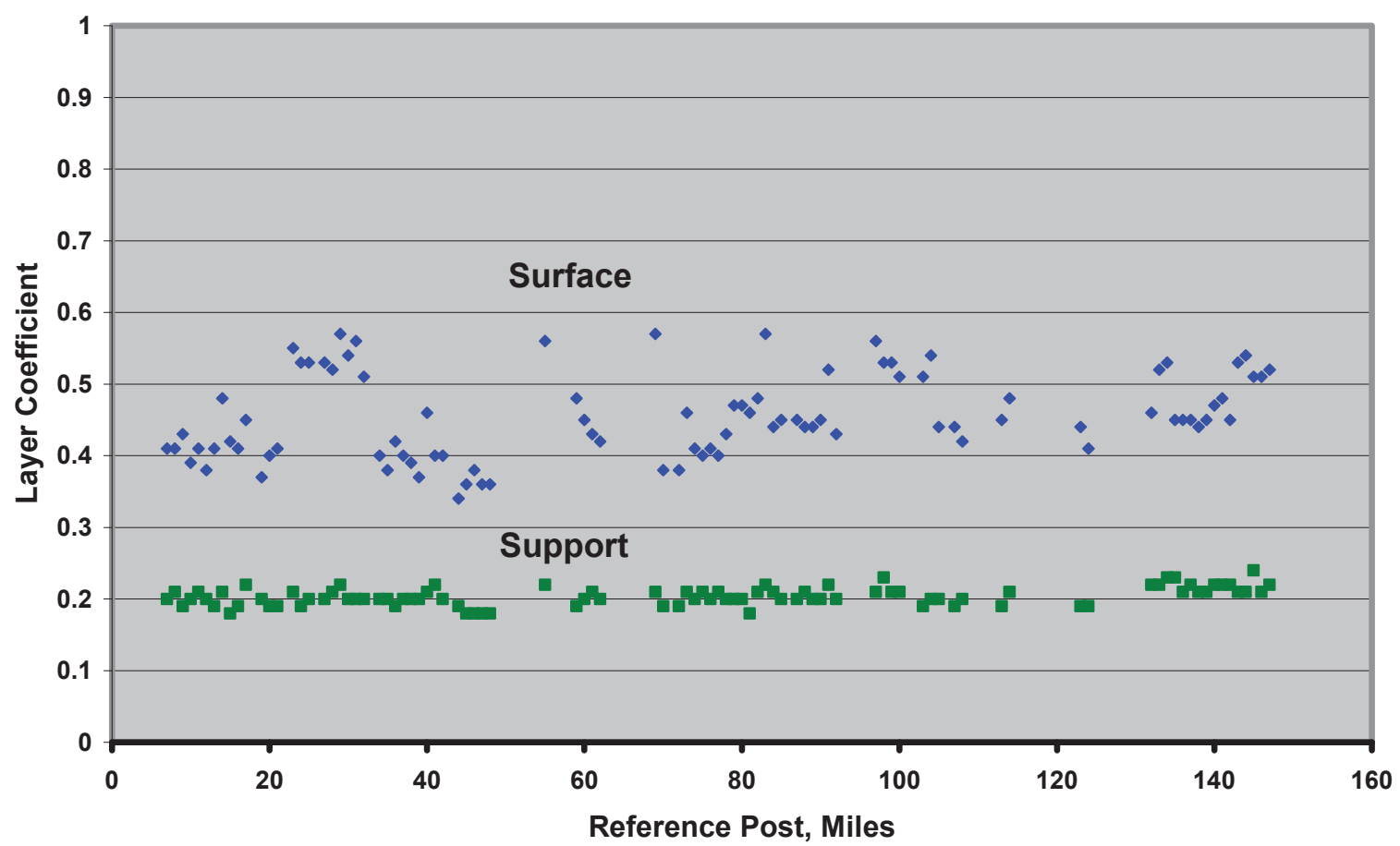

I - 69 South Bound Driving Lane

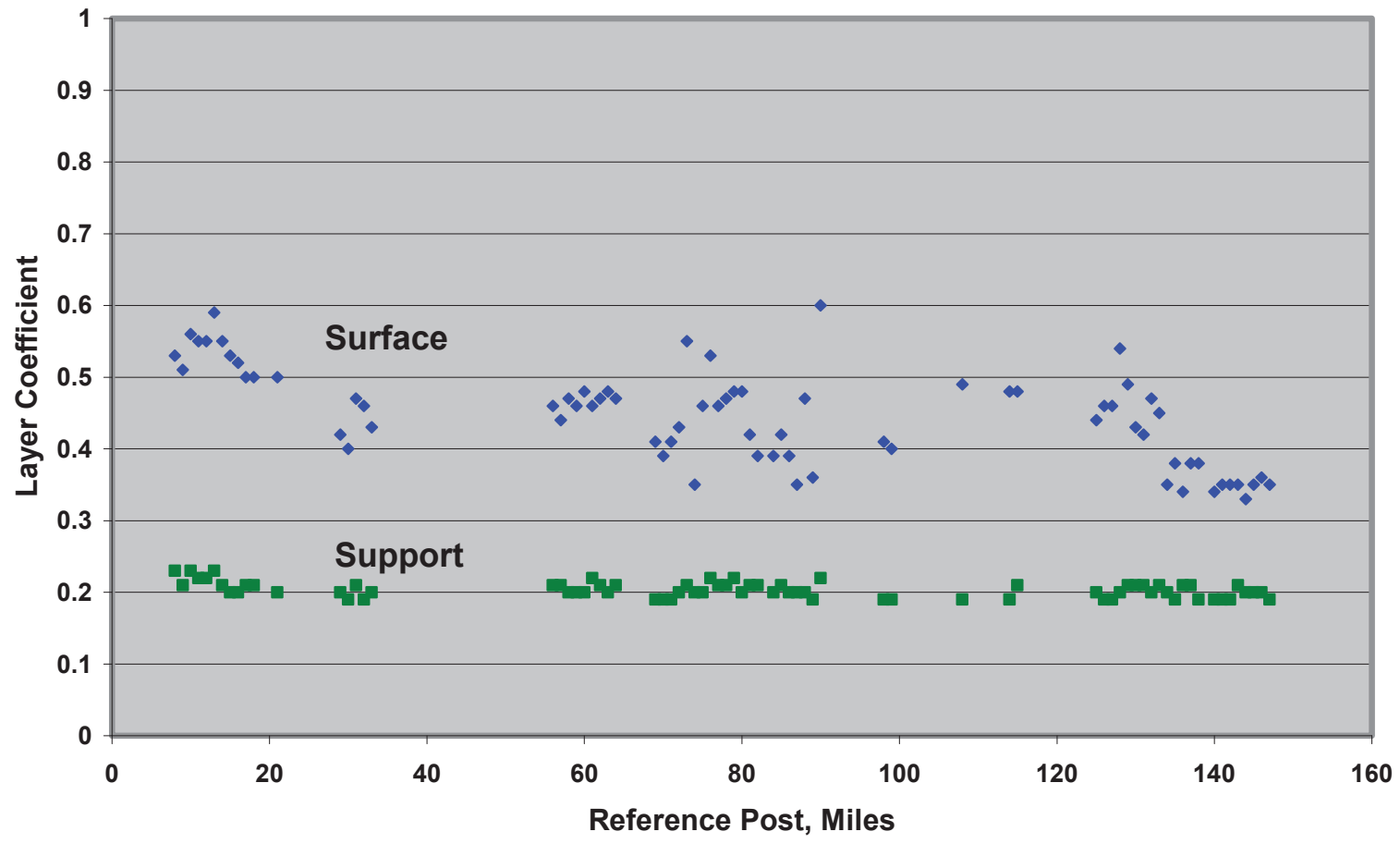

Figure 4.6 c: Profile of Pavement Layer Coefficients along Interstate I - 69 
I - 69 North Bound Driving Lane

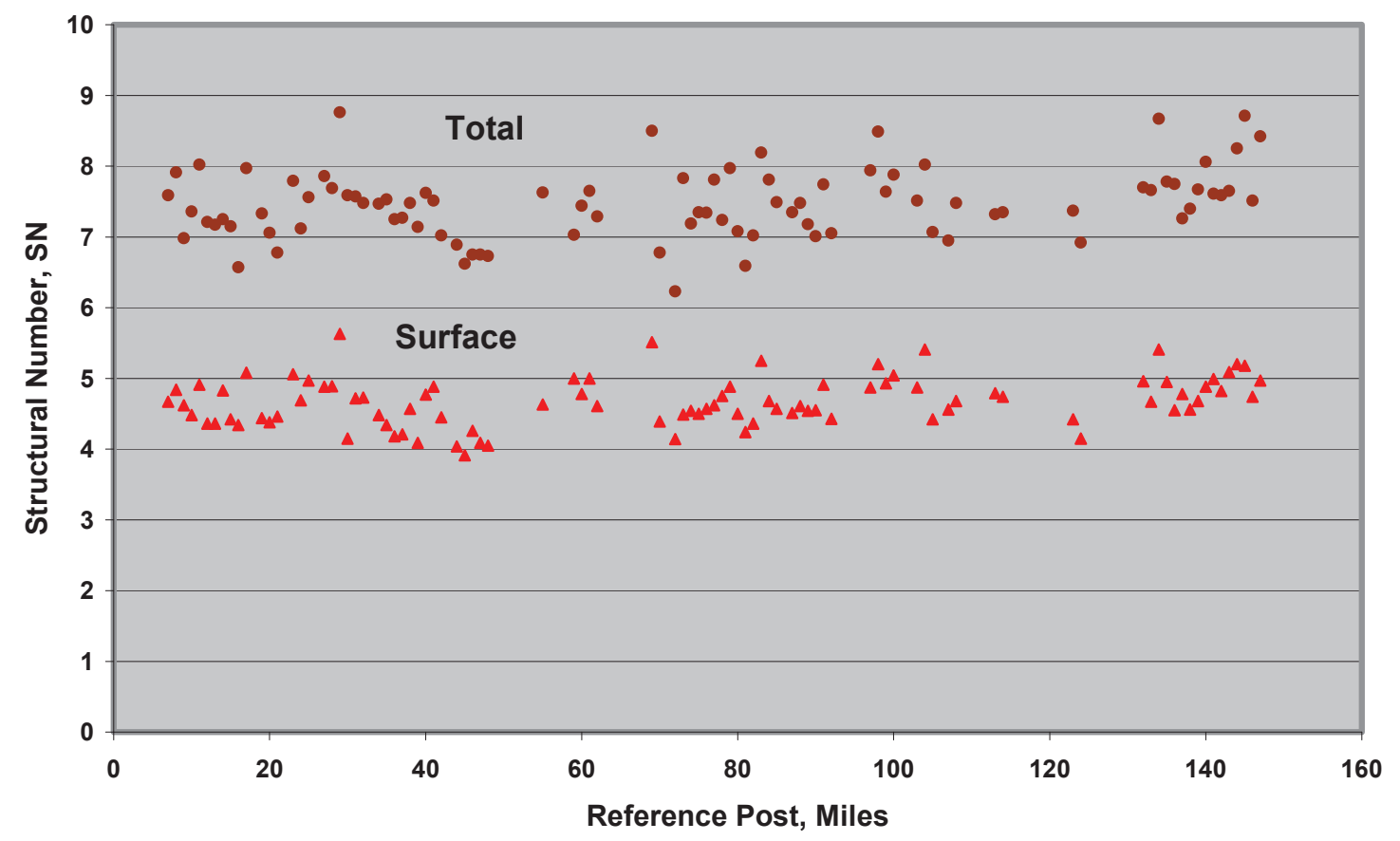

I - 69 South Bound Driving Lane

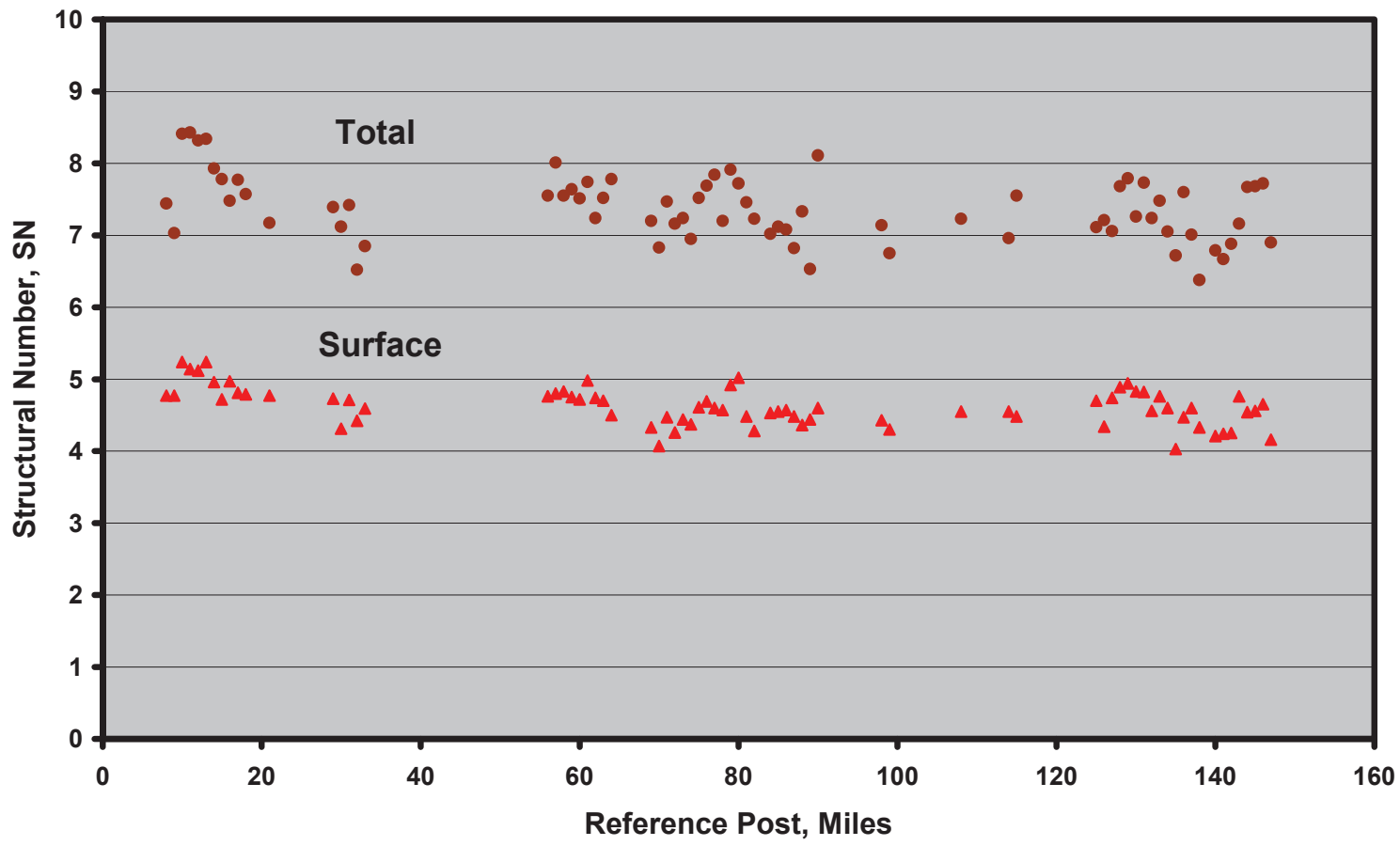

Figure 4.6 d: Profile of Pavement Structural Numbers along Interstate I - 69 


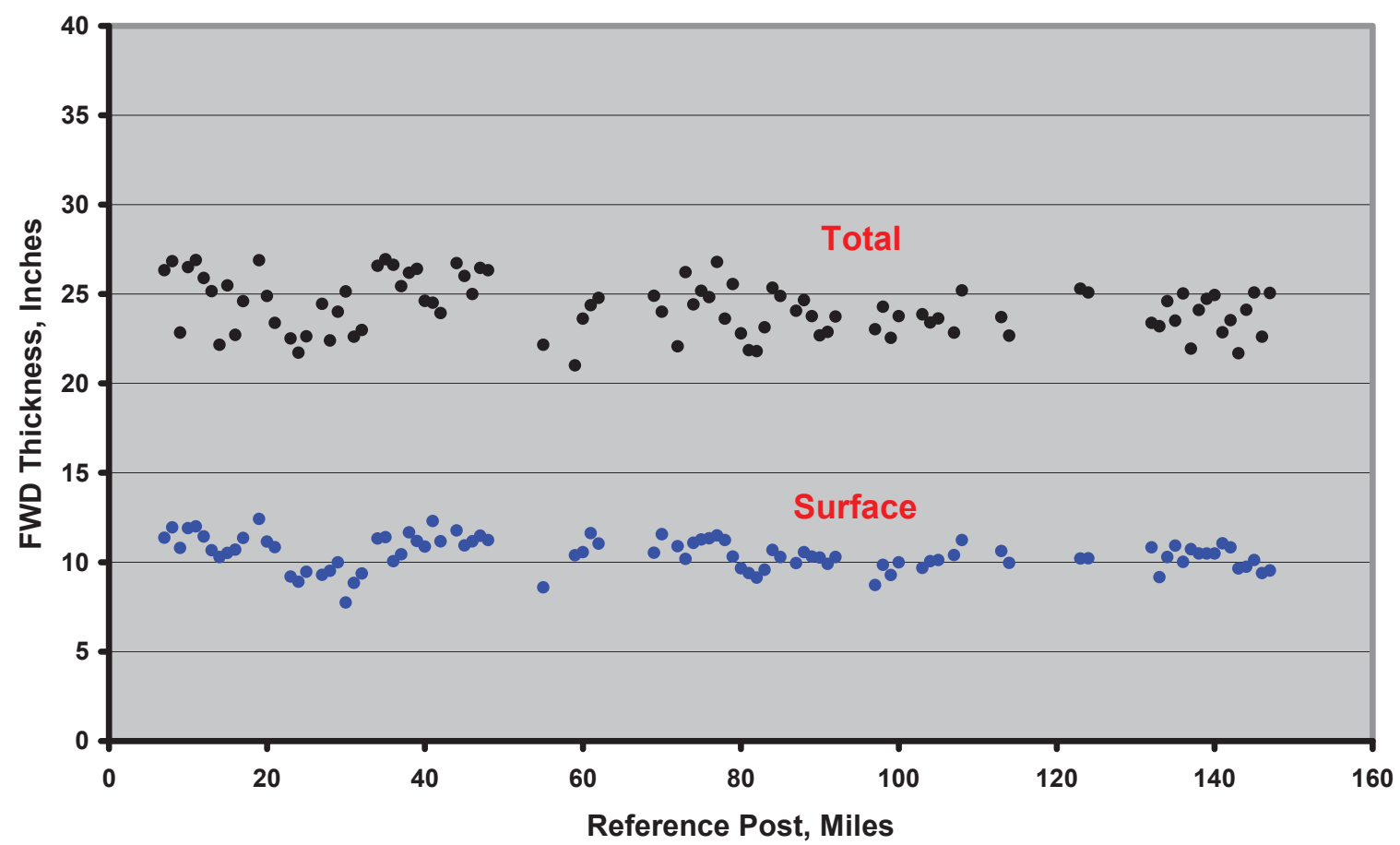

I - 69 South Bound Driving Lane

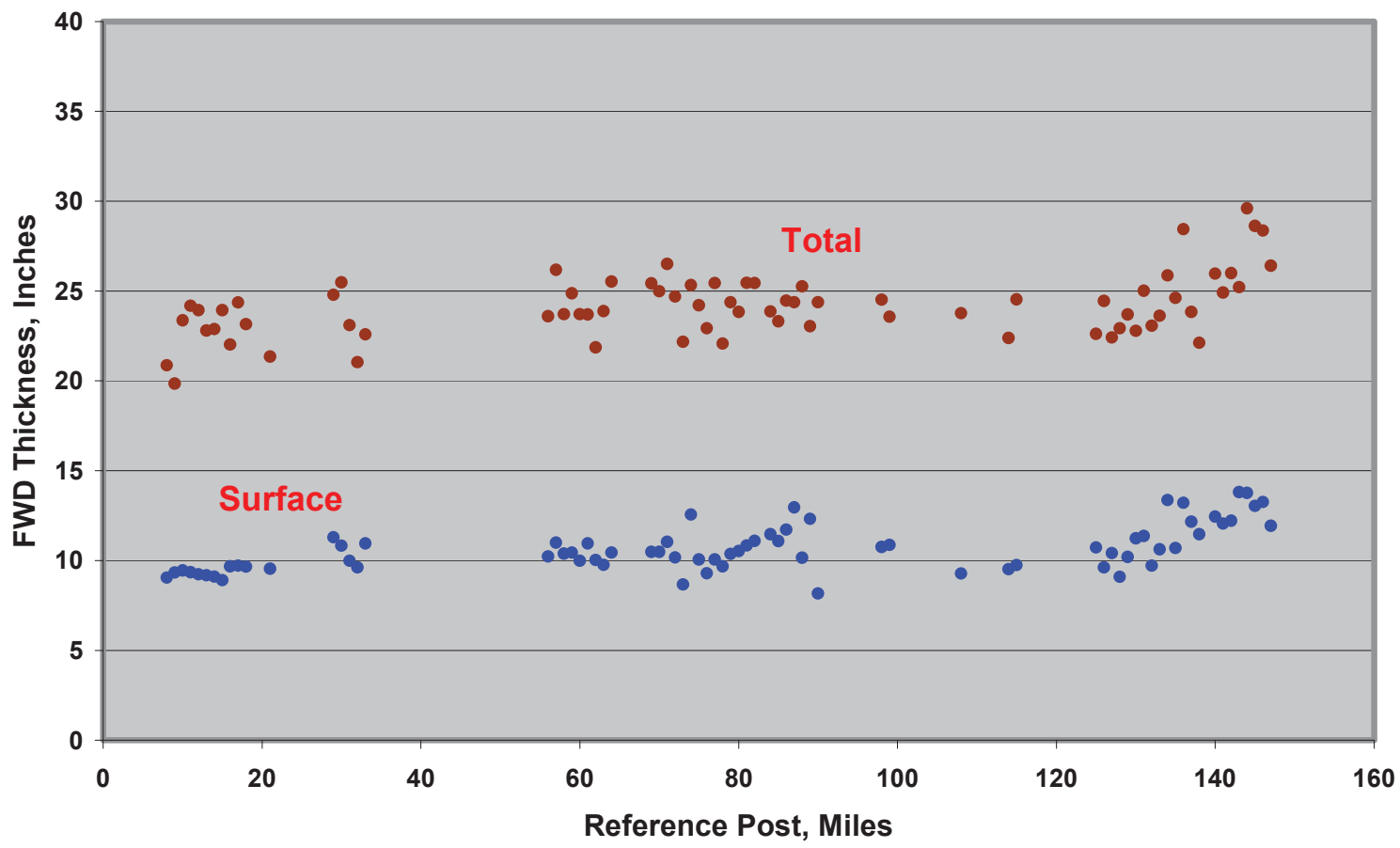

Figure 4.6 e: Profile of Pavement Layers Thickness along Interstate I - 69 


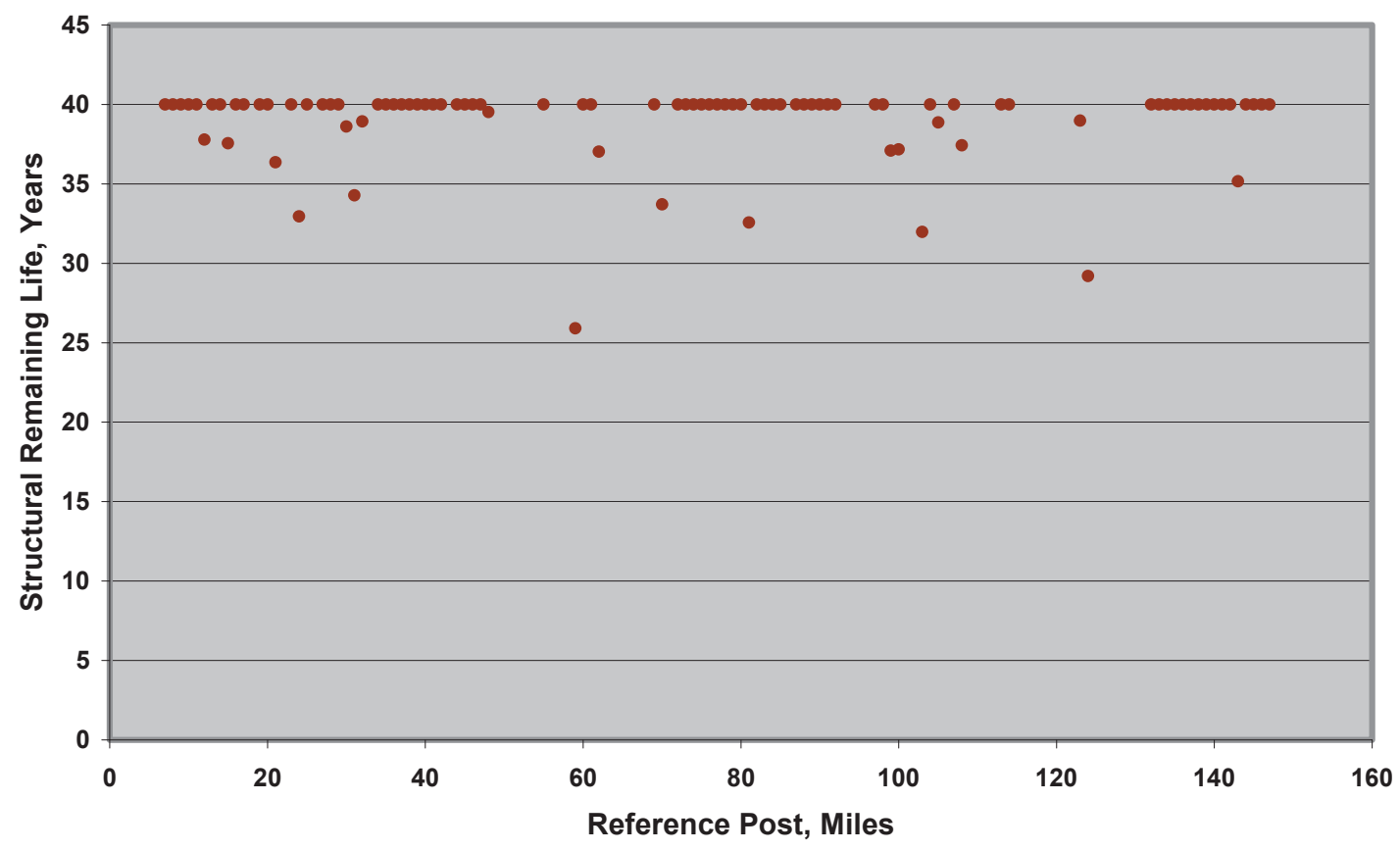

Figure 4.6 f: Profile of Pavement Remaining Life along Interstate I - 69 I - 69 North Bound Driving Lane

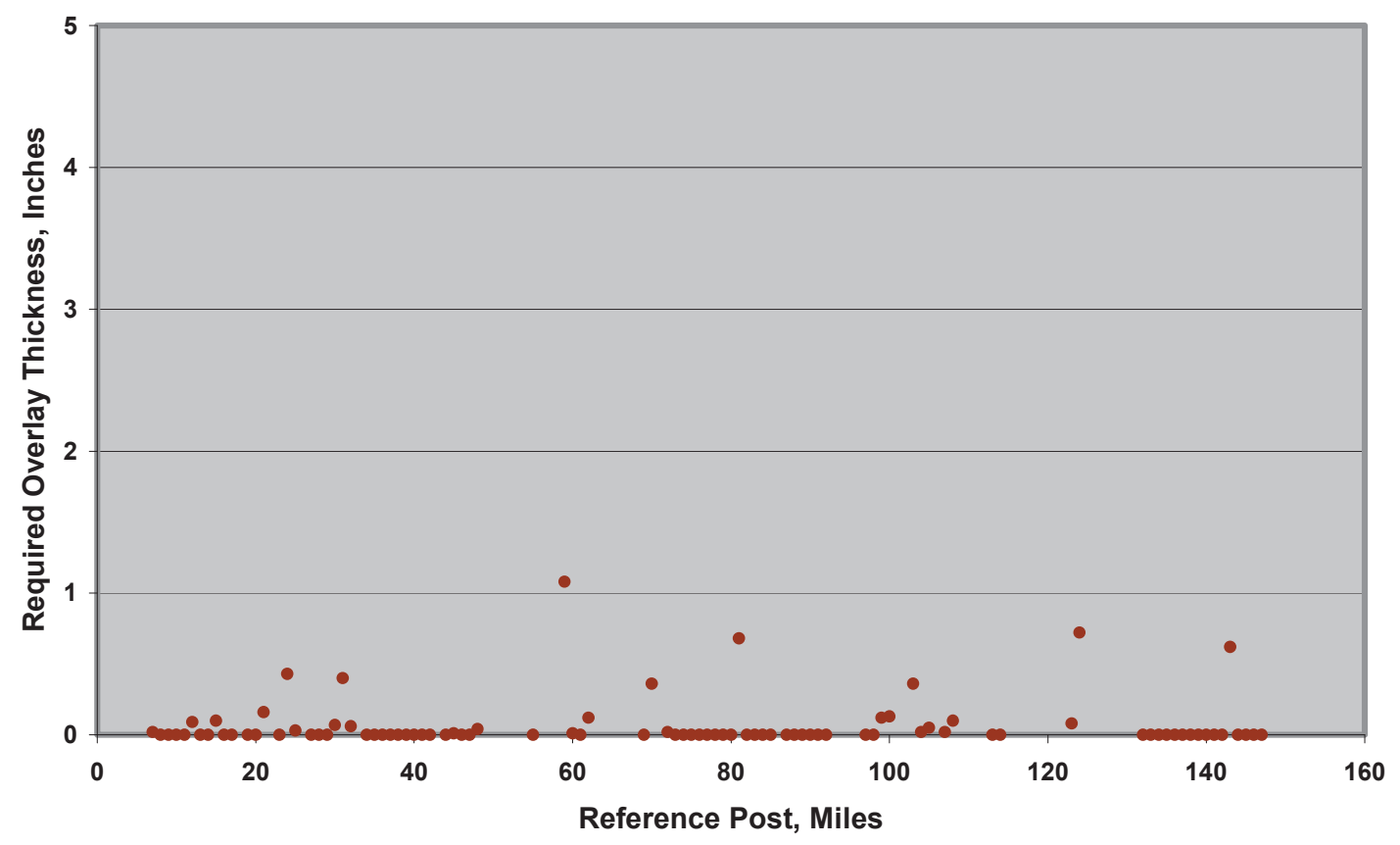

Figure 4.6 g: Profile of Required Overlay Thickness along Interstate I - 69 


\section{I -70 East Bound Driving Lane}

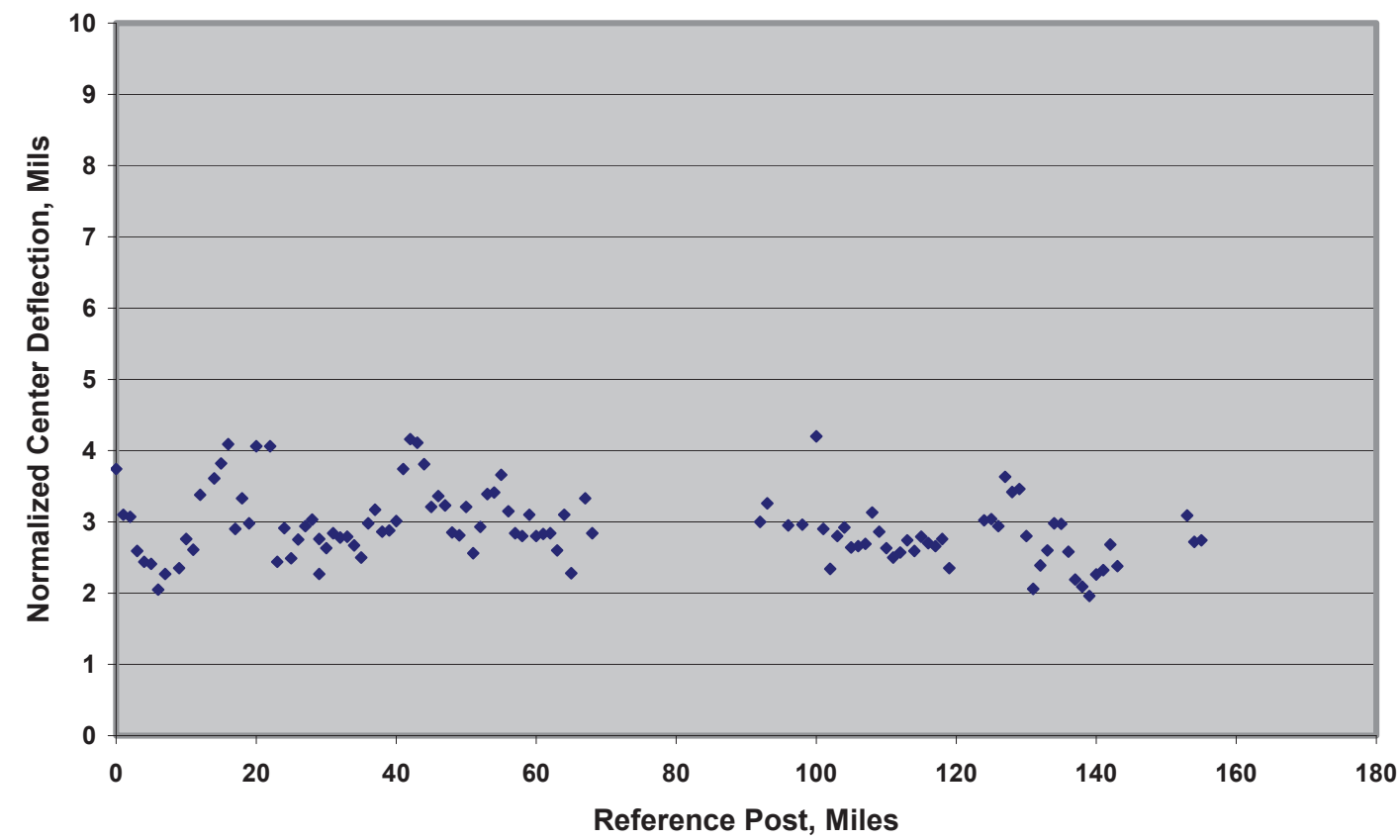

I - 70 West Bound Driving Lane

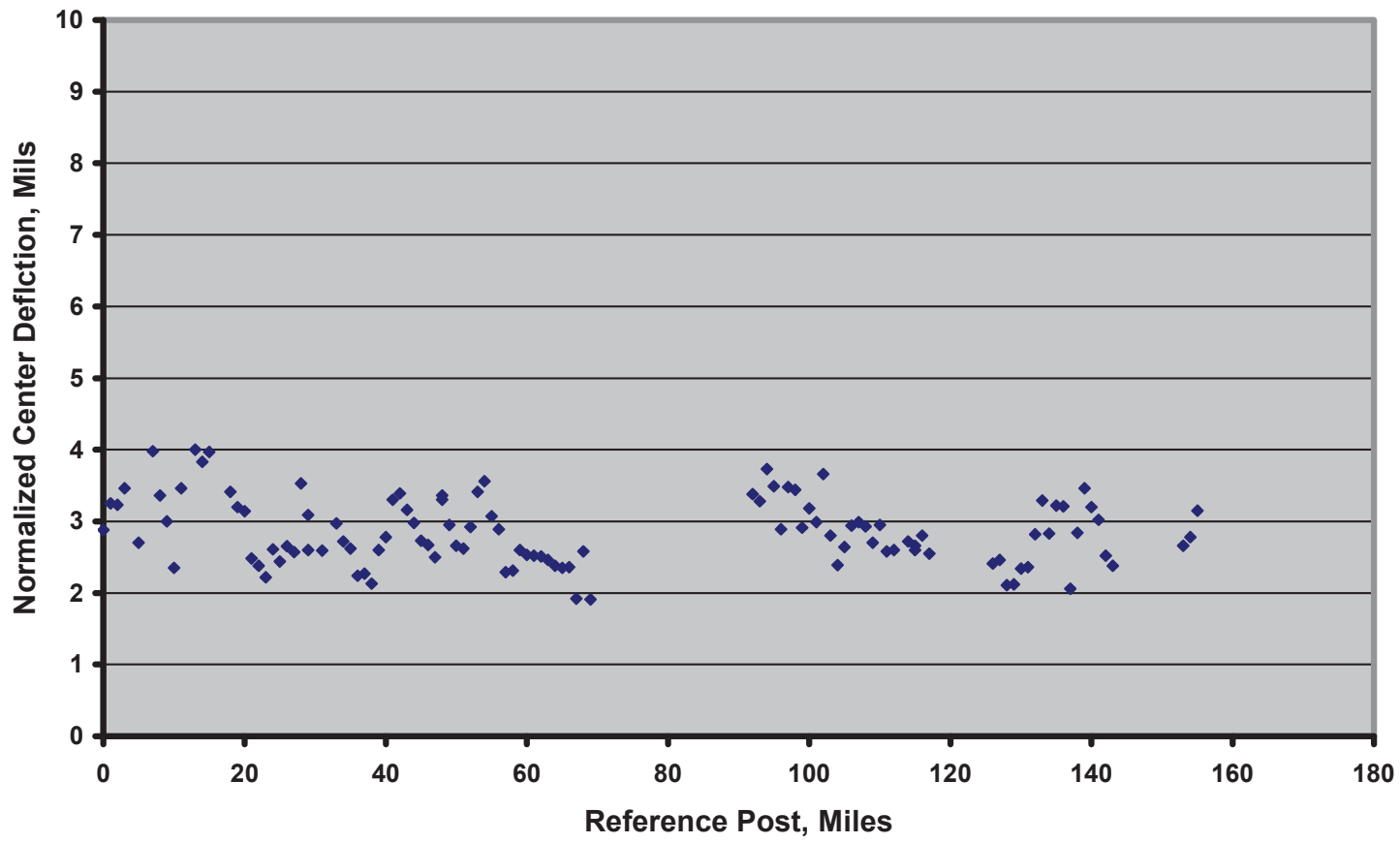

Figure 4.7 a: Profile of Pavement Surface Deflection along Interstate I - 70 


\section{I - 70 East Bound Driving Lane}

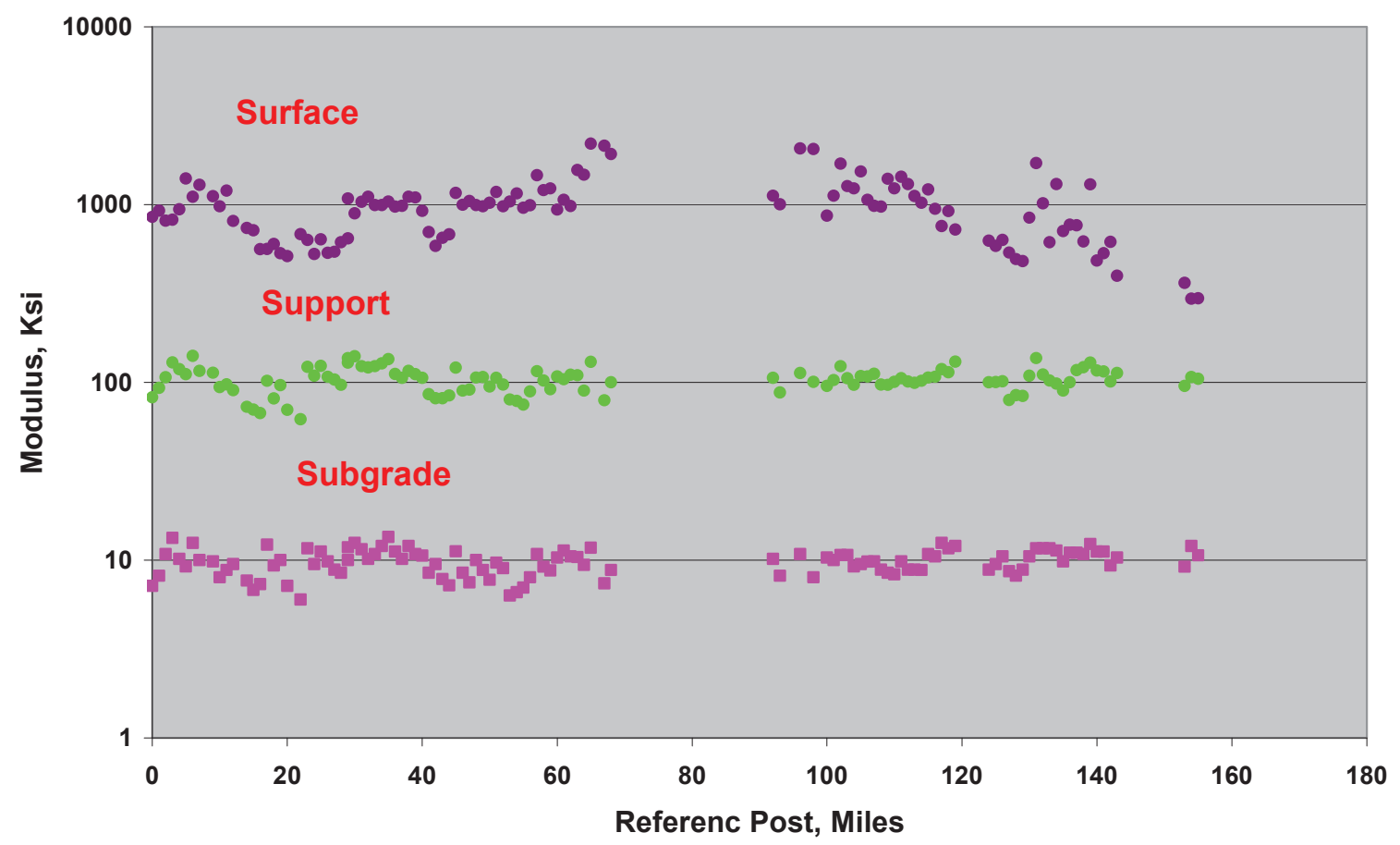

I - 70 West Bound Driving Lane

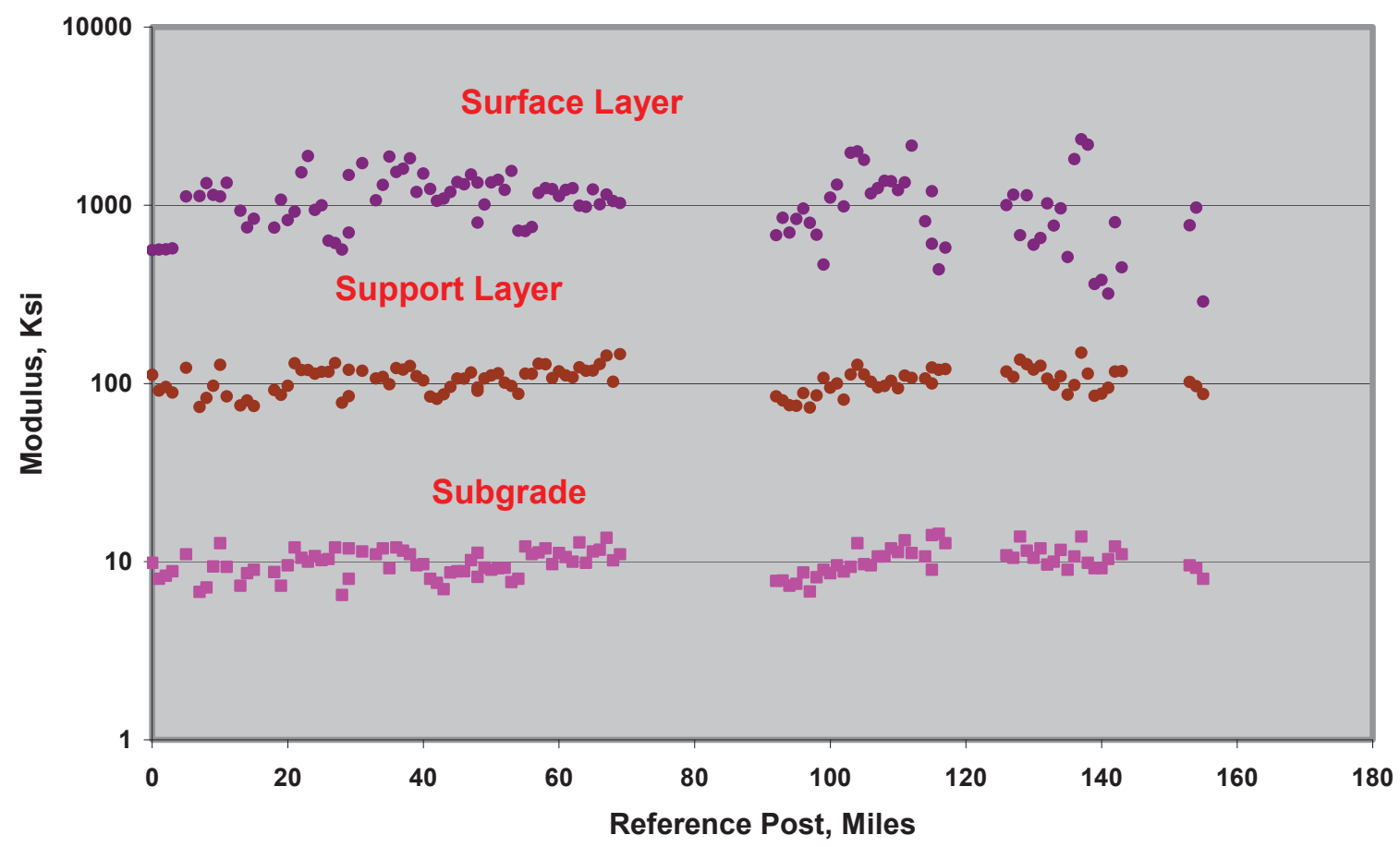

Figure 4.7 b: Profile of Pavement Layer Moduli along Interstate I - 70 


\section{I - 70 East Bound Driving Lane}

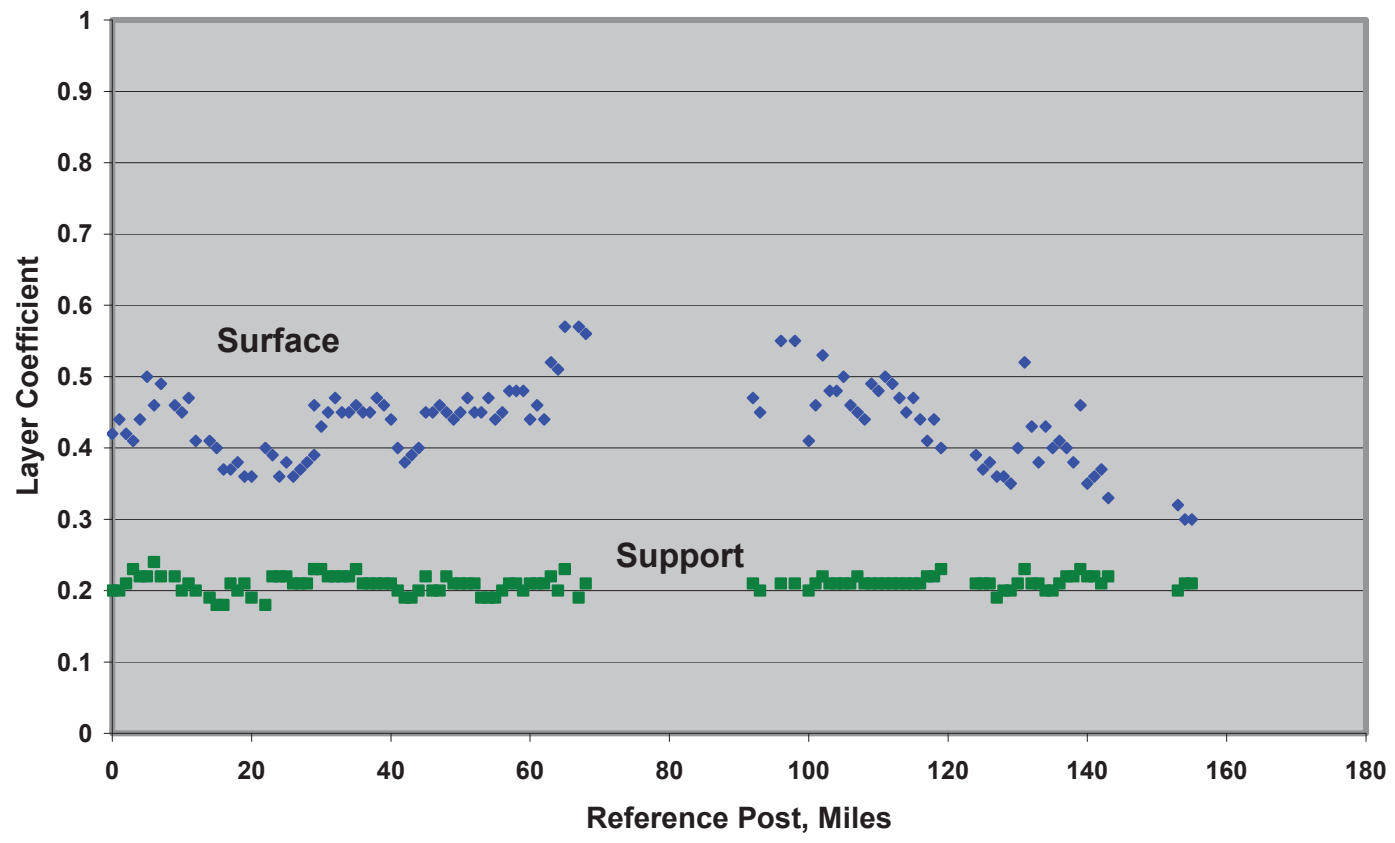

I - 70 West Bound Driving Lane

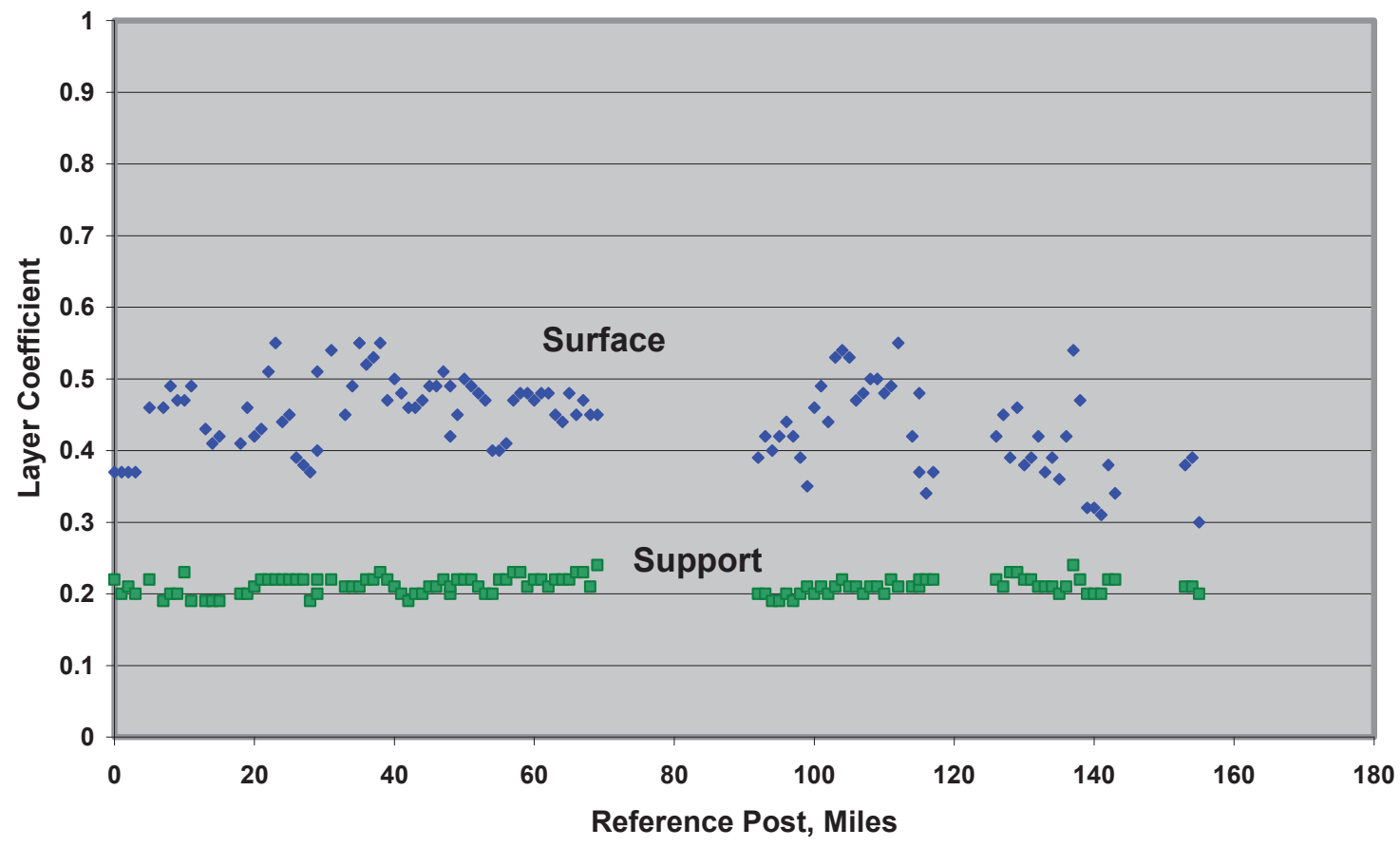

Figure 4.7 c: Profile of Pavement Layer Coefficients along Interstate I - 70 


\section{I - 70 East Bound Driving Lane}

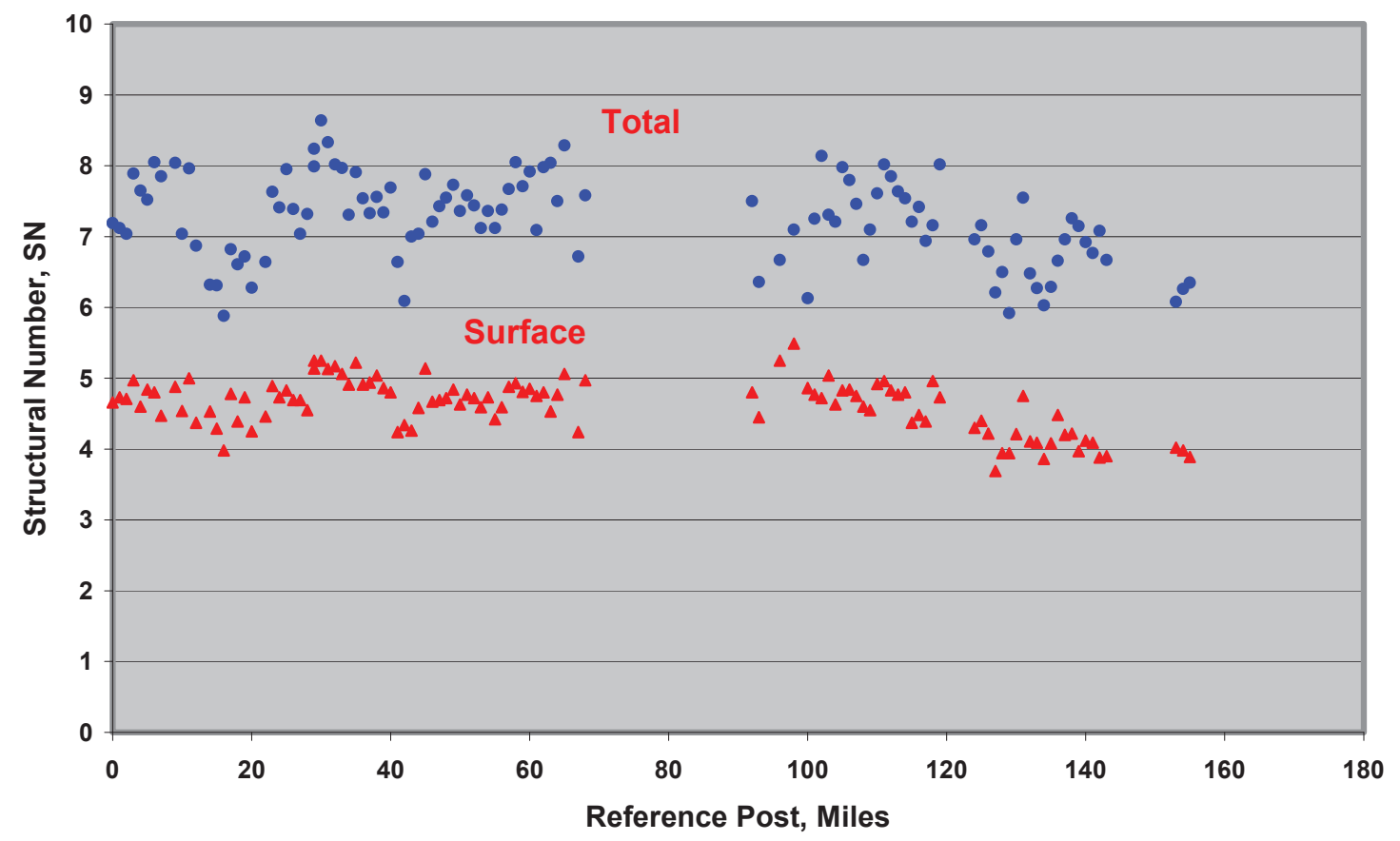

I - 70 West Bound Driving Lane

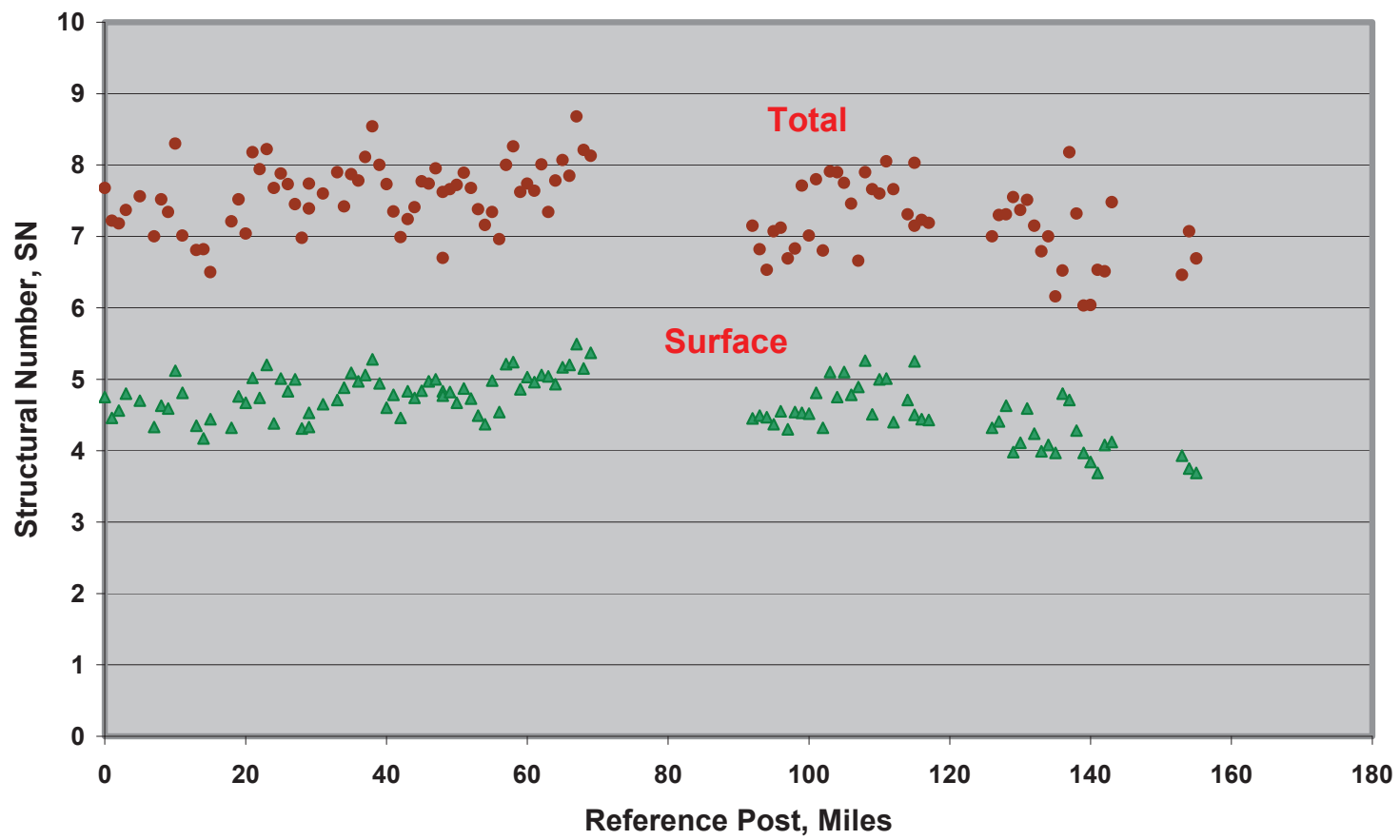

Figure $4.7 \mathrm{~d}$ : Profile of Pavement Structural Numbers along Interstate I - 70 


\section{I - 70 East Bound Driving Lane}

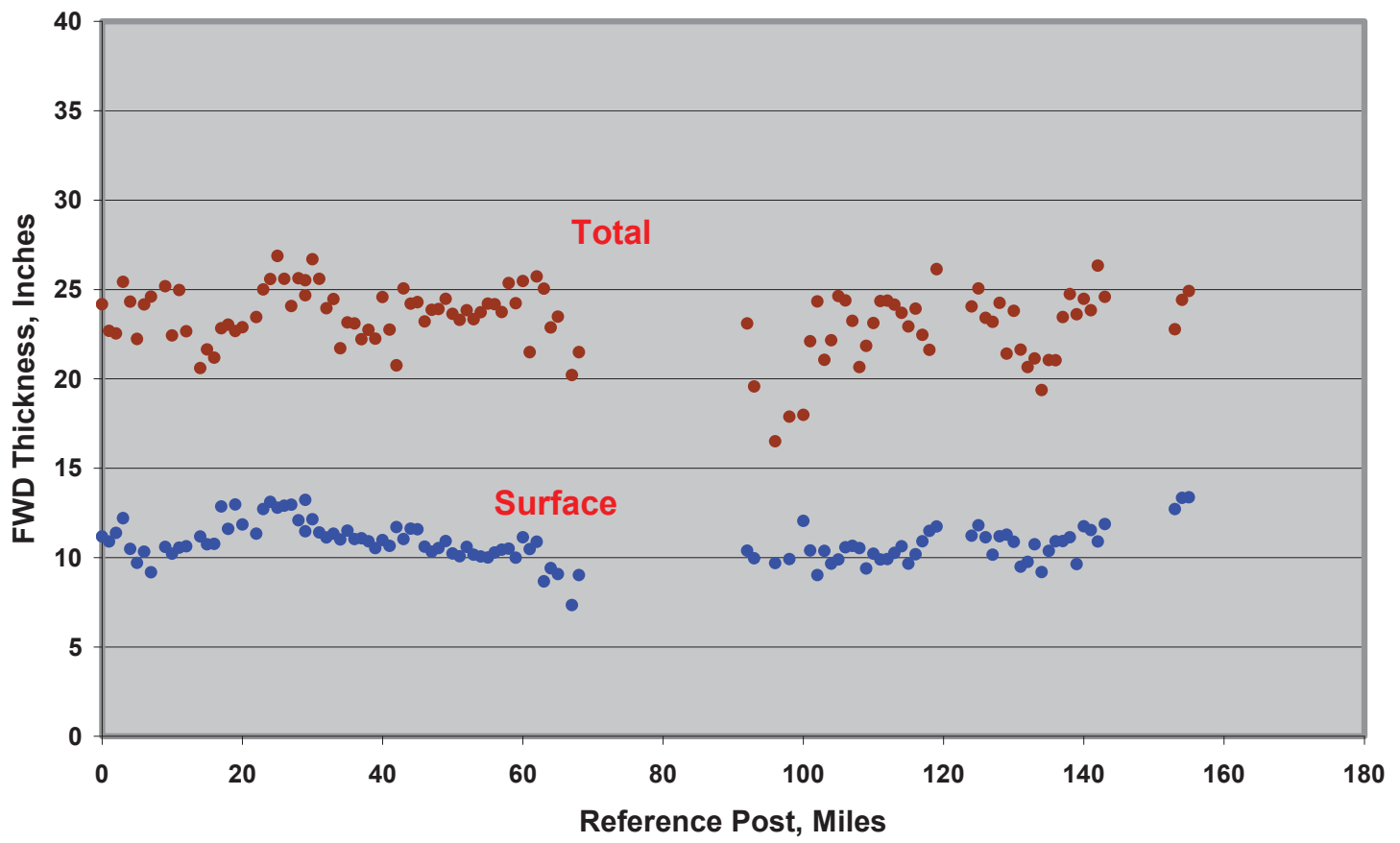

I - 70 West Bound Driving Lane

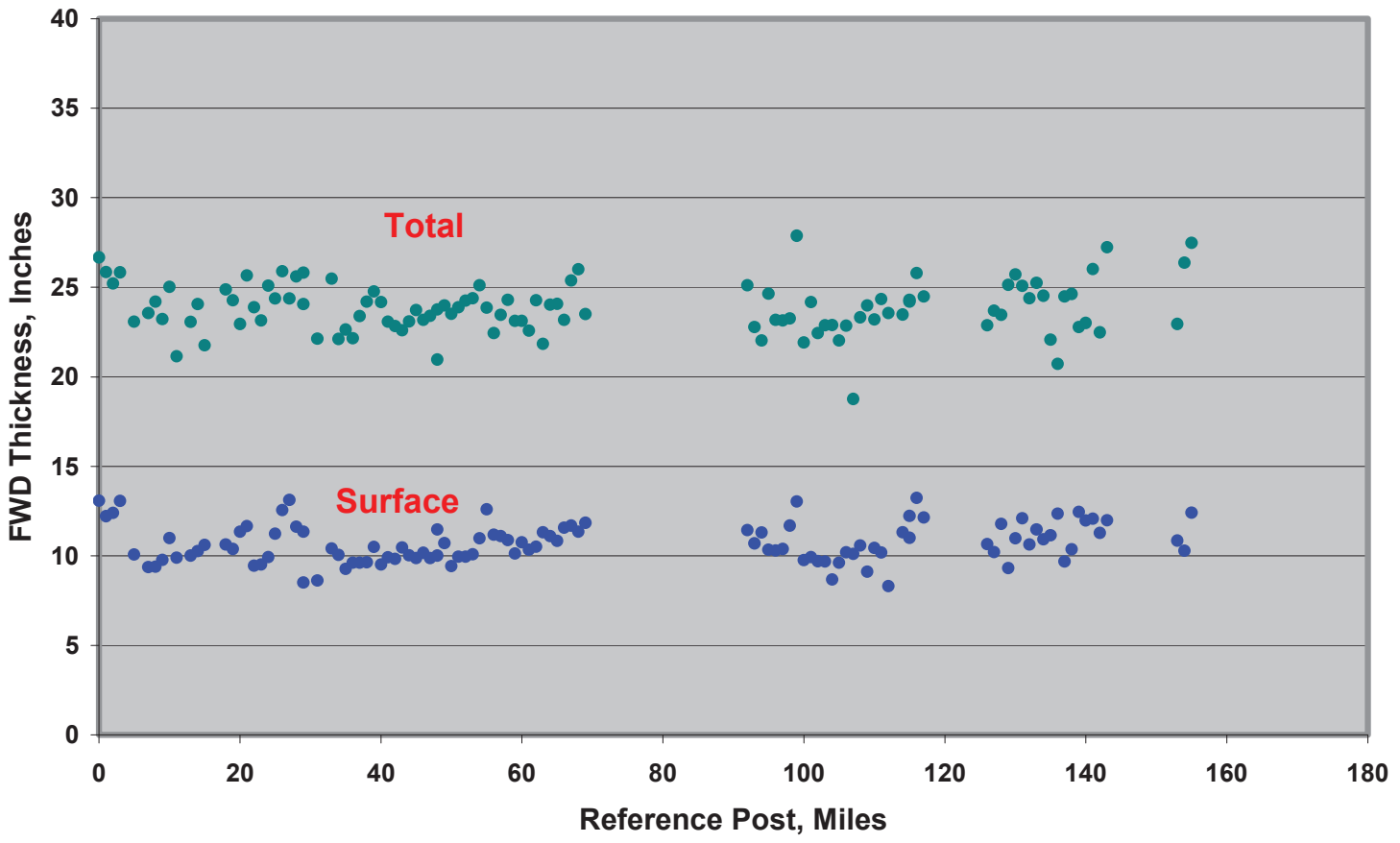

Figure 4.7 e: Profile of Pavement Layers Thickness along Interstate I - 70 
I - 70 West Bound Driving Lane

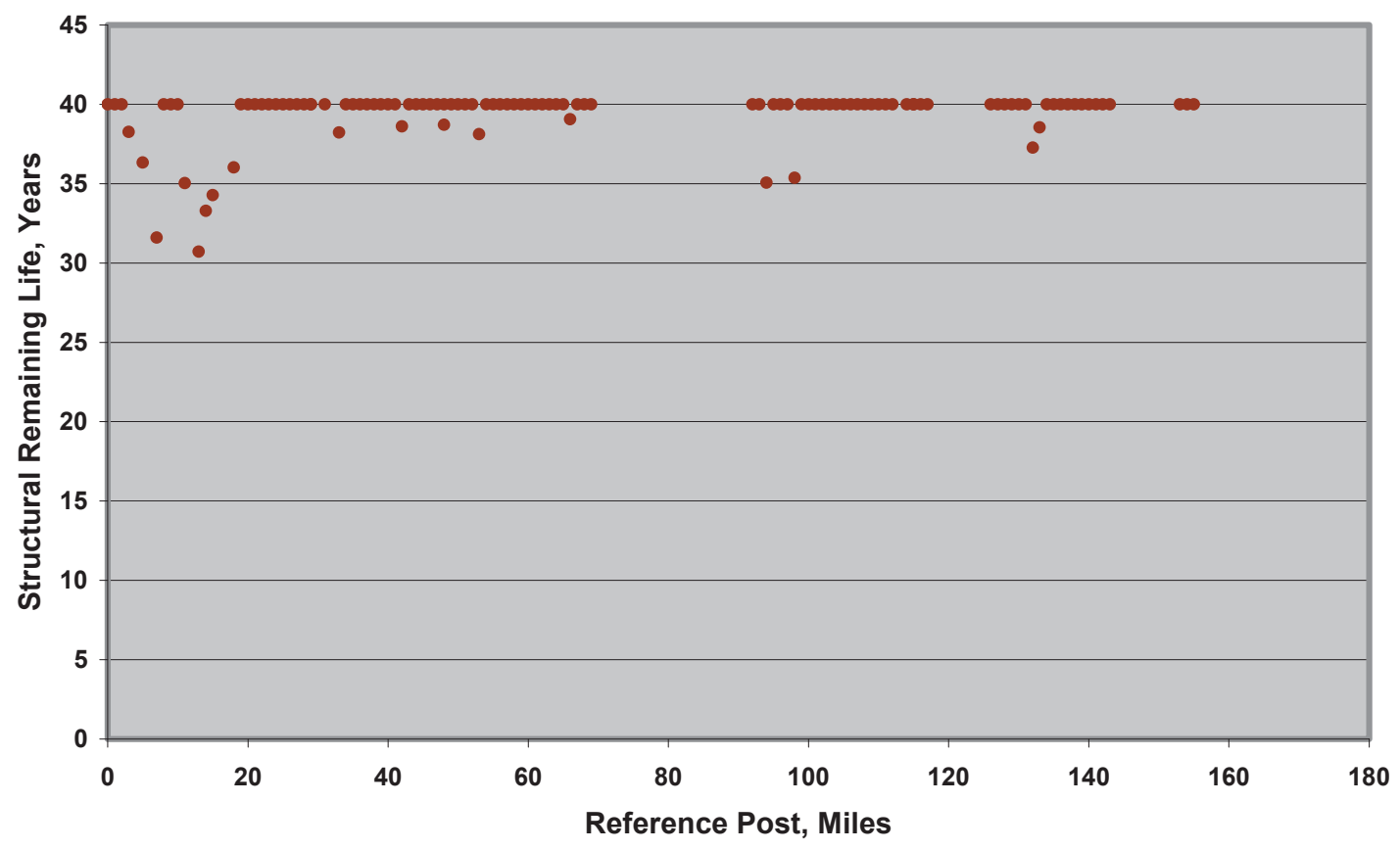

Figure 4.7 f: Profile of Pavement Remaining Life along Interstate I - 70

I - 70 West Bound Driving Lane

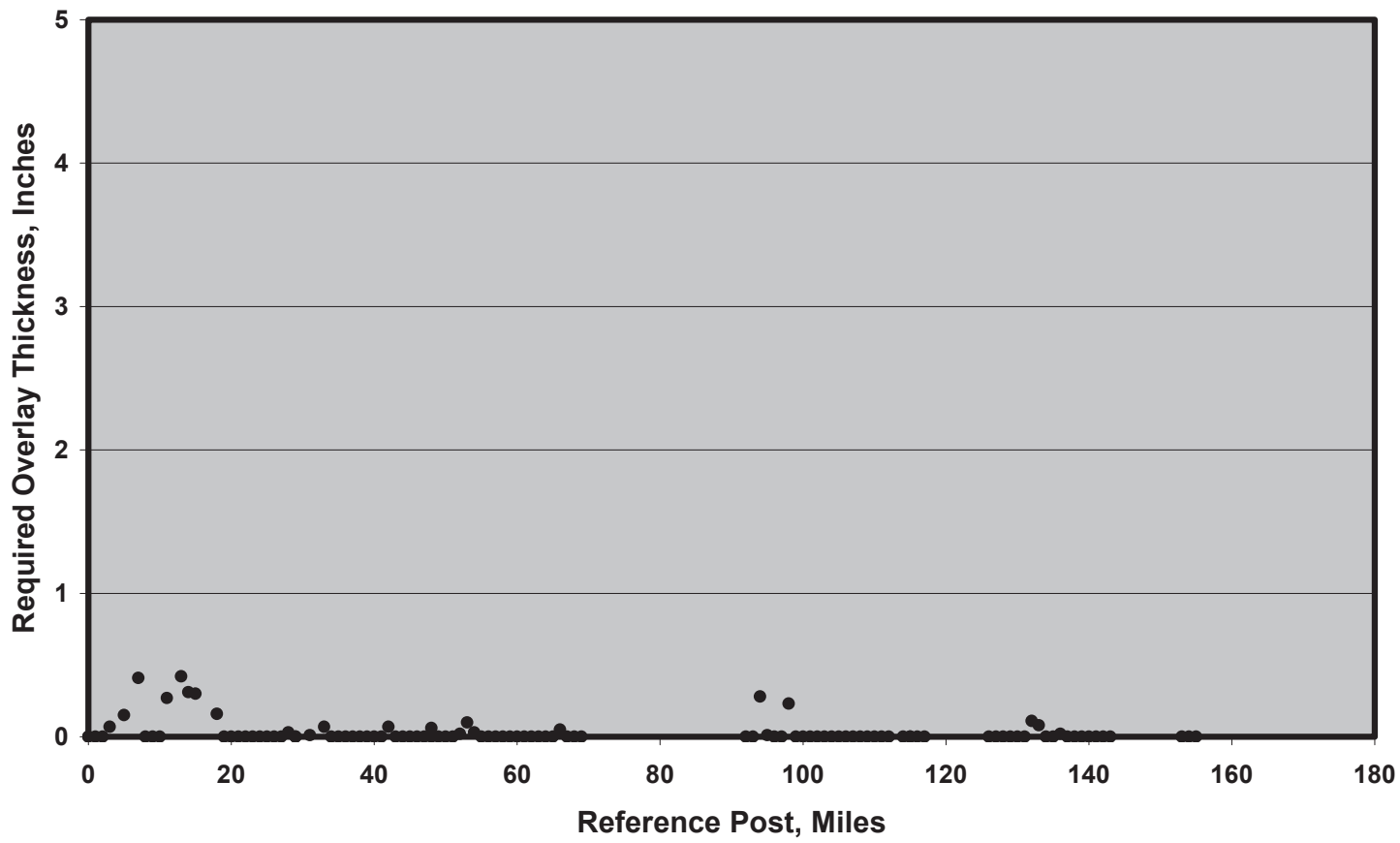

Figure 4.7 g: Profile of Required Overlay Thickness along Interstate I - 70 


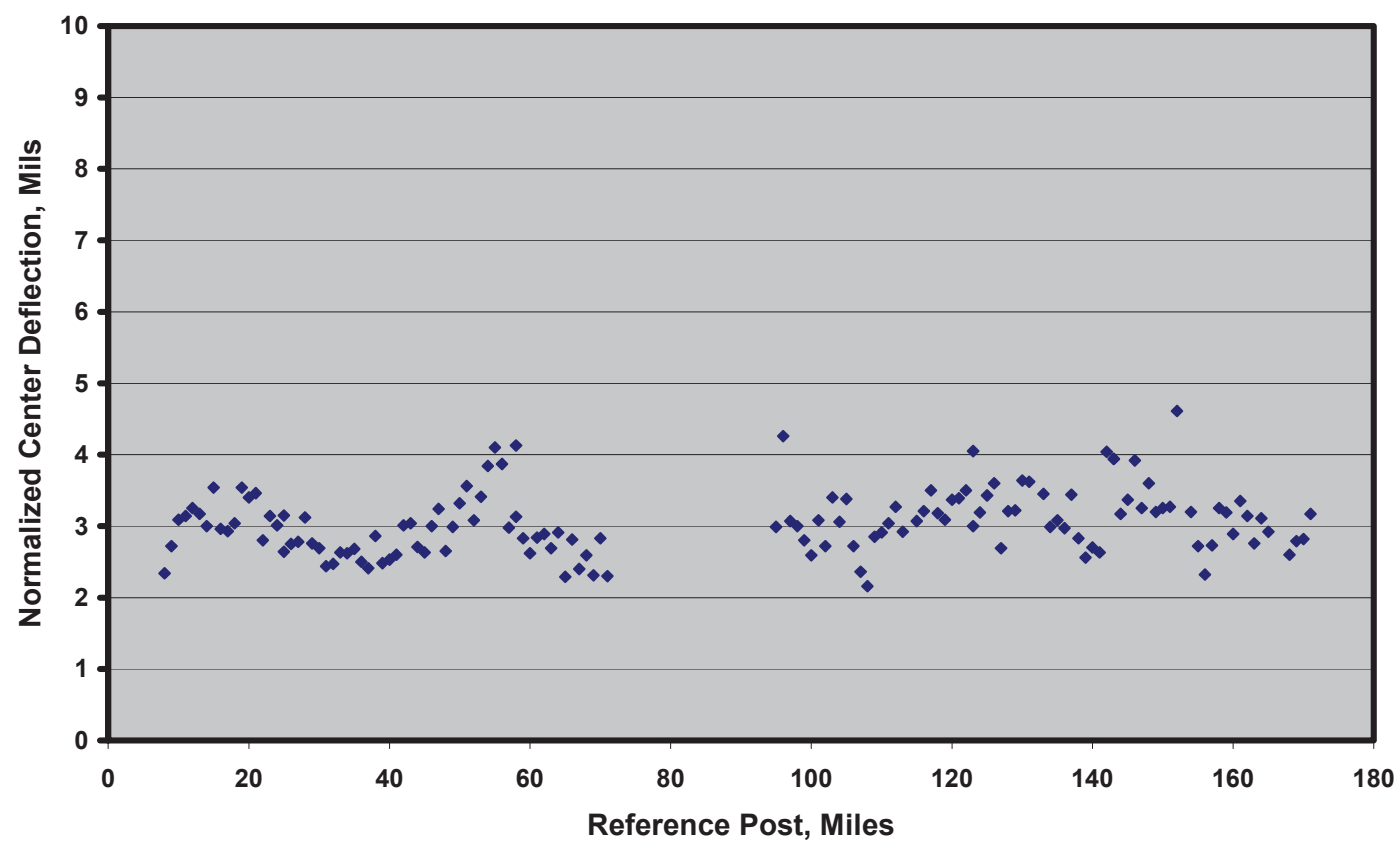

I - 74 West Bound Driving Lane

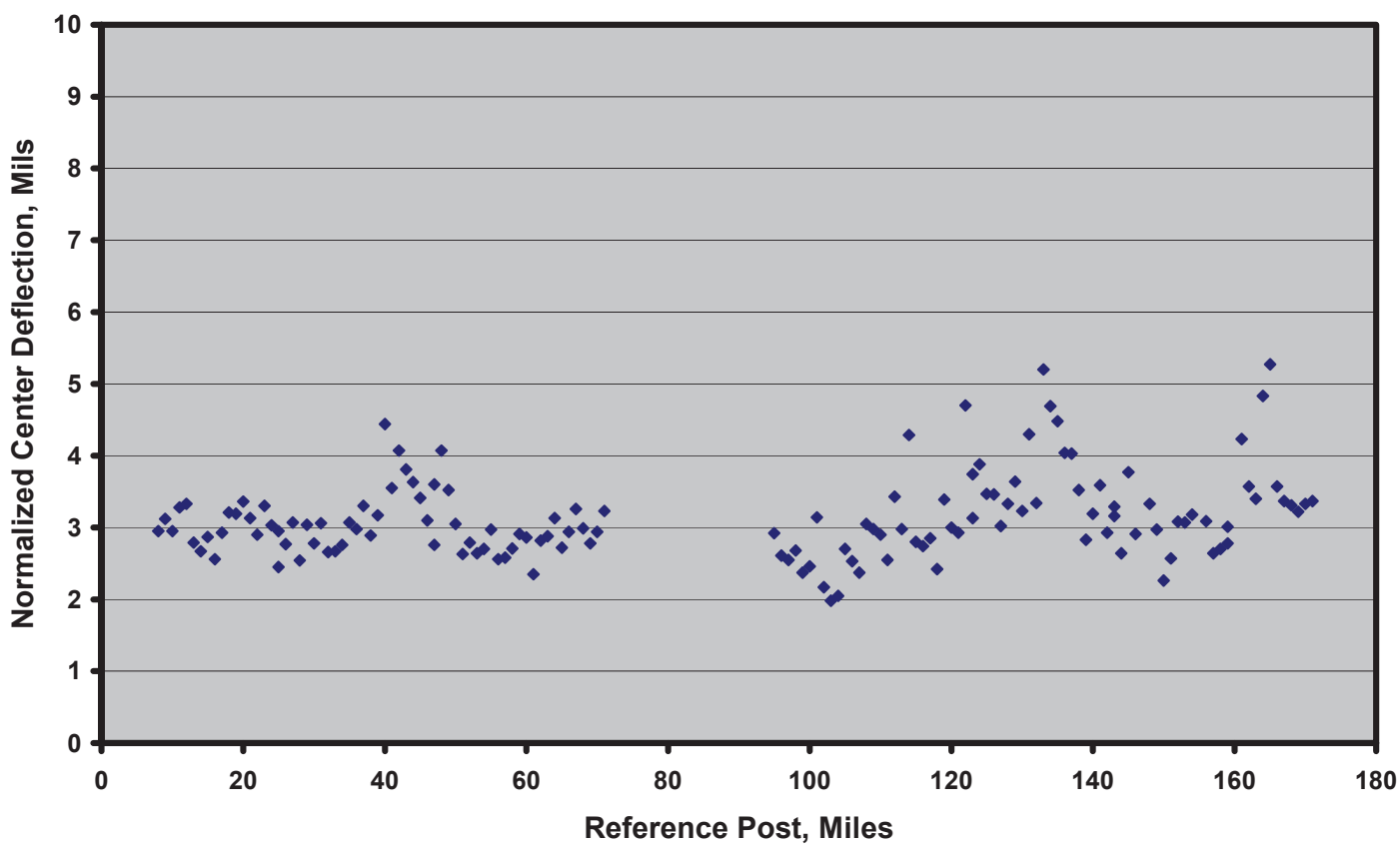

Figure 4.8 a: Profile of Pavement Surface Deflection along Interstate I - 74 


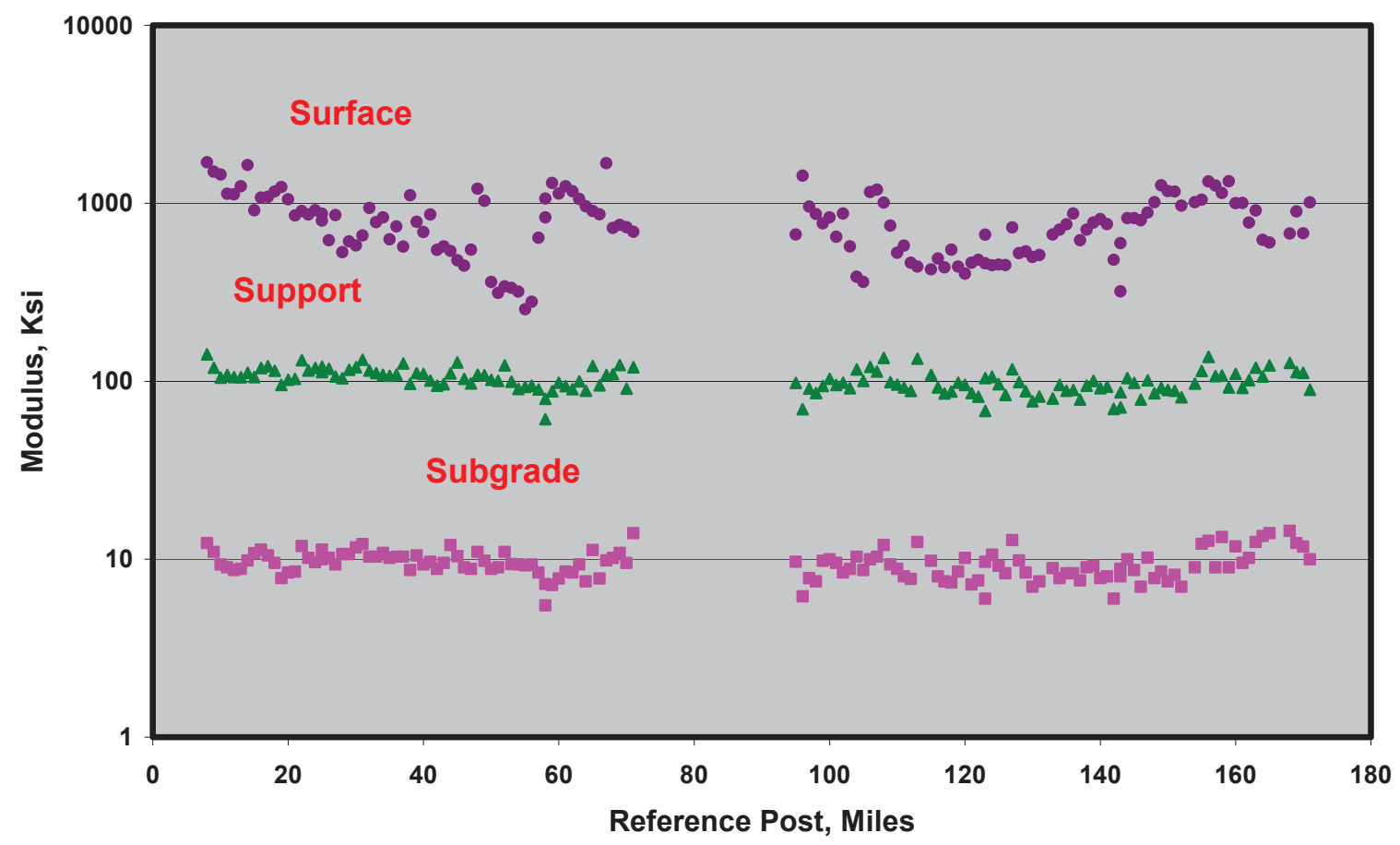

I - 74 West Bound Driving Lane

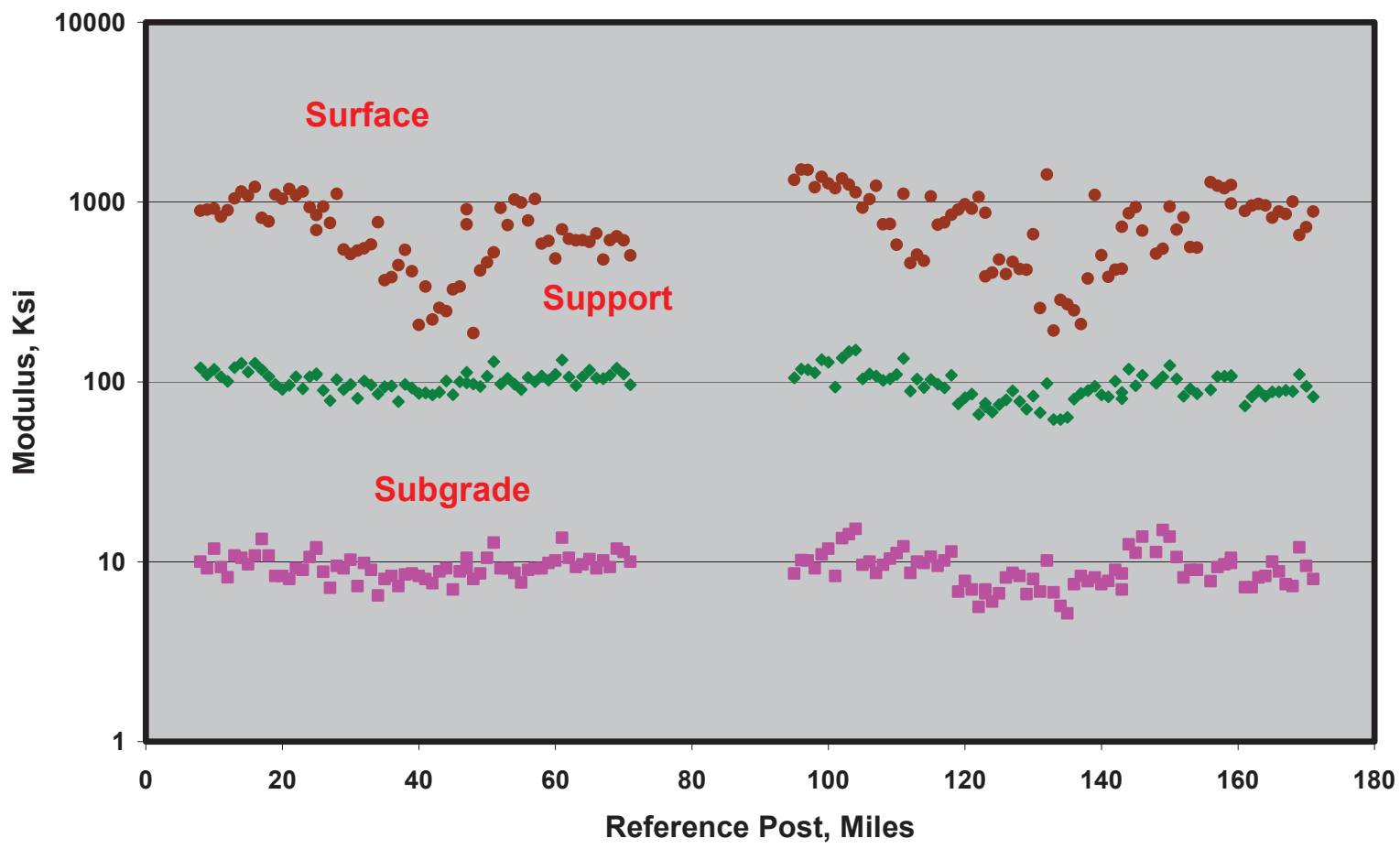

Figure 4.8 b: Profile of Pavement Layer Moduli along Interstate I - 74 


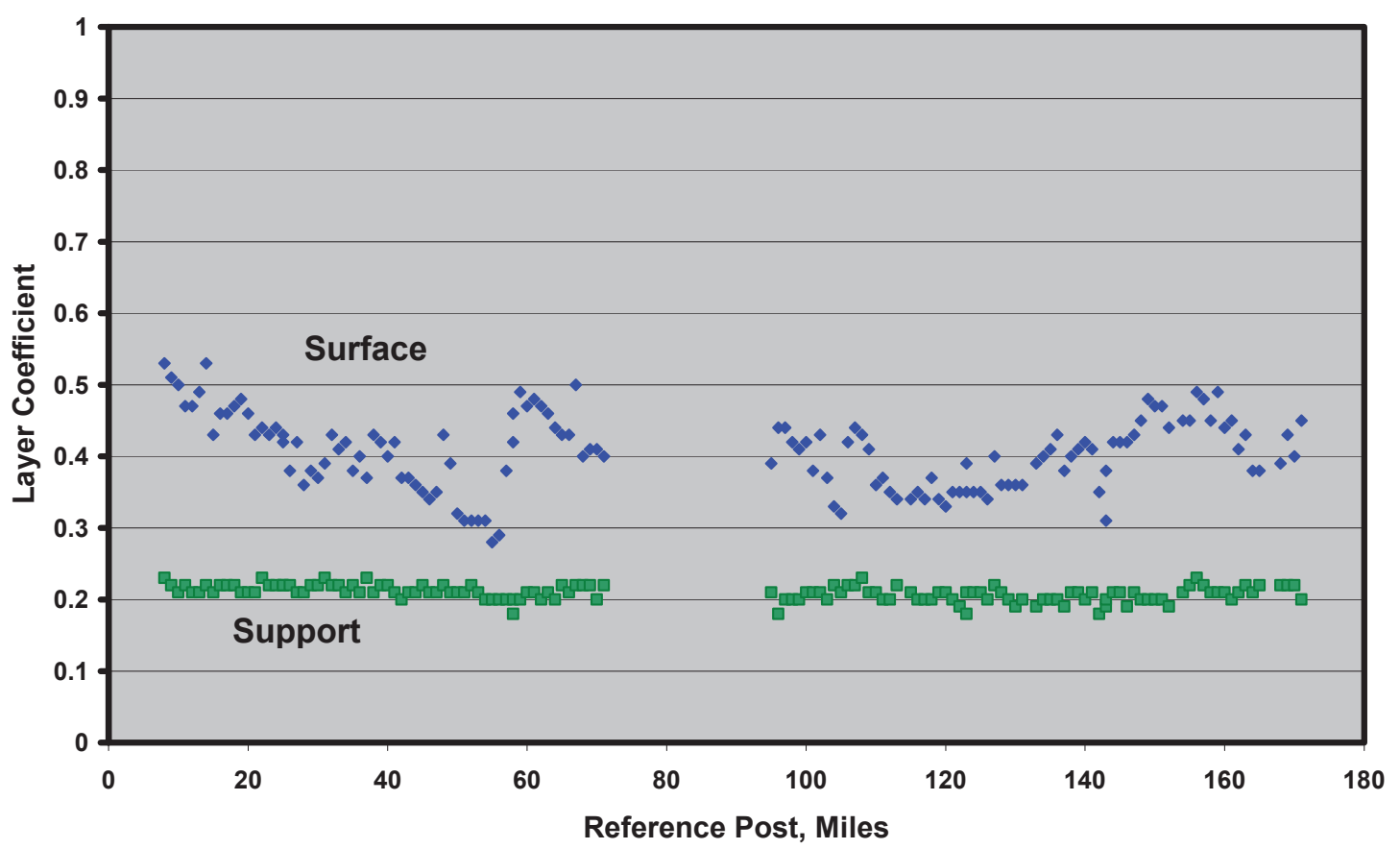

\section{I - 74 West Bound Driving Lane}

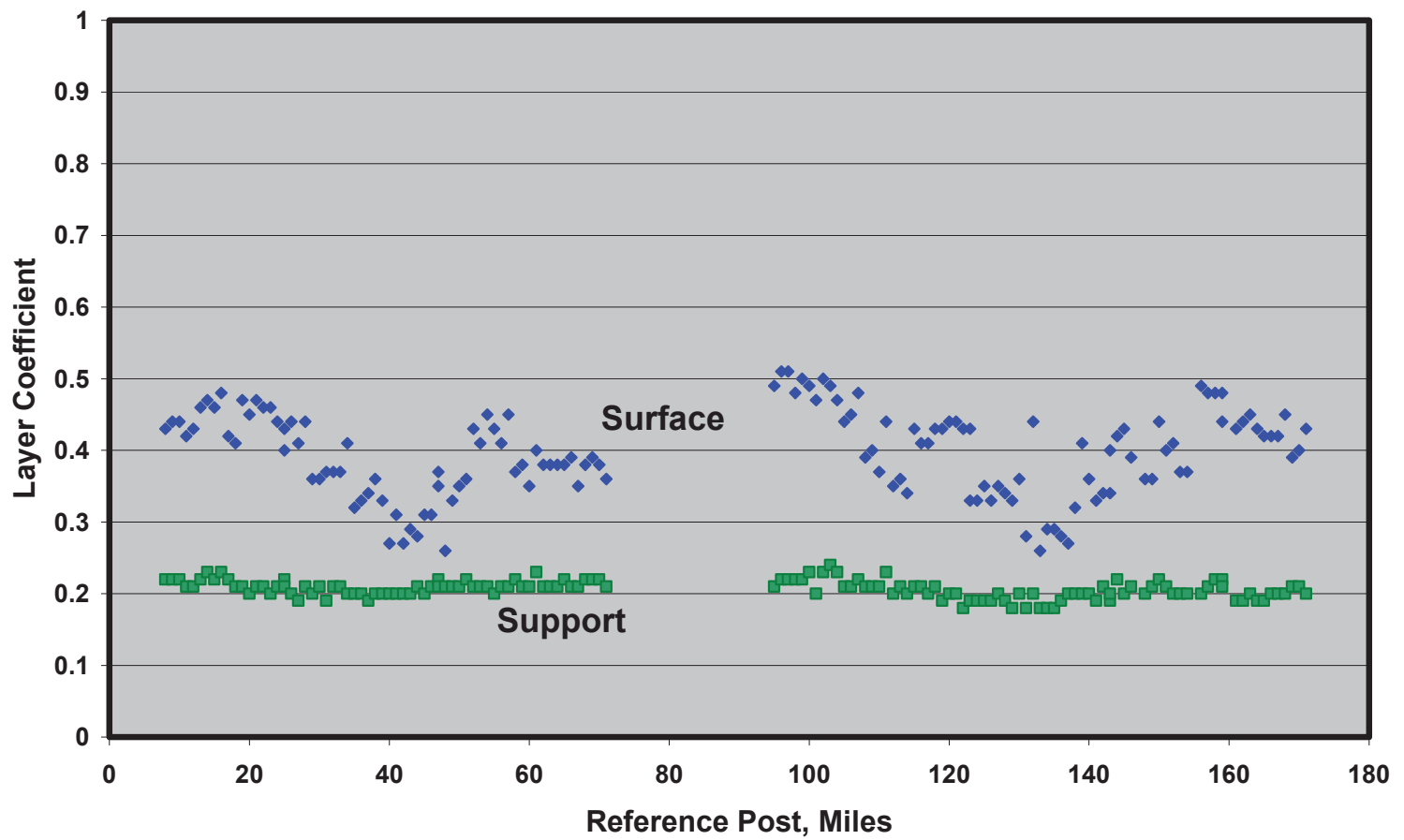

Figure 4.8 c: Profile of Pavement Layer Coefficients along Interstate I - 74 


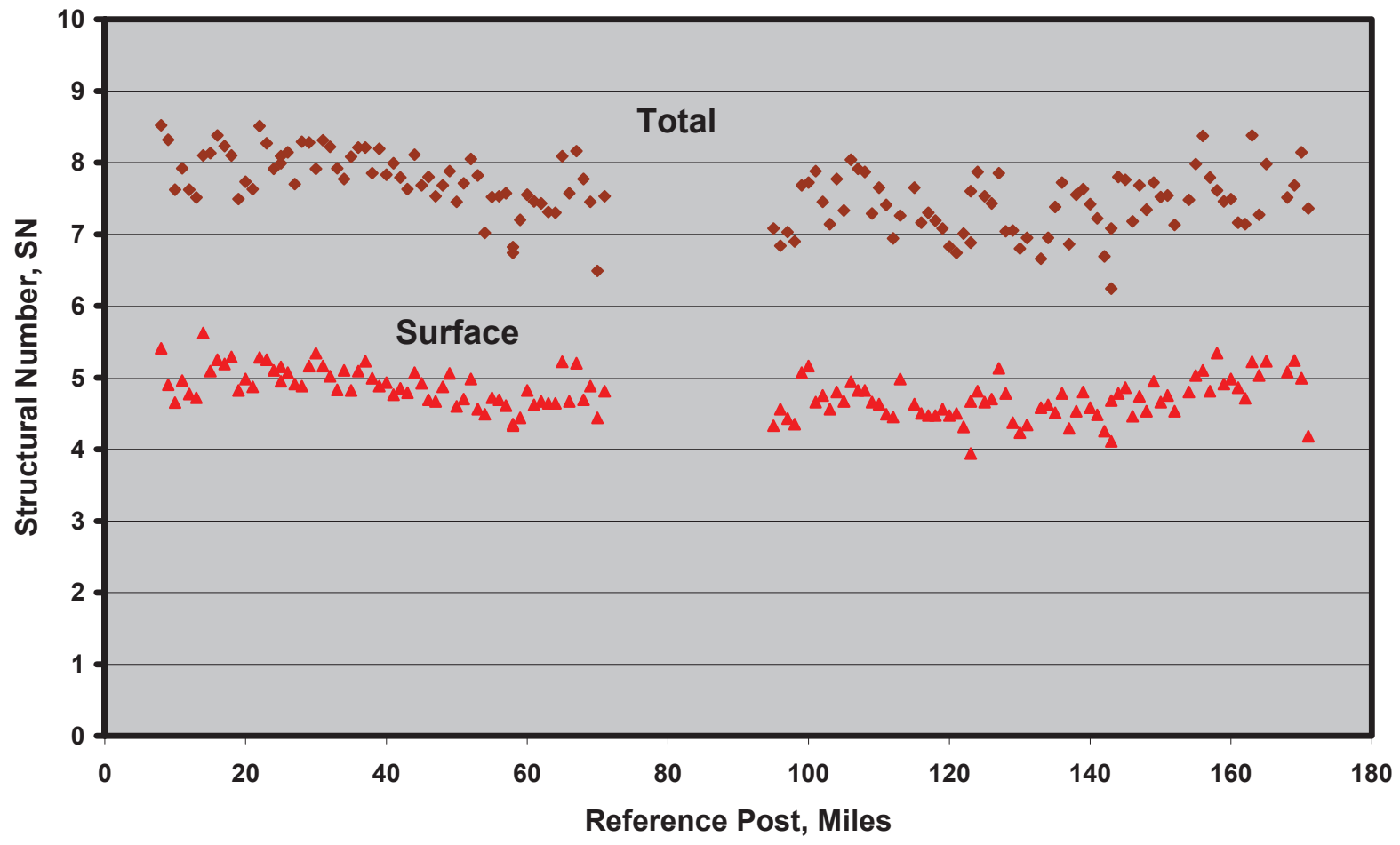

I - 74 West Bound Driving Lane

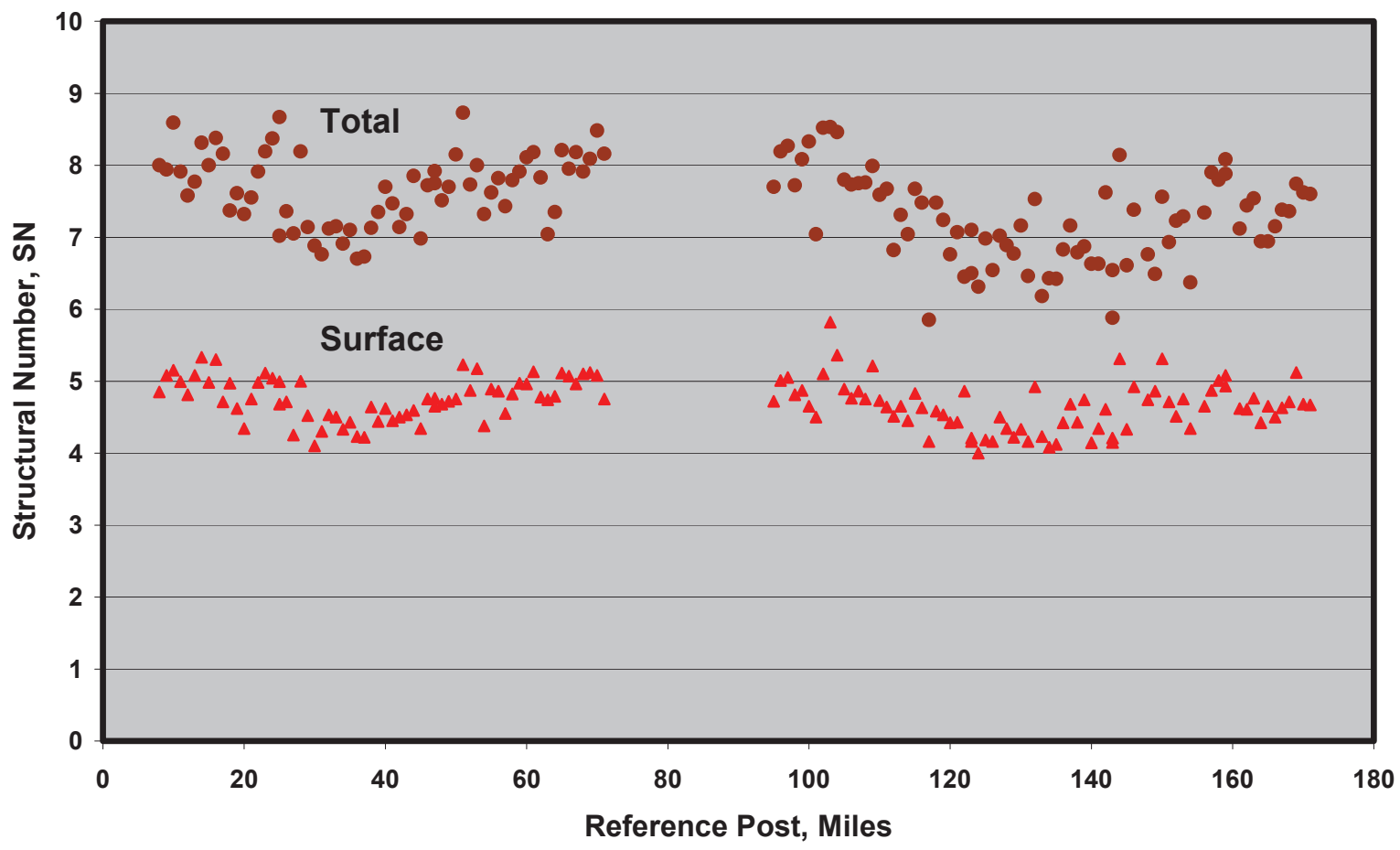

Figure 4.8 d: Profile of Pavement Structural Numbers along Interstate I - 74 


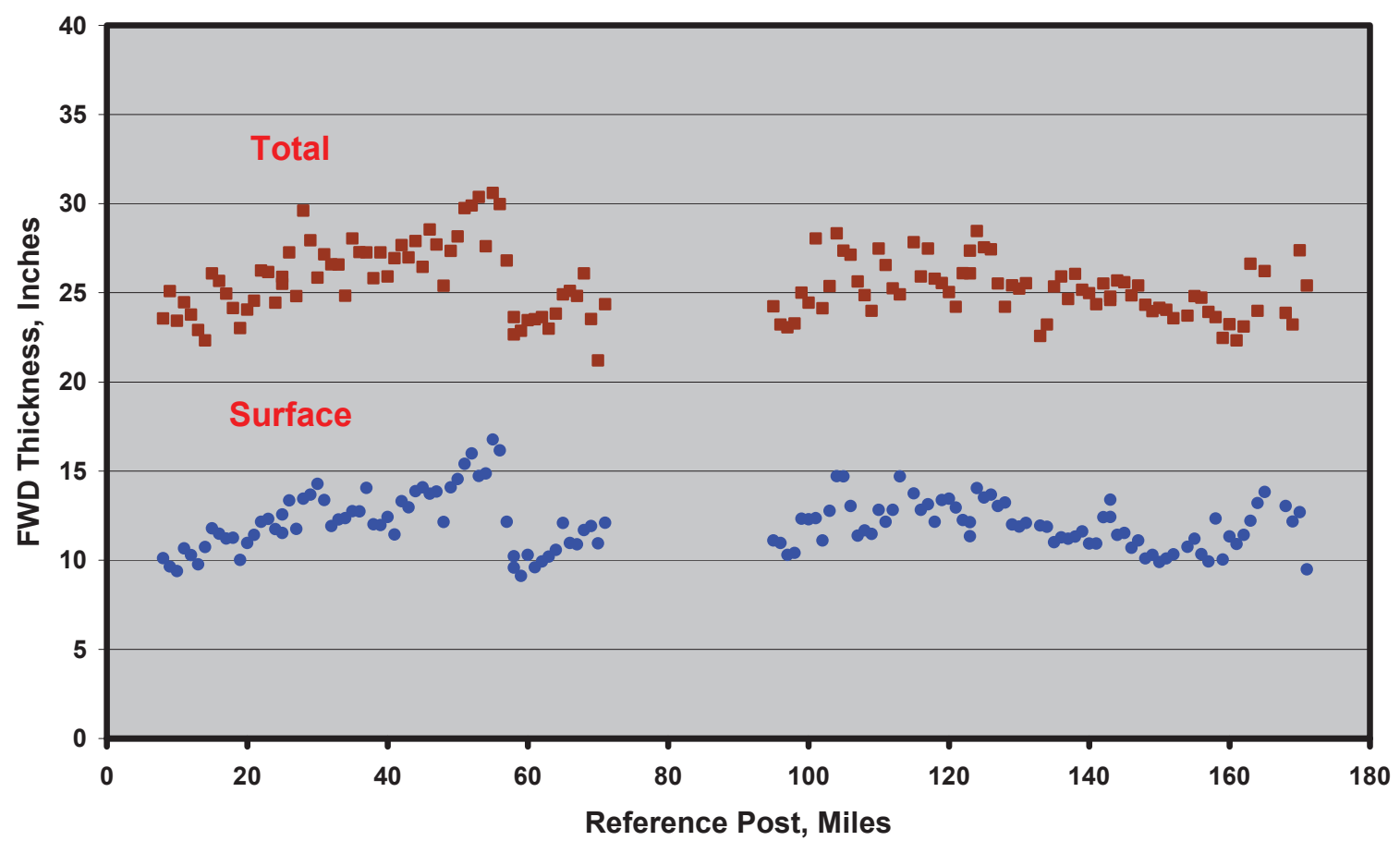

I - 74 West Bound Driving Lane

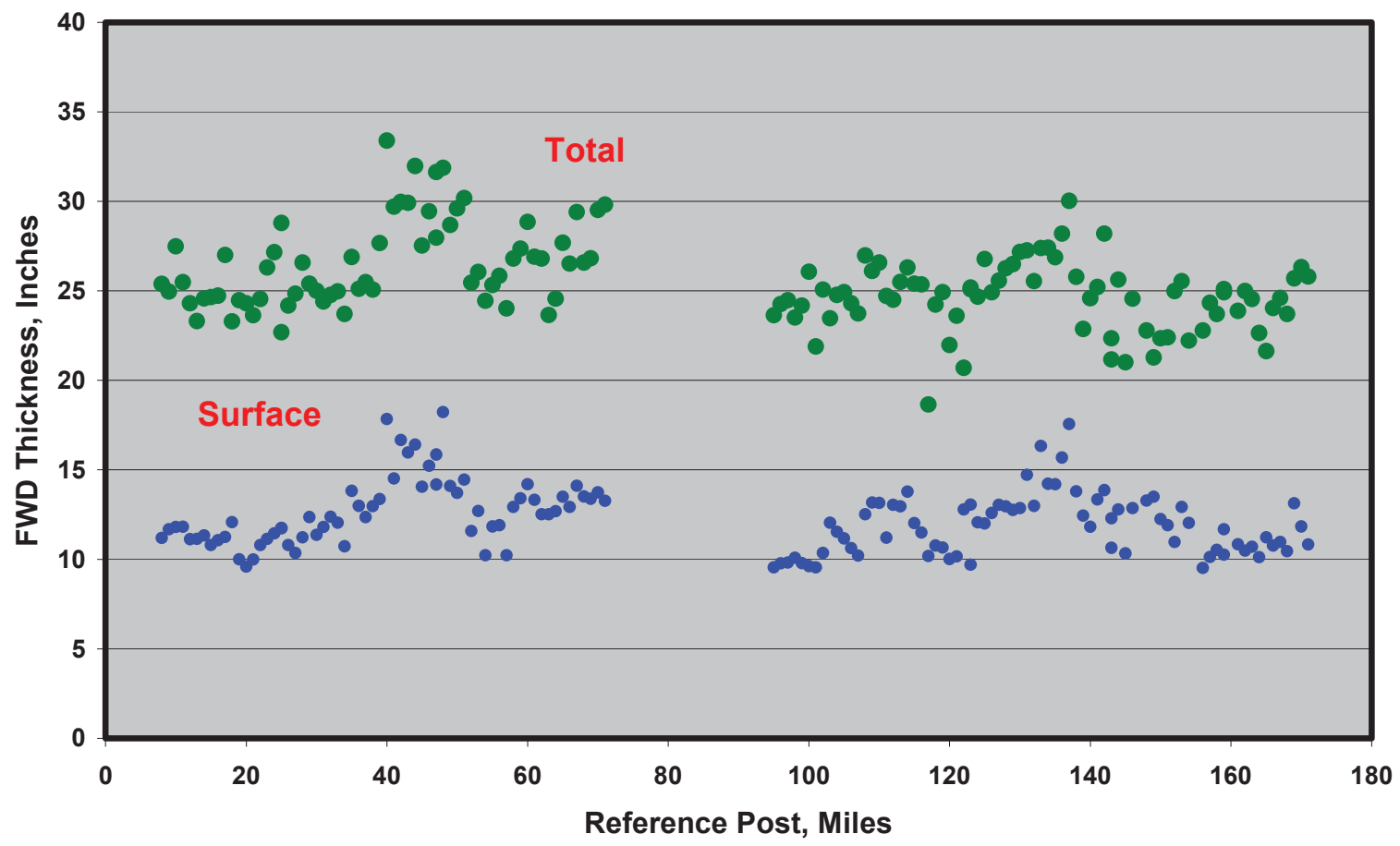

Figure 4.8 e: Profile of Pavement Layers Thickness along Interstate I - 74 
I - 74 East Bound Driving Lane

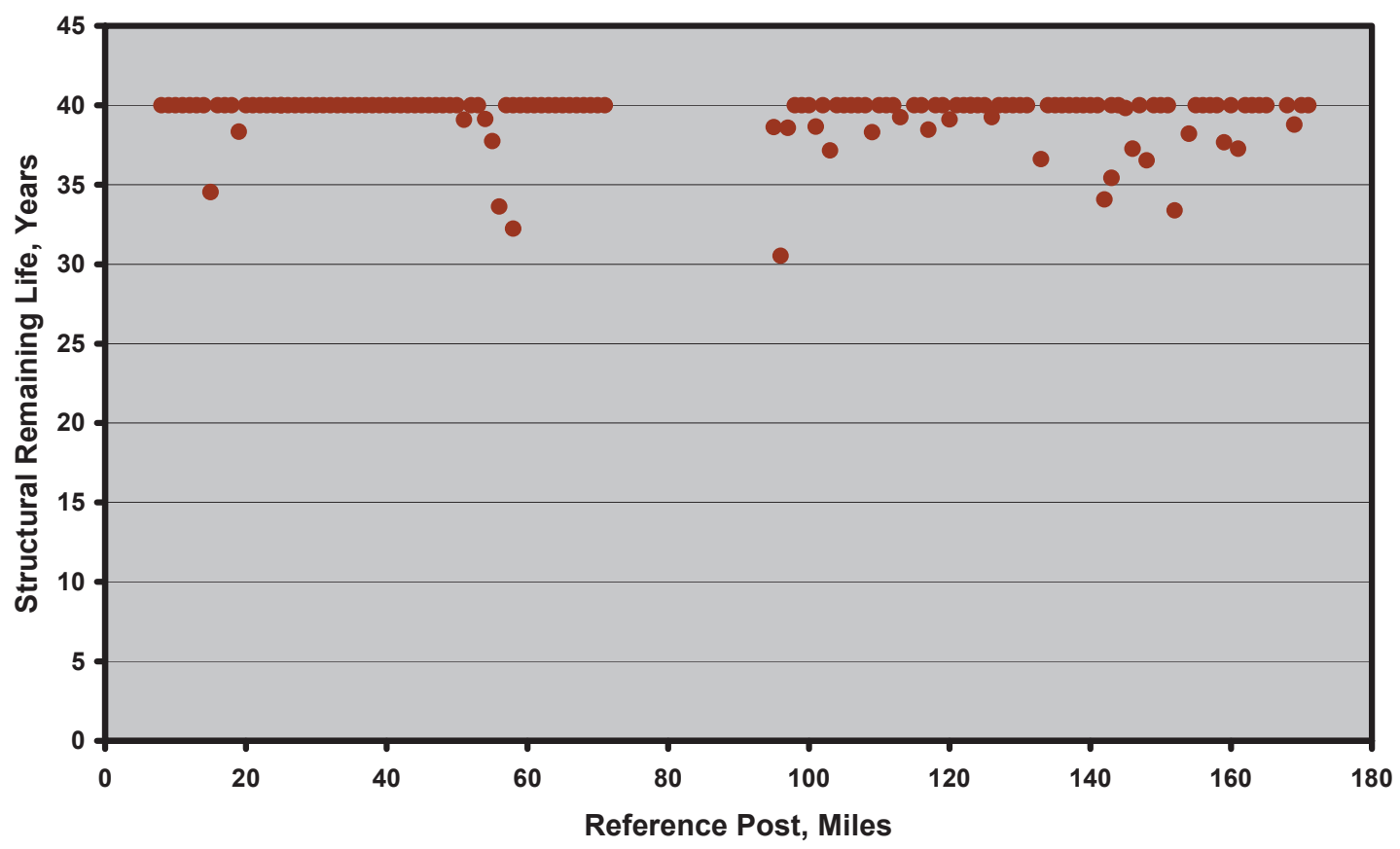

Figure 4.8 f: Profile of Pavement Remaining Life along Interstate I - 74

I - 74 East Bound Driving Lane

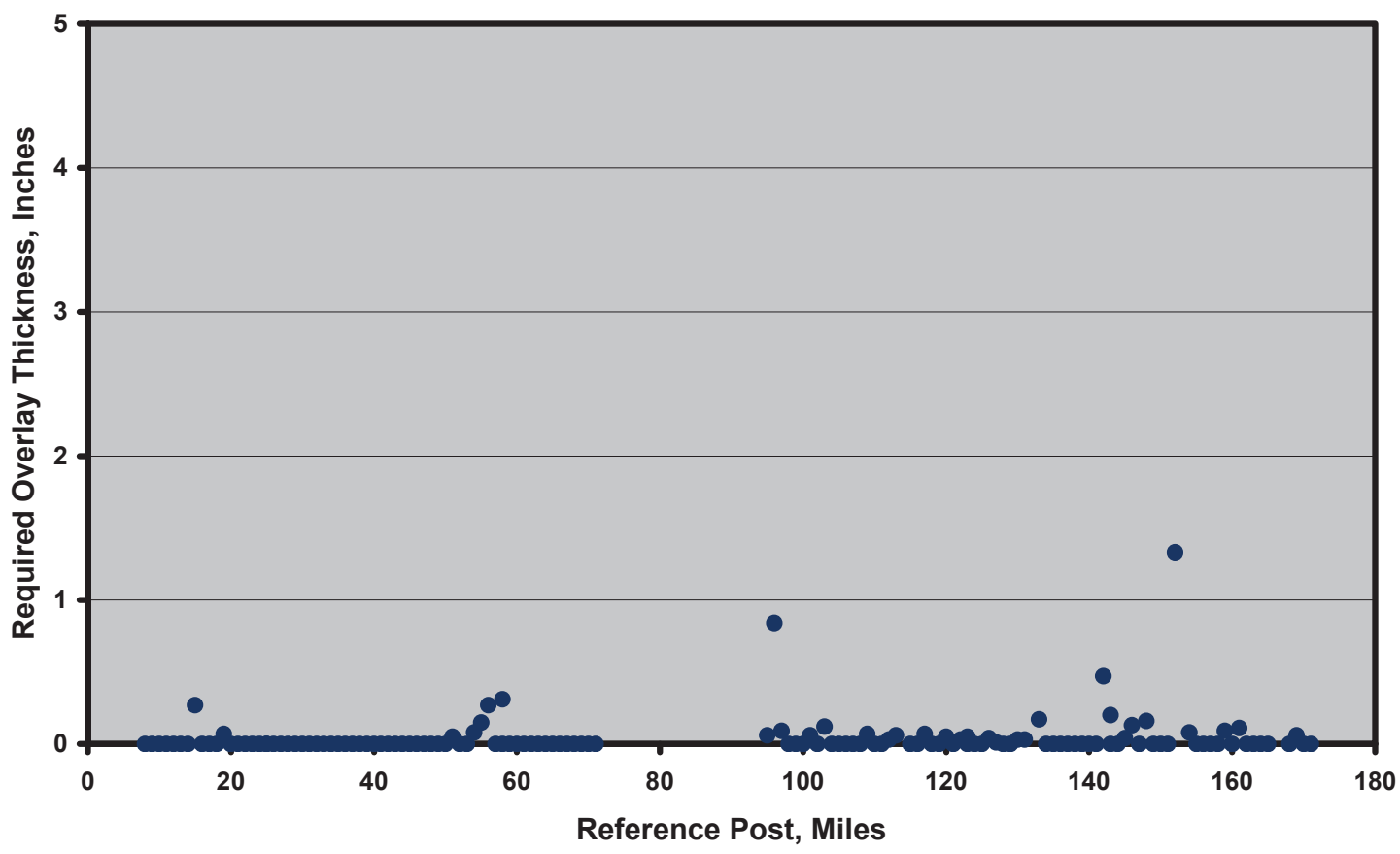

Figure 4.8 g: Profile of Required Overlay Thickness along Interstate I - 74 


\section{$\underline{\text { 4.2.2 Interstates Structural Comparisons }}$}

Figure 4.9 (a to f) presents structural comparisons between all Indiana Interstate Highways selected in the study (both bound directions). Dotted lines represent the maximum and minimum values and solid lines represent mean values. It can be observed that the mean structural conditions for both bound directions are almost identical for every Interstate. It can be concluded that FWD network level testing of pavements for a direction of an Interstate may be representative of both directions. Implications of this conclusion are essential for possible reduced future testing at the network level.

Figure 4.9 b shows estimated in situ California Bearing Ratio, Subgrade CBR, values for each direction of every Interstate at the time of testing. With the exception of I - 64 mean values of all interstates is about $6 \%$ with a minimum value of about $3 \%$.

Comparisons presented in Figure 4.9 suggest that the pavement structural conditions of Indiana Interstates are also almost identical. This was expected since these Interstates have similar designs and are exposed to similar traffic classifications and number of traffic repetitions.

Modeling reliability in pavements was investigated academically and practically by many pavement researchers $(30-33)$. Figure 4.10 presents the overall pooled standard deviation of pavement performance (defined by the 1993 AASHTO Guide as the combined standard error of traffic prediction and pavement materials performance prediction), "S," calculated for every Interstate selected in the study using the procedure reported by Noureldin et al. $(30,31)$. Pooled value for all INDOT interstates is 0.497 compared to the value estimated by the 1993 AASHTO Guide of 0.49 . "S $\mathrm{S}_{\mathrm{o}}$ " values, however, lie within the range $(0.4-0.6)$ as shown on Figure 4.10 indicating typical and acceptable variability in both material and traffic characteristics.

Figure 4.11 presents existing pavement design factors of safety calculated for each direction of every Interstate selected in the study. Interstates structural condition has a reliability level of $90 \%$ with a safety factor in the range of $3.8-5.2$. Factors of safety are calculated based on the following equation;

$$
\text { Factor of Safety }=(10)^{\mathrm{Z}_{\mathrm{R}} \mathrm{S}_{\mathrm{o}}}
$$

Where;

$\mathrm{S}_{\mathrm{o}}=$ Overall Standard Deviation

$\mathrm{Z}_{\mathrm{R}}=$ Standard Normal Deviate corresponding to each reliability level

$\begin{array}{lccccc}\text { Reliability, \% } & 50 & 80 & 90 & 95 & 99 \\ \mathrm{Z}_{\mathrm{R}} & 0 & 0.841 & 1.282 & 1.645 & 2.327\end{array}$




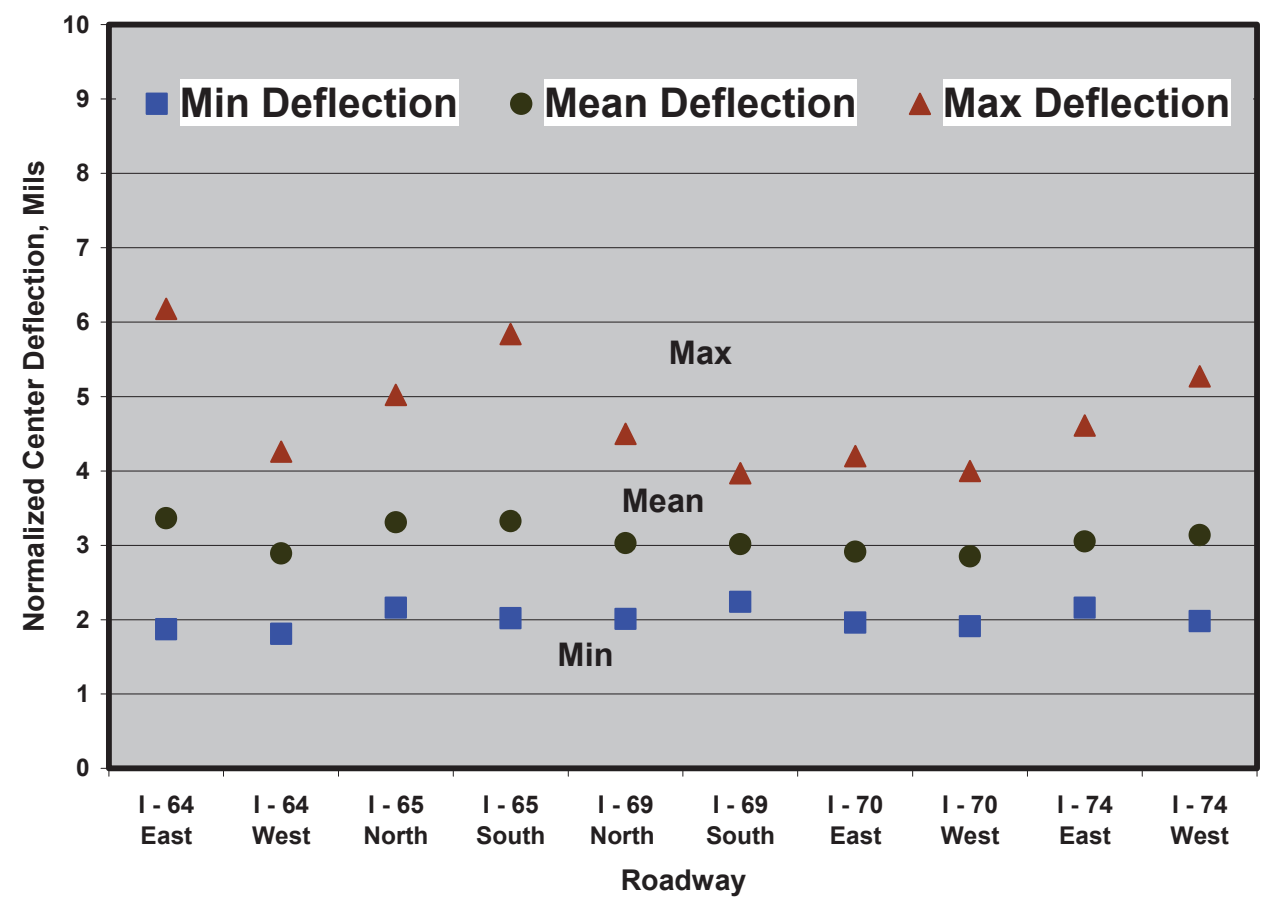

Figure 4.9 a: Interstate Comparisons; Pavement Surface Deflection

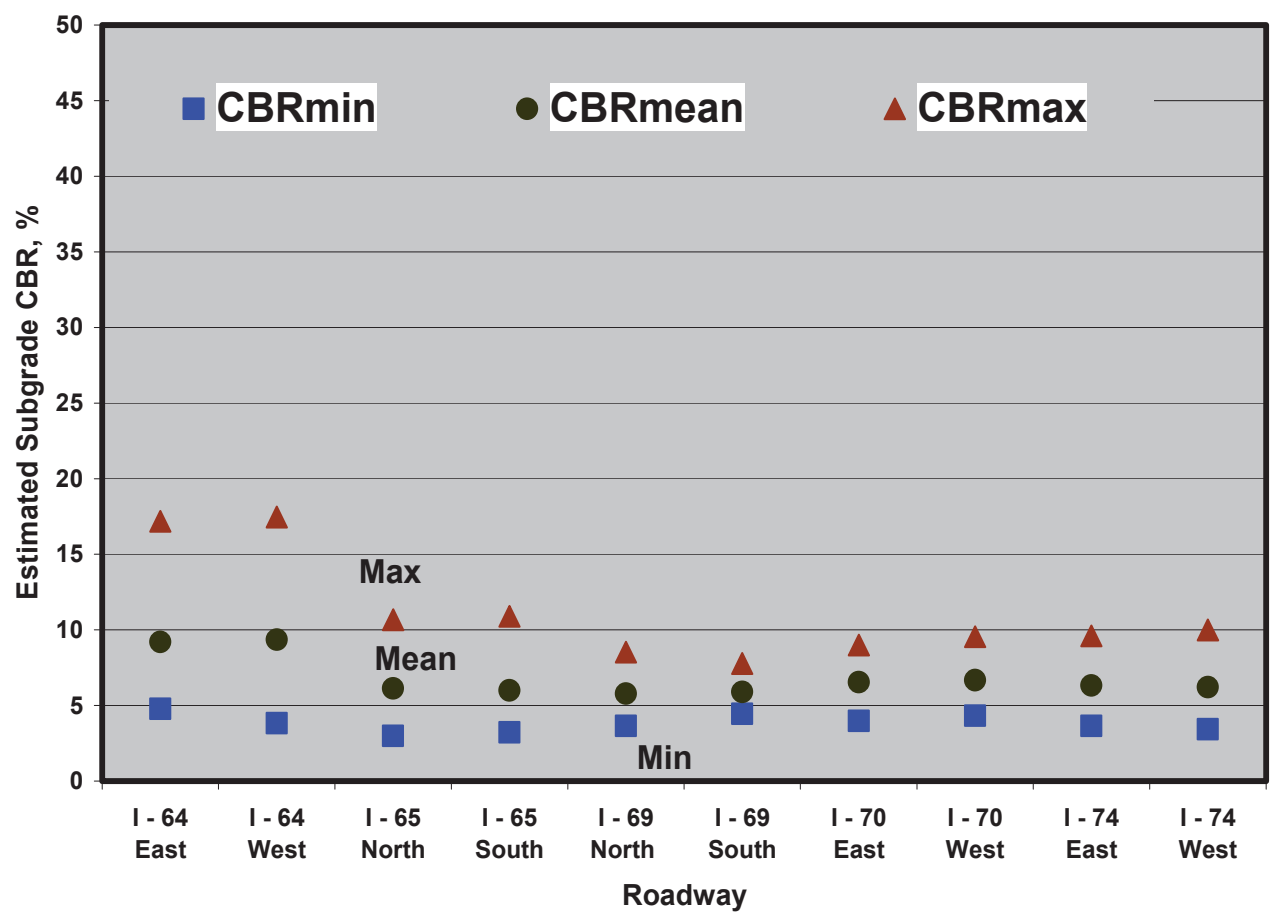

Figure 4.9 b: Interstate Comparisons; Estimated in situ Subgrade CBR 


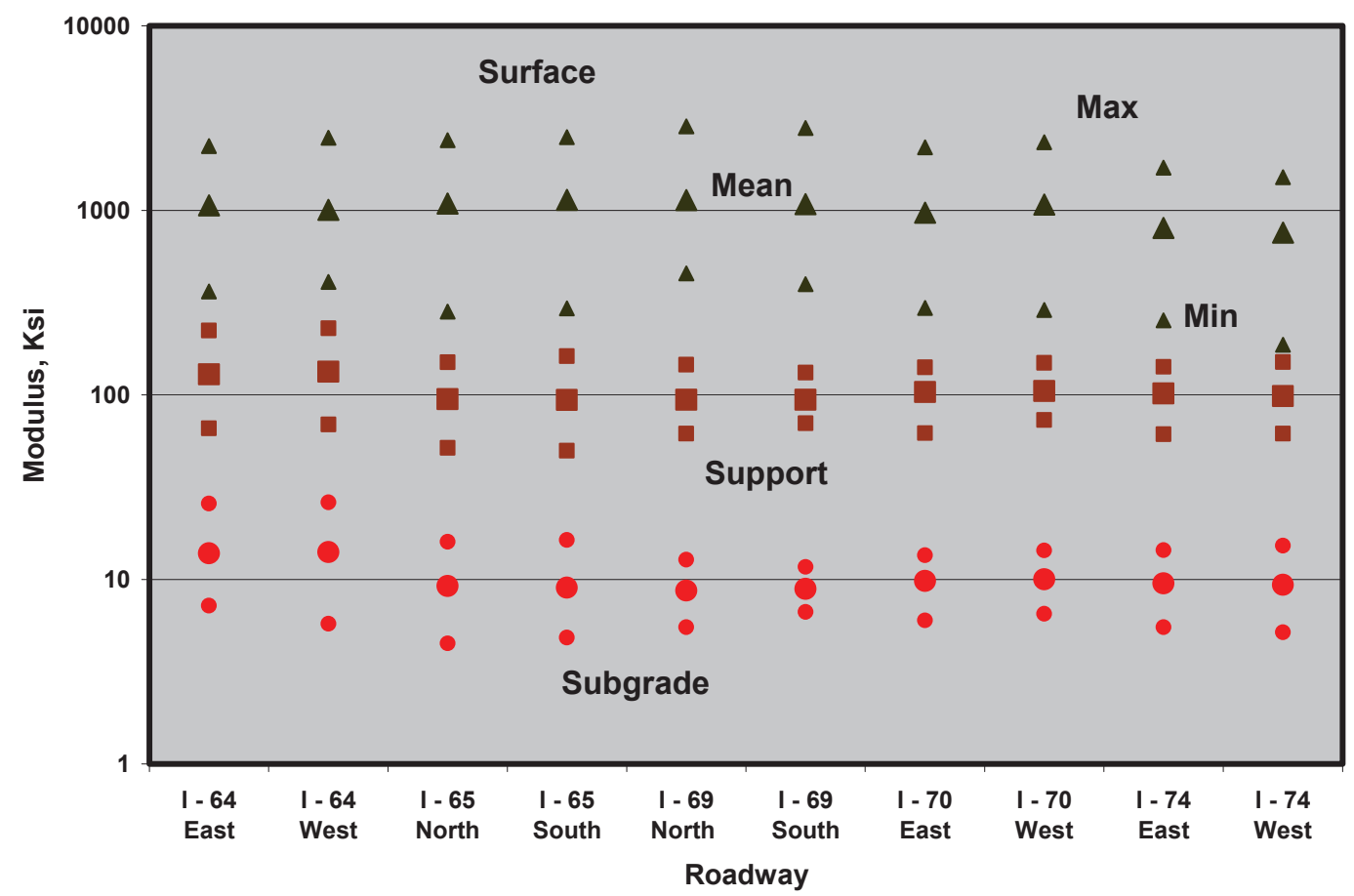

Figure 4.9 c: Interstate Comparisons; Backcalculated Pavement Layer Moduli

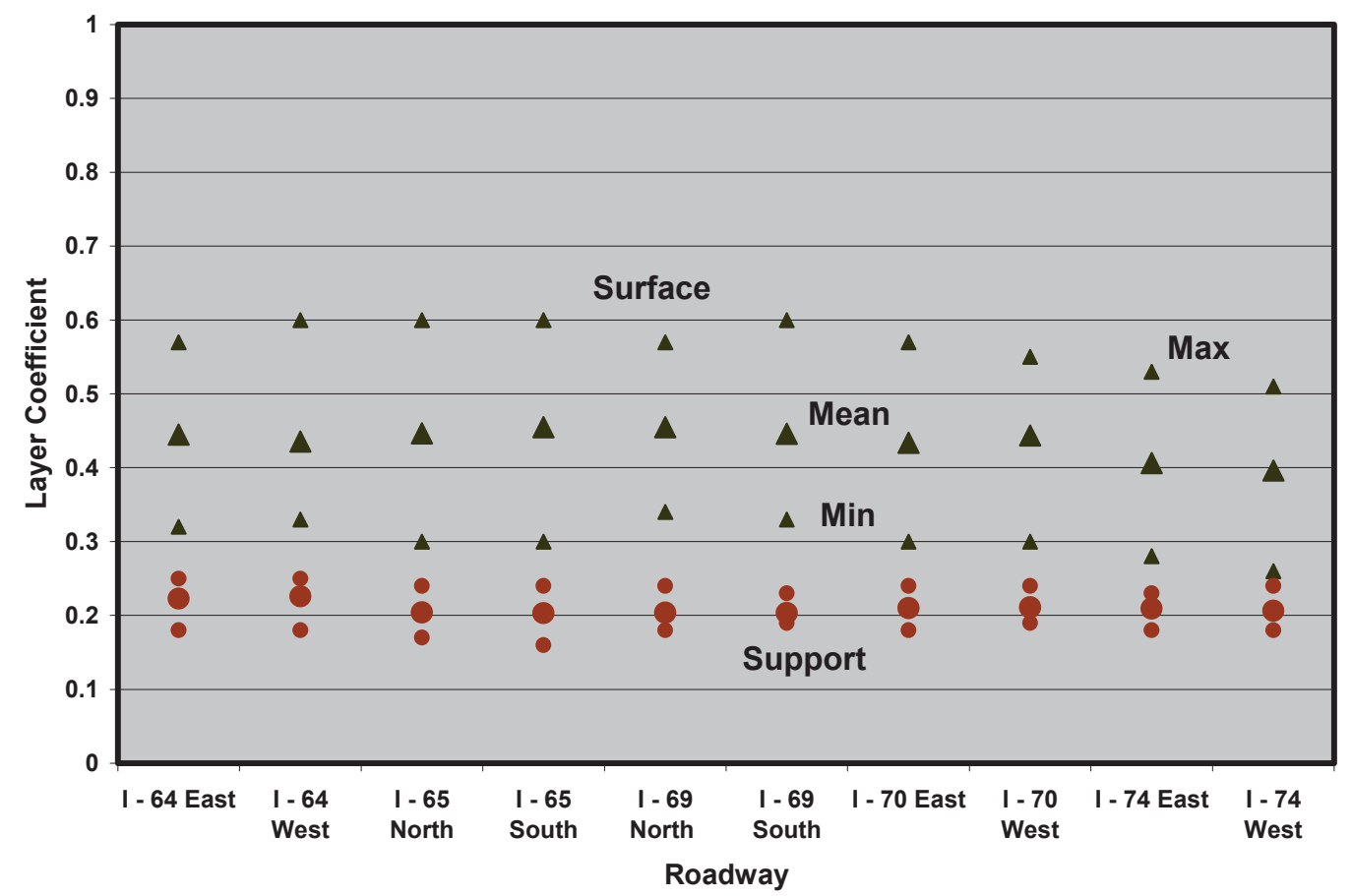

Figure 4.9 d: Interstate Comparisons; Pavement Layer Coefficients 


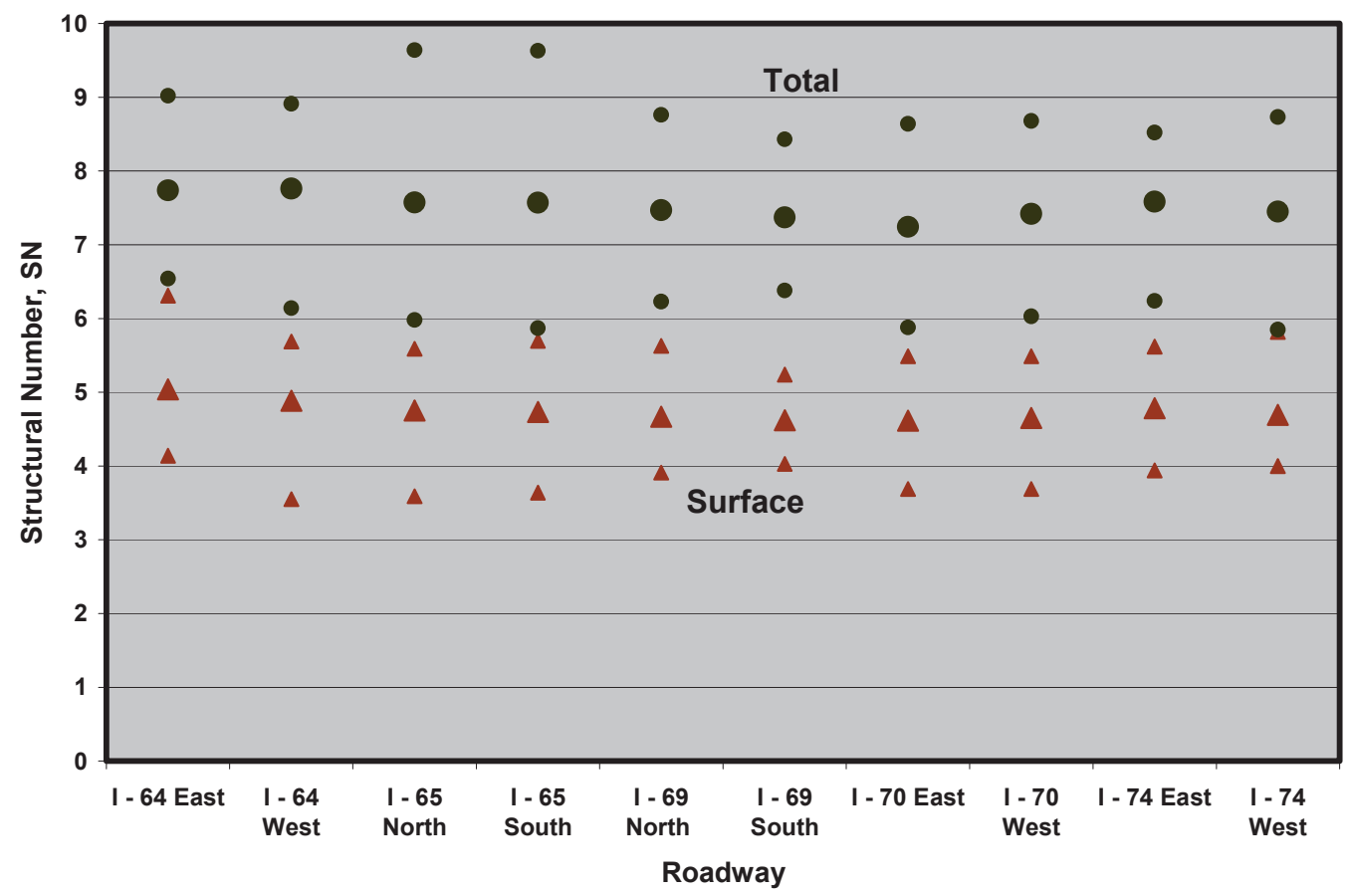

Figure 4.9 e: Interstate Comparisons; Pavement Structural Numbers

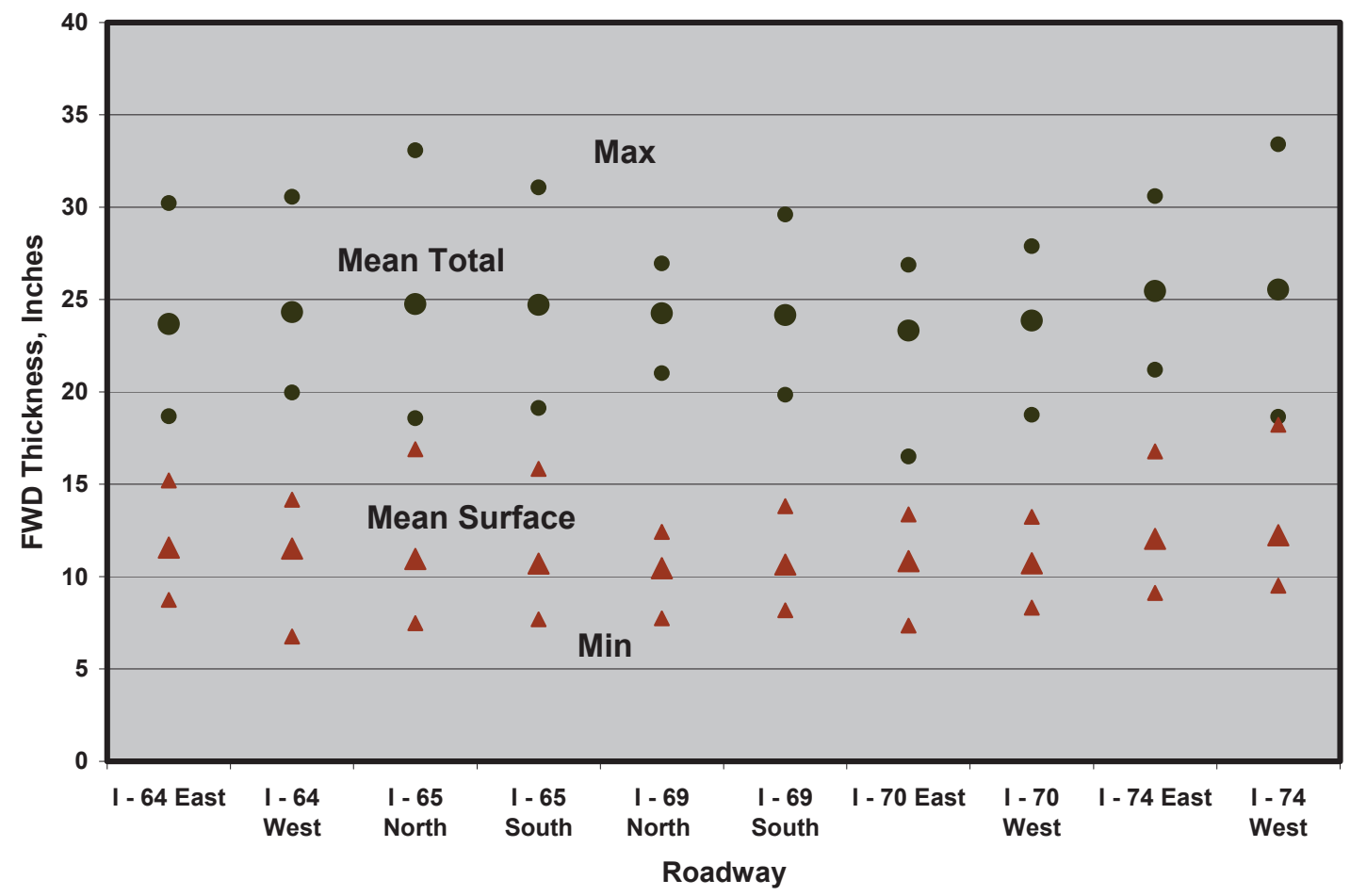

Figure 4.9 f: Interstate Comparisons; Estimated Pavement Layers Thickness 


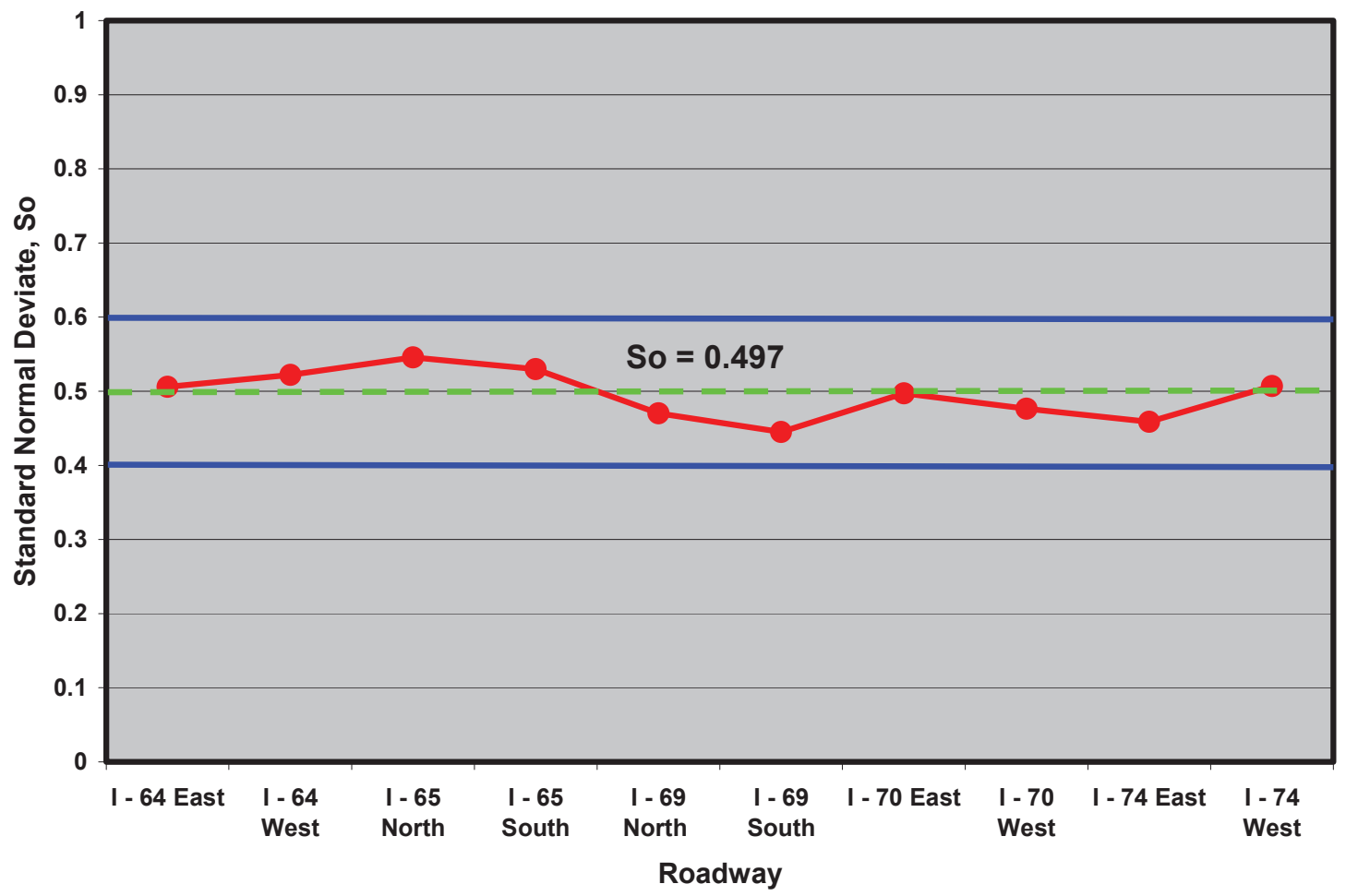

Figure 4.10: Standard Normal Deviate, $S_{0}$, for each Direction of every Interstate

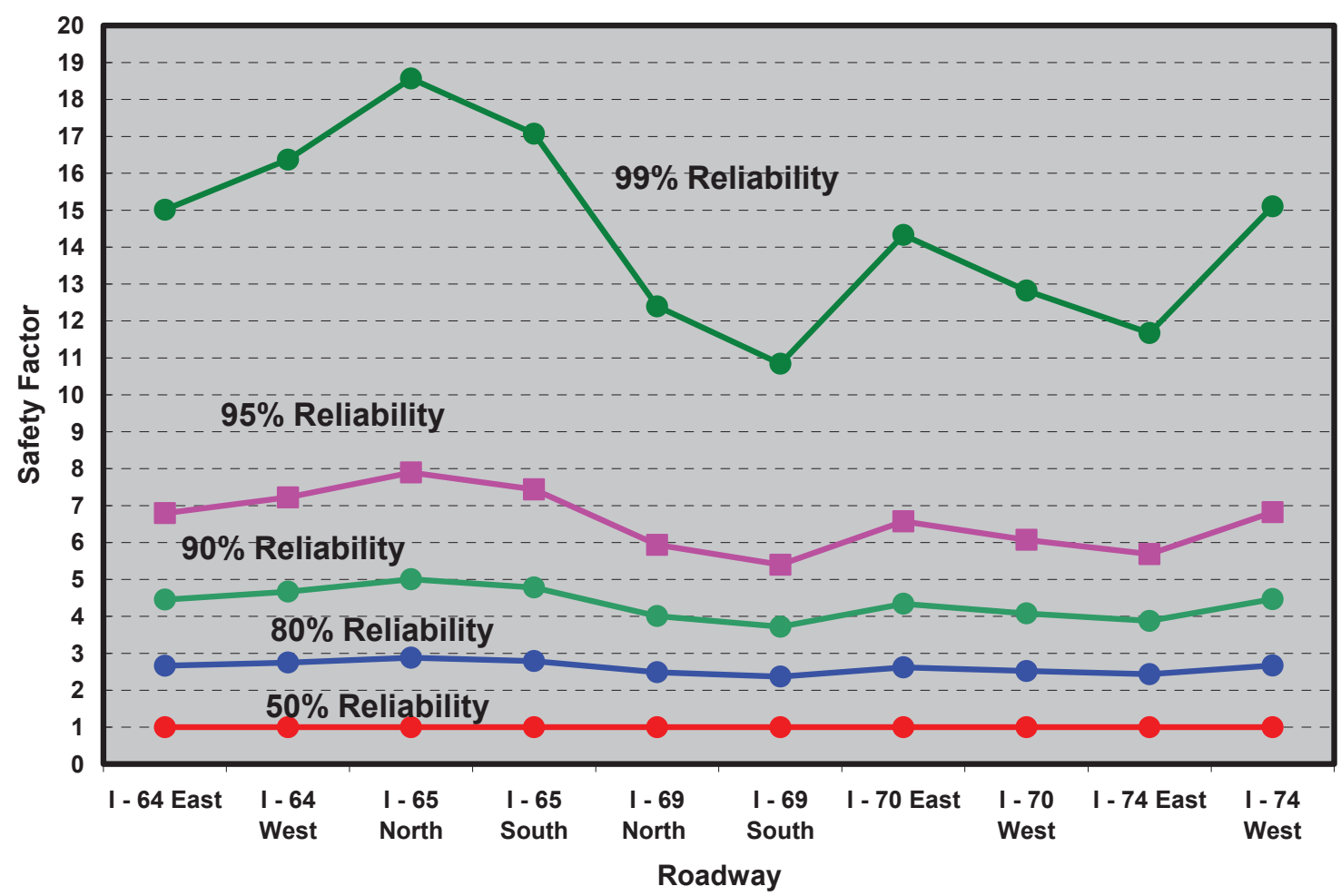

Figure 4.11: Existing Pavement Design Factor of Safety for each Direction of every Interstate 


\section{$\underline{\text { 4.2.3 U.S. Roads and State Routes Structural Conditions }}$}

Figures 4.12 and 4.13 (a to h) present profiles of normalized and temperature corrected FWD center deflections, estimated in situ subgrade CBR, pavement layer moduli, pavement layer coefficients, pavement layer structural numbers and thicknesses along a 40 mile north bound segment of SR - 32 (Figure 4.12) and a 20 miles west bound segment of SR - 250 (Figure 4.13), respectively. Profiles of remaining life in terms of ESALs and required overlay thickness are also presented.

Pavement deflection profile (Figure 4.12a) suggests that some sections of SR - 32 may need structural overlays to reduce pavement deflection to the value recommended by Table 2.3. The section between RP - 62 and RP - 70 may need a thick overlay and the section between RP -70 and RP - 77 may need a thin overlay. The rest of the segment to RP -100 appears to be in a good structural condition. Same conclusions can be drawn from profiles presented in Figures 4.12g and 4.12h. Figure 4.12b shows profile of estimated in situ Subgrade CBR along SR - 32. Subgrade CBR values range from only 2 to $5 \%$ suggesting weak subgrade conditions.

Sections of SR - 250 also may need structural overlays (Figure 4.13a). These overlays may be needed to reduce pavement deflection to the value recommended by Table 2.3. The section between RP - 5 and RP - 13 may need a thick overlay and the sections between RP -1 to RP -3 and RP - 15 to RP - 20 may need a thin overlay. The need for assigning a budget for rehabilitation of these segments and triggering project level pavement evaluations is apparent.

Figure 4.14 (a to f) presents profiles of normalized and temperature corrected FWD center deflections, estimated in situ subgrade CBR, pavement layer moduli, pavement layer coefficients, pavement layer thicknesses and effective structural numbers along a 100 mile segment of US - 41 north bound driving lane. The wealth of information that can be obtained from these profiles and used for pavement design, maintenance, rehabilitation and management purposes is apparent. Deflection profiles suggest that this segment of US - 41 is in a very good structural condition based on the criteria given in Table 2.3. However, the road may need repair for improving its functional conditions.

Figure 4.15 presents profiles of normalized FWD center deflections, estimated in situ subgrade CBR and pavement layer moduli, along a 20 mile segment of concrete pavement on SR - 37. This segment is in a very good structural condition. However, it may need repair for improving the functional conditions. 
SR - 32 East Bound Driving Lane

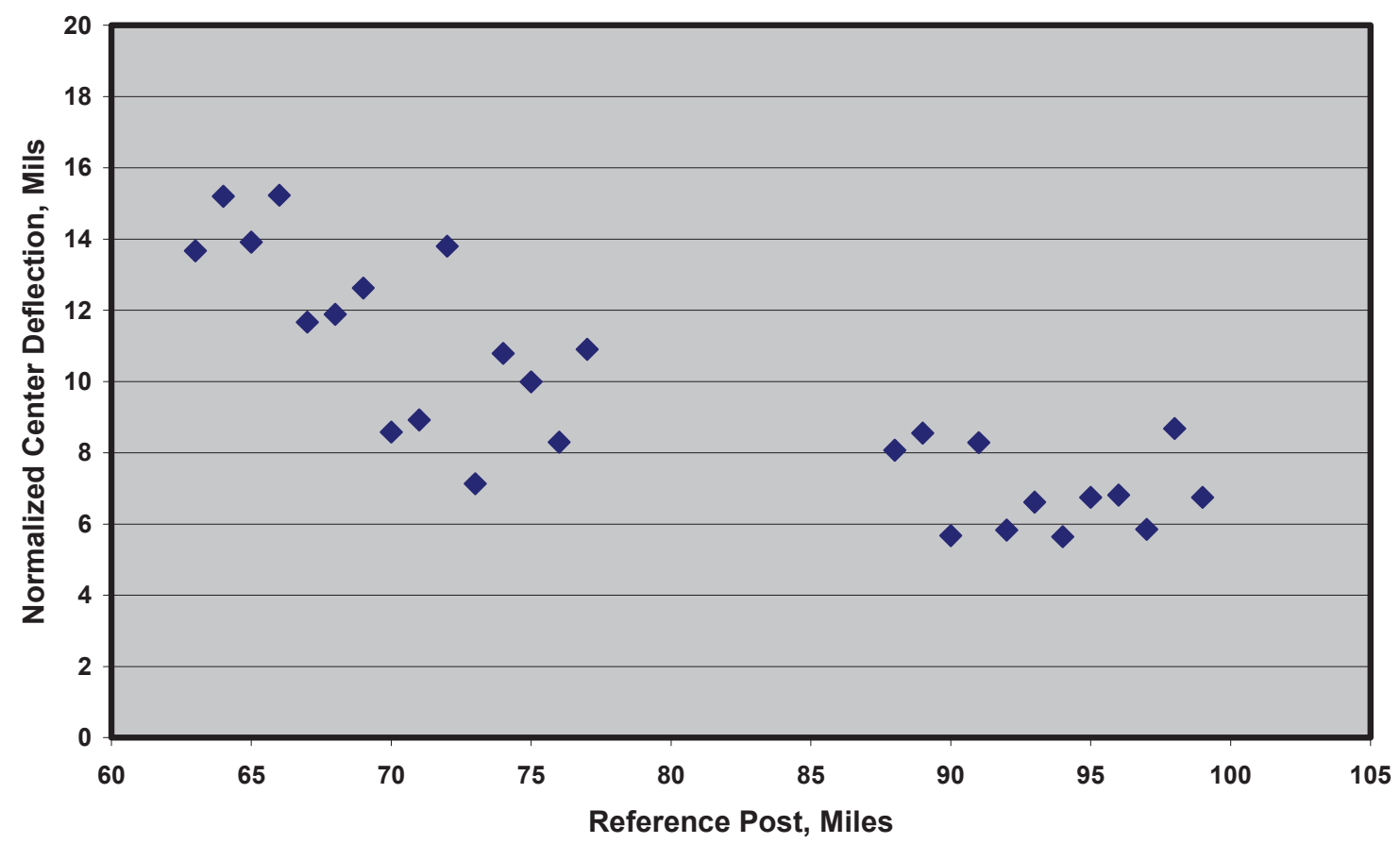

Figure 4.12 a: Profile of Pavement Surface Deflection along a Segment on SR - 32

SR - 32 East Bound Driving Lane

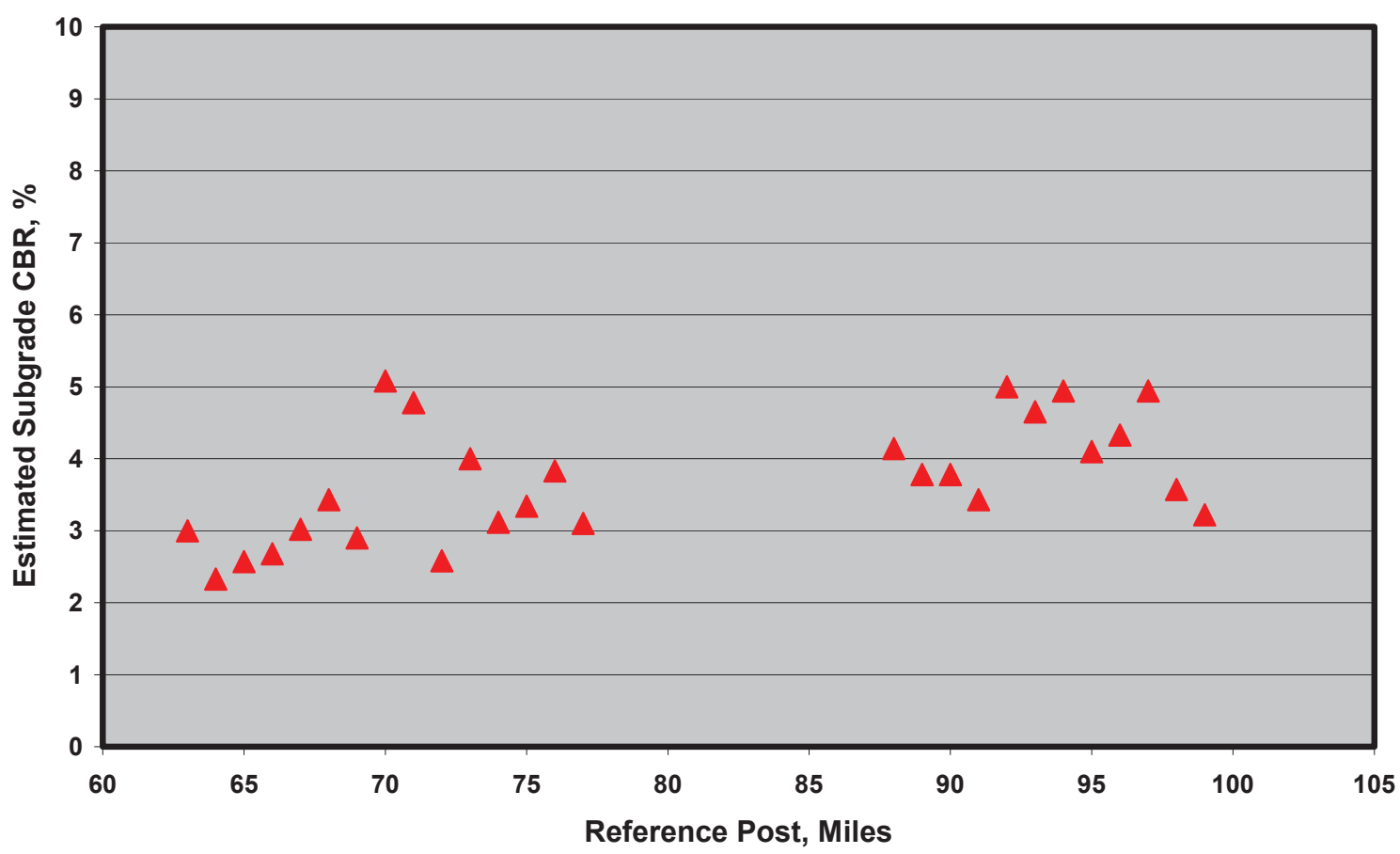

Figure 4.12 b: Profile of Estimated in situ Subgrade CBR along a Segment on SR - 32 
SR - 32 East Bound Driving Lane

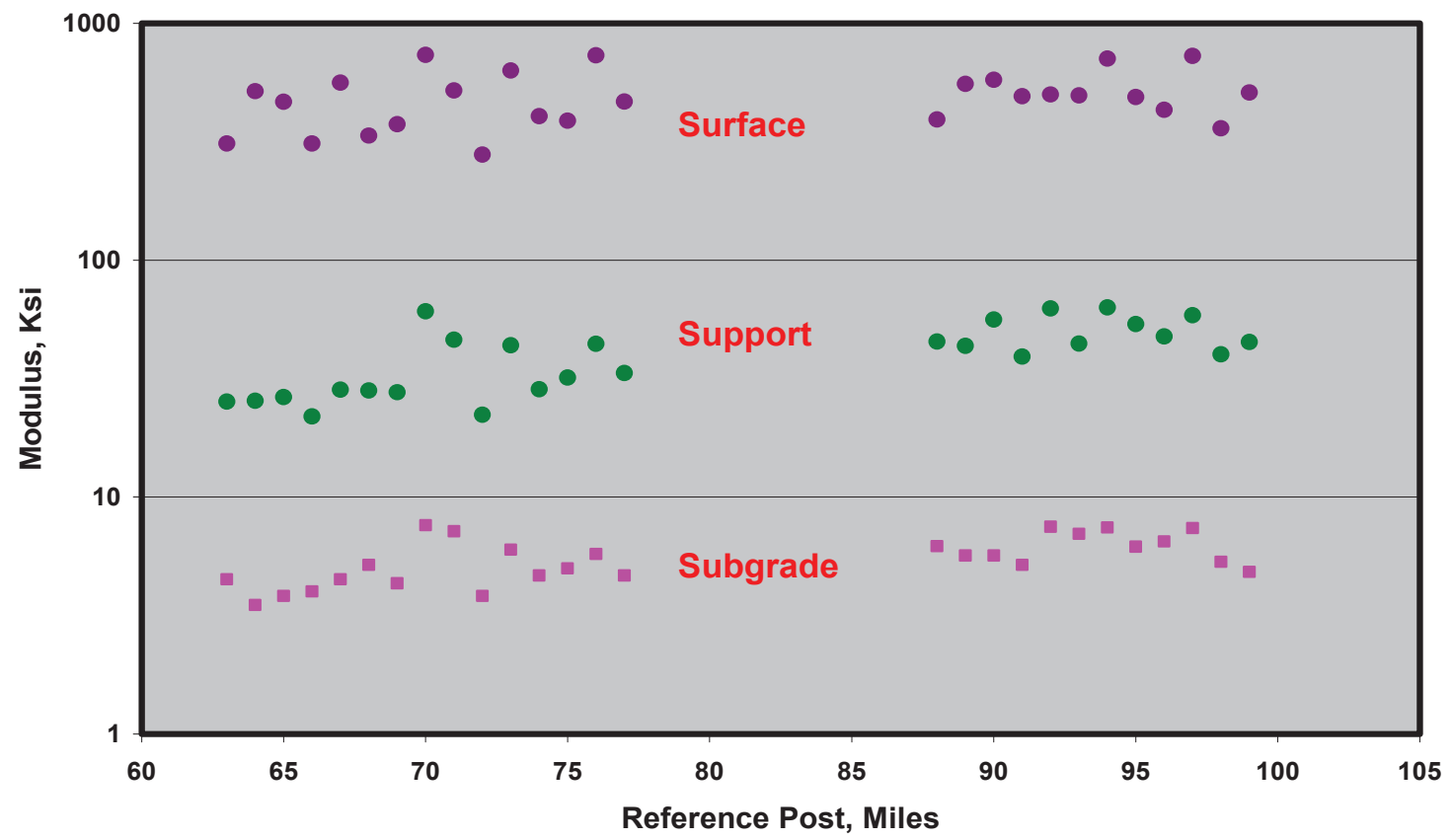

Figure 4.12 c: Profile of Pavement Layer Moduli along a Segment on SR - 32

SR - 32 East Bound Driving Lane

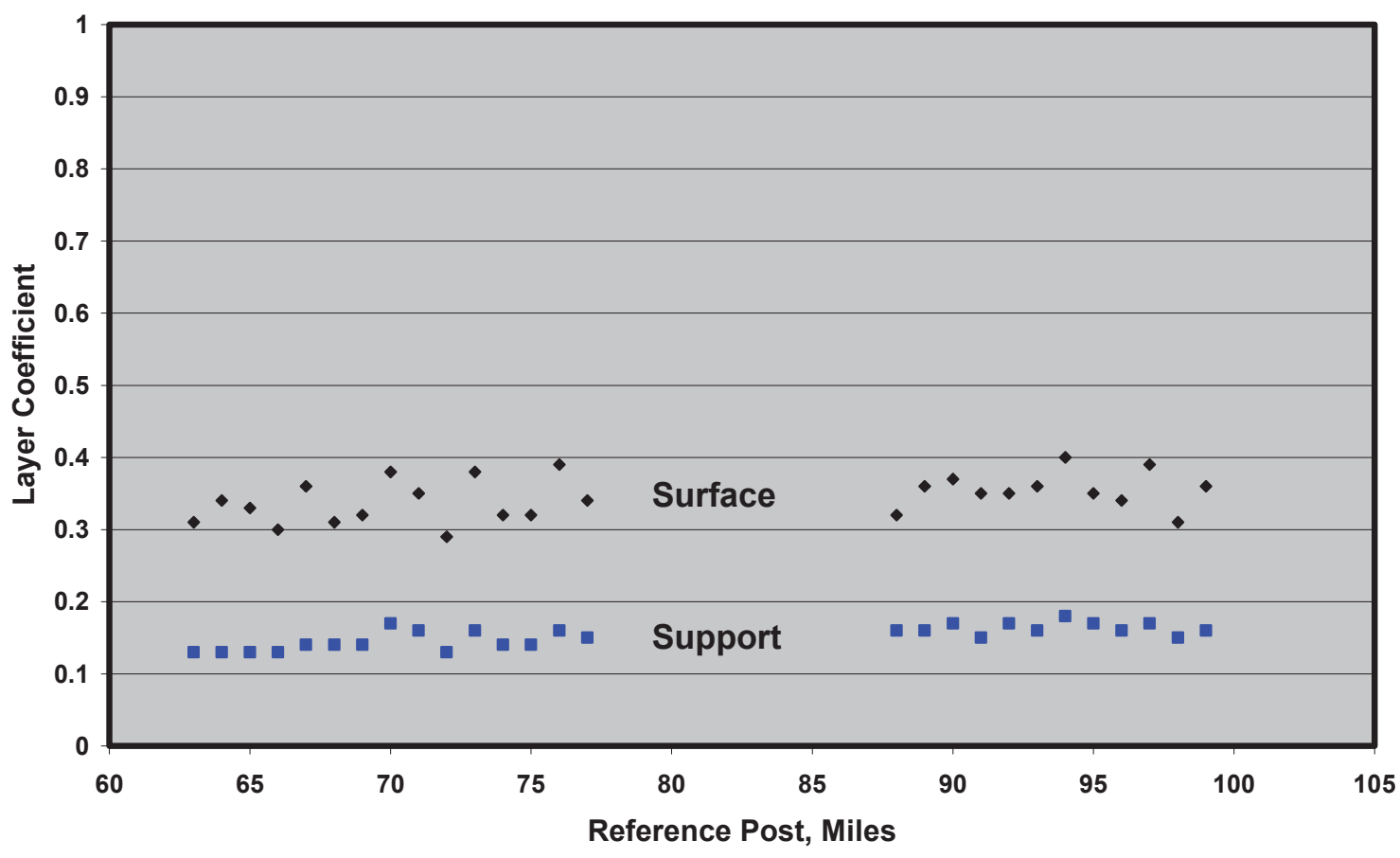

Figure 4.12 d: Profile of Pavement Layer Coefficients along a Segment on SR - 32 
SR - 32 East Bound Driving Lane

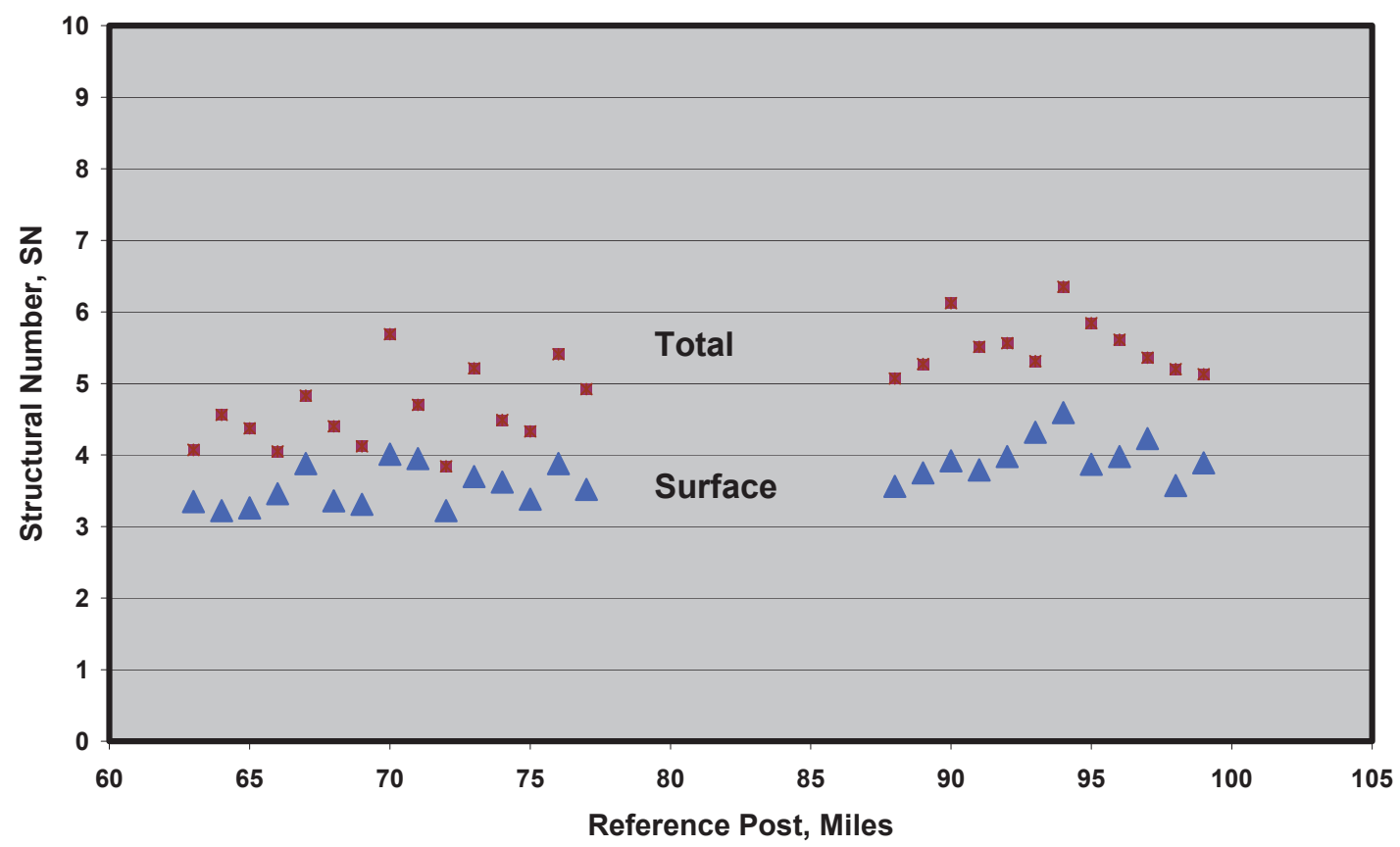

Figure 4.12 e: Profile of Pavement Structural Numbers along a Segment on SR - 32

SR - 32 East Bound Driving Lane

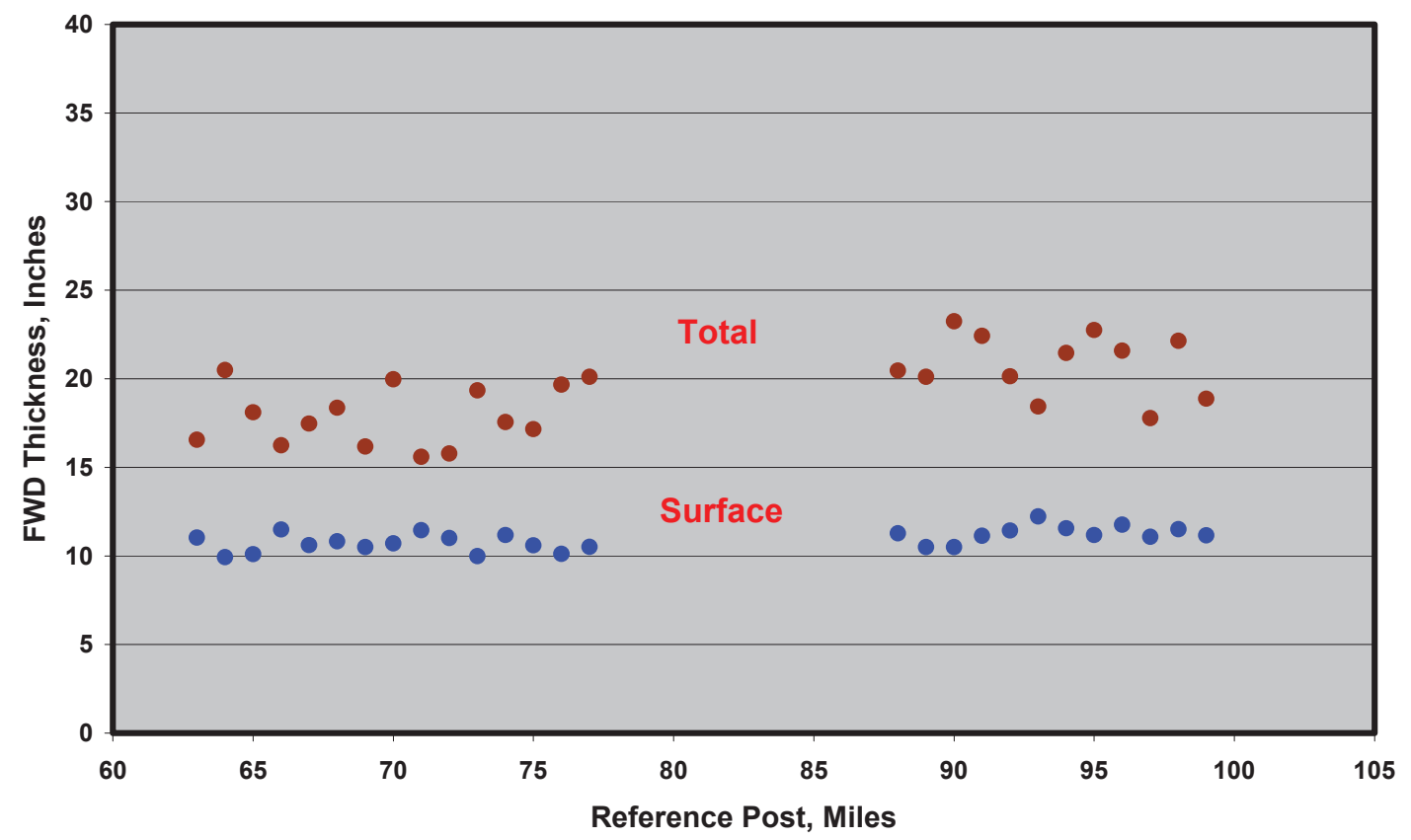

Figure 4.12 f: Profile of Pavement Layers Thickness along a Segment on SR - 32 
SR - 32 East Bound Driving Lane

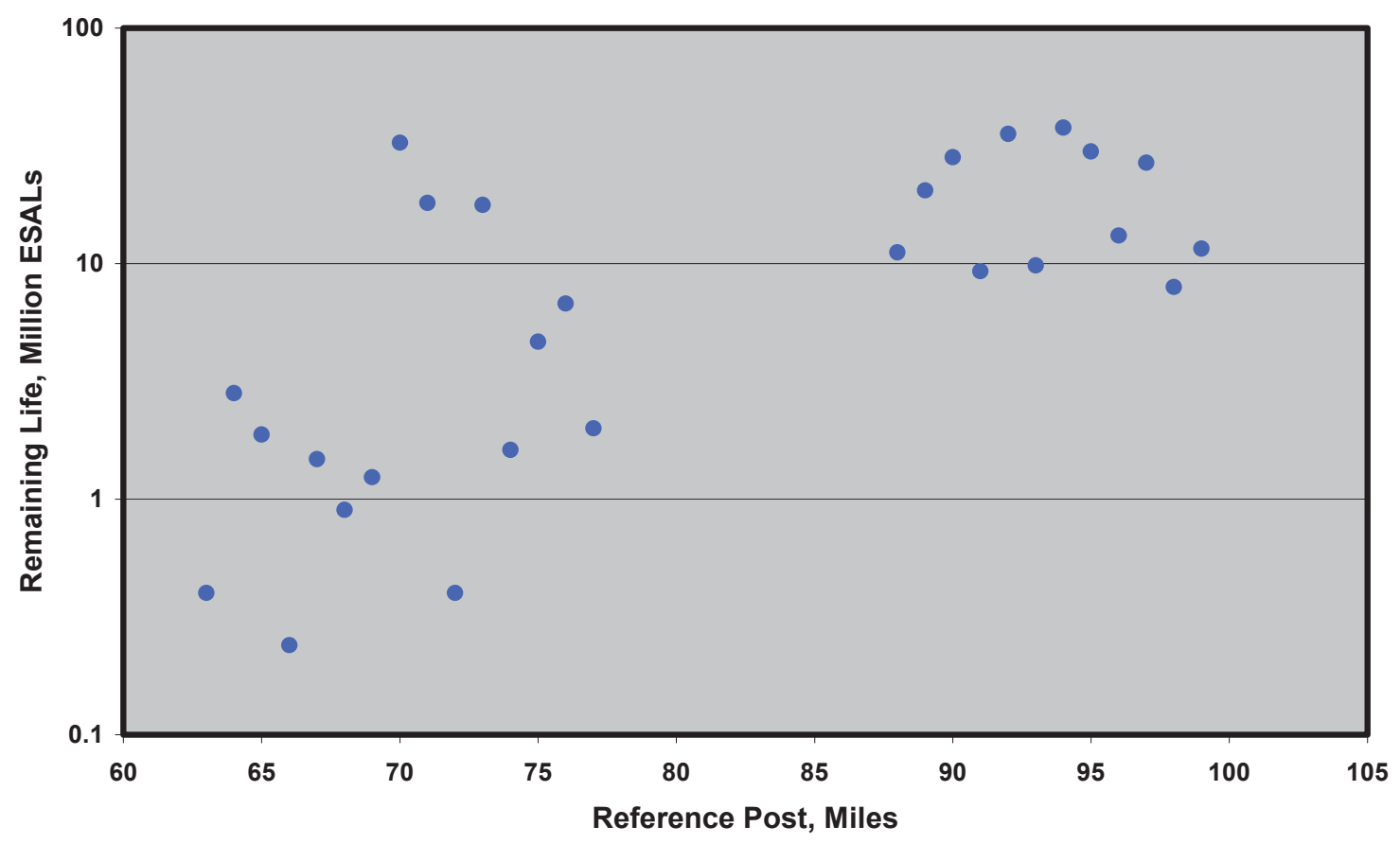

Figure 4.12 g: Profile of Pavement Remaining Life along a Segment on SR - 32

SR - 32 East Bound Driving Lane

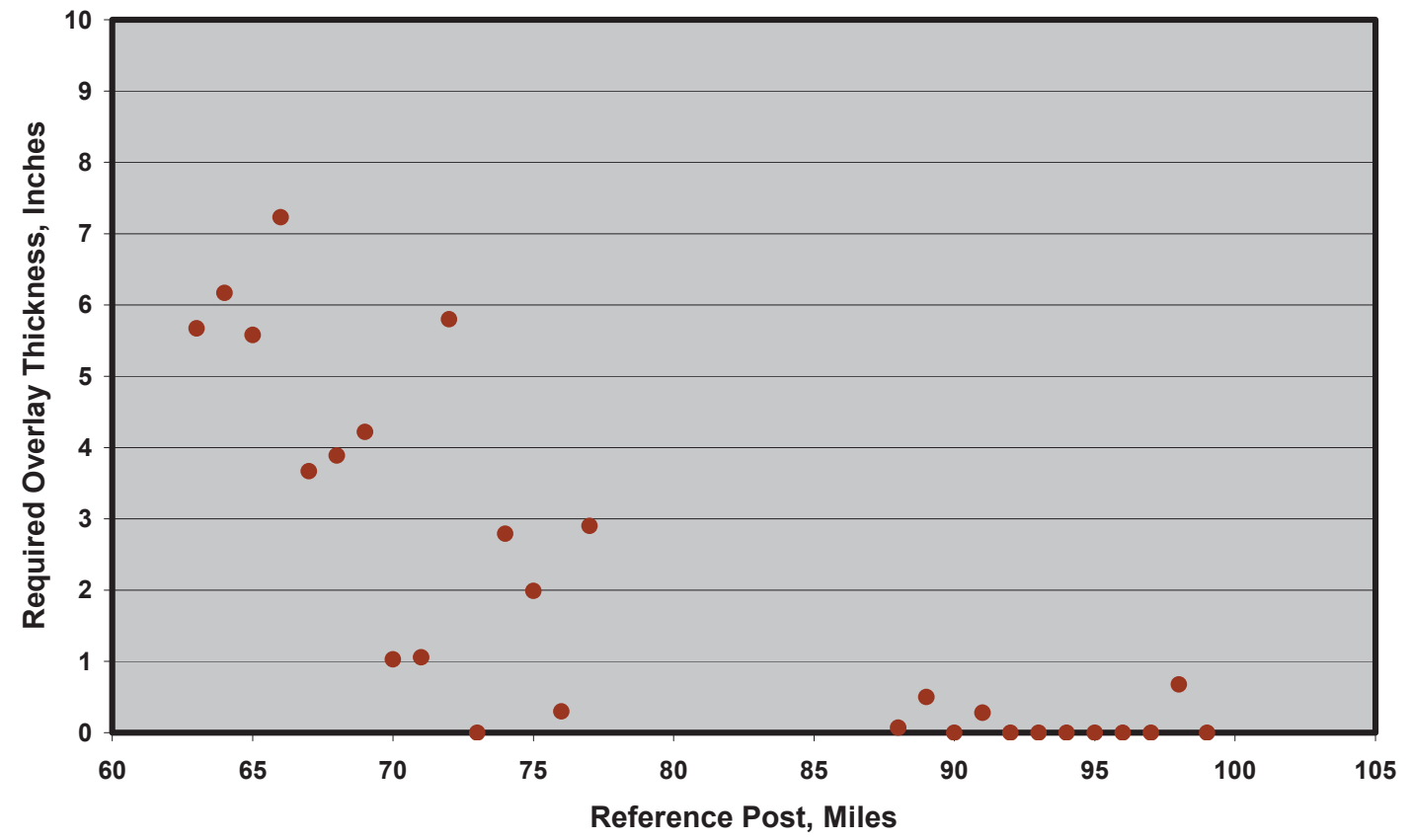

Figure 4.12 h: Profile of Required Overlay Thickness along a Segment on SR - 32 
SR - 250 West Bound

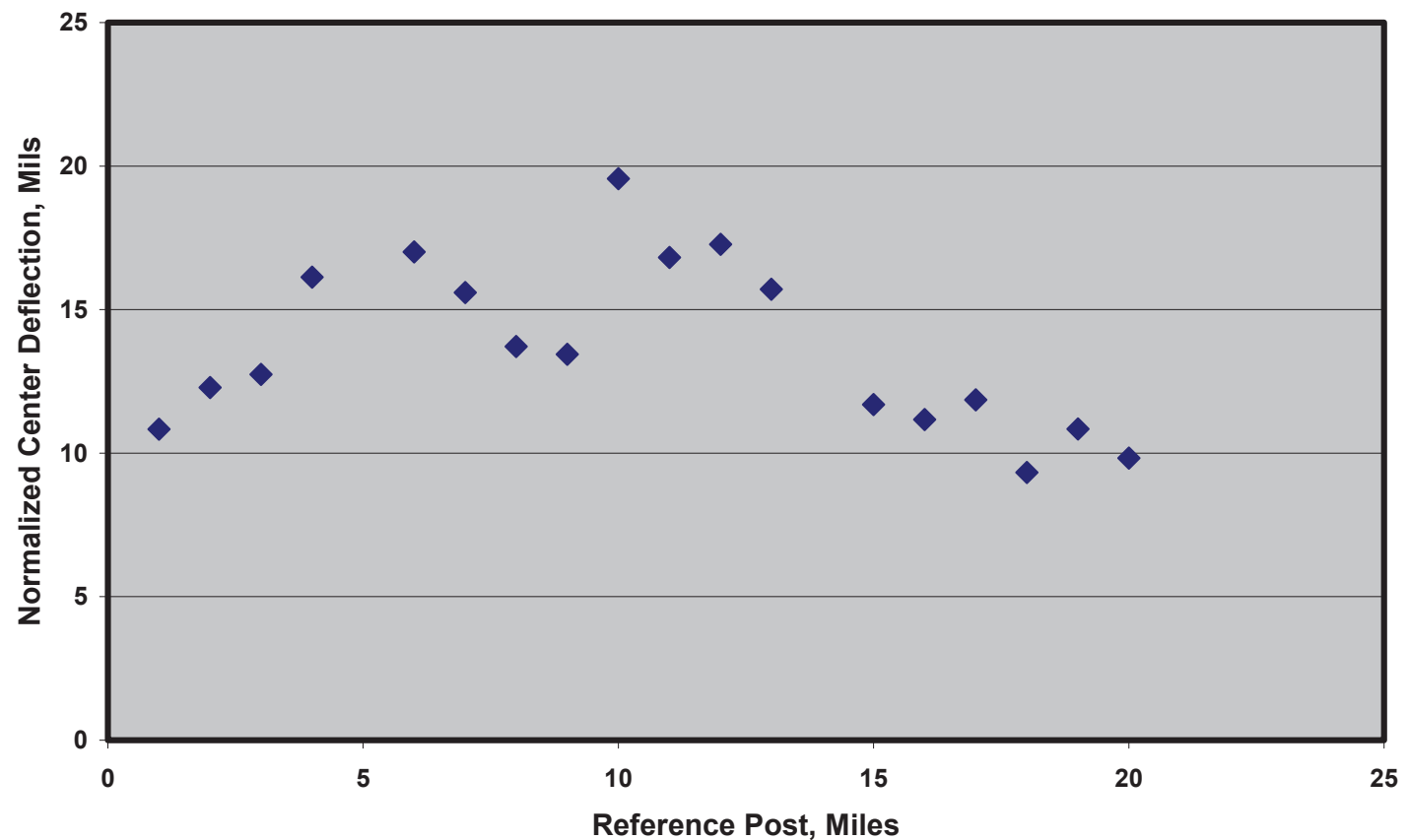

Figure 4.13 a: Profile of Pavement Surface Deflection along a Segment on SR - 250 SR - 250 West Bound

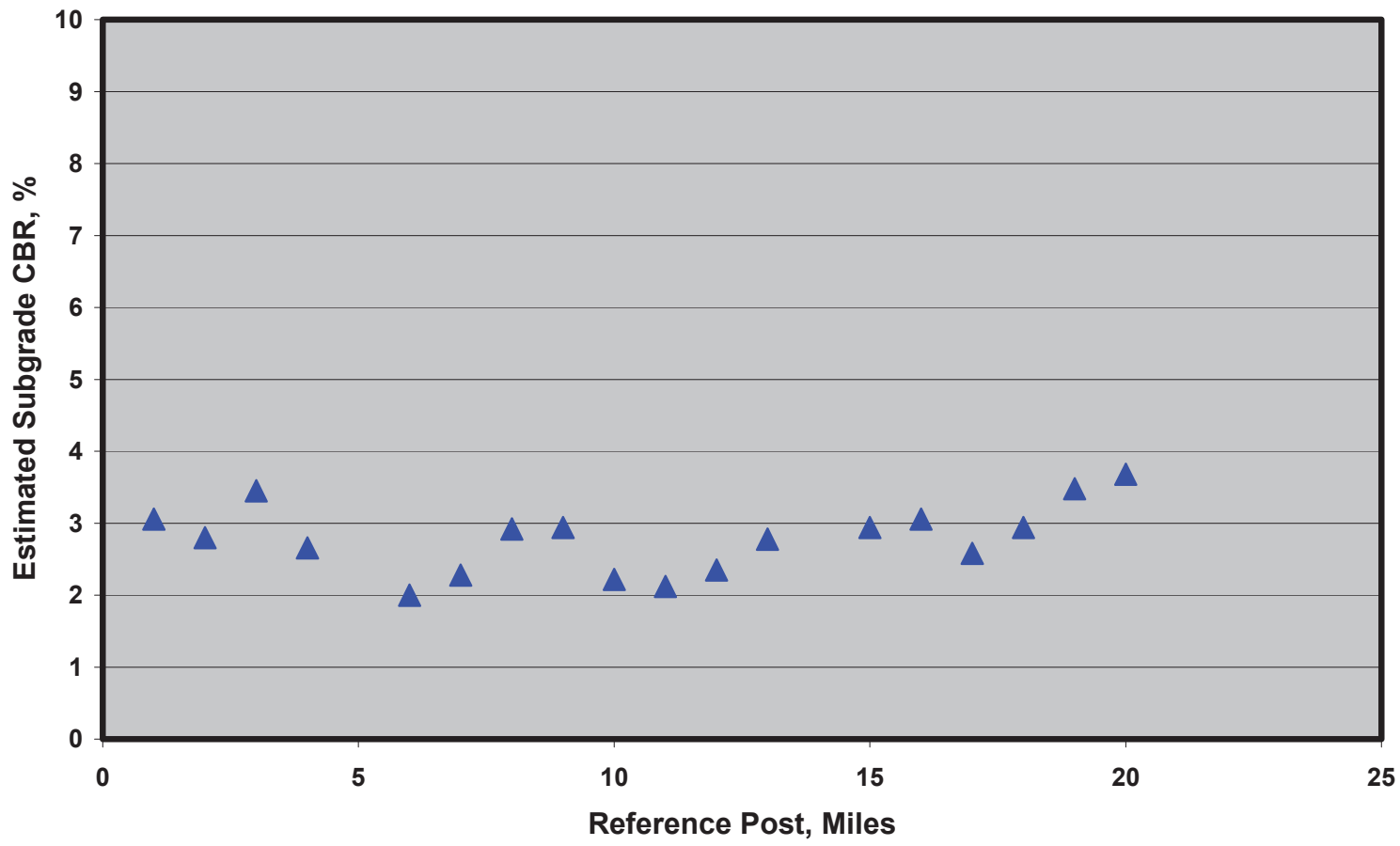

Figure 4.13 b: Profile of Estimated in situ Subgrade CBR along a Segment on SR - 250 


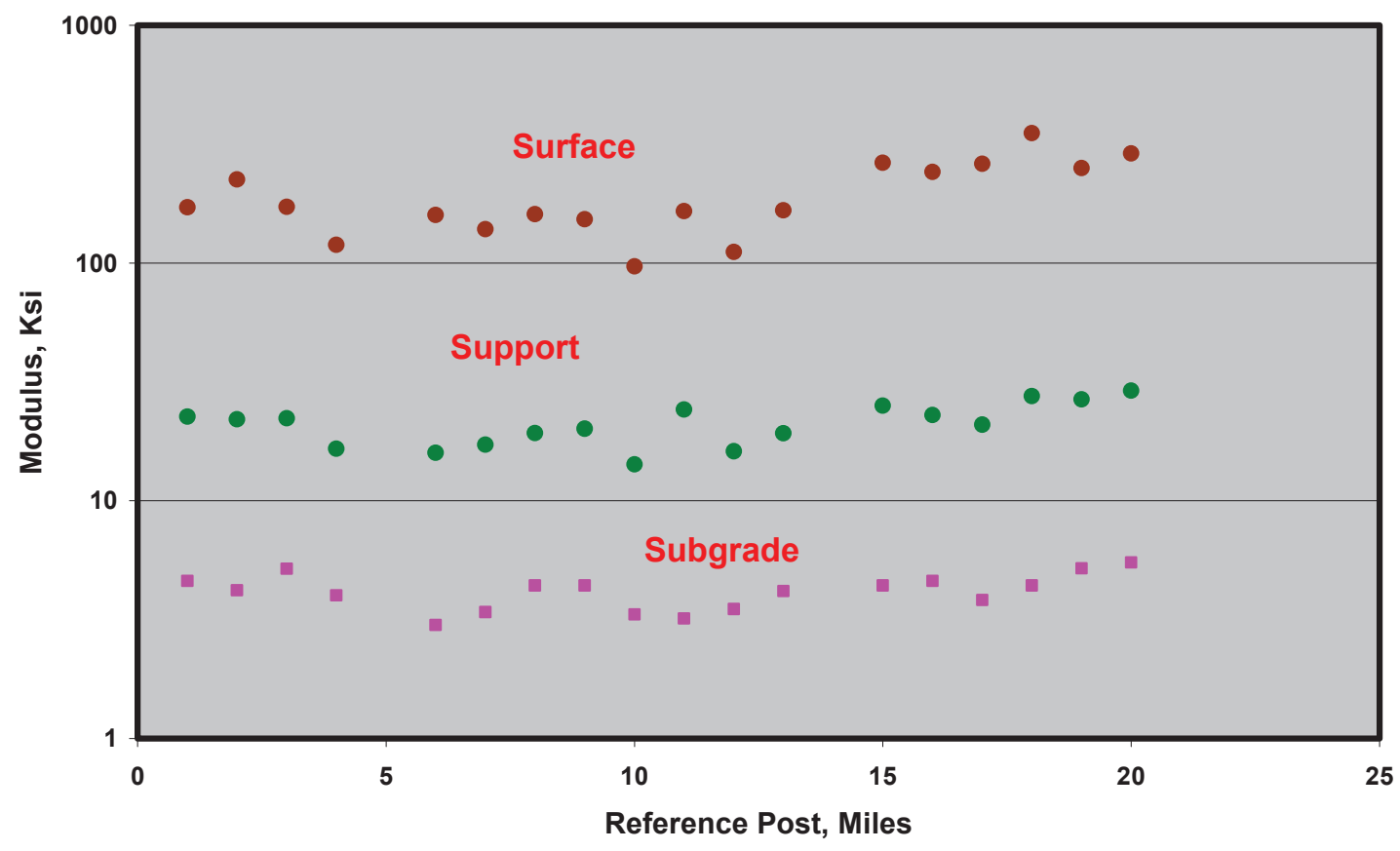

Figure 4.13 c: Profile of Pavement Layer Moduli along a Segment on SR - 250 SR - 250 West Bound

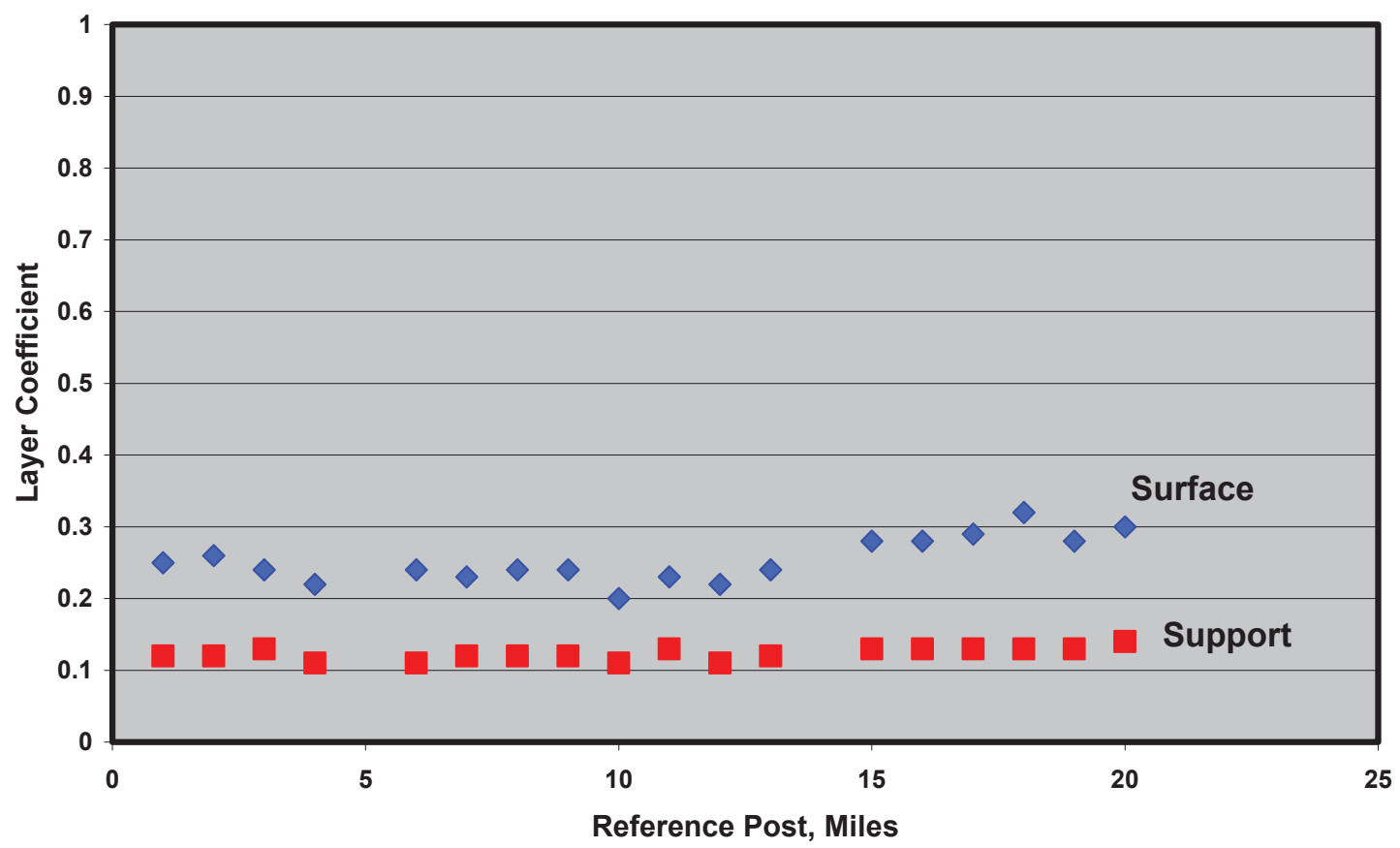

Figure 4.13 d: Profile of Pavement Layer Coefficients along a Segment on SR - 250 
SR - 250 West Bound

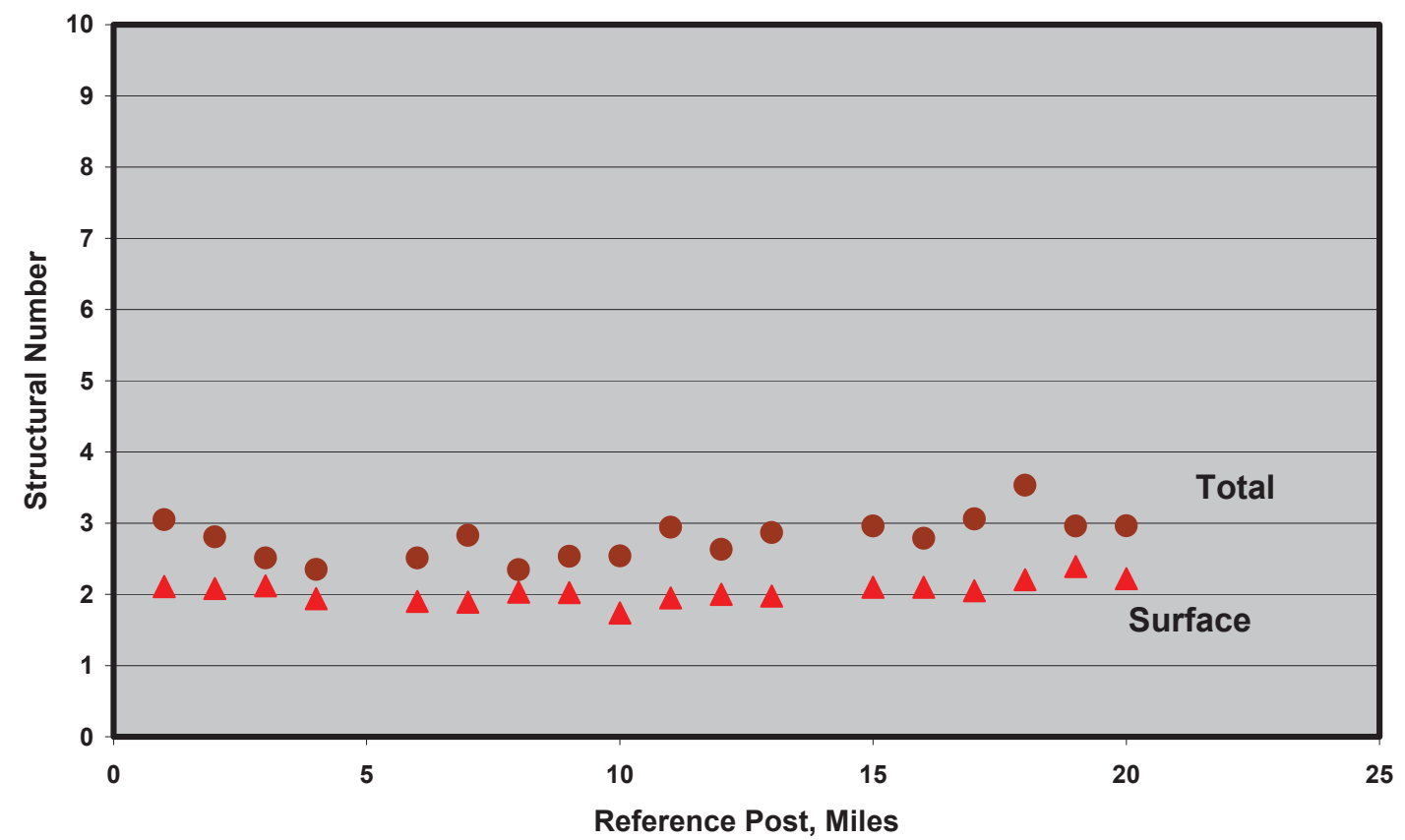

Figure 4.13 e: Profile of Pavement Structural Numbers along a Segment on SR - 250

SR - 250 West Bound

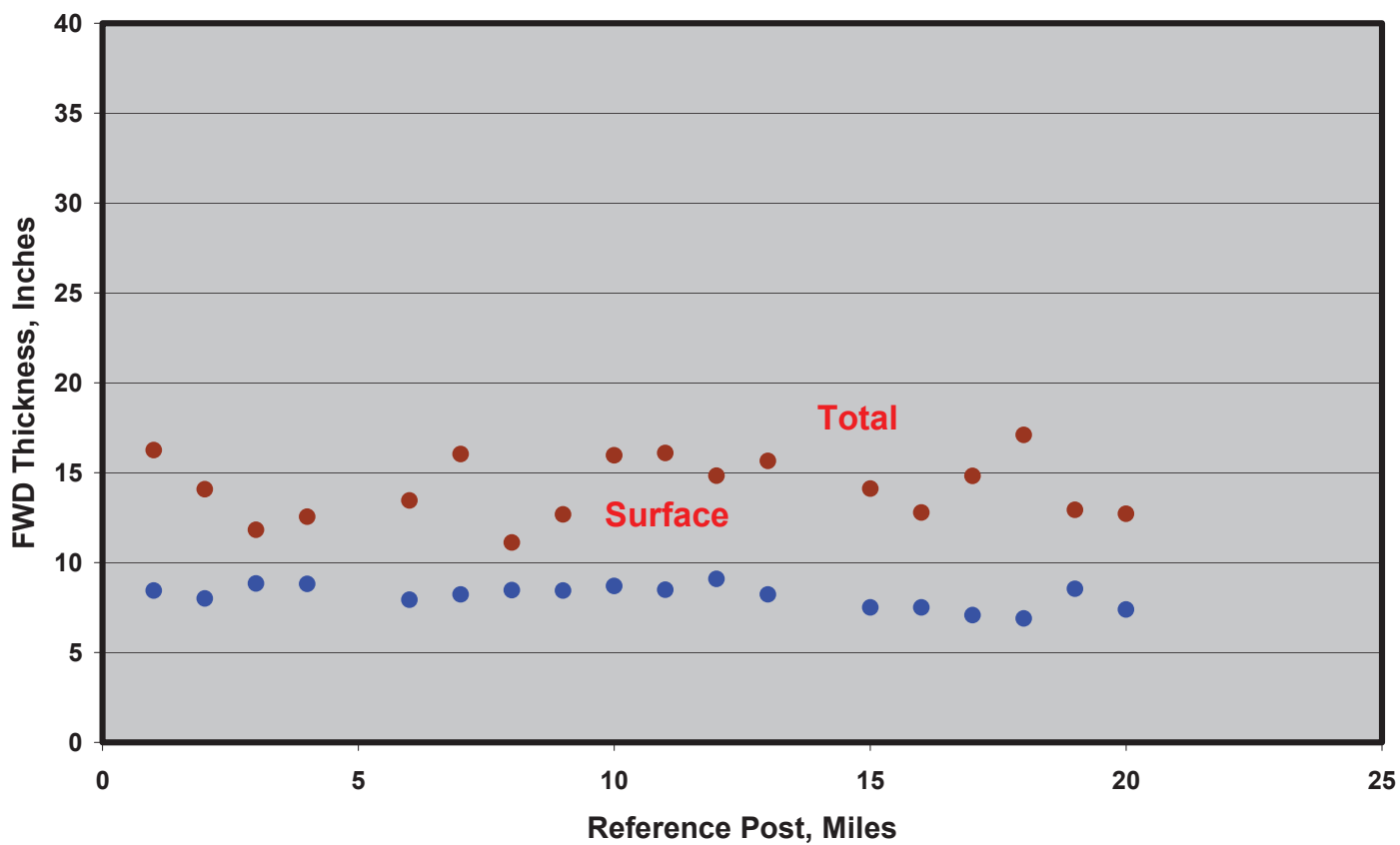

Figure 4.13 f: Profile of Pavement Layers Thickness along a Segment on SR - 250 
SR - 250 West Bound

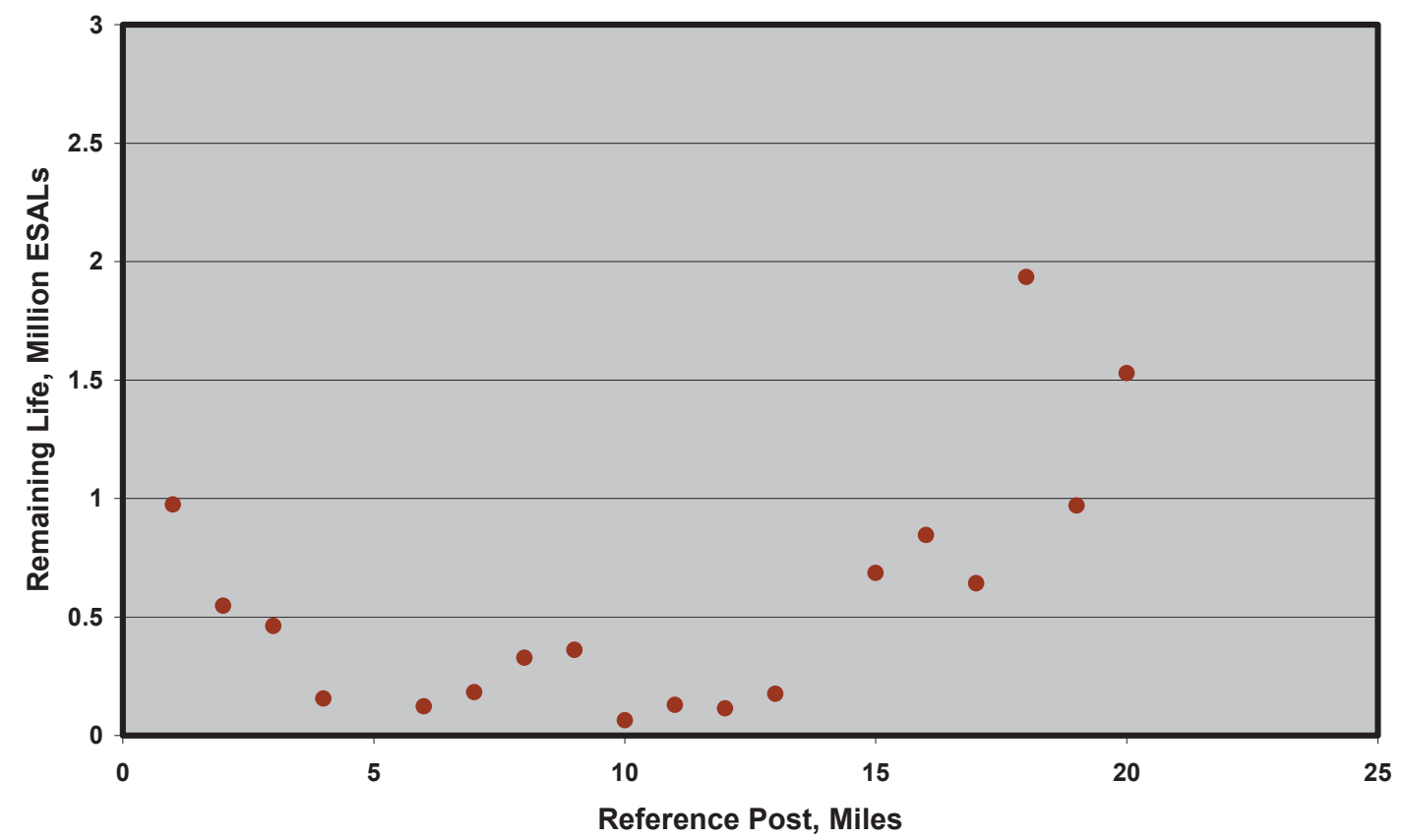

Figure 4.13 g: Profile of Pavement Remaining Life along a Segment on SR - 250

SR - 250 West Bound

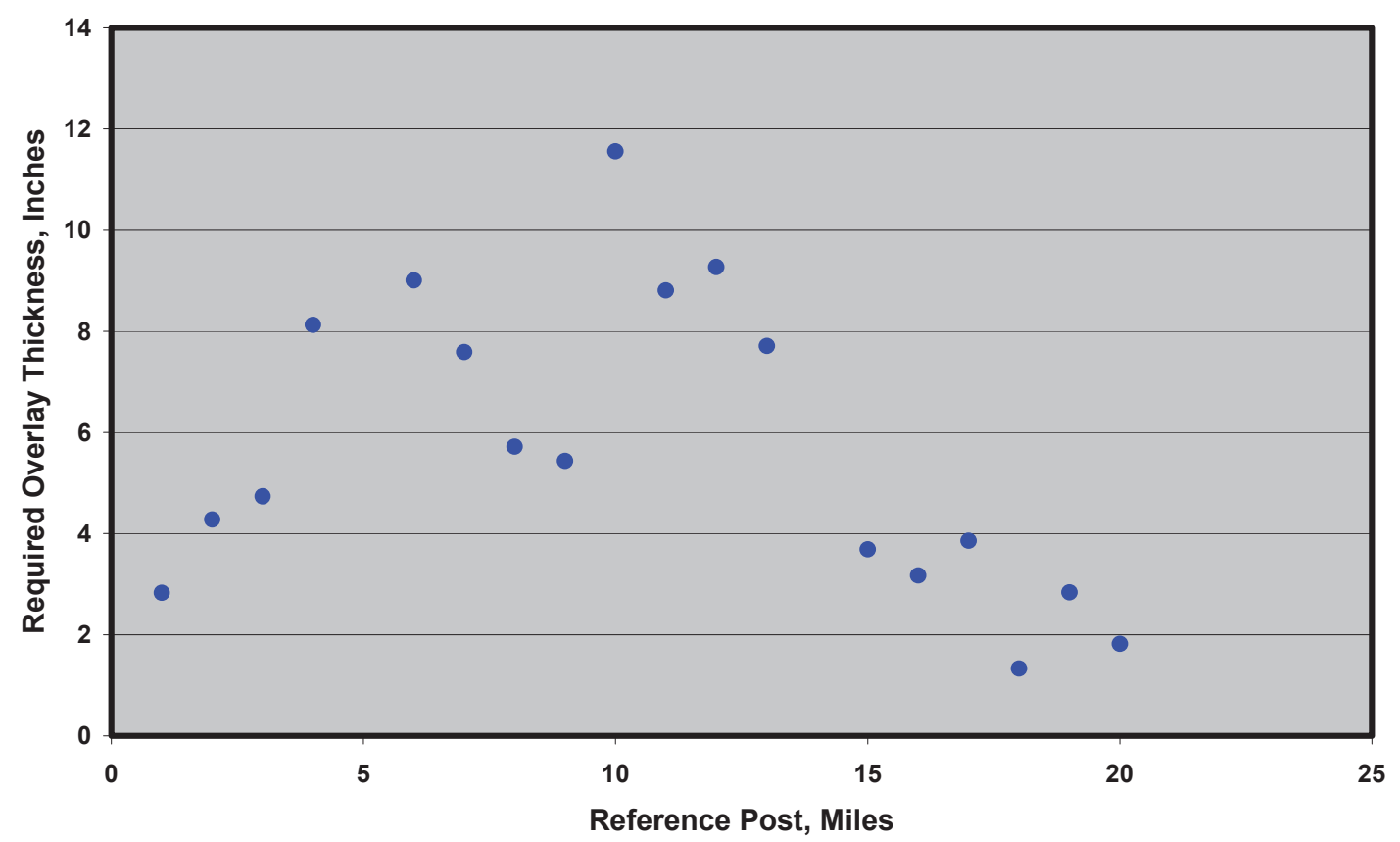

Figure 4.13 h: Profile of Required Overlay Thickness along a Segment on SR - 250 
US - 41 North Bound Driving Lane

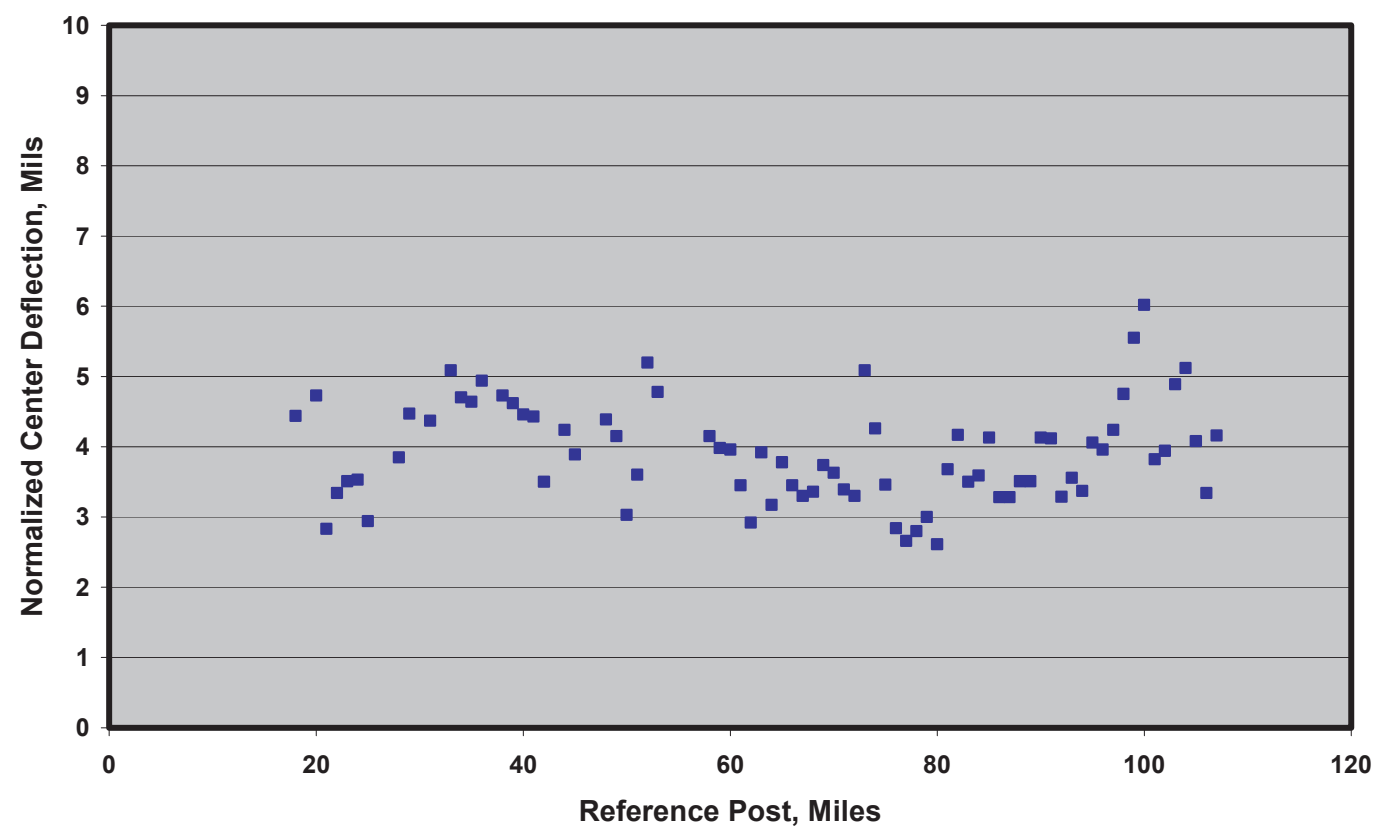

Figure 4.14 a: Profile of Pavement Surface Deflection along a Segment on US - 41

US - 41 North Bound Driving Lane

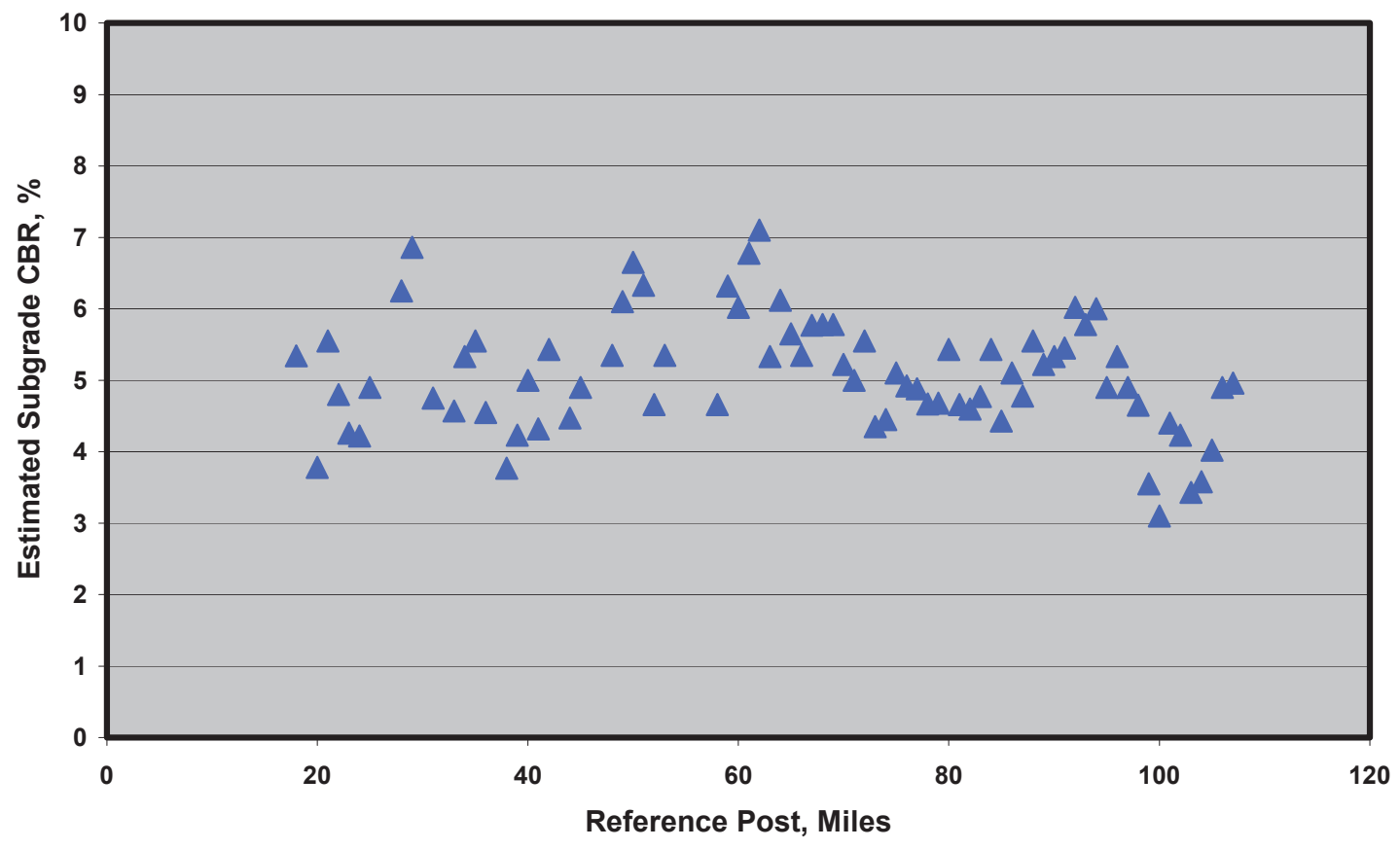

Figure 4.14 b: Profile of Estimated in situ Subgrade CBR along a Segment on US - 41 


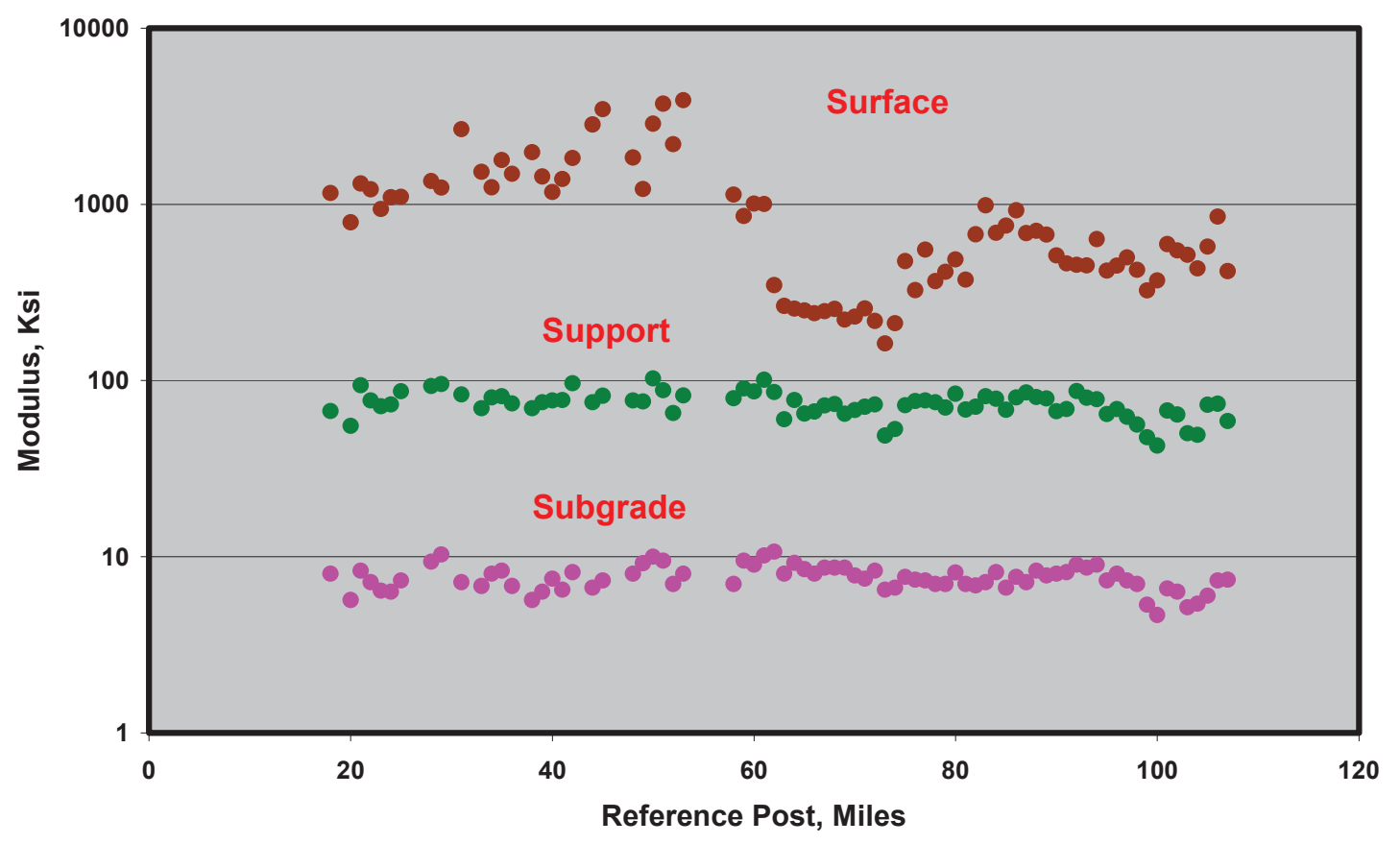

Figure 4.14 c: Profile of Pavement Layer Moduli along a Segment on US - 41 US - 41 North Bound Driving Lane

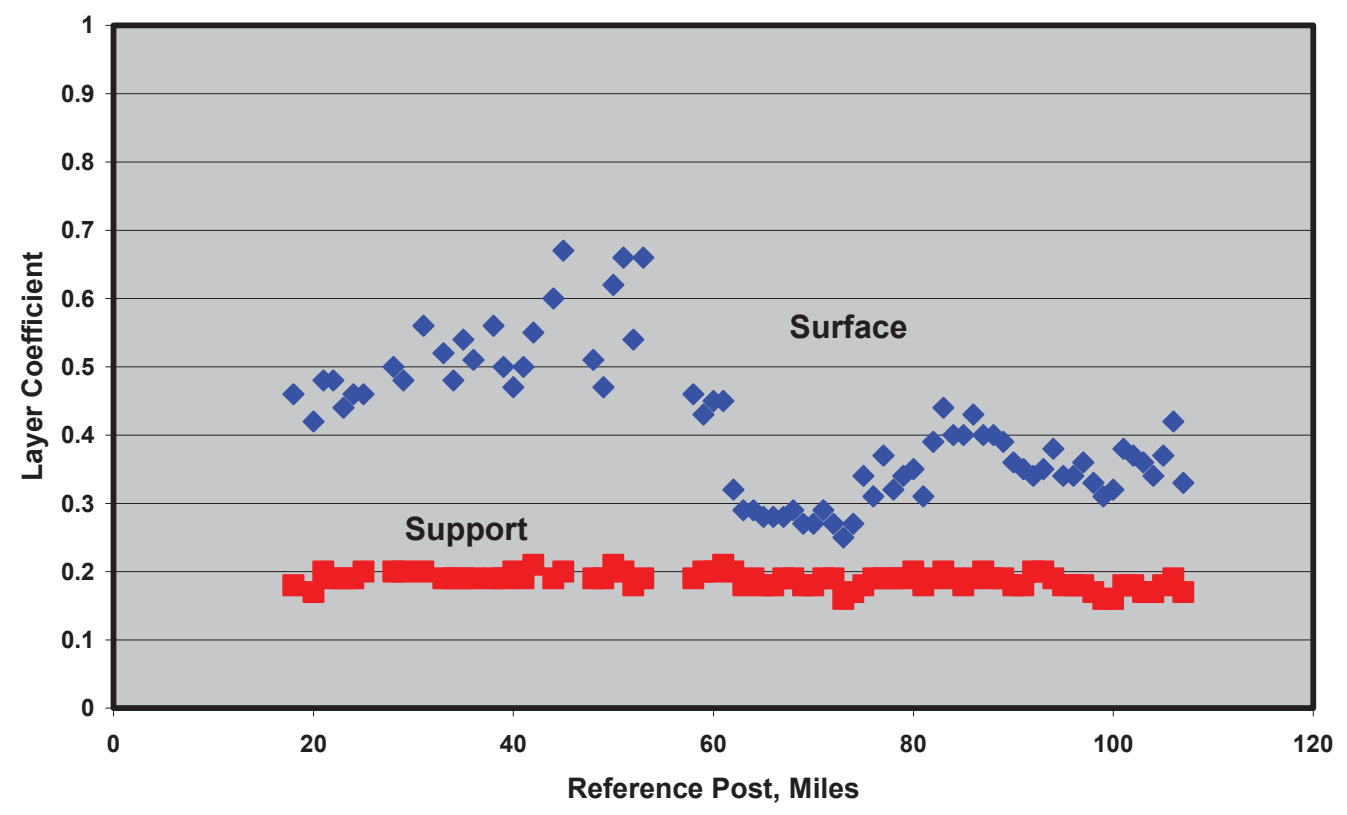

Figure 4.14 d: Profile of Pavement Layer Coefficients along a Segment on US - 41 
US - 41 North Bound Driving Lane

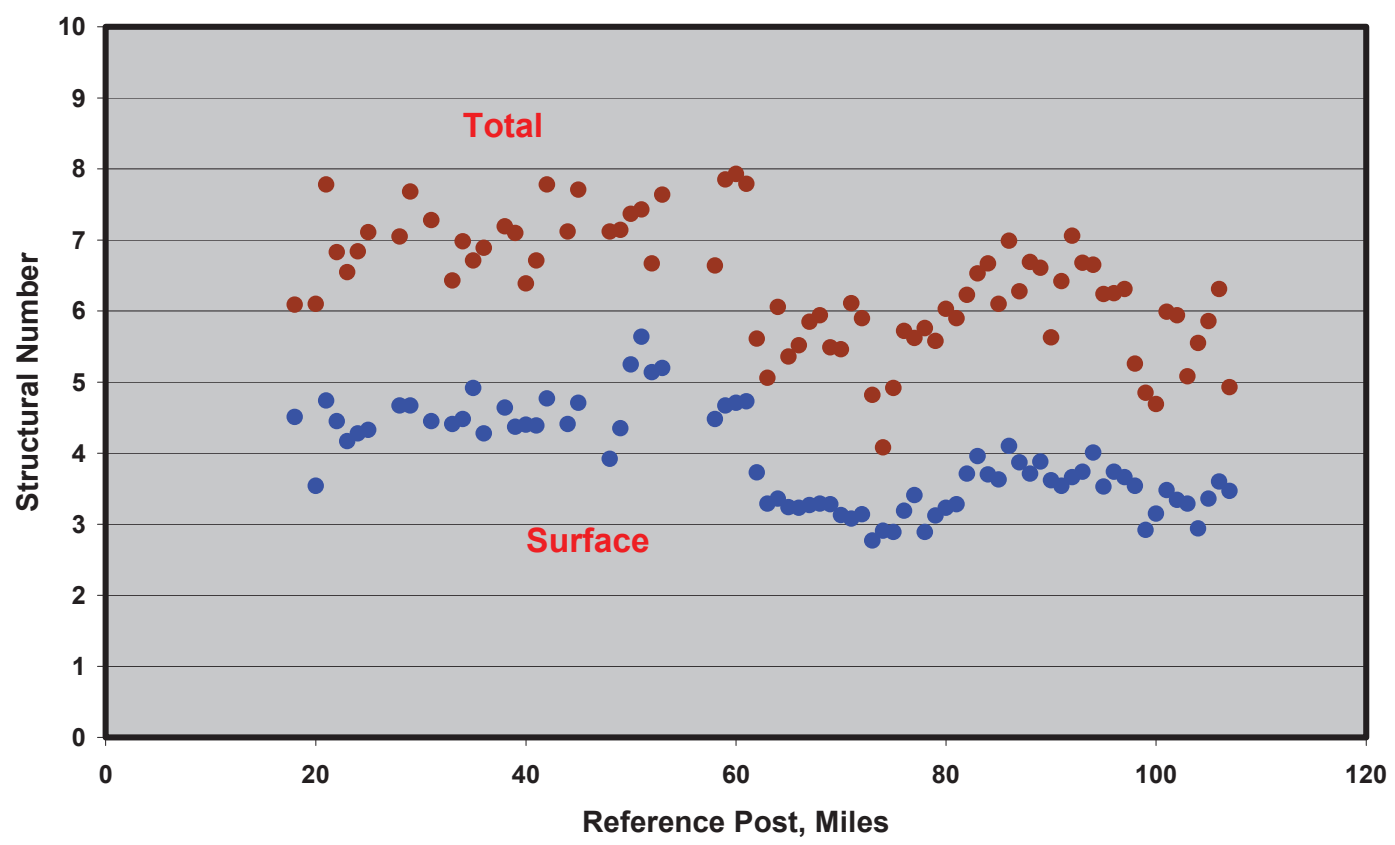

Figure 4.14 e: Profile of Pavement Structural Numbers along a Segment on US - 41 US - 41 North Bound Driving Lane

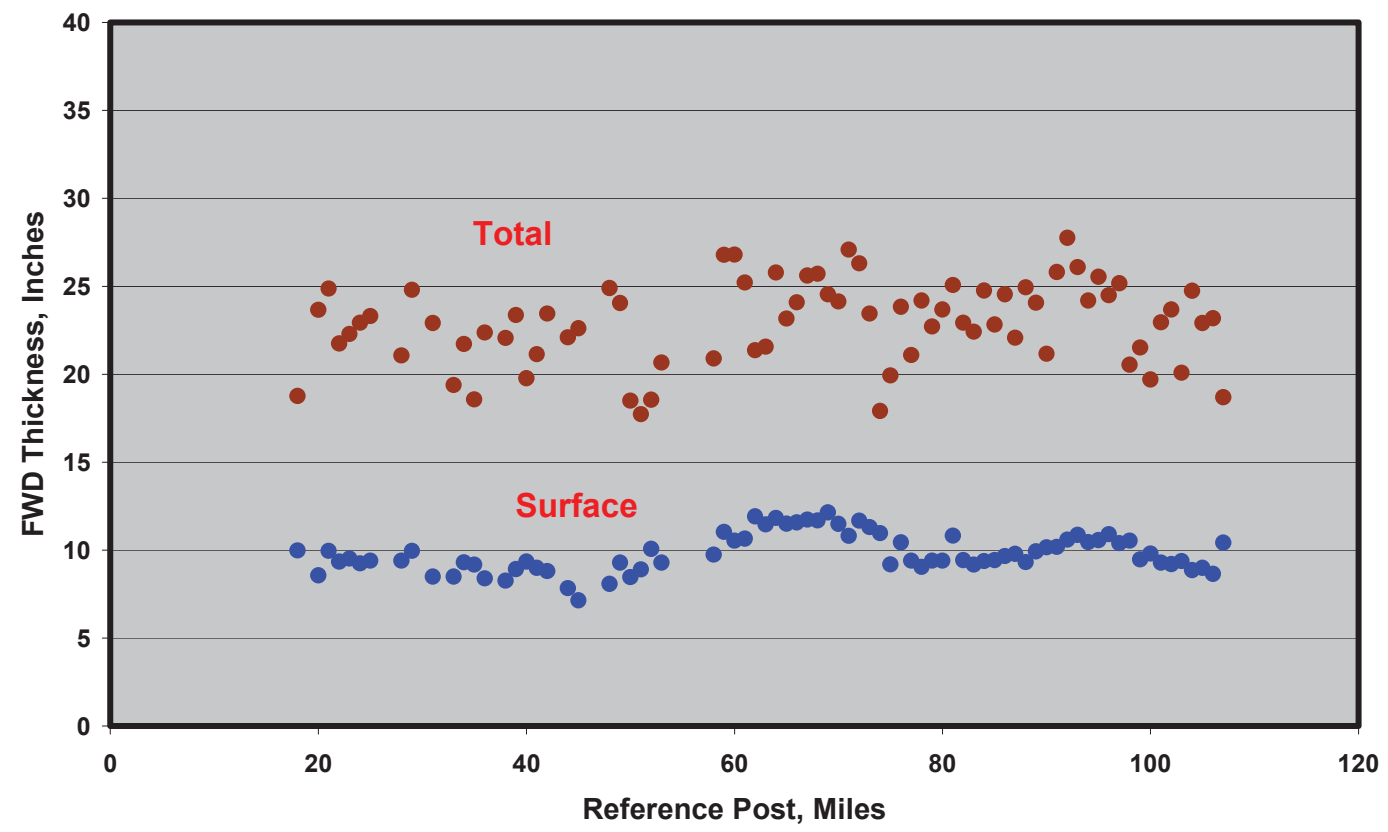

Figure 4.14 f: Profile of Pavement Layer Thickness along a Segment on US - 41 
SR 37 North Bound Driving Lane

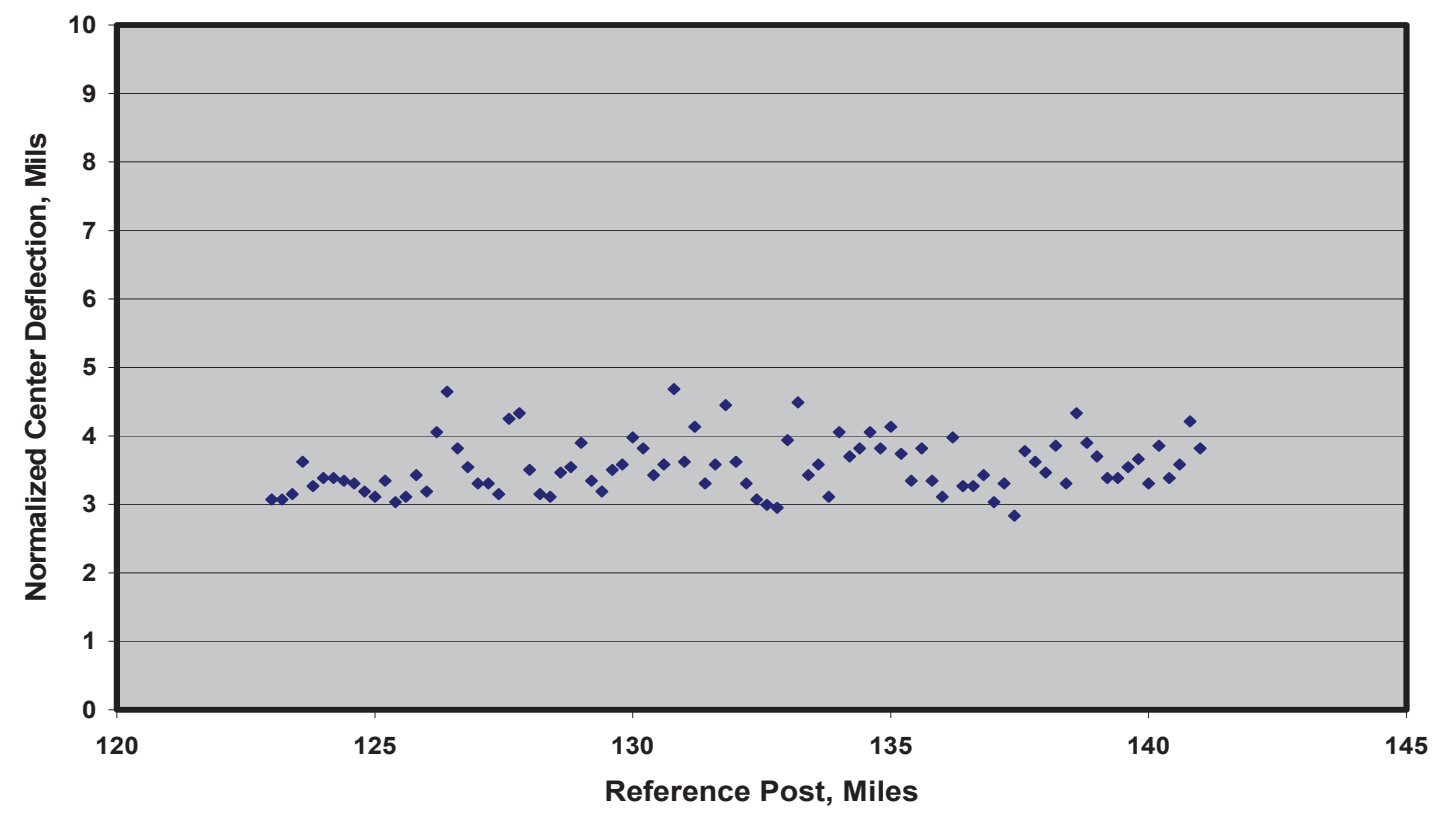

Figure 4.15 a: Profile of Pavement Surface Deflection along a Segment on SR - 37

SR - 37 North Bound Driving Lane

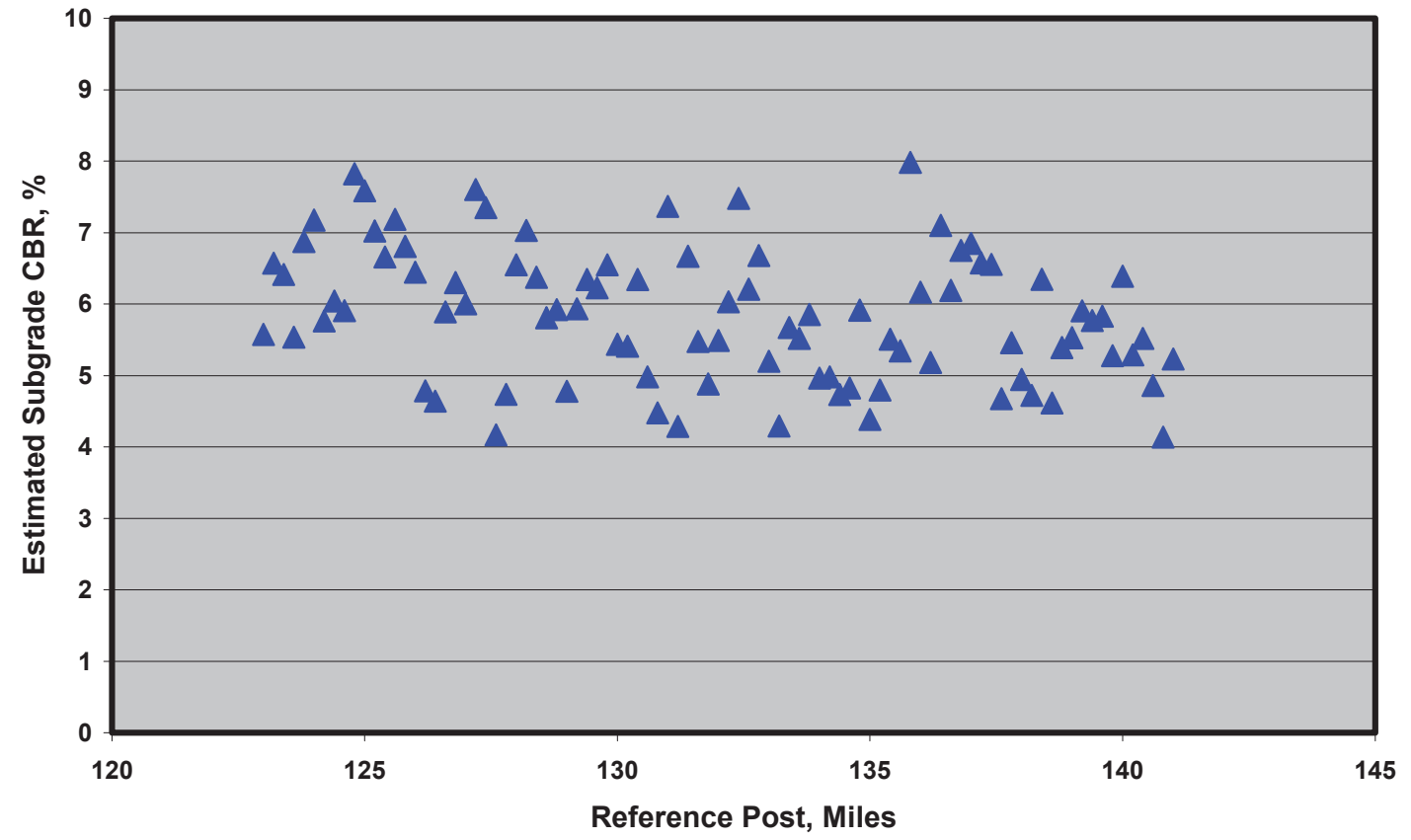

Figure 4.15 b: Profile of Estimated in situ Subgrade CBR along a Segment on SR - 37 
SR - 37 North Bound Driving Lane

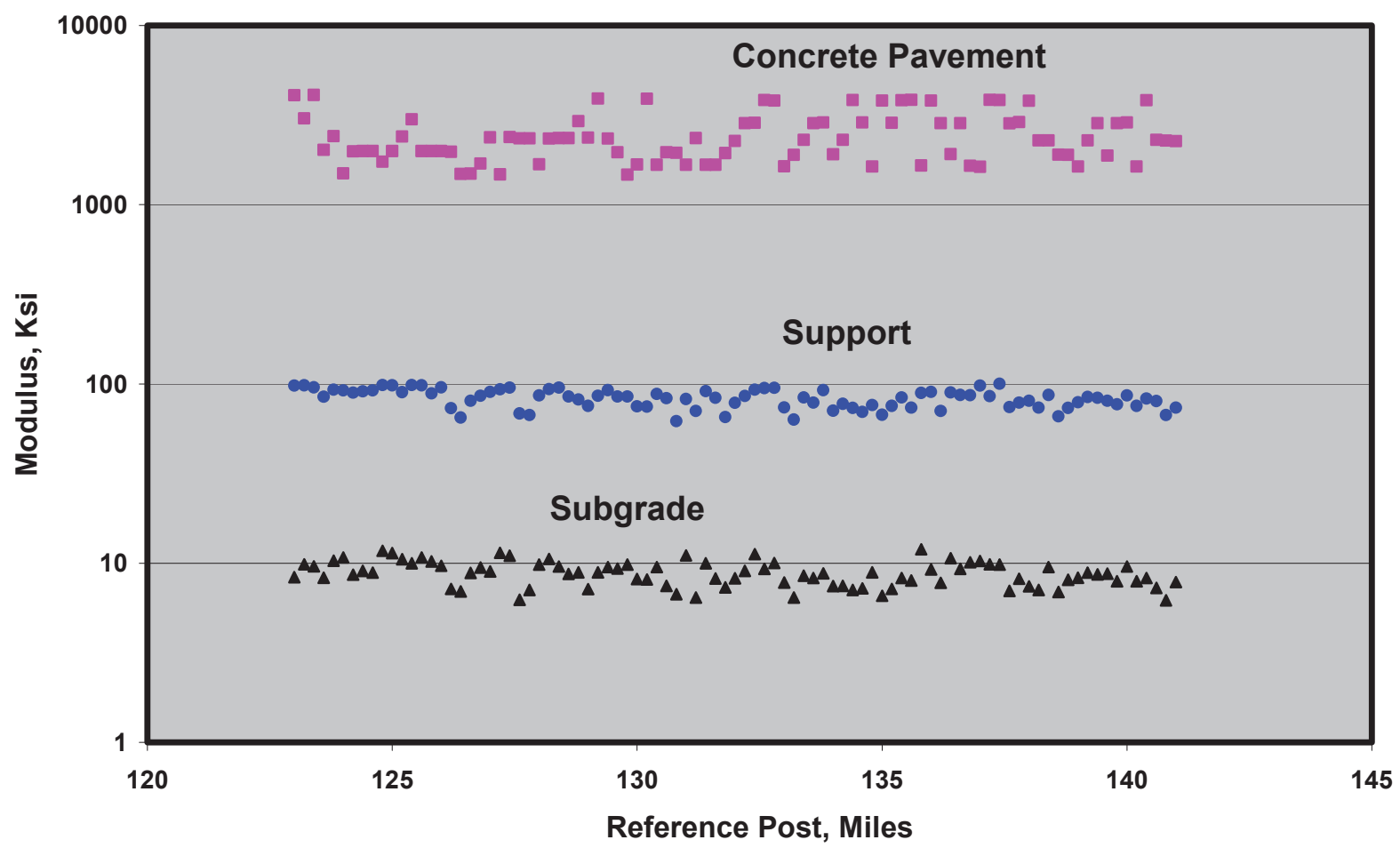

Figure 4.15 c: Profile of Pavement Layer Moduli along a Segment on SR - 37 


\subsubsection{U.S. Roads and State Routes Structural Comparisons}

Figure(s) 4.16 (a to c) present pavement structural comparisons between all Indiana U.S. Roads and State Routes selected in the study. Comparisons presented are for subgrade CBR, pavement layer moduli and pavement layer coefficients. While subgrade CBR values are similar (Figure 4.16 a), it can be observed that the pavement structural conditions are not as identical as when comparing Interstates. This is expected since these roadways do not have similar designs and are not exposed to similar traffic classifications and number of traffic repetitions. This suggests that for future testing at the network level, U.S. Roads and State Routes may need more emphasis in network level testing than Interstate Highways.

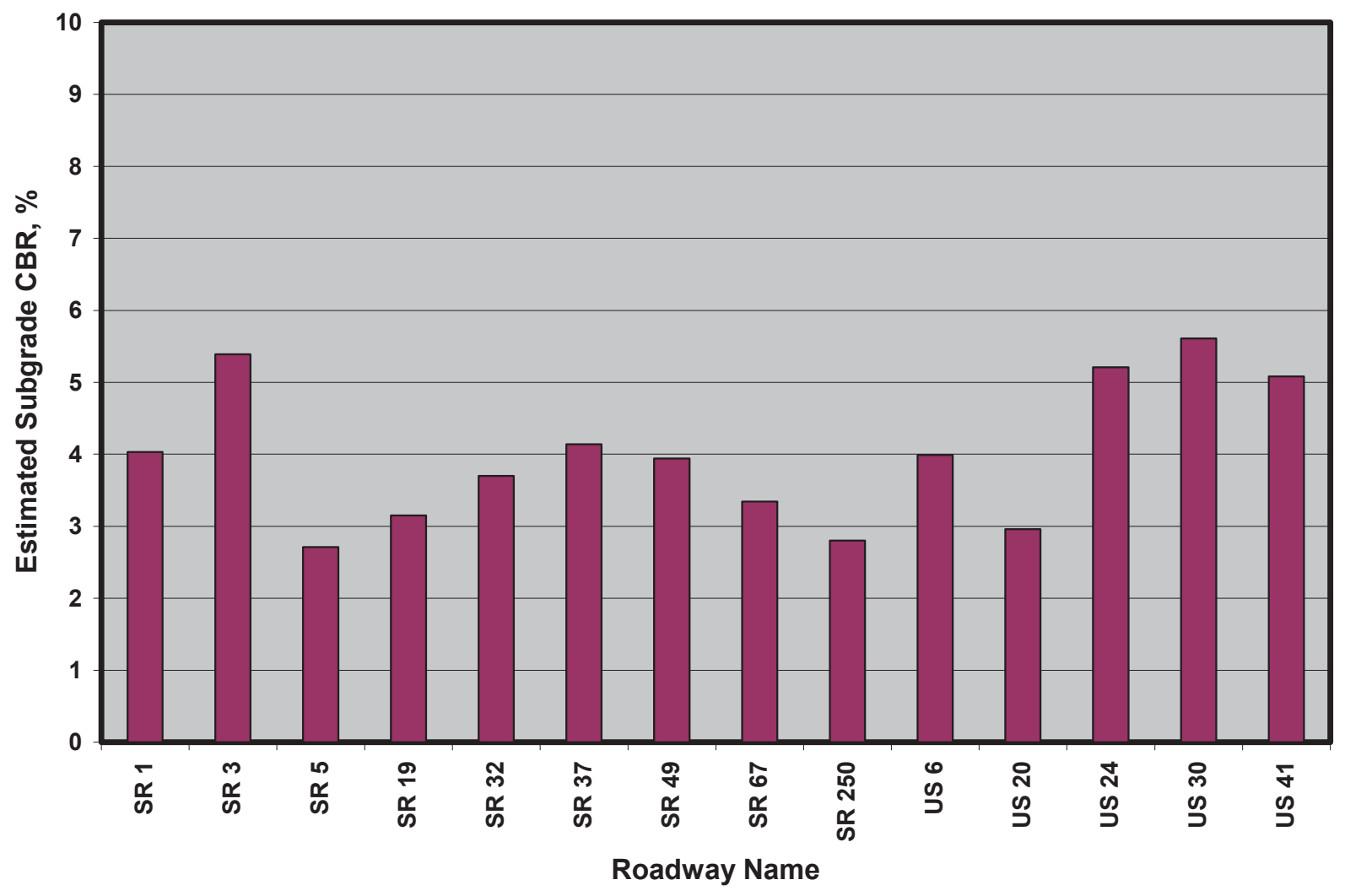

Figure 4.16 a: U.S. Roads and State Routes Comparisons; Estimated Subgrade CBR 


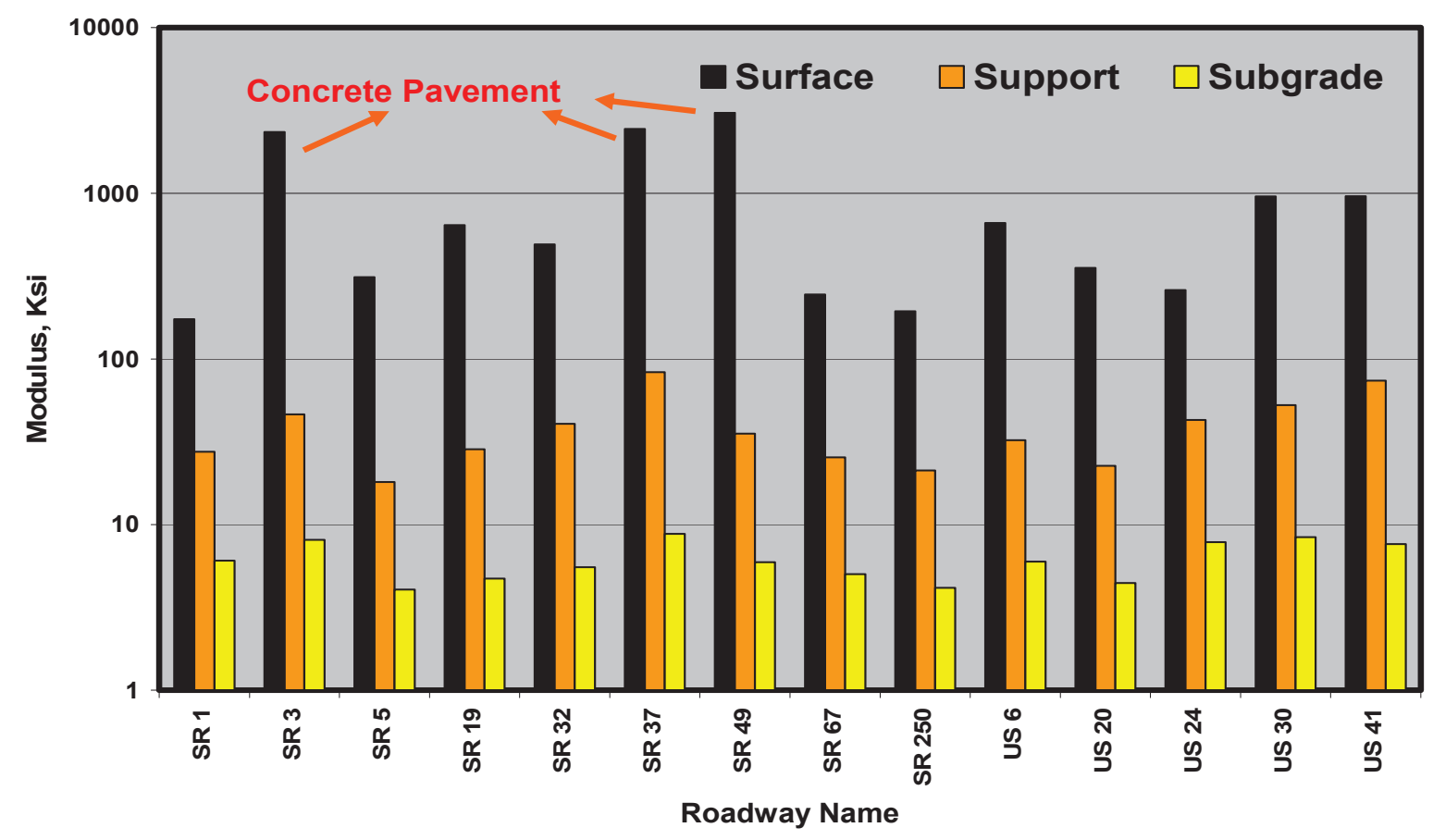

Figure 4.16 b: U.S. Roads and State Routes Comparisons; Pavement Layer Moduli

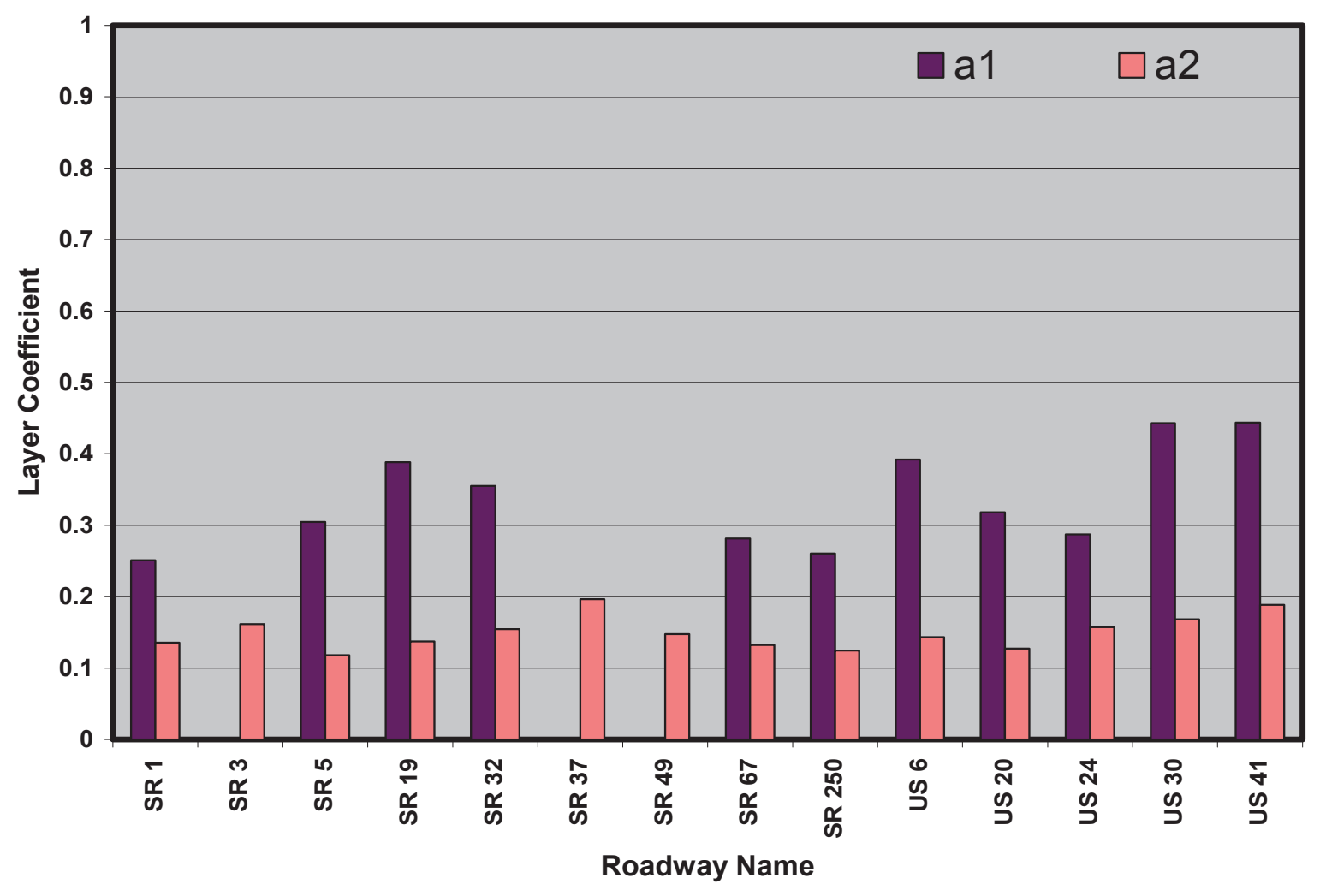

Figure 4.16 c: U.S. Roads and State Routes Comparisons; Pavement Layer Coefficients 


\subsection{GPR at the Network Level}

\subsubsection{GPR - FWD Thickness Comparisons}

Figures 4.17 through 4.23 present profiles of GPR and FWD thickness estimations along, I - 64, I $-65, \mathrm{I}-69, \mathrm{I}-70, \mathrm{I}-74$ (both north and south bound directions), US -41 and SR -32 .

FWD provided an estimate of the total pavement thickness while the GPR did not. GPR provided an estimate for the thickness of the top surface portion of the combined surface layers while the FWD did not. Top surface portion thickness information is very important for those situations where mill - fill operations are needed.

Thickness profile of combined surface layers estimated using the FWD matched the profile of combined surface layers estimated using the GPR in some segments and was lower than that profile in other segments. This suggests that FWD underestimates the thickness of combined surface layers in some locations. The amount of error, however, is relatively small and can be acceptable for network level evaluation purposes. 


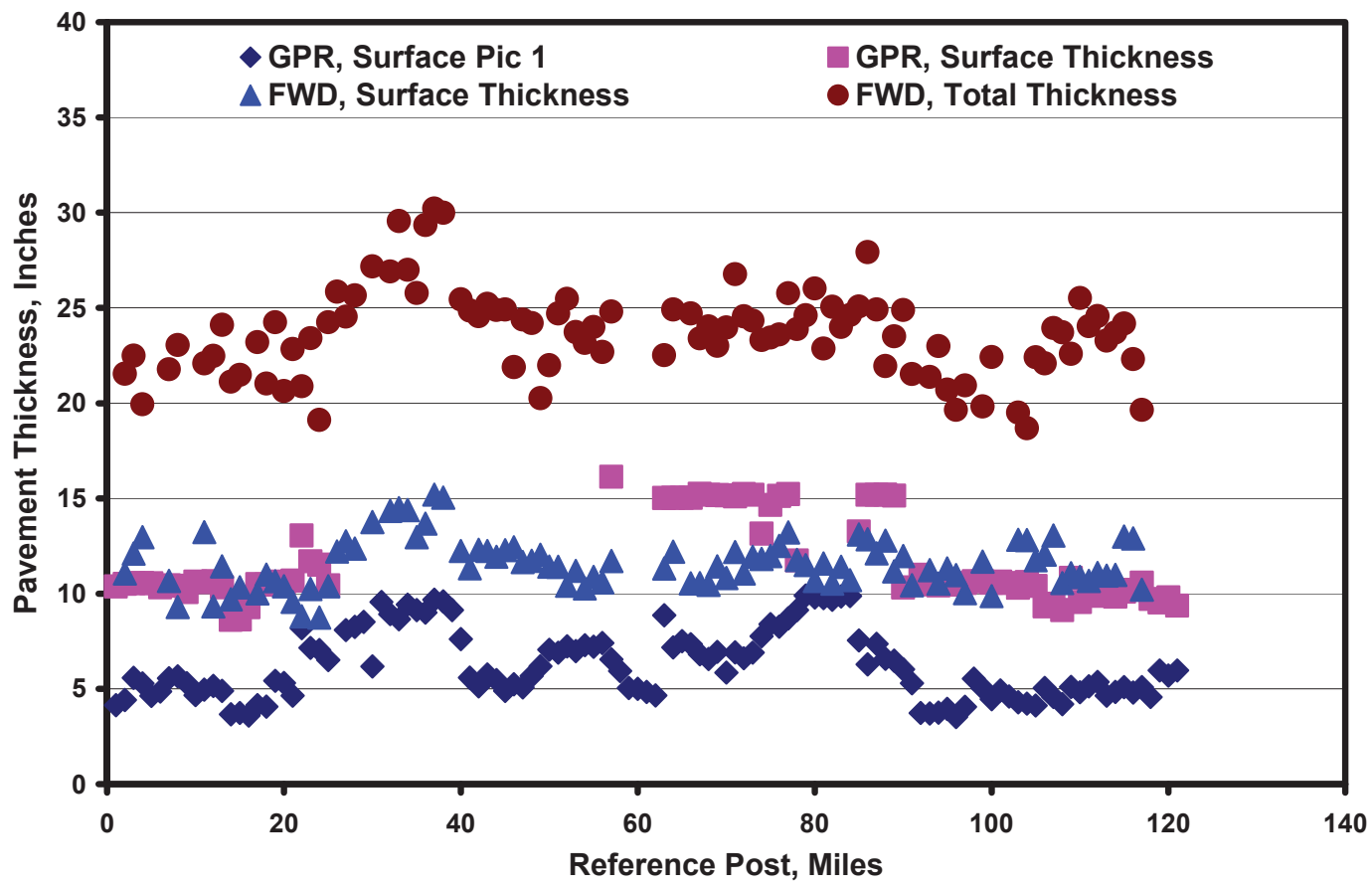

I - 64 West Bound Driving Lane

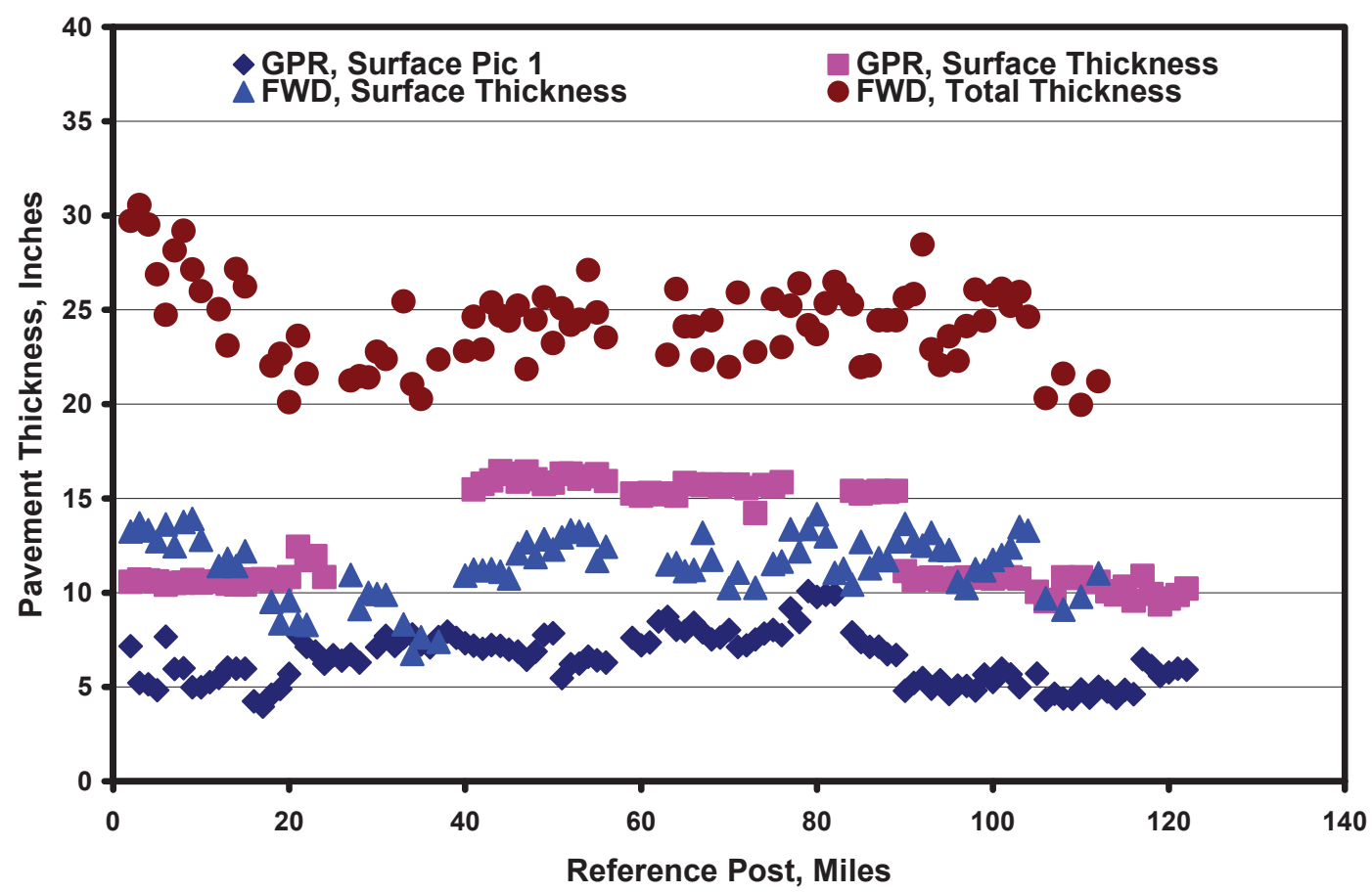

Figure 4.17: Profile of GPR and FWD Thickness Estimation along I - 64 


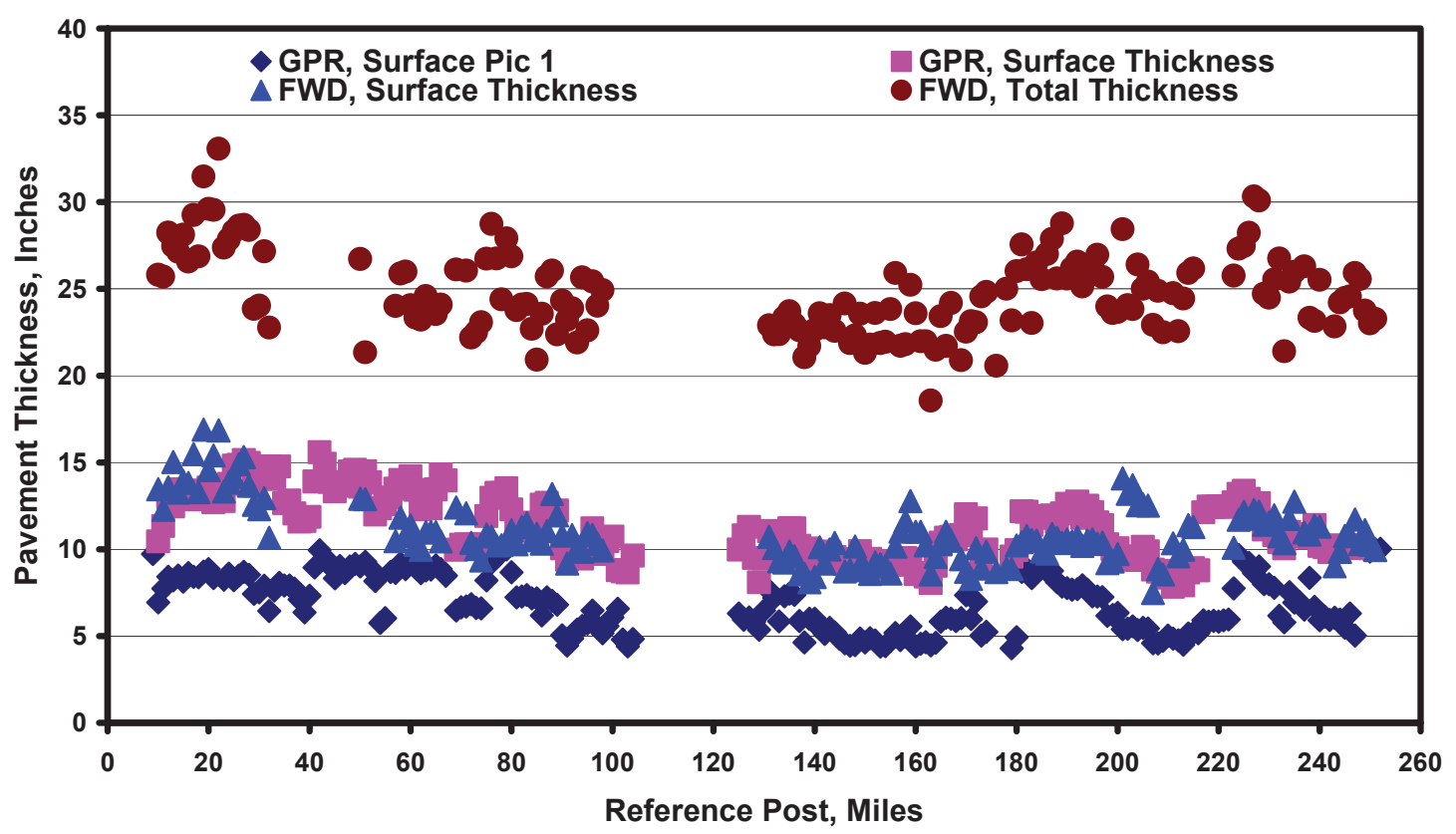

I - 65 South Bound Driving Lane

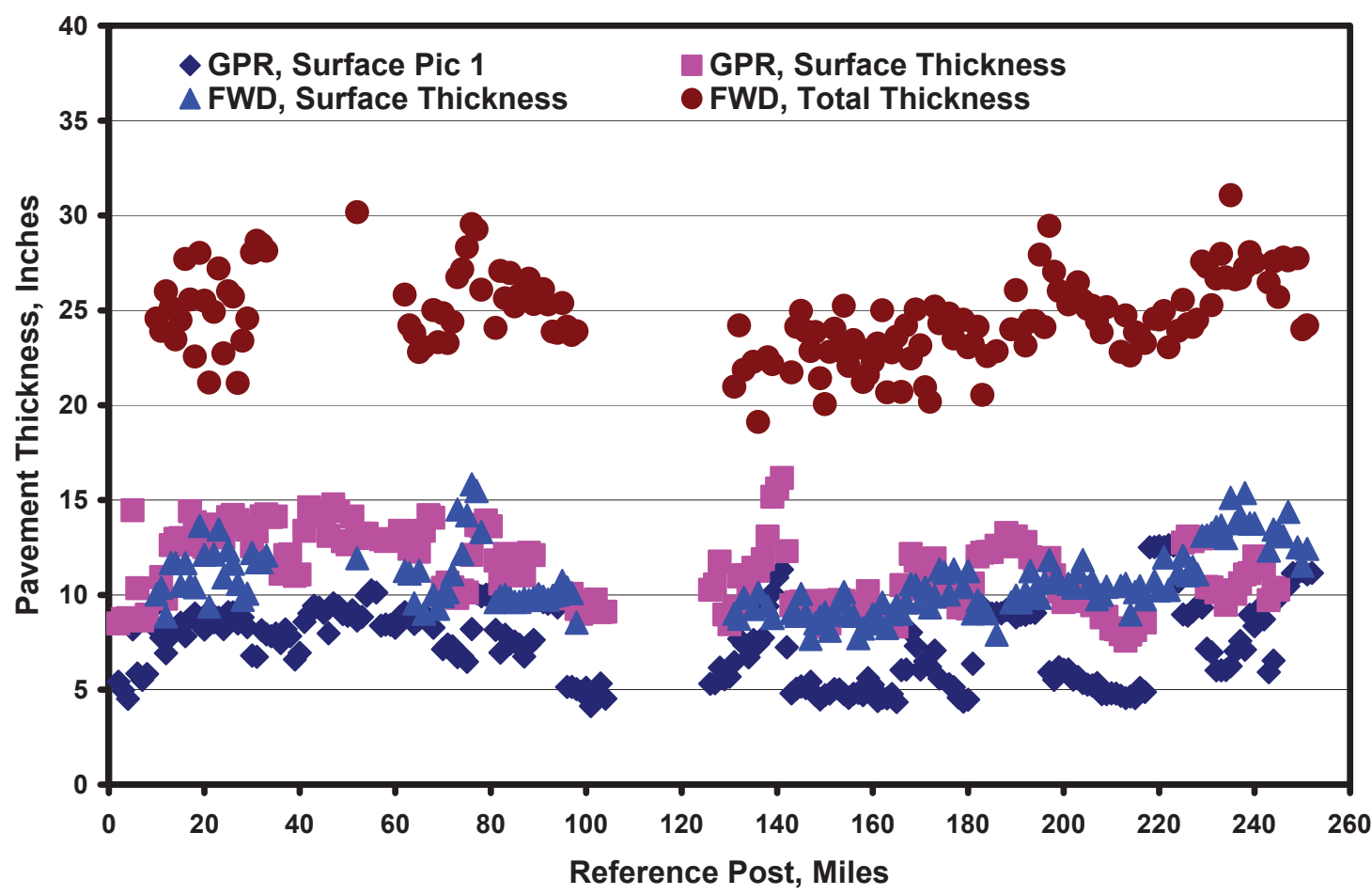

Figure 4.18: Profile of GPR and FWD Thickness Estimation along I - 65 


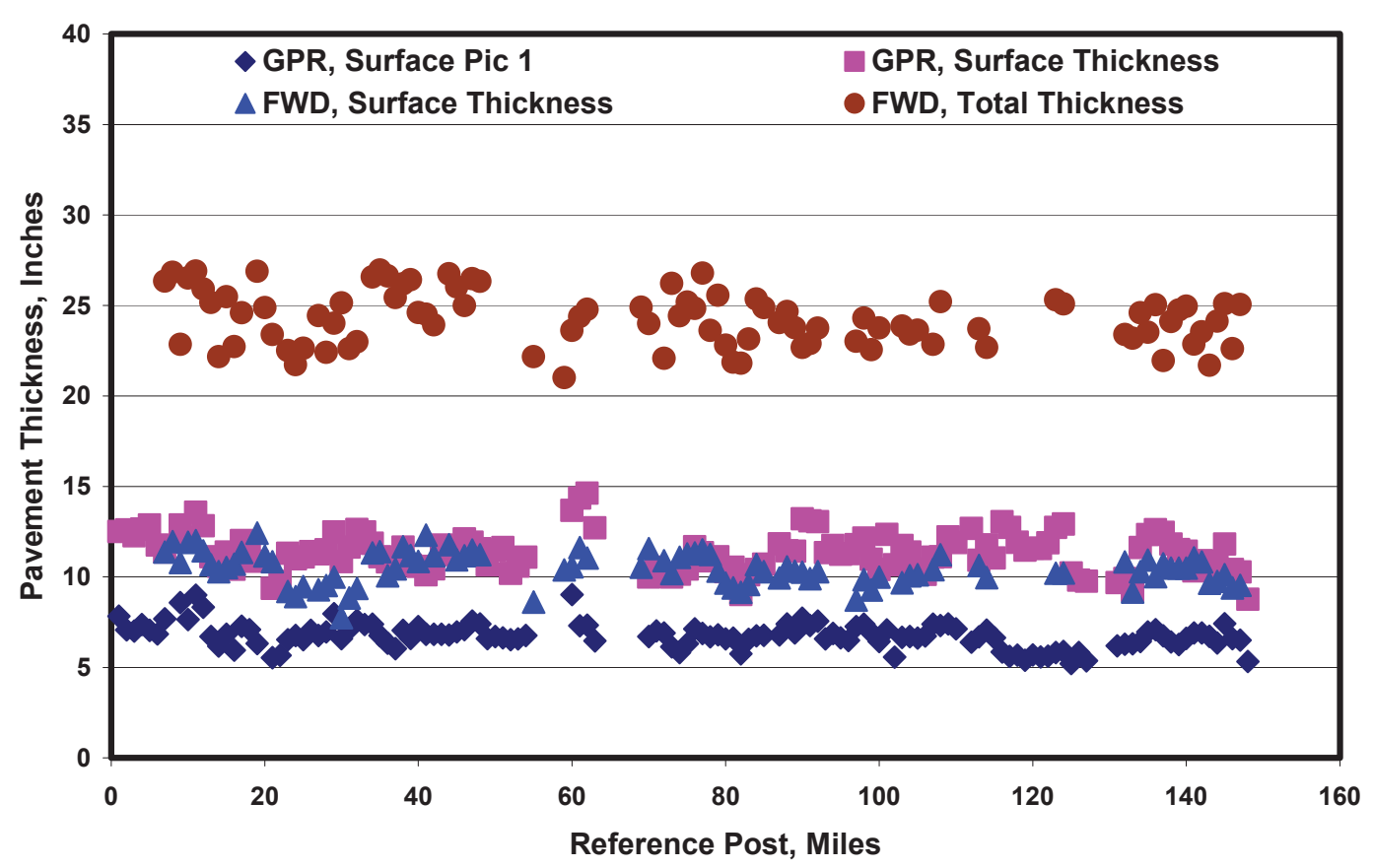

I - 69 South Bound Driving Lane

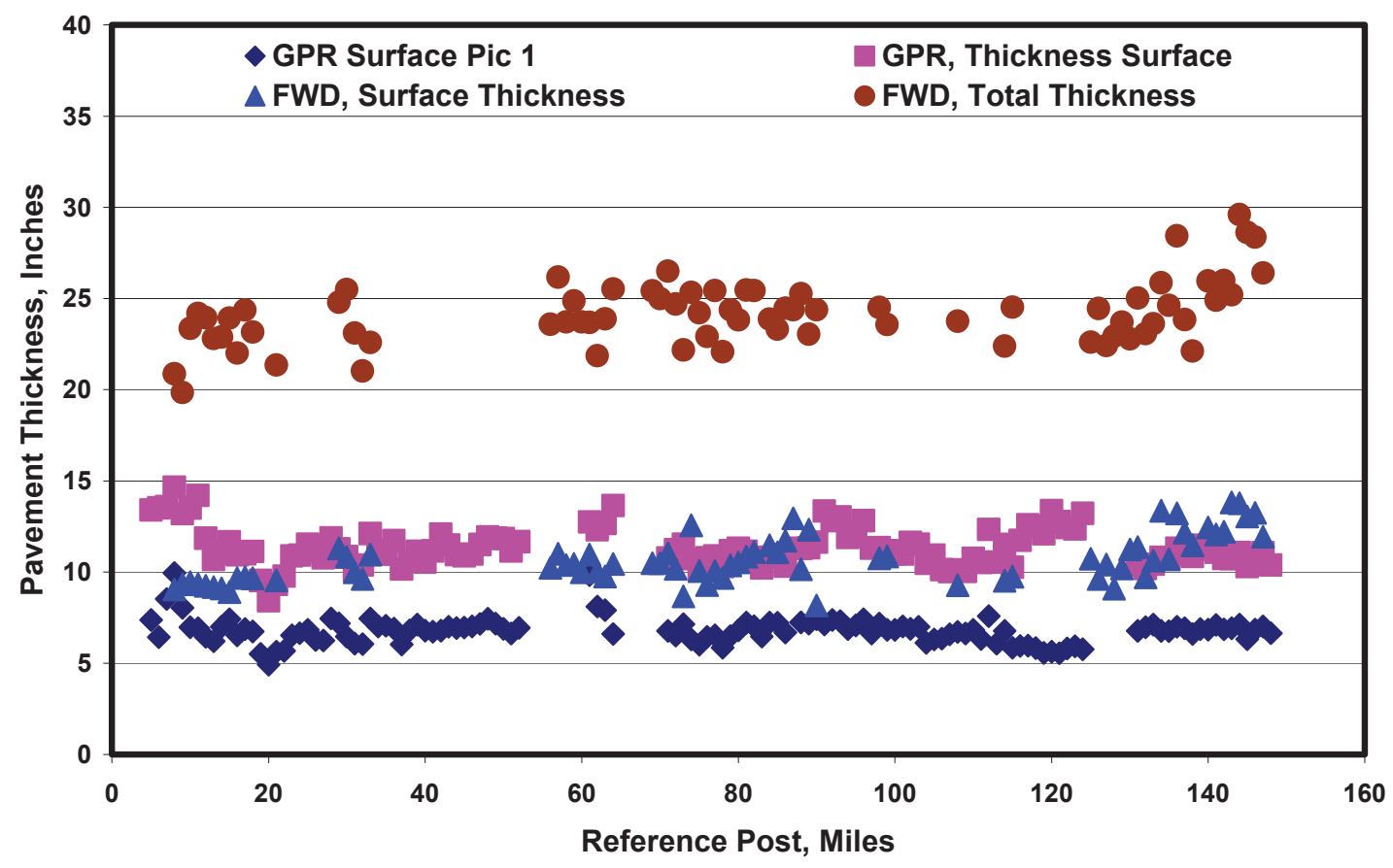

Figure 4.19: Profile of GPR and FWD Thickness Estimation along I - 69 


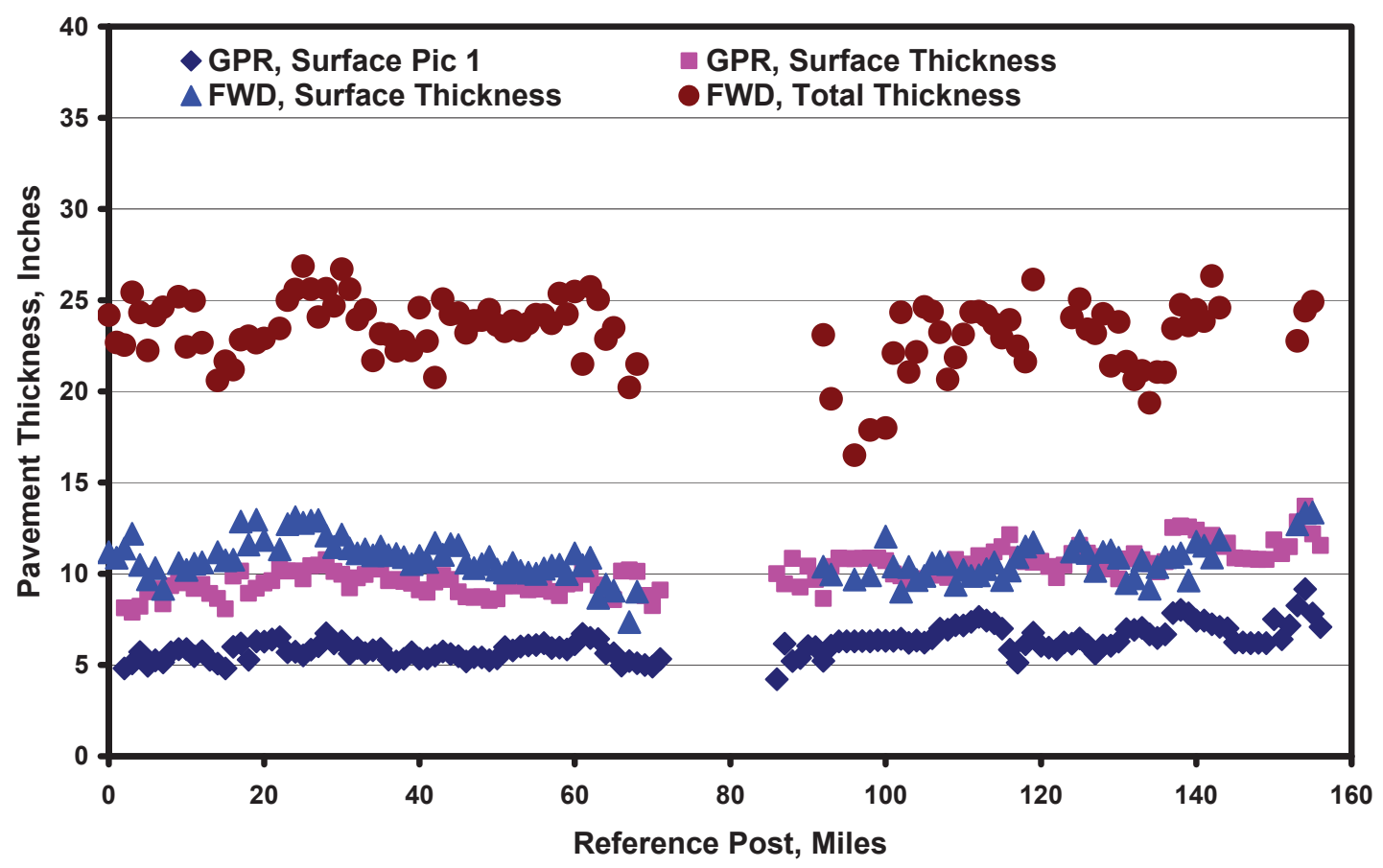

I - 70 West Bound Driving Lane

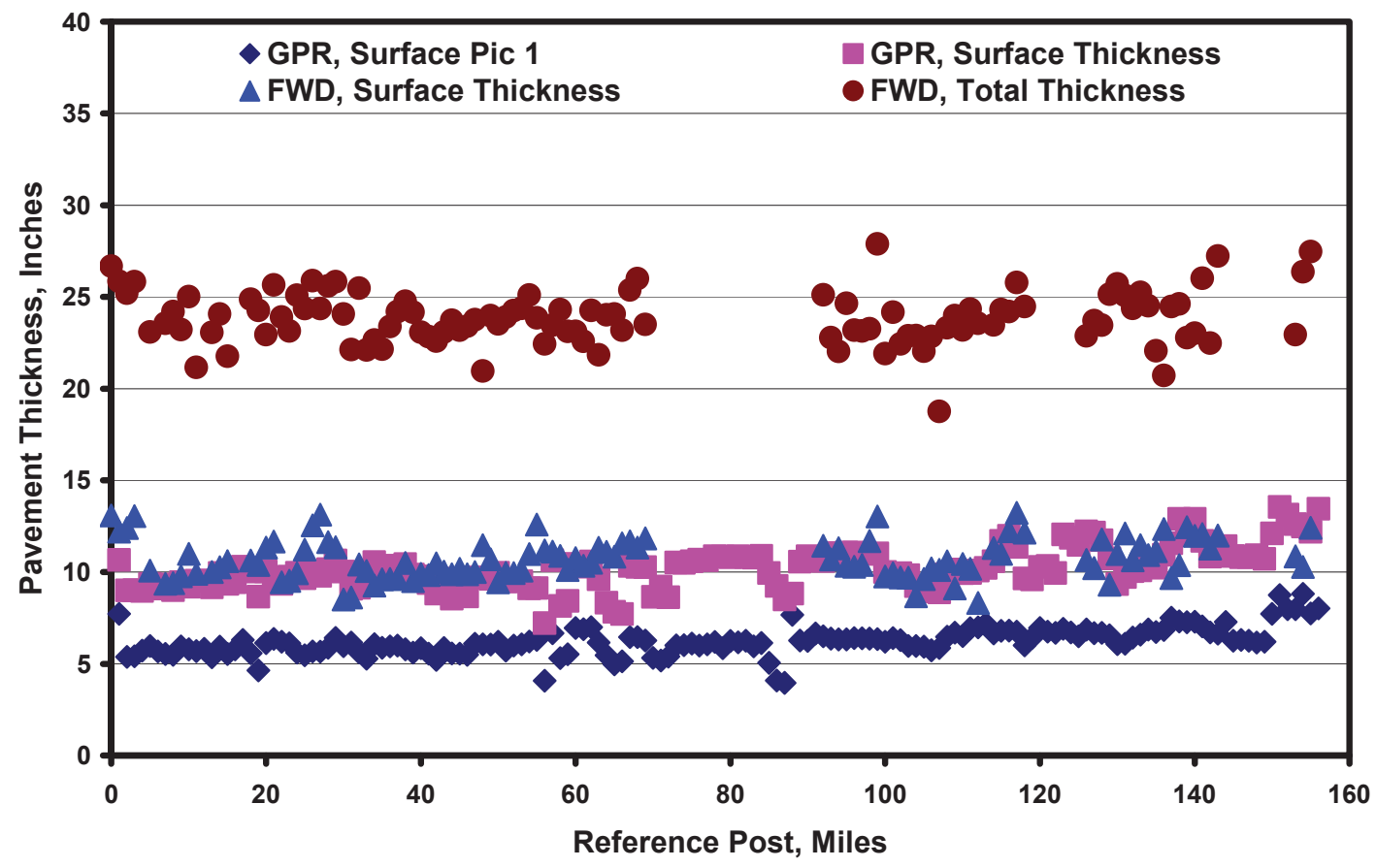

Figure 4.20: Profile of GPR and FWD Thickness Estimation along I - 70 


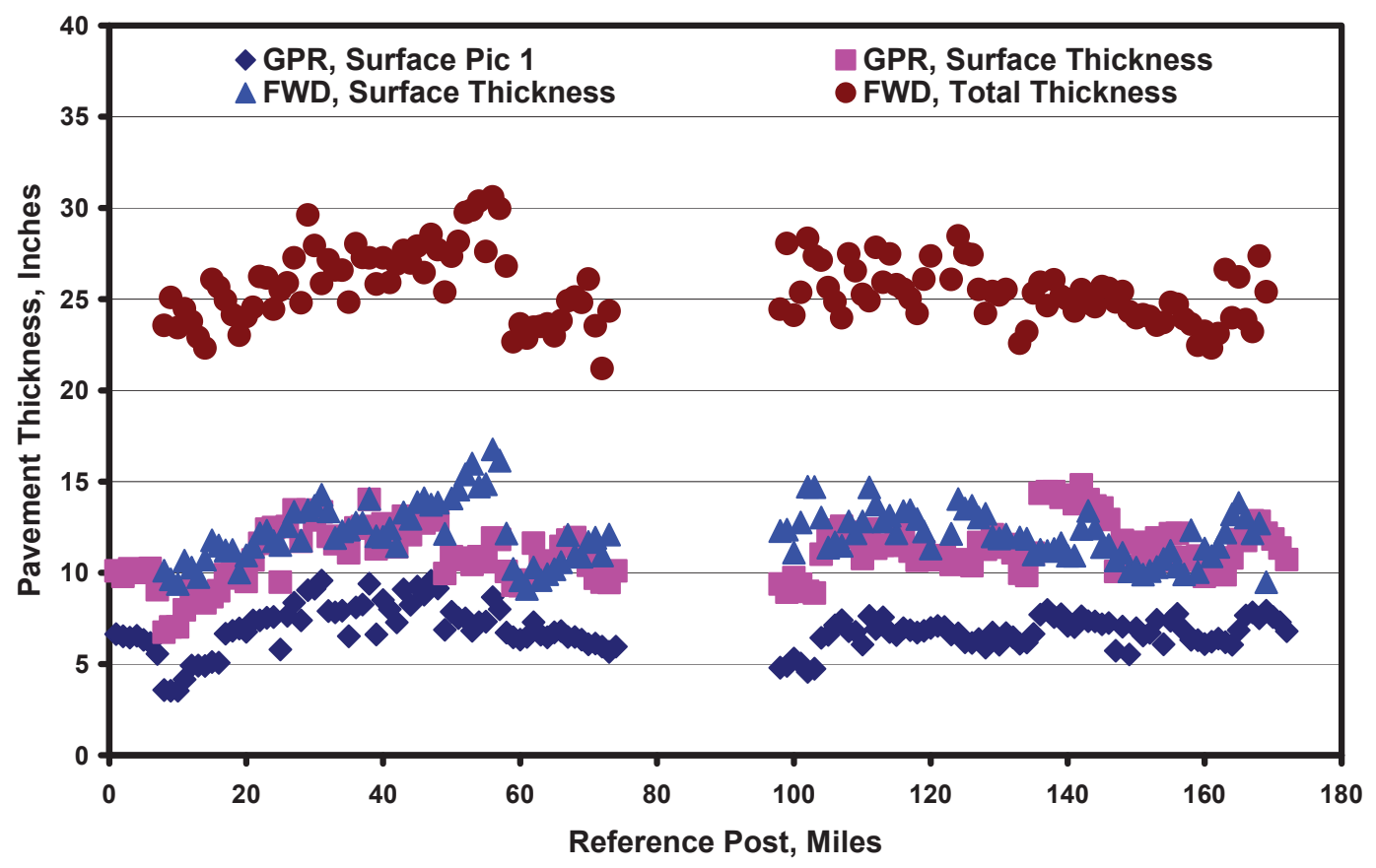

I - 74 West Bound Driving Lane

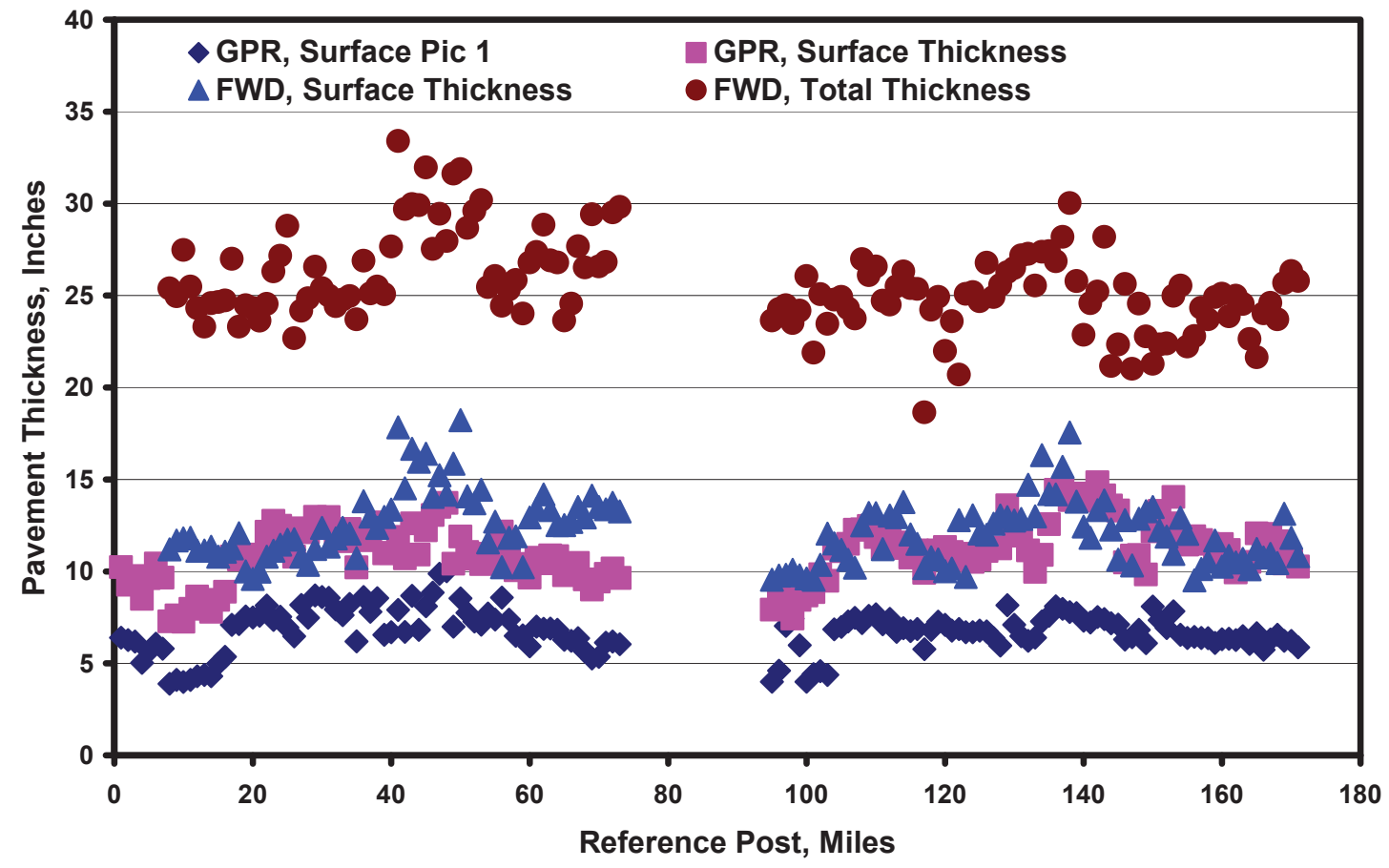

Figure 4.21: Profile of GPR and FWD Thickness Estimation along I - 74 
US - 41 North Bound Driving lane

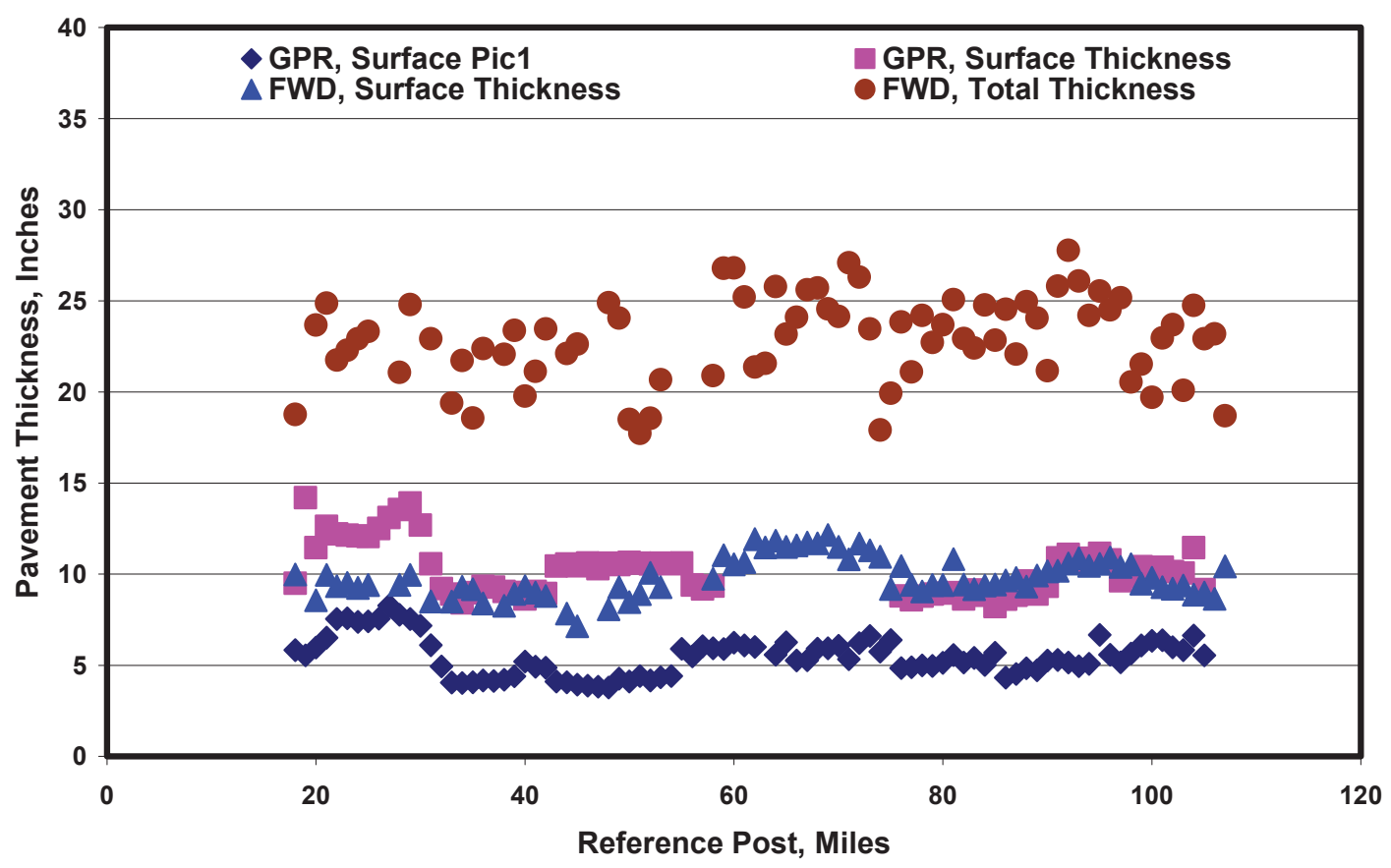

Figure 4.22: Profile of GPR and FWD Thickness Estimation along US - 41

SR - 32 East Bound Driving Lane

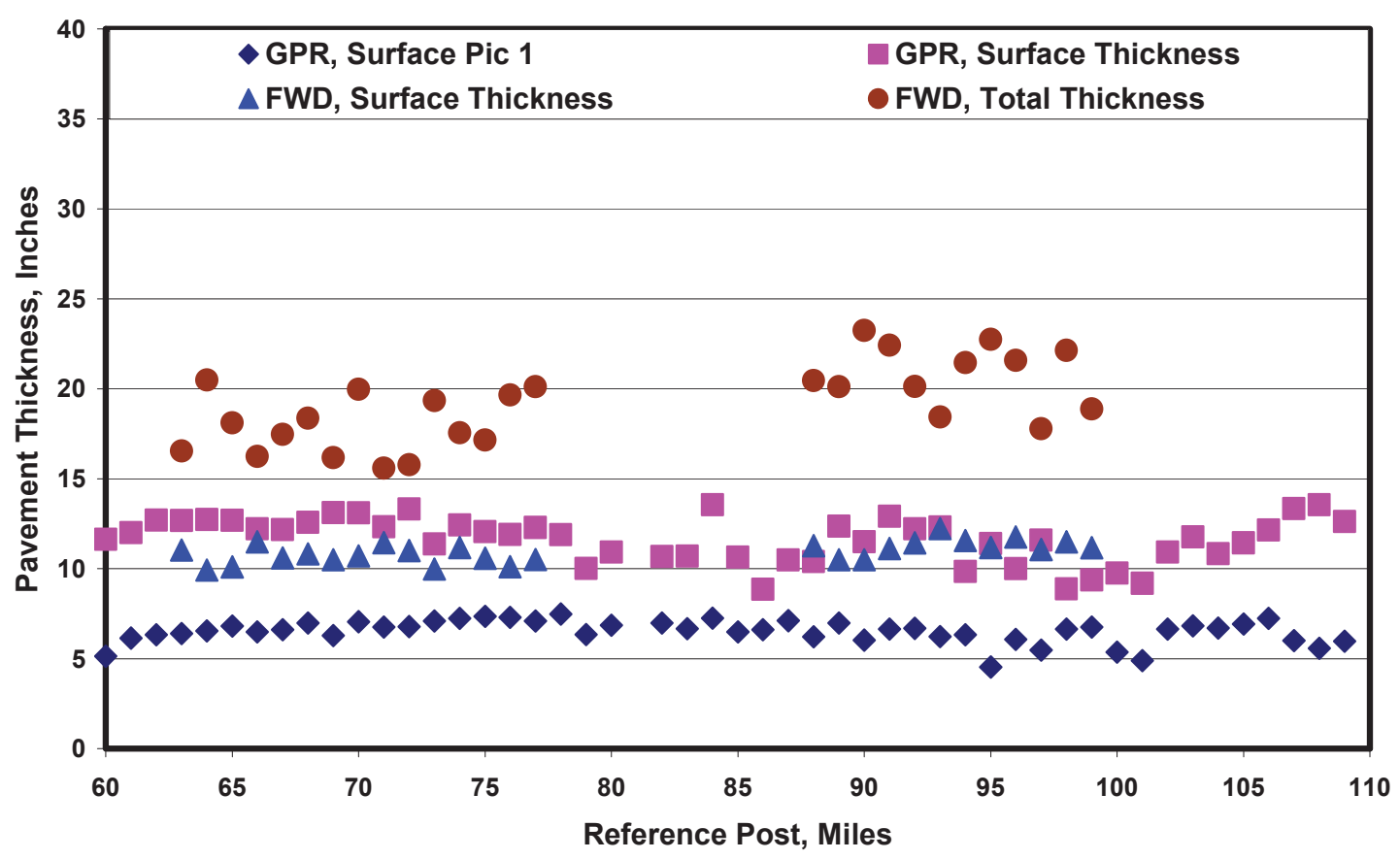

Figure 4.23: Profile of GPR and FWD Thickness Estimation along SR - 32 


\subsection{Coring - GPR Thickness Comparisons}

Figures 4.24 and 4.25 present profiles of Coring - GPR thickness comparisons along a segment of US - 41 (5" HMA over 10" concrete slab over 8" aggregate base in some segments and 10" concrete slab over 8" aggregate base in other locations). GPR thickness profile matched the coring thickness profile in the concrete segment. GPR HMA thickness profile (surface pick 1) matched the coring thickness profile for the HMA layer in the composite segment also perfectly. However, GPR estimate for the combined surface was lower than coring by 2 to 5 inches but followed a similar pattern to coring profile. It might be important to indicate herein that during coring, rebar was detected at the locations that are picked by the GPR as an interface. Authors believe that the first GPR pick is consistently accurate. However, limited coring may still be needed to adjust the measurements of second and or third picks. The second and third picks (when detected) appear to be accurate in some situations and need adjustments in other situations.

US - 41 North Bound Driving Lane

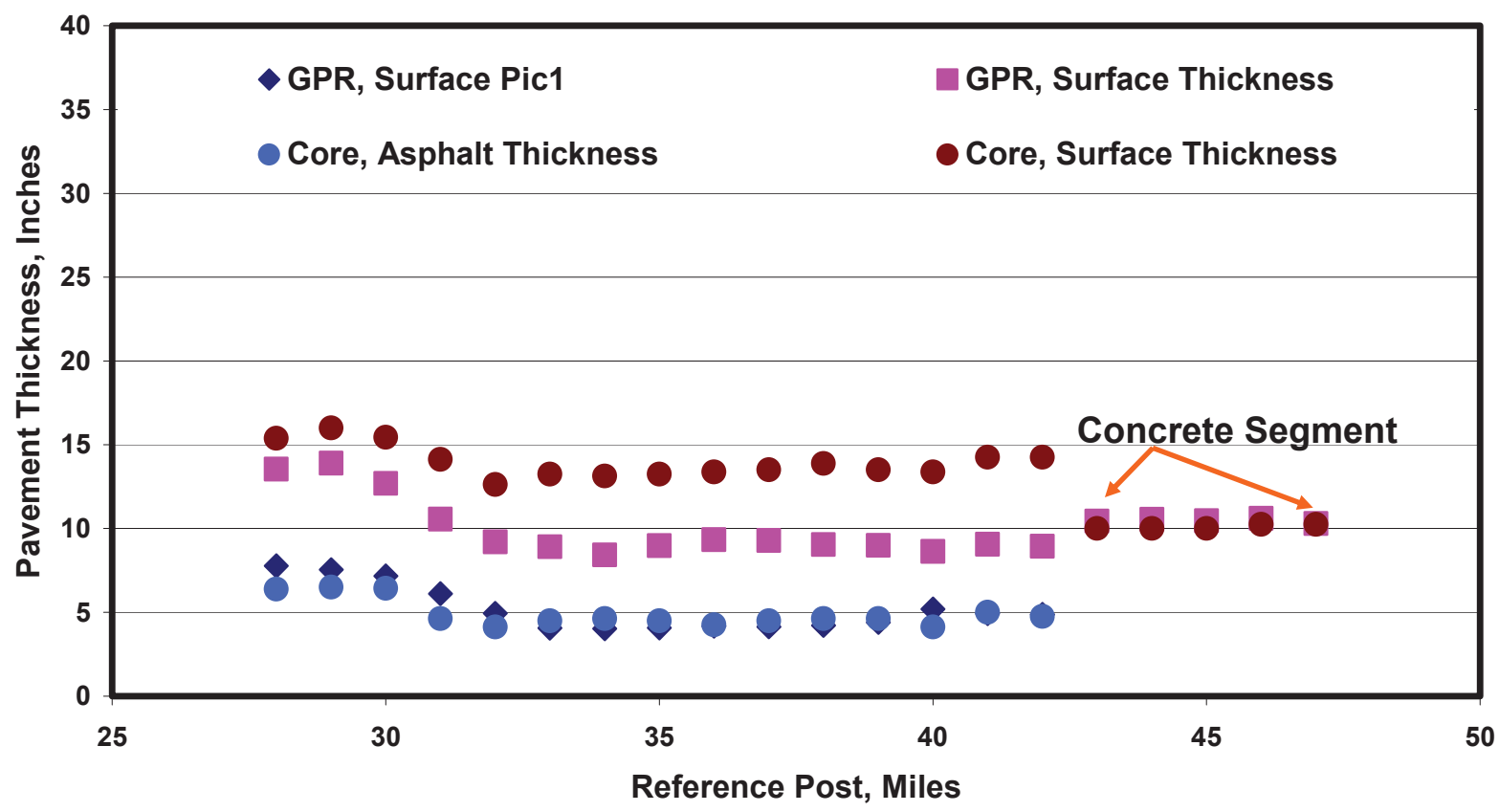

Figure 4.24: Profile of GPR and Core Thickness along US - 41 
SR - 32 East Bound Driving Lane

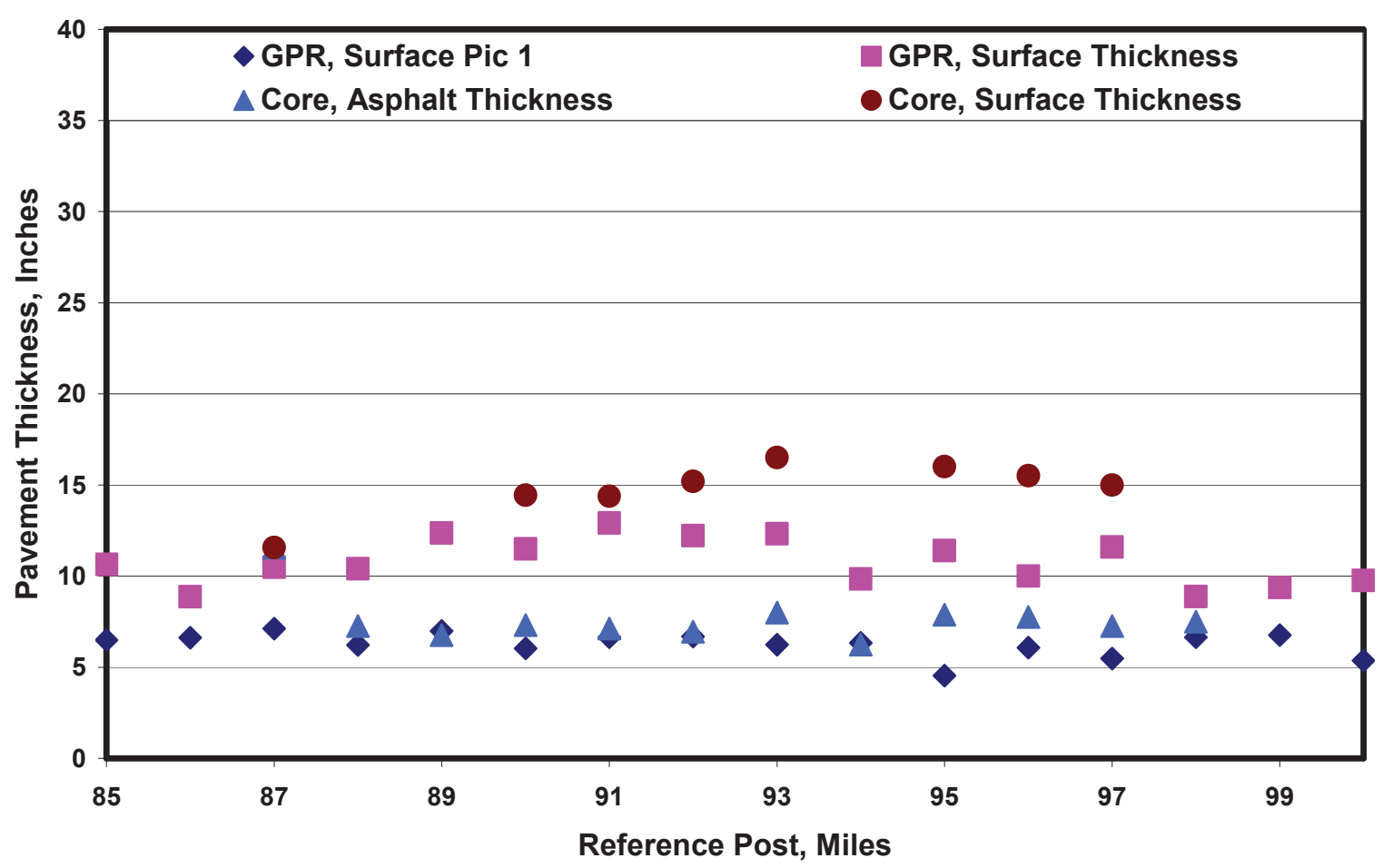

Figure 4.25: Profile of GPR and Core Thickness along SR - 32 


\section{Chapter 5}

\section{FINDINGS AND RECOMMENDATIONS}

Nondestructive testing has become an integral part for evaluation and rehabilitation strategies of pavements in recent years. Pavement evaluation employing the Falling Weight Deflectometer (FWD) and the Ground Penetrating Radar (GPR) can provide valuable information about pavement performance characteristics and be a very useful tool for project prioritization purposes and estimation of construction budget at the network level.

This report presents Indiana experience in pavement evaluation with the FWD and GPR at the network level. A network level FWD and GPR testing program is implemented as a part of a study to overcome traditional obstacles for the use of FWD and GPR in pavement evaluation at that level namely; expenses involved in data collection, limited resources and lack of simplified analysis procedures. This testing program included Interstate Highways I - 64, I - 65, I - 69, I 70 and I - 74 and a number of U.S. Roads and State Routes.

\subsection{Findings}

Main findings can be summarized as follows:

- Network level testing employing the FWD and GPR is a worthwhile, technically sound program that will provide a baseline of structural capacities of in - service pavements in Indiana. Periodical generation of necessary data will be useful for determining how best to quantify the loss in structural capacity and help estimate annual construction budget.

- Information that is obtained through network level testing can be used for pavement design, maintenance, rehabilitation and management purposes.

- U.S. Roads and State Routes may need more emphasis in network level deflection testing than Interstate Highways.

- A pavement thickness and structural capacity inventory of INDOT Interstate Highways is created. INDOT Interstate Highway pavements are currently in a very good structural condition.

- GPR estimates concrete thickness of concrete pavements, HMA thickness of flexible pavement and HMA thickness of composite pavements almost perfectly. GPR thickness estimation of pavement layers underneath these layers is not as accurate and needs adjustment through very limited coring. GPR (used in this study) did not provide any estimate of unbound pavement layers or total pavement thickness.

- FWD estimates total pavement thickness when using the simplified method presented in this paper. FWD also estimates combined surface thickness. This estimate matched the GPR estimate in some situations or was slightly lower. 
- GPR is not expected to completely eliminate the need for coring. GPR can be used to establish the coring requirements to help interpret the GPR data fill the gaps in thickness estimation and verify thickness results.

- Pooled overall standard deviation for INDOT interstate highways is 0.497.

\subsection{Recommendations}

\subsubsection{Recommendations for Implementation}

- FWD data on 2200 lane miles of the INDOT network is recommended annually for network level pavement evaluation. Only three FWD tests per mile in the driving lane of one bound direction are recommended. The information collected will allow the equivalent of $100 \%$ coverage of the whole network in 5 years.

- GPR data is recommended to replace cores extracted for the purposes of both pavement and shoulder thickness evaluation. GPR data collection is also recommended at the project level and for special projects.

- GPR data is recommended to be collected once every 5 years for pavement thickness inventory purposes.

- Both FWD and GPR data is recommended to be used as part of the pavement management system (together with automated collected data of international roughness index, IRI, pavement condition rating, PCR, rut depth, pavement quality index, PQI, texture and skid resistance).

\subsubsection{Recommendations for Further Research}

- Develop prediction models using FWD center deflection as a pavement performance indicator.

- Develop an automated structural adequacy index employing both the FWD data and automated distress identification data (especially structural related distress component of PCR) for pavement management purposes

- Use the GPR to characterize the dielectric characteristics of pavement surfaces especially those with potential to trap moisture. 


\section{REFERENCES}

1. Haas, R., Hudson, W.R., and J.P. Zaniewski, “Modern Pavement Management”, Krieger Publishing Co., Malabar, Florida, 1994.

2. AASHTO, "AASHTO Guide for Design of Pavement Structures", American Association of state Highway and Transportation Officials, 1993.

3. Thompson, M.R. Mechanistic-Empirical Flexible Pavement Design: An Overview. In Transportation Research Record 1539, TRB, National Research council, Washington, D.C., 1996.

4. Nondestructive Testing of Pavements and Backcalculation of Moduli, STP 1198, American Society for Testing and Materials, ASTM, H. L. Von Quintus, A. J. Bush, and G. Y. Baladi, Editors, December 1994.

5. Von Quintus, H. L., and B. Killingsworth, "Backcalculation of Layer Moduli of SHRP LTPP General Pavement Study (GPS)", Publication No. FHWA - RD - 97 - 086, Federal Highway Administration, July 1997.

6. Noureldin, A. S., Sharaf, E., Arafah, A., and Al-Sugair, F., "Use of Falling Weight Deflectometer to Determine Pavement Deflection Characteristics", Proceedings, $12^{\text {th }}$ IRF World Congress, Madrid, Spain, May 1993.

7. Noureldin, A. S., "New Scenario for Backcalculation of Layer Moduli of Flexible Pavements", TRR 1384, Washington, D.C., 1993.

8. Noureldin, A. S., "Influence of Stress Levels and Seasonal Variations on In-Situ Pavement Layer Properties”, TRR 1448, Washington, D.C., 1994.

9. Noureldin, A. S., Sharaf, E., Arafa, A., and Al-Sugair, "Rational Selection of Factors of Safety in Reliability Based Design of Flexible Pavements", TRR 1540, Washington, D.C., 1996.

10. Noureldin, A. S., "Seasonal Deflections and In Situ Moduli Patterns of Polymer Modified Versus Unmodified Asphalt Pavements", Proceedings, Mechanical Tests for Bituminous Materials, Lyon, France, March 1997 RILEM, PP 583-590.

11. "Standard Testing of Materials", Vol. 4.03, Road and paving Materials, ASTM, Philadelphia, PA, 2003.

12. Standard Specifications for Highway Materials and Methods of Sampling and Testing", AASHTO, Washington, D.C, 2003. 
13. SHRP Product Catalog, Strategic Highway Research Program, National Research Council, Washington, D.C., 1992.

14. Wenzlick, J., Scullion, T. and K. R. Maser, "High accuracy Pavement thickness Measurement Using Ground Penetrating Radar", Final Report, RDT 99 - 003, R I96 11, PTP, Missouri Department of Transportation, February 1999.

15. NCHRP Synthesis No. 255, "Ground Penetrating Radar for Evaluating Surface Conditions for Transportation Facilities", A Synthesis for Highway Practice, TRB Synthesis Studies, National Research Council, Washington, D.C.

16. J. J. Daniels, "Fundamentals of Ground Penetrating Radar", Soft Earth Associates Inc., Westerville, Ohio, 1990.

17. J. B. Hasted, “Aqueous Dielectrics", London, Chapman and Hall, 1973

18. Ulriksen, C., F. Peter “Application of Impulse Radar in Civil Engineering”, Doctoral Thesis, Department of Engineering Geology, Lund University of Technology, Lund Sweden, reprinted and distributed by Geophysical Survey Systems Inc., North Salem, New Hampshire, 1982.

19. D. A. Harris, "A GPR Based Underground Workings Monitoring Program for Surface Mines", M.S. Thesis, Department of Mining Engineering, Montana Tech of the University of Montana, Butte, MT, 1998.

20. Noureldin, A. S., Zhu, K., Li, S. and D. Harris; "Network Pavement Evaluation Using Falling Weight Deflectometer and Ground Penetrating Radar", in Transportation Research Record, TRR 1860, Journal of the Transportation Research Board, National Research Council, Washington, D.C., January 2003. PP 90 - 99.

21. Finn, F., C.L. Saraf, R.Kulkarni, K. Nair, W. smith, and A. Abdullah, NCHRP Report 291 : Development of Pavement Structural Subsystem., TRB, National Research council , Washington, D.C., 1986.

22. Thompson, M.R. and R.P. Elliot. ILLI-PAVE Based Response Algorithm for Design of Conventional Flexible Pavements. In Transportation Research Record 1043, TRB, National Research Council, Washington, D.C., 1985.

23. Huang, Y., H. Pavement Analysis and Design, Prentice Hall, Englewood Cliffs, N.J., 1993.

24. Shell Pavement Design Manual-Asphalt Pavements and Overlays for Road Traffic, Shell International Petroleum Company, Ltd., London, England, 1978 .

25. Research and Development of the Asphalt Institute Manual (MS-1), 9th ed. Report 82-2, Asphalt Institute, 1982. 
26. Pierce, L.M., N.C. Jackson, and J.P. Mahoney, Development and Implementation of a Mechanistic, Empirically Based Overlay Design Procedure for Flexible Pavements In Transportation Research Record 1388, TRB, National Research Council, Washington, D.C. , 1992 .

27. Richter, C.A., and J.B. Rauhut, SHRP Plans for Nondestructive Deflection Testing in the Development of Pavement Performance Prediction Models" ASTM, STP 1026 A.J. Bush III and G.Y. Baladi, ASTM, Philadelphia, 1989.

28. Yoder E., and M. Witczack, Principles of Pavement Design, 2nd ed., John Wiley \& Sons, Inc., New York, 1975.

29. Burmister, D. M., "The Theory of Stresses and Displacement in Layered Systems", Proceedings, Highway Research Board, 1943.

30. Noureldin, A.S., Sharaf, E., Arafah, A., and F. Al-Sugair, "Estimation of Standard Deviation of Predicted Performance of Flexible Pavements Using AASHTO Model", In Transportation Research Record No.1449, TRB; National Research Council, Washington, D.C., 1994.

31. Arafah, A., Al-Sugair, F., Sharaf, E., and A.S. Noureldin, "Adaptation of A Reliability Based Code for the Design of Flexible Pavement in the Kingdom of Saudi Arabia , Final Report, Volume 2, KACST, Saudi Arabia, 1995.

32. Lytton, R. L. and D. Zollinger, Modeling Reliability in Pavement, presented at $72^{\text {nd }}$ Annual Meeting of the Transportation Research Board, Washington, D.C., January 1993.

33. Harr, M.E., Reliability Based Design in Civil Engineering, McGraw Hill, New York, 1987. 